Florida International University FIU Digital Commons

7-22-1992

\title{
Depth-related variations of trace metal abundances in south Florida sediments
}

Donna Wade Booth

Florida International University

DOI: $10.25148 /$ etd.FI14051193

Follow this and additional works at: https://digitalcommons.fiu.edu/etd

Part of the Geology Commons

\section{Recommended Citation}

Booth, Donna Wade, "Depth-related variations of trace metal abundances in south Florida sediments" (1992). FIU Electronic Theses and Dissertations. 1730.

https://digitalcommons.fiu.edu/etd/1730

This work is brought to you for free and open access by the University Graduate School at FIU Digital Commons. It has been accepted for inclusion in FIU Electronic Theses and Dissertations by an authorized administrator of FIU Digital Commons. For more information, please contact dcc@fiu.edu. 


\title{
FLORIDA INTERNATIONAL UNIVERSITY
}

Miami, Florida

\author{
Depth Related Variations of Trace Metal Abundances \\ in South Florida Sediments
}

\begin{abstract}
A thesis submitted in partial satisfaction of the requitements for the degree of Master of Science in Geology
\end{abstract}

by

Donna Wade Booth 
ABSTRACT OF THE THESIS

Depth Related Variations of Trace Metal Abundances

in South Florida Sedinents

by

Donna Wade Booth

Florida International University, 1993

Miami, Florida

Professor Rosemary Hickey-Vargas, Major Professor

\begin{abstract}
Variations in trace element abundances with depth in soils and sediments may be due 10 natural processes or reflect anthropogenic intluences. The depth related variations of five major elenents ( $\mathrm{Fe}, \mathrm{Si}$, Al, $\mathrm{Ca}$ and $\mathrm{Mg}$ ), seventeen trace elements (Mn, $\mathrm{Cr}, \mathrm{Ti}, \mathrm{P}, \mathrm{Ni}, \mathrm{Ba}, \mathrm{Sc}, \mathrm{Sr}, \mathrm{Sb}, \mathrm{Zn}, \mathrm{Pb}$, $\mathrm{Cd}, \mathrm{Co}, \mathrm{V}, \mathrm{Be}, \mathrm{Cu}$ and $\mathrm{Y}$ ) and volatile loss patterns were examined for sediment cores from five sites in South Florida (Lake Okeechobee, SFWMD Water Conservation area 3B, F.L.U., the Everglades and Chekika State Recreation Area). Principal component analysis of the chemical data combined with microscopic examination of the soils reveal that depth-related variations can be explained by varying proportions of three natural soil constituents and one anthropogrenic component. The results can be used as a geochemical baseline for human infuence on South Florida soils.
\end{abstract}


To Professors Hickey-Vargas, Clement, and Maurrasse:

This thesis, having been approved in respect to form and mechanical execution, is referred to you for judgement upon its substantial merit.

Dean Arthur Herriot1

College of Arts and Sciences

The thesis of Donna Wade Booth is approved.

Bradford Clement

Florentin Maurrasse

Rosemary Hickey-Vargas,

Major Professor

Date of Examination: 22 July 1992

Dean Richard Campbell

Division of Graduate Studies

Florida International University, 1993 


\section{ACKNOWLEDGEMENTS}

Many people were instrumental in the completion of this thesis. I am very appreciative of their support and encouragement. I would like to thank Tom Beasley of the geology deparment and Mr. Wu of the physics deparment for their help in sample preparation. Thank you to Dr. Charles Connor for the principal component analysis, and to Dr. Grenville Draper for his assistance with the computers. Many thanks to my umesis commitee for their critical review of this work. I would like to thank Dr. Rosemary Hickey+Vargas for her invaluable advice, assistance and encouragement through the comse of this work. I would like to close this by thanking my husband Frank and son Brian for their consideration and undersianding during this time. 


\section{TABLE OFCONTENTS}

CHAPTER ONE INTRODUCTION

\section{CHAPTER TWO BACKGROUND INFORMATION}

Geographic and geologic setting of the

Soun Florida region 5

Origin and composition of soils 7

Sources of metals in soils 9

Known geochemical behavior of elements 11

CHAPTER THREE SAMPLE DESCRIPTIONS 21

Core descriptions

LOTI

WCA3B-2 26

$\begin{array}{ll}\text { FIU } & 29\end{array}$

$\begin{array}{ll}\text { KCEO } & 33\end{array}$

$\begin{array}{ll}\text { CSRA } & 37\end{array}$

CHAPTER FOUR CHEMICAL ANALYSIS

CHAPTER FIVE RESULTS AND INTERPRETATIONS 43

Results $\quad 43$

Data Analysis $\quad 43$

$\begin{array}{ll}\text { Discussion } & 117\end{array}$

$\begin{array}{ll}\text { Summary and Conclusions } & 129\end{array}$

REFERENCES 135

APPENDICES 


\section{LIST OF FIGURES}

1

2

3

4

5

$6-2$

26-45 CSRA elements vs depth plots

46-65 LOTl elements vs depth plots

66-85 FCEG elements vs depth plots

86-91 CSRA enrichment/depletion of organic and carbonate fractions relative to $\mathrm{Al}$

92-96 FCEG enrichment/depletion of organic and carbonate fractions relative to $\mathrm{Al}$

97-104 FIU enrichment/depletion of organic and carbonate fractions relative to Al

105-108 LOTI enrichment/depletion of organic and carbonate fractions relative to $\mathrm{Al}$

109-112 WCA3B-2 enrichment/depletion of organic and carbonate fractions relative $10 \mathrm{Al}$

113 Ca vs Sr from FIU core

$114 \quad$ Fe vs Cd from LOTI core

$115 \quad F C E G<550^{\circ} \mathrm{C}$ volatile loss vs Cd

$116 \quad$ FiU $>550^{\circ} \mathrm{C}$ volatile loss vs $\mathrm{Ca}$

117 


\section{LIST OF TABLES}

1 Known geochemical behavior of the elenents 12

2. World and Florida ranges 45

3 Depth comparison between cores 46

4 Peak element concentrations with depth 47

5 Enrichmentdepletion of elements in organic 109 and carbonate fractions relative to $\mathrm{Al}$

6 Correlation matrix of clement vs element

7 Correlation coefficients of elements vs volatile loss

8 Volatile loss study

\section{LIST OF PLATES}

1 Core from Lake Okeechobee

2 Core from Water Conservation District $3 \mathrm{~B} \quad 28$

3 Core from Florida Intemational University 32

4 Core from Everglades $\quad 36$

5 Core from Chekika Recreation Area 40 
LIST OF APPENDICES

A Sites sampled but not analyzed 136

B Sample collection 140

C Sample preparation and chemical analysis 142

D Volatile loss procedure and resuls 148

E Raw data and data quality 150

F Whole soil concentrations correcled for 169

dilution

G Definitions 


\section{CHAPER ONE}

\section{INTRODUCTION}

In recent decades a considerable amount of work has been catried out on trace element concentration and behavior in the earth surface environments. Studies have included analyses of trace element concentrations in plants, animals, soils and sediments in different enviromments such as the oceans, rivers, lakes, wetlands and forests. Background concentrations accepted as natural and presumably safe in the case of toxic elements have been determined based on concentrations commonly encountered in these studies. For example, since soils develop in situ from inorganic (rock) and organic parent materials, trace and major element concentrations should reflect natural processes such as weathering and the accumulation of organic material in the soil profile. Anthropogenic inputs of trace elements in contrast, should produce distinct geochemical signals.

South Florida presents a unique situation for study of background trace elcment concentrations in soils because of its unique natural enviroment. Many South Florida soils contain a large proportion of organic material as reflected by the proliferation in the Holocene of the Everglades, a large freshwater marsh. Since organic matter acts as a sink for certain elements, a high organic content will influence the trace element composition of a soil.

The large amount of organic matter in the area is related to the water saturated conditions for a greater part of the year as Soun Florida receives runoff of fresh water from Lake Okeechobee, and receives steady as well as significant precipitation $(150 \mathrm{~cm} / \mathrm{yr})$ in non-drought years. Thus, some 
areas ate water saturated except during dry periods. In addition, water is always abundant close to the surface because of the presence of the Biscayne aquifer, a surface limestone aquifer. The overall flow pattern of water in South Florida is southward through agriculural areas and along natural depressions or sloughs, where eventually it reathes the man-made canal systems, the Gulf of Mexico, or Florida Bay. Therefore, sediments and trace elements are transported over a wide area in the flow and deposited along the route.

Vertical variations in the geochemistry of soils and sediments can result from a variely of processes. In underwater environments, vertical changes largely reflect time-related variations in inputs of transported materials. In subaerial environments, vertical changes are commonly related to the development of a soll profile by progressive weathering of bedrock and downward migration of soluble elements. In the Soun Florida environment, altemate poriods of wet and dry conditions lead to unique processes affecting vertical geochemical profiles. Fluctuations in the water table causes upward and downward migration of soluble elements within the soil column. In addition the altemate proliferation and drying of plant mater produces significant changes in the organic content of soils and sediments. These processes should be reflected in unique geochemical signatures.

This thesis addresses the causes of depth-related geochemical variations in South morida soils and sediments. The purpose of this study is twofold: 
1) to determine variations in elemental abundances with depth in South Florida soiss and explain the observations based on geochemical and sedimentological principles.

2) 10 determine if variations produced by natural and anthropogenic processes can be distinguished, including the variations produced by verical migration and changes in whole soil composition.

To this end cores of soils and sediments were collected from South Florida sizes inchuding Lake Okeechobee, South Florida Water Management District Conservation Area 3B, Florida International University, the Everglades and Chekika State Recreation Area (Fig. 1). The cores were divided into vertical segments and geochemical analyses were conducted on the carbonate and organic fractions (humic and fulvic acids) and the whole soil (bulk) composition of each segment. Major soil clements Fe, Al, $\mathrm{Si}, \mathrm{Ca}$ and $\mathrm{Mg}$; and race elements $\mathrm{P}, \mathrm{Ni}, \mathrm{Ba}, \mathrm{Mn}, \mathrm{Cr}, \mathrm{Ti}, \mathrm{Sc}, \mathrm{Sr}, \mathrm{Sb}, \mathrm{Zn}, \mathrm{Pb}, \mathrm{Cd}$, $\mathrm{Co}, \mathrm{V}, \mathrm{Be}, \mathrm{Cu}$ and $\mathrm{Y}$ were determined. Interpretations are based on: i) a knowledge of the sampling sites, including their history of use; microscopic examination of the cote segments; 3) statistical interpretation of chemical trends and 4) principles of elemental behavior in natural materials. The results of the present sudy contribute important information on the geochemical behaviors of major and trace elements in South Florida soils and sediments, including "baseline" concentrations produced by natural processes, against which anthropogenic influence can be measured. Furthermore, the present results adid to the accumulating body of knowledge which deals with the abundances and behaviors of trace elements in soils and sedments worldwide. 


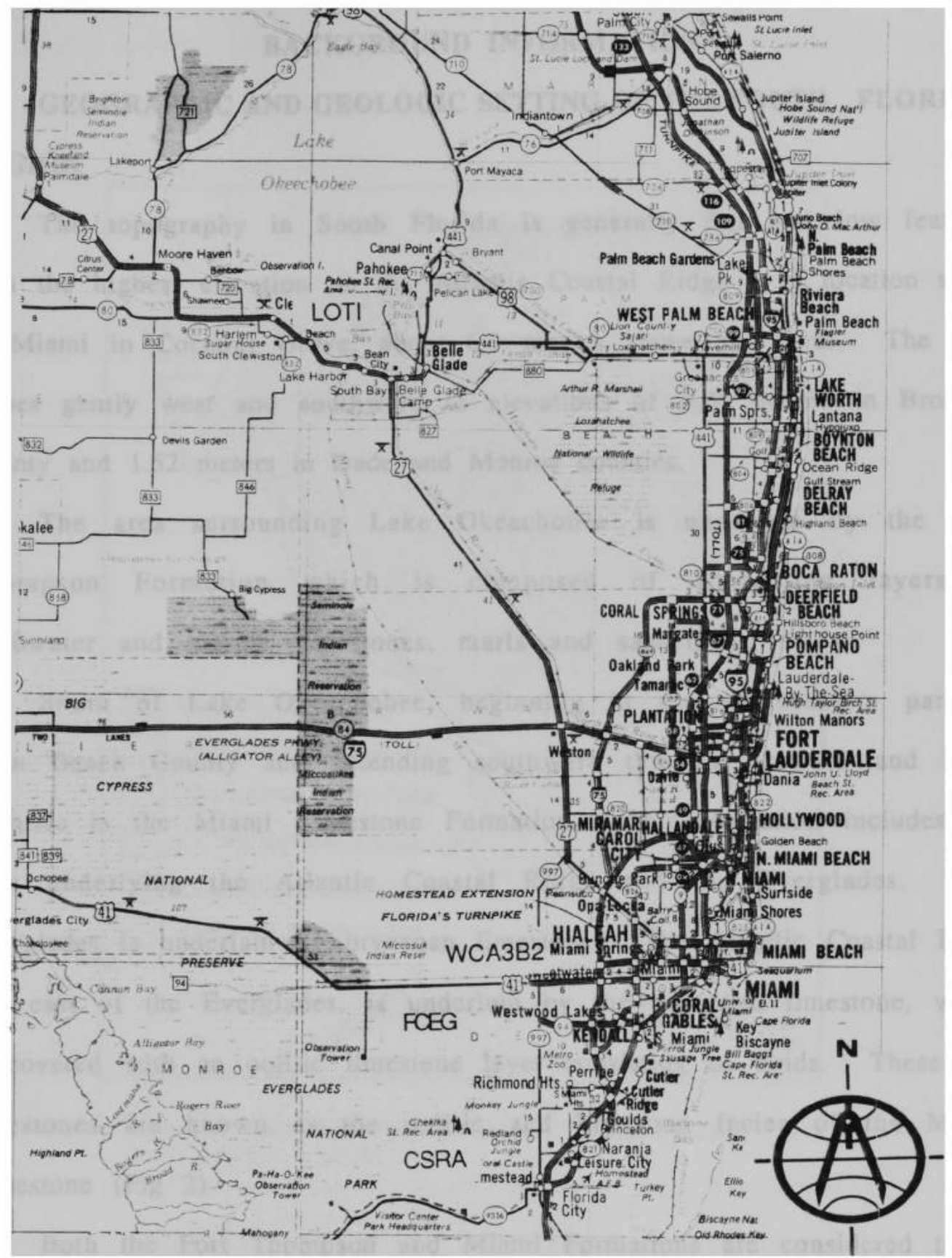

Fig. 1: Map of South Florida with core sites (from Rand McNally, 1991). 


\section{CHAPTER TWO}

\section{BACKGROUND INFORMATION}

\section{GEOGRAPHIC AND GEOLOGIC SETTING OF THE SOUTH FLORIDA}

REOION

The topography in Soun Florida is generally nat and low featured with the highest elevation on the Atantic Coastal Ridge at a location south of Miami in Coconut Grove, about 6.1 meters above sea level. The land slopes gently west and southward to elevations of 3.05 meters in Broward County and 1.52 meters in Dade and Monroe counties.

The area surrounding Lake Okeechobee is underlain by the Fort Thompson Formation which is composed of alternating layers of freshwater and marine limestones, marls and sandstones.

South of Lake Okeechobee, beginning in the southeastern part of Palm Beach County and extending southward through Broward and Dade counties is the Miami himestone Formation. This formation includes the rock underlying the Atanic Coastal Ridge and the Evcrgades. The Everglades is underlain by bryozoan limestone. The Atlantic Coastal Ridge lies east of the Everglades, is underlain by the bryozoan limestone, which is covered with an olitic limestone layer consisting of ooids. These two limestones are known as the oolitic and bryozoan facies of the Mianj Limestone (Fig 2),

Botl the Fon Thompson and Miami Formations are considered to be approximately 100,000 years old (Hofmeister, 1974). 


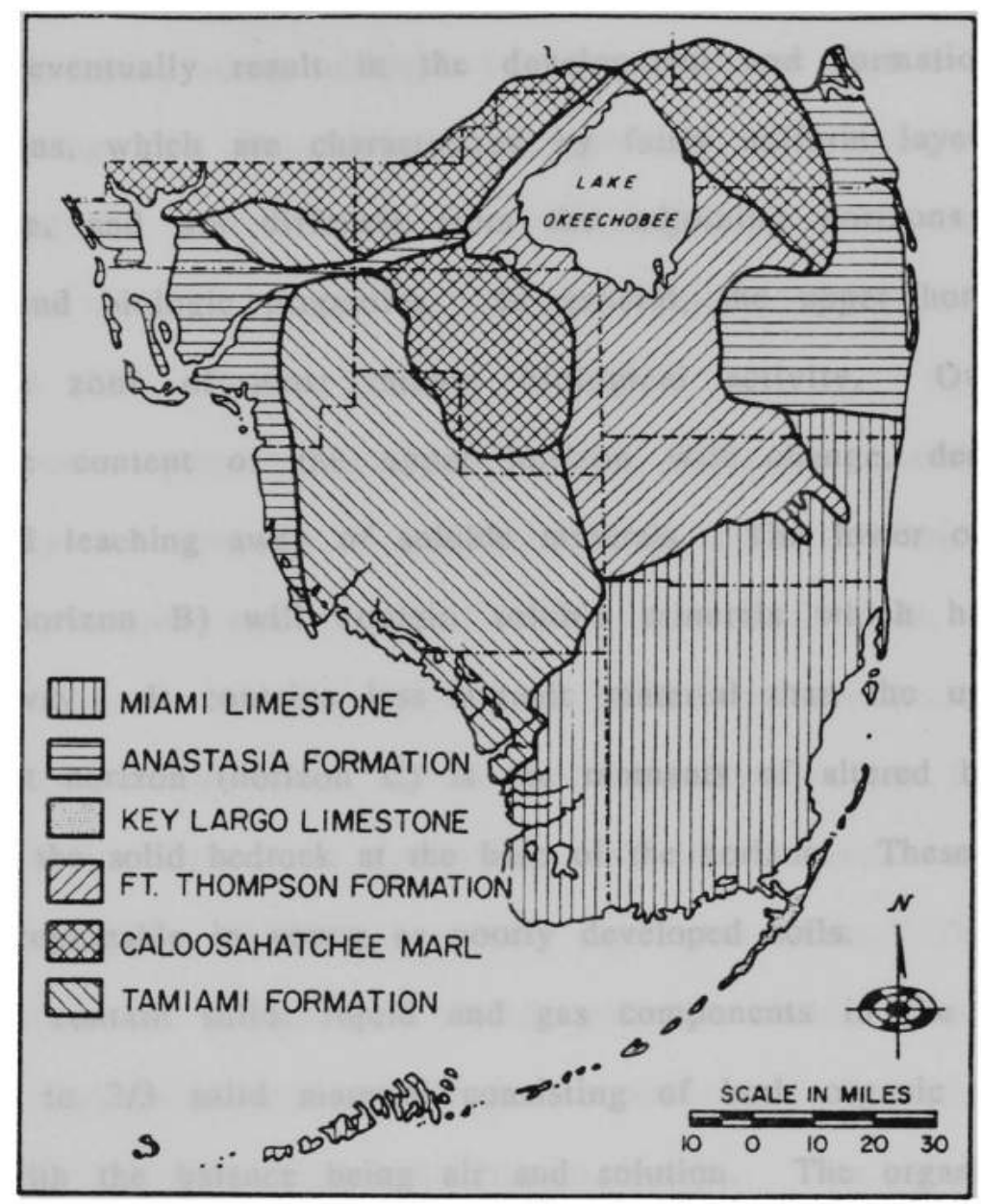

Fig. 2: Geologic map of South Florida (from Hoffmeister, 1974). 


\section{ORIGIN AND COMPOSITION OF SOLLS}

Solls develop slowly over lime as a result of the local or regional climate which influences physical and chemical weathering of bedrock and the gradual accumulation of organic material. These interacting processes eventually result in the development and formation of mature soil horizons, which are characterized by fairly uniform layers parallel to the surface, and are different from the adjoining horizons in physical, chemical and biologic properties. In general, the upper horizon (horizon A) is the zone of most intense biological activity. Over time the mineralogic content of the upper horizon will change, decreasing with the gradual leaching away of soluble minerals. The lower or intermediate horizon (horizon B) will contain soluble minerals which have not been leached away. It contains less organic material than the upper horizon. The lowest horizon (hotizon $C$ ) is the remnants of altered bedrock which grade into the solid bedrock at the base of the horizon. These horizons may not be recognizable in young or poorly developed soils.

Solls contain solid, liquid and gas components in the proportion of about $1 / 2$ to $2 / 3$ solid material consisting of both organic and inorganic matters, with the balance being air and solution. The organic fraction of soils in general is typically less than $10 \%$ of the total soil, and in most soits does not exced $2 \%$. However, in certain solls, peat and muck soils, which are found in South Florida, the organic fraction may account for up to $50 \%$ of the soil volume. Peat soils are composed of undecomposed or slightly decomposed organic matter accumulated under water in anaerobic conditions. Muck solls consist of the very decomposed organic material in which the original plant components are not recognizable. Muck is 
Ustally darker than peat and contains more minerals (Sposino, 1989; Adriano, 1986).

The coarse fraction of soils contain all the materials which are recognizable as unaltered or partially altered flota or fauna, along with mineral aggregates, rocks, etcetera having a diameter greater than 1 mm. The remaining fine fraction consists of mineral particulates, and the organic material which cannot be positively identified with complete accuracy and which is known as humus (FitzPatrick, 1979; Kabata-Pendias and Pendias, 1984; Sposito, 1989).

The humus plays a significant role as it absorbs quantities of water, adds solidity and structure to soil, exhibits a strong binding capacity, and can be flocculated and dispersed like clays (FilzPalrick, 1979). The structure of hamus is complex, and the biochemical processes by which it forms is not yet completely understood (Kabata-Pendias and Pendias, 1984; Sposito, 1989). Humus is categorted as having humic and non-humic substances. Mumic substances are dark organic materials. The structure of mumic substances is that of coiled polymer chains which contain a relatively high proportion of oxygen containing functional groups such as phenolic hydroxyl, carboxyl and carbonyls. The large number of functional groups in the matrices bind with trace elements known to have affinity for organic matter. Humic substances have the ability to react chemically with metal ions and this is reflected in the present study as one of the main carriers of lons found in the smples.

Humic substances may be further divided into the fractions of humic acid, fulvic acid and humin, which are similat in structure but are fractionated on the basis of lueir differing solubility reactions. Humic 
substances are adsorbed by oxides and clays and have the ability to form organometallic complexes with cations.

Because of these characteristics soils are an important geochemical sink, acting as boh a reservoir and a natural buffer for trace elcments. Thus, soll characteristics (e.g. organic mater present in the sall) influence the transport of trace elements. their accumulation and availability to plants (Kabatampendias and Petudias, 1984; Sposito, 1989). In addition to trace elements associated with the organic components of soils, water borne trace elements exist in soluble forms for short periods of time, being present mainfy as suspended colloids of particulates, and may become fixed to mineras or organic materials. (Kabatamendias and Pendias, 1984).

\section{SOURCES OF METALS IN SOILS}

As discussed in the preceding section, solls not influenced by anthropogenic input derive their metal content from the weathering of the parent material from which they evolved. In the case of South Florida which is underlain by limestone formations, the natural major mineral consituent is calcim carbonate in the fom of calcite and aragonte. However, these minerals rarely occur naturally in compositionally pure phases, and the elements Mg, Fe, Sr, Ba, Mn, Co, Cd, Cu, Ni, Pb and Zn are frequently included in their mineralogy as a trace element (Brownlow, 1979; Sposito, 1989).

The redistribution of trace clements in soil results from leaching, adsomption onto soil surfaces, translocation, incorporation into platsts and their producis of decay or co-precipitation (Appendix $G$ ) of minerals 
(FitzPatrick, 1979; Kabata-Pendias and Pendias, 1984; Bohn, MeNeal and O'Connor, 1985; Sposito, 1989). For instance, soils that experience periods of water saturation may show motting, as a result of the reduction of leached iron which produces soil colors characteristic of the valance state of iron. These color changes can be a helpful characteristic in identifying areas subject to periodic saturation, with reddish colors associated with $\mathrm{Fe}^{3+}$ and biue or grayish colors associated with $\mathrm{Fe}^{2+}$

Anthropogenic influences are chronicled by increasing levels of frace elements, not limited to those elements which are found in the parent material. The sources of these elements are numerous, including, but not limited to, input from fertilizer, pesticides, herbicides, sewage shage, animal wastes, municipal refuse, waste and irrigation waters, fossil fuel combustion, mining and smelting operations, and auto emissions. Since trace elements are released into the atmosphere and hydrosphere and can be tralsported and deposited over greal distances, the sources of increased levels of trace elements is not necessarily a localized or pointsource phenomenon.

Dissolved consituents in soils are constanty being mobilized by meteoric waters which percolate downward and flow laterally carying along differen types of ions. The manslocated ions can be sorbed by soils or sediments, or may be absorbed or adsorbed by plants. The uptake of trace elements by plants, along with the strong affinity humic substances have for certain trace clements can lead to the accumulation of trace clements at or near the soil surface. The prinuaty mothod of arace clement uptake by plants is through active and passive adsorption by roots. Trace elements are also adsorbed by foliar upeake through non-metabolic 
cuticular penetration fassive adsorption from aerial sources througt the leaves) and metabolic mechanisms accounting for element accumulations across a concentration gradient facive transport across the plasma membrane into the cell protoplast), as well as absorption by plant roots.

\section{KNOWN GEOCHEMICAL BEHAVIORS OF ELEMENTS}

Cerain elements exhibit similar chemical behaviors that are reflected by their placement on the periodic table. The knowledge of elemental behavior provides a useful tool in the use of elements as tracers for other elements, materials or processes.

Twenty-two elements were selected for investigation in this study. This section and accompanying table (Table 1) summarize the known geochemical behaviors of the elements in this study.

\section{Geochemical Behaviors of Main Elements in Soils}

\section{Aluminum}

Aluminum occurs in soils as the stable ion Al3t, and along with oxygen containing ligands forms in the solid phase hydroxide $\mathrm{Al}(\mathrm{OH}) 3$. This form and other $\mathrm{Al}$ hydroxides develop during weathering and form the structural components of clay minerals. Aluminum hydroxides are more mobile in acidic soils, and are not very soluble in the moderate range of $\mathrm{pH}(5.8)$, and their general solubility decrease with age. Aluminum is known to be associated with the trace elements beryllium, yotrium and chromium. 


\section{TABLE 1}

\section{A SUMMARY OF KNOWN GEOCHEMICAL BEHAVIORS OF THE ELEMENTS IN THIS STUDY}

1. Major soil constituents: $\mathrm{Fe}, \mathrm{Si}, \mathrm{Al}, \mathrm{Ca}, \mathrm{Mg}$

2. Trace elements from carbonates: $\mathrm{Sr}, \mathrm{Mg}, \mathrm{Ba}, \mathrm{Mn}, \mathrm{Fe}, \mathrm{Cd}, \mathrm{Pb}, \mathrm{Zn}, \mathrm{Co}, \mathrm{Cu}$, $\mathrm{Ni}, \mathrm{Sc}, \mathrm{Be}$

3. Trace elements from silicates/clays: $\mathrm{Fe}, \mathrm{Mn}, \mathrm{T}, \mathrm{Cr}, \mathrm{Y}, \mathrm{V}, \mathrm{Co}, \mathrm{Zn}, \mathrm{Pb}, \mathrm{Cu}$, $\mathrm{Be}, \mathrm{Se}, \mathrm{Sr}$

4. Toxic elements from anthropogenic sources: $\mathrm{Cd}, \mathrm{Cu}, \mathrm{Pb}, \mathrm{Co}, \mathrm{Be}, \mathrm{Ba}, \mathrm{Mr}$, $\mathrm{Zn}, \mathrm{Ni}, \mathrm{Fe}, \mathrm{Cr}, \mathrm{Sr}, \mathrm{Sb}$

5. Elements from anthropogenic pollutants: $\mathrm{Pb}, \mathrm{Ni}, \mathrm{P}, \mathrm{Cd}, \mathrm{Cr}, \mathrm{Cu}, \mathrm{Be}, \mathrm{Ba}$, $\mathrm{Mn}, \mathrm{Zn}, \mathrm{Fe}, \mathrm{V}, \mathrm{Co}, \mathrm{Sb}$

6. Elements known to have a strong organic affinity: $\mathrm{Be}, \mathrm{Sb}, \mathrm{Cd}, \mathrm{Ni}, \mathrm{Cu}$, $\mathrm{Zn}, \mathrm{Mn}$ 


\section{Antimony}

Antimony occurs usually as $\mathrm{Sb}^{3+}$ and infrequently as $\mathrm{Sb}^{5+}$. Virtully nothing is known about its weahering reactions and behavior in soils. It is round in coat, peat and Fe hydroxides (Kabata-Pendias and Pendias, 1984), and if present in soils in a soluble form probably is substituing for p5+ in phosphates (Adriano, 1986).

\section{Barium}

Barium is most often associated with potassium bearing minerals because its ionic radius is so similar to $\mathrm{K}^{+}$. Barim is released through weathering of potassium bearing minerals, but its mobility seems to be limited in soils due to the fact that it is concentrated into mathganese and phosphorous concretions and minerals, and is easily precipitated into sulfates (Kabatamendias and Pendias, 1984).

\section{Bervlliutr}

Beryllium is an alkaline earh and may substitute for calcium, but it is not raplaced by the other akaline earth metals (Mg. Sr, Ba) due to its smallet atomic size. Beryllium forms complex organo-metallic compounds and accumulates in organic materials (plants and the humus of soiss), thus coals in some cases may be cnriched in this metal and combustion result in beryllium being released into the amosphere (Adtiano, 1986). The most common form in soils is $\mathrm{Be}^{2+}$, but rore complex forms also occur [Be(OH)CO3.] (Kabata-Pendias and Pendias, 1984). Soluble salts of beryllum, $\mathrm{BeCl}_{2}$ and $\mathrm{BeSO}_{4}$ are fainly mobile in solls. 


\section{Cadmium}

Cadnium like zinc and mercury, is a transition metal of group IIB of the periodic table and its natutat concentration in solls is derived from the parent rock. The abundances of cadmium are generally low less than 1.1 ppm on average (except for soils derived from shales or near cadmium bearing deposits of impacted by anthropogenic activity). Cadmium exists in a variety of forms in soils; incorporated as an oxide, hydroxide or hydrous oxide of Fe or Mn particulates, or as a coating on clays. It is adsorbed onto organic particulates, and forms chelates with organic matter as well as stable sulfides and lonic species in soll solutions. Anthropogenic impact in its abundance is significant by increased concentrations in humus enriched near surface layers. The largest. anthropogenic sources of $\mathrm{Cd}$ are atmospheric fallow from smelting operations, application of sewage sludge and phosphatic fertilizers (Adriano, 1986).

\section{Calcium}

Calcium tends to form simple ionic species and coordinates with oxygen donors, e.g. $\mathrm{CaCO}_{3}$. The most common cation in solutions of most soiks is $\mathrm{Ca}^{2+}$, and a high concentration of this ion is an indication of a near neutral pH. The trace elements most commonly associated with calcim are magnesium, strontium and barium; also commonly found are iron, manganese, cobalt, cadmium, copper, nickel, lead, uranium, and zinc. Magnesium is the most prevalent as some calcitic skeletal materials contain abundant magnesium carbonale (Brownlow, 1979). 


\section{Chrominm}

Chromium in soiss occurs in various oxidation states, with $\mathrm{Cr}^{3}+$ and Crtat being the most common. The 111 form is similar in geochemical properties and ionic size to $\mathrm{Al}^{3+}$ and Fe ${ }^{3+}$, and is more stable than the more oxidized state. Chromium asso forms complex jons, e.g. Cr(OH)2r, $\mathrm{CrO}_{4}{ }^{2}$. Much chromium in soils occurs as $\mathrm{Cr}^{3}+$ in Fe or $\mathrm{Cr}$ oxides but also complexes with humic and fulvic acid (Adriano, 1986). In solls of ph greater than 5.5 $\mathrm{Cr}^{3+}$ exhibits limited mobility as it precipitates, except when organically complexed. The more soluble $\mathrm{Cr}+$ form is more readily sorbed by clays and oxides in acid conditions and more mobile in alkaline conditions. Chromium which is added to the soil as a result of anhropogenic activity is asually accumulated in the thin surface layer.

\section{Sobalt}

Cobalt follows the general distribution of iron, being found in many Fe-bearing minerals. Cobalt is not mobile as a soluble phase in soils except during weathering in an oxidizing acid environment. It forms $\mathrm{Co}^{2}+$ and $\mathrm{Co}^{3}$ axidation states and is sorbed easily by fe and Mn oxides. The profile of $\mathrm{Co}$ in soils may resemble that of $\mathrm{Fe}$, or $\mathrm{Mn}$ if enrichment of $\mathrm{Mn}$ minerals exists in that particular soil. Cobalt forms organic complexes and is mobile iil sois in a chelated form.

\section{Copper}

Copper occurs in the oxidation state $\mathrm{Cu}^{+}$and $\mathrm{Cu}^{2}$, and can substitute for $\mathrm{Fe}^{2+}, \mathrm{Mg}^{2+}$, and $\mathrm{Zn}^{2+}$. It exisss as the native metal and in compounds 
such as sulfides and oxides. The copper content of a pristine soll will reflect the Cu content of its parent material and will show a fairly uniform distribution in a soil profile. Copper is adsorbed onto $\mathrm{Mn}$, Fe and Al oxides, and clays, and is adsorbed and complexed by organic matter. It is one of the more immobile trace elemens when bound in soils. When delivered to a soil, e.g. from atmospheric fallout or direct application, it tends to remain in place because it is so strongly fixed by organic materials, the oxides and clays. Therefore, copper enrichment occurs within the first few centimeters at the top of the soil profile.

\section{Lron}

Iron is one of the most prevalent elements in the ishosphere, it occurs in soils primarily as small particulates of oxides and hydroxides or as surface coatings on other minerals. It also forms mobile organic complexes, and occurs primarily as cholates in organic rich soils allowing Fe to mobilize between horizons and be leached from the soil. In soils that are periodically water saturated increased solubility of iron occurs due to the reduction of $\mathrm{Fe}^{3}+$ to $\mathrm{Fe}^{2+}$.

\section{Lead}

Lead exists primarily in the oxidation states $P^{2+}$ and is known to occur less frequently as $\mathrm{Pb}^{4+}$. I occurs in many different minerals with PbS, galena, being the most common. Lead also substitutes for $K$, Sr, Ba, $\mathrm{Na}$ and $\mathrm{Ca}$, so it is present as a trace element in other minerals as well. As lead is weathered out it is adsorbed onto $\mathrm{Mn}$, Fe, and Al oxides. The natural lead concentration in solss is denved from the parent material, but lead 
polution (from industrial and automobile emissions) is so widespread now that soils are likely to be entiched. The accumblation of lead often observed at the sufface of the soil profite is loough to result from its fixation by organic matter.

\section{Magnesium}

Magnesium occurs as a divalent cation, is adsorbed by Fe and Mn oxides, can substitue for calcim and be replaced by some of the same trace elements that replace $\mathrm{Ca}^{2}+$, i.e. $\mathrm{Sr}, \mathrm{Ba}, \mathrm{Pb}$.

\section{Manganese}

Manganese is one of the more abundant elements in the lithosphere. It is similar in behavior and natural occurrence to iron. Manganese exists commonly in three oxidation states, $2+, 3+$ and $4+$. It is widely distributed. forms oxide and uydroxide coatings on soil particles. The lonic size of $\mathrm{Mn}$ is similar to Fe, $C a$ and $\mathrm{Mg}$, allowing substitution for these elements in a wide variety of minerals in igneous, sedmenary and metamorphic rocks. Higher concentrations of $\mathrm{Mn}$ have been noted for soils which contain large amounts of organic tmaterial. This reflects fixation of manganese by organic complexing, and may result in higher concentrations in surface soils where manganese has been added by anthropogenic means, e.g. sewage sludge. Manganese also concentrates in horizons where entichment of iron oxides and hydroxides have occurred. 


\section{Nickel}

Nickel distribution is similar to iron, as is its behavior. Nickel is mobile as $\mathrm{Ni}_{2}+$, relatively stable in aqueous solution and may be transported over far distances. Nickel occurs as soluble chelates or other organic compounds in surface materials, and also co-precipitates with $\mathrm{Fe}$ and $\mathrm{Mn}$ oxides. Although widely distributed in the natural environment, $\mathrm{Ni}$ has become a pollutant as a result of atmospheric emissions from fossil fuel combustion, smelting operations and the surface applications of phosphate fertilizers and sewage shudge.

\section{Phosphorus}

Phosphorus exists in soils as the only stable oxidation state, phosphate $\left(\mathrm{PO}_{4}\right)$, and forms complex mixtures of iron, aluminum and calcium phosphates. It competes with arsenic for chemical binding sites in these mixtures. Some rock phosphates are enriched in trace clements, e.g. $\mathrm{Cd}$, $\mathrm{Ba}, \mathrm{Cu}, \mathrm{Mn}, \mathrm{Pb}, \mathrm{Sr}, \mathrm{Zn}$ and others. The application of phosphatic fertilizers can carry these trace elements into the environment.

\section{Scandium}

Scandium oecurs as $\mathrm{Sc}^{3+}$ and can substisute for $\mathrm{Al}^{3+}, \mathrm{Fe}^{3+}, \mathrm{Ti}^{3+}$, and $\mathrm{Y}^{3+} . \quad \mathrm{It}$ is found in ferromagnesian minerals, e.g. pyroxene and homblende, and forms complexes with phosphates, and sulfates. It has been detected in ash residues of some coals, fuel oils and peat which could indicate future environmental entichment due to atmospheric fallout from fossil fuels combustion (Kabata-Pendias and Pendias, 1984). 


\section{Silicon}

Silicon is one of the most stable and abundant dements in soils occurring in quart 2 minerals and amorphous silicates.

\section{Strontium}

Strontium is a fairly common element in the lithosphere whose concentration in soils is dependent upon the parent rock and climate. It is biogenically precipitated as a trace element in the calcareous tests of invertebrates, and daring weathering is readily incorporated into clays and forms chelates.

\section{Tisanium}

Like silicon, itanium is also abundart in the lithosphere, It most commonly occurs as $\mathrm{Ti}^{4}+$, may substitute for Al in igneous minerals (pyroxene, homblende, biotite) and is associated with igneous rocks, silicates, titanites, and oxides. Titanium minerats are stable in soils, and its oxides and hydroxides are only weakly soluble in aqueous solutions.

\section{Vanadium}

In general not much information is available on the geochemistry of vanadium, It occurs in oxidation states of $\mathrm{V}^{2}+, \mathrm{V}^{3}+, \mathrm{V}^{4}+$ and $\mathrm{V}^{5+}$ and can replace $F e, A l$ and $T i$ in parent rock mineral structures. Vanadium weathers out and is incorporated or sorbed onto $\mathrm{Fc}$ oxides and clays in soils. It is also found in crude oils and organic chelates. Varadium frequently exhibits a high correlation with Fe in soil studies and can be expected to accumulate where soils are rich in Fe oxides and clays. 


\section{Ylrium}

Yttrium is a faiply common element in the lithosphere and is distributed somewhat evenly among the different rock types. Geochemically its properties are like the lanthanides or rare earths (the trivalent form is most common and is concentrated in argillaceous sediments and phosphorites) but it is also associated with ahuminum. Yttrium occurs as $Y^{3+}$ and is found in silicates, oxides and phosphate minerals. Ytrium apparently does not accumulate in organic material as its abundances in coals is reponed to be small.

\section{Zinc}

Zinc occurs only in the $I 1$ oxidation state. It is a constituent of many igneous, metamorphic and sedimentary rock forming minerals, particularly those rich in iron. Weathering releases the zinc from the crystal lattices in the parent materials, in alkaline environments it precipitates into hydroxides on clay surfaces, in neatral or acid enviromments it exists as one of the $\mathrm{zn} 2+$ ions. Zine as been observed to accumulate in organic rich surface solis and in some peats. If forms organic complexes and chelates. It is known to substitute for $\mathrm{Mg}^{2}+$ in silicates, and is absorbed and coprecipitated in Fe, Al, and Mn oxides. 


\section{CHAPTER THREE}

\section{SAMPLE DESCRIPTIONS}

The samples taken for the present study are from locations in South Florida (Fig 1). The sites are underlain by limestone of the Miami or Fort Thompson Formations. The soils which have developed over this limestone generally are shallow (less than 1 meter).

Twelve cores were obtained along with eleven surface samples from sites which were not sutable for coring (Appendix A). Five of the cores covering a broad area of South Florida were selected for this project analysis. Coring sites were chosen based on accessibility and depth of sediment present. Sediment thickness was determined by the insertion of a probe and if greater than $50.8 \mathrm{~cm}$ a core was collected adjacent to, but not including the path of the probe. Samples were collected using either the Wildco Hand Corer model 2420 , or a rigid plastic tube which was covered with a board and hammered into the subsurface, of a land operated piston corer. When the core was removed, it was capped both ends, labeled and transported upright to avoid disruption of the cored material and hrozen upright to preserve any sedimentary structures which might be present. Appendix $B$ has more details on sampling methods.

The division of cores into segments for analysis was based on three factors; the presence of stratigraphic features, the lack of features and packing. If the core contained stratigraphic features which could be used as a guide for segmentation, I followed the feaures when selecting the segments. In the cores which were laminated, but had no other obvious primary sedimentary structures, I tred to keep the segments as equal as 
possible. In the instances in which the cores were loosely packed, I compensated for this by dividing slightly longer segments. In addition to these three factors an effor was made 10 divide the segments somewhat equally. 


\section{CORE DESCRIPTIONS}

\section{Lotru}

\section{Lofation:}

Latitude: $\quad 26042^{1} \mathrm{~N}$

Longinude: $\quad 80042^{3} \mathrm{~W}$

Site description: Lake Okeechobee (see comments below)

Site condition: under $61 \mathrm{~cm}$ water

Map quadrangle: USGS topographic map, Belle Glade, Florida

Method of collection: Wildco Hand Corer

Length of core: $\quad 24.5 \mathrm{~cm}$

Date collected: 9 fuly 1991

Comments: The sample was collected one meter north of the bank directly across from the Torry Island Campground in the southeastem quadrant of Lake Okechobee (Fig. 1). This site was selected because it was under water and had sufficient depth to be sampled. The lake has been and is presently used for recreational purposes, boating, fishing, etc. The Wildco Hand Corer was used due to its weight, it was placed into the soft sediments and allowed to gradually sink downard, thus minimizing disturbance to the sediments.

DESCRIPTION:

\section{Macroscopic}

General:

The upper $4.5 \mathrm{~cm}$ of the core was loosely packed with clumps of sediment and organic material separated from the sediment below. The sediments were fine grained 
and thinly laminated throughout, the laminae are generally less than $1 \mathrm{~mm}$ in thickness, and are not clearly visible in plate one.

0.4.5cm: Soft, watermaturated sediment, blackish red $(5 \mathrm{R} 2 / 2)$, with visible roots.

4.24.5cm: $\quad$ Sof1, water saturated sediment, grayish brown $(4 Y R$ R/2) roots visible to $5.5 \mathrm{~cm}$.

\section{Microscopic}

General: Sediment constituents are mostly micrite will rare quartz, ostracod, mollusk and gastropod fragments.

Surface: Mostly micrite, mixed with rare quartz and very rare osiracods.

$13 \mathrm{~cm}$ : Mostly micrife nixed with partially decayed plants, very ware quartz and very rare mollusk fragments.

$22 \mathrm{~cm}$ : Micrite, some quartz, very rare gastropod.

\section{Segmentalion of core:}

This core showed lamination, but no other primary sedimentary structure was visible. The core was divided into 4 segments.
1 upper $8 \mathrm{~cm}$
$8 \mathrm{~cm}$
$28+13 \mathrm{~cm}$
$5 \mathrm{~cm}$
$3 \quad 13-18 \mathrm{~cm}$
$5 \mathrm{~cm}$
$4 \quad 18-24.5 \mathrm{~cm}$
$6.5 \mathrm{~cm}$ 


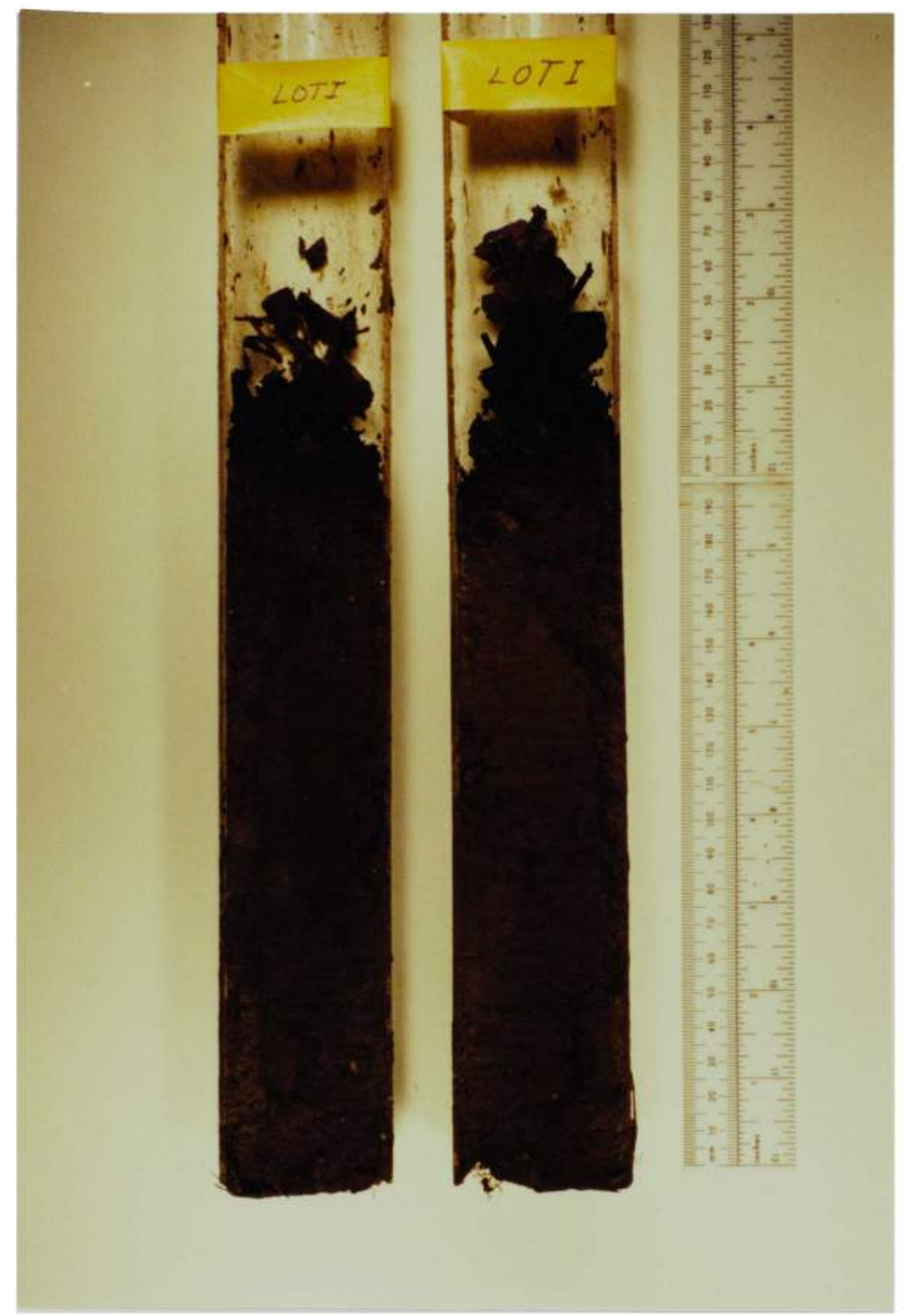

Plate one: Core from Lake Okeechobee 


\section{WCA $3 B-2$}

\section{Location:}

Latitude: $\quad 25046^{\prime} \mathrm{N}$

Longitude: $\quad 800.30^{\circ} \mathrm{W}$

Site description: Water Conservation Area 3B

Site condition: Dry at the time of sampling

Map quadrangle: USGS topographic map Coopertown, Florida

Method of collection: plastic tube

Length of core: $23 \mathrm{~cm}$

Date collected: 29 March 1991

Comments: The site is located approximately $.8 \mathrm{~km}$ north of the $\$-235$ spillway on canal C.4 (Tamiami canal) within the francis B. Taylor Preserve of the South Florida Water Management Water Conservation District $3 B$, approximately $2.4 \mathrm{~km}$ west of US 27 (Fig. 1). Usage of the conservation area is dependent upon seasonal conditions. This site was chosen because it was well within the confines of the water conservation area and high levels of mercury had previously been reported by the South Florida Water Management District (Richard Pfeuffer, personal communication, 1991). The site was accessible when sampled because the Water Conservation Area was dry. The plastic tube method was chosen as this had proven with my experience to be the best method in firm, dry sediments. 


\section{DESCRIPTION:}

\section{Macroscopic}

General:

The core consists of very dusky red (10R 2/2) peaty organic material with visible roots. No visible sedimentary structures present in this core (Plate 2).

\section{Microscopic}

General:

Sediment constituents are mostly decayed organic matter and some spicules, which may be phytoliths due to their very small size, and some carbonized plant remains and micrite.

$1-2 \mathrm{~cm}:$

Mostly decayed organic matter and some minute spicules (phytoliths) cemented with micrite.

$15 \mathrm{~cm}:$ Mostly plant parts and decomposed organic matter cemented with micrite and very rare spicules as noted above.

$22 \mathrm{~cm}:$

Partially decayed carbonized plant remains and micrite.

\section{Segmentation of core:}

Due to the fact that the core lacked sedimentary structures and was not tightly packed, it was divided into four even segments.
1 upper $6 \mathrm{~cm}$
$6 \mathrm{~cm}$
$2 \quad 6-12 \mathrm{~cm}$
$6 \mathrm{~cm}$
$3 \quad 12.17 \mathrm{~cm}$
$6 \mathrm{~cm}$
$4 \quad 17-23 \mathrm{~cm}$
$6 \mathrm{~cm}$ 


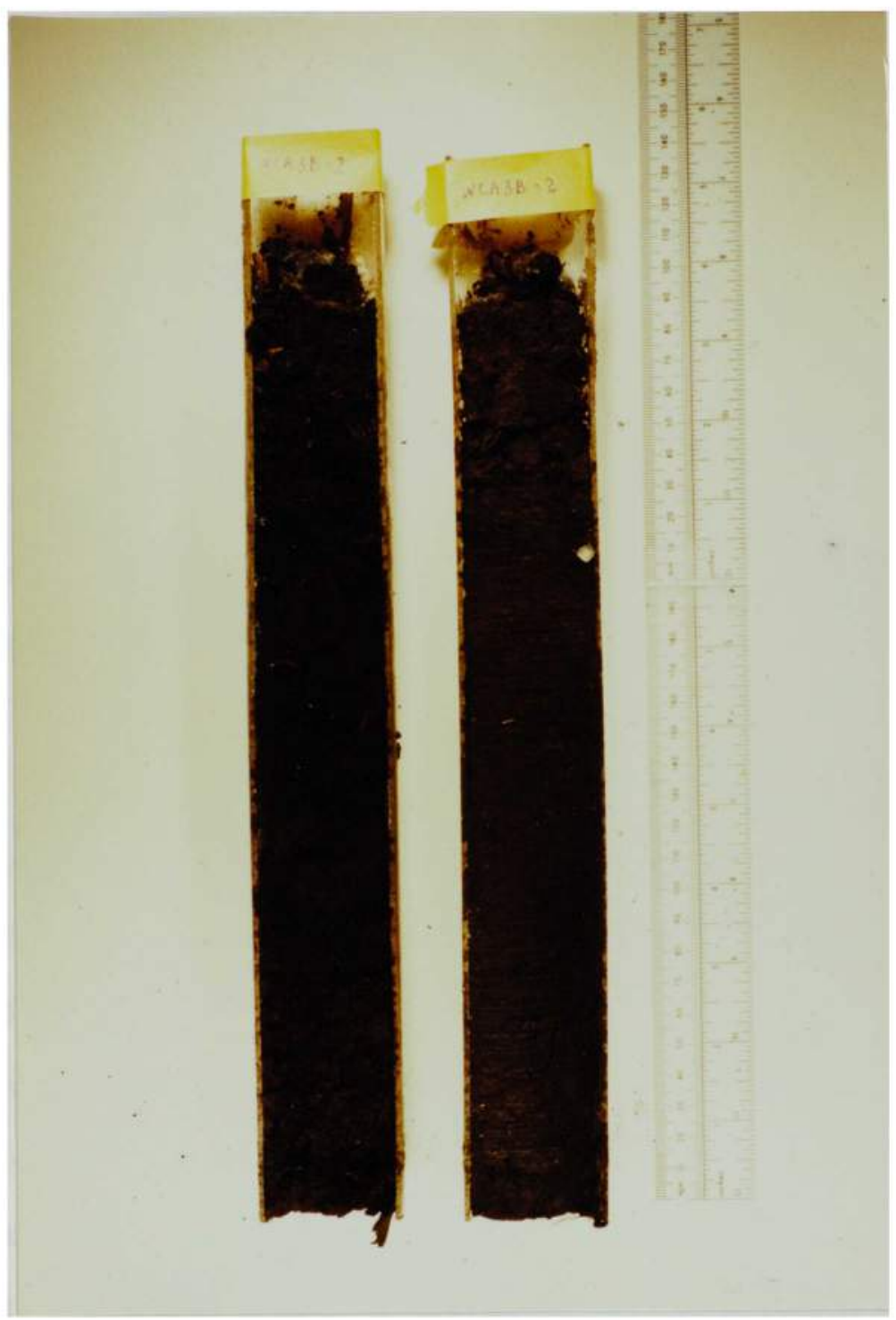

Plate two: Core from Water Conservation Area 3B 
FIU

\section{Location:}

Latitude: $\quad 25045^{\circ} 30^{\prime \prime} \mathrm{N}$

Longitude: $\quad 80023 \mathrm{~W}$

Site description: Florida International University Nature Preserve

Site condition: dry, firm surface

Map quadrangle: USGS topographic map Hialeah, S.W., Florida

Method of collection: plastic tube

Length of core: $39.5 \mathrm{~cm}$

Diate collected: 9 March 1991

Comments: The core was collected from a slight depression approximately the center of the nature preserve, south of Tamiami Trail (US 41) and west of SW 104th Ave, approximately 13.7 meters from the permeter road and from the edge of the preserve across from the runway parking area (Fig. 1). This site was selected because the preserve area exhibits topographical variations which appeared natural, soils follow the topography, with thicker accumulations in depressions. This area was once part of an airport and may have been disrupled by construction or other ase activities prior to 1972. The nature preserve was established in 1972 and has not been disturbed since the airport was moved out, except in 1974 when a large number of non indigenous trees were temoved. The plastic tube method was chosen because sediment at the site was firm and dry. 


\section{Macroscopic}

General:

$19.5-29.5 \mathrm{~cm}$

29.5-39.5 cm:

$0-19.5 \mathrm{~cm}:$

$19.5-29.5 \mathrm{~cm}:$

29.5-39.5 cm:
This core consists of layers of different colors and constiments (Plate 3).

Dark grey (5YR 3 N3) loose clumps of mixed quartz and organic matter with visible roots to 9 $\mathrm{cm}$. Gradational boundary from 18 to $19.5 \mathrm{~cm}$.

Quarkz sand, humus and sponge spicules in layered deposits of 1 to $7 \mathrm{~mm}$ thick, moderately brown (5YR 3/4) alternating with grayish ycllow (5YR 8/4).

Abrupt boundary, generally thicker lamination, very fine textured grayish yellow (5YR 8/4) micrite, with some 1 to $10 \mathrm{~mm}$ moderately brown (5YR 3/4) layers rich in decayed organic material.

\section{Microscopic}

Clumps of quartz cemented with organic matter and spicules,

Predominately quartz and sponge spicules, and humus.

Mostly pure micrite, with some very decayed organic material and quartz (Miami Limestone). 


\section{Segmentation of cors:}

The division of this core was based on the presence of the sedimentary features. The first four segments were comprised of the upper layer of the core. The following two segments contained the middle, quart $z$ sand enriched layer. The last two segments were the bottom layer, the Miami Limestone.

$\begin{array}{lll}1 & \text { upper } 5 \mathrm{~cm} & 5 \mathrm{~cm} \\ 2 & 5-10 \mathrm{~cm} & 5 \mathrm{~cm} \\ 3 & 10-15 \mathrm{~cm} & 5 \mathrm{~cm} \\ 4 & 15-19.5 \mathrm{~cm} & 4.5 \mathrm{~cm} \\ 5 & 19.5-24.5 \mathrm{~cm} & 5 \mathrm{~cm} \\ 6 & 24.5-29.5 \mathrm{~cm} & 5 \mathrm{~cm} \\ 7 & 29.5-34.5 \mathrm{~cm} & 5 \mathrm{~cm} \\ 8 & 34.5-39.5 \mathrm{~cm} & 5 \mathrm{~cm}\end{array}$




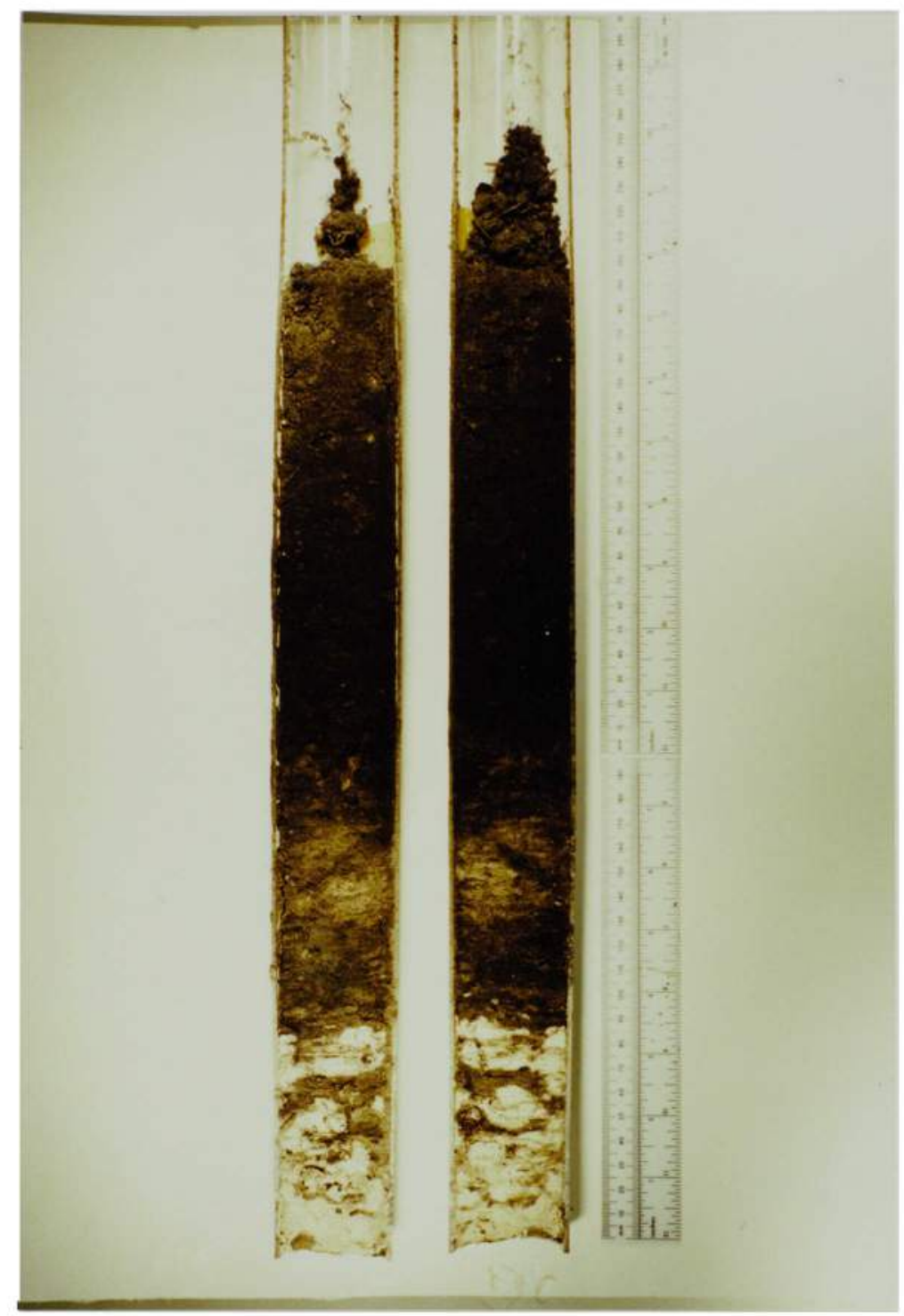

Plate three: Core from Florida International University 


\section{FCEG}

\section{Location:}

Latitude: $\quad 25043^{+} \mathrm{N}$

Longitude: $\quad 8003630^{\circ} \mathrm{W}$

Site description: Everglades, southwest of Frog City

Site condition: dry at time of sampling

Map quadrangle: USGS topographic map South of Cooperown, Flotida

Method of collection: plastic tube

Length of core: $29.3 \mathrm{~cm}$

Date collected: 5 July 1991

Commens: The site selected is on a hammock elevated above the surrounding flat, fooded terrain, approximately $2.8 \mathrm{~km}$ south of canal Cu4 (at Frog City) and $1 \mathrm{~km}$ east of the Blue Shanty canal (Fig 1). The site is 25 meters southeast from the nothwest bank of the hammock and is accessible only by airboat. When sampled, the site was dry and the sampling method selected was the plastic tube. The site was selected because it was well within the Everglades and because it was indicated to me by local inhabitants that there had once been a camp on this hammock and some dumping may have occured there. The camp bumcd down in 1988 and was not rebuilt. There was little evidence of its having been there, (other than a clearing) no charred structure, supports or foundations were seen, Vegetation was plentiful. A boa slip had been dug out of the hammock. There was no refuse pile visible, and tho only other sign of dumping was an old piece of furniture. 


\section{DESCRIPTION:}

General:

$0-16 \mathrm{~cm}:$

$11+23.5 \mathrm{~cm}:$

$19.5-29.3 \mathrm{~cm}:$

$1.2 \mathrm{~cm}:$

$16-18 \mathrm{~cm}:$

$27-29 \mathrm{~cm}:$

\section{Macroscopic}

Laminac, less than $1 \mathrm{~mm}$, are noted throughout the length of the core. Roots are present throughout (Plate 4).

Mostly brownish black (5YR 2/1) soft sediment mixed with micrite.

Mostly soft sediment and micrite with gradational color change from 11 to $16 \mathrm{~cm}$. Light brown mottles $(5 Y \mathrm{R} 5 / 6)$ of $\mathrm{l}$ to $10 \mathrm{~mm}$ diameter in brownish black (5YR 2/1) matrix.

Soft sediment and micrite with a gradational color change from 19 to $20.3 \mathrm{~cm}$. Grayish orange (10 YR 7/4) sand sized grains in dark yellowish-brown (10YR 4/2) matrix. The matrix lightened with depth to moderate yellowish-brown (10YR 5/4).

\section{Microseopic}

Predominately fine decayed organic matter with clumps of micrite aggregate and quartz. Occasional gastropod test fragments.

Mostly micrite and organic matter mixed with Fo oxide and carbonized organic material. Some unidentified tiny mollusk fragments.

Fine humic material mixed with micrite and unidentifiable shell fragments. 
Segmentation of core:

The only primary sedimentary feature in the core was the presence of lamination. The core contaned gradational color changes which were so diffuse that boundaries were not clearly identifiable.

$\begin{array}{lll}1 & \text { upper } 7 \mathrm{~cm} & 7 \mathrm{~cm} \\ 2 & 7-12 \mathrm{~cm} & 5 \mathrm{~cm} \\ 3 & 12-17 \mathrm{~cm} & 5 \mathrm{~cm} \\ 4 & 17-23.5 \mathrm{~cm} & 6.5 \mathrm{~cm} \\ 5 & 23.5-30 \mathrm{~cm} & 6.5 \mathrm{~cm}\end{array}$




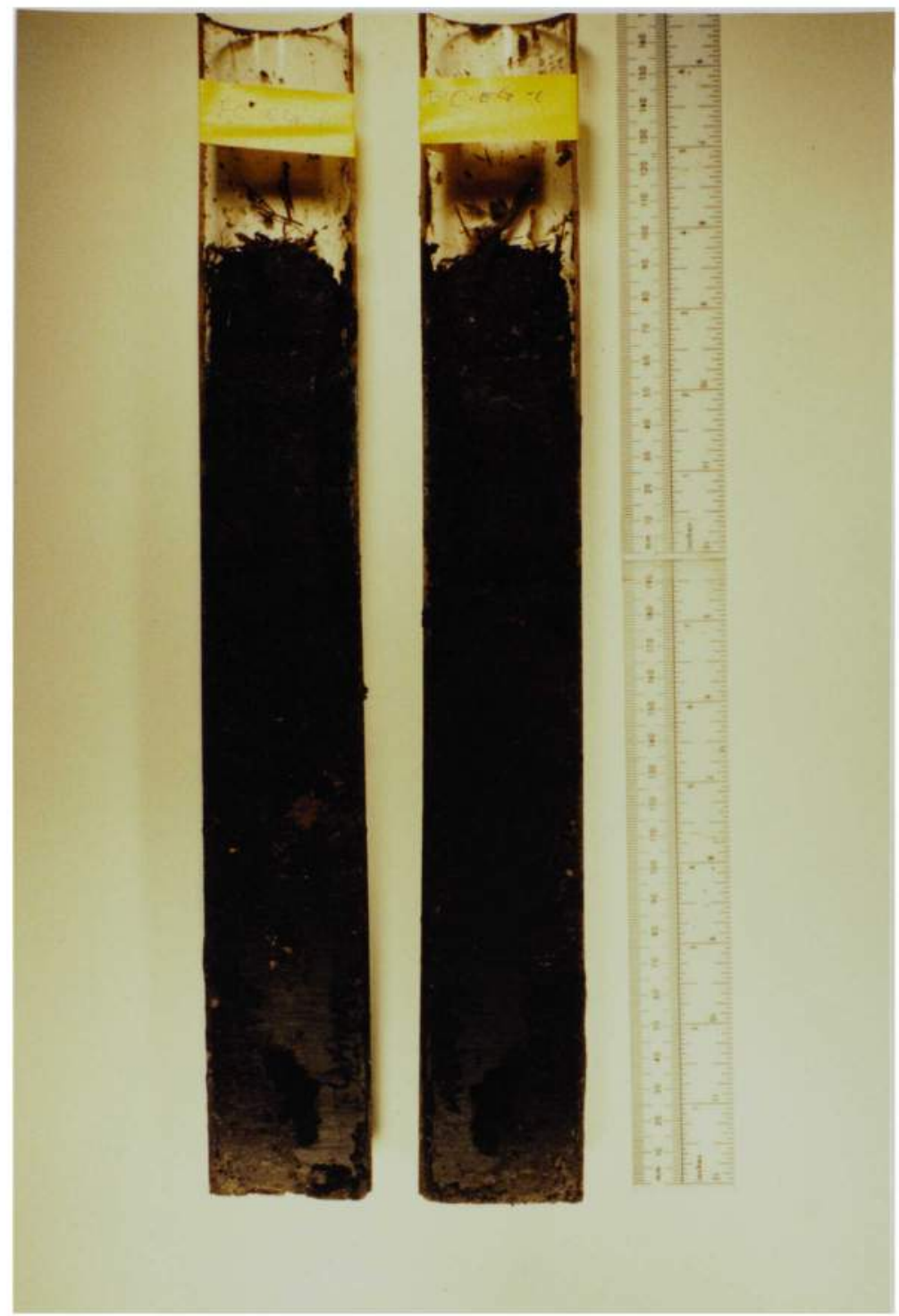

Plate four: Core from the Everglades 


\section{CSRA}

\section{Location:}

Latitude: $\quad 25 \circ 37^{\prime} \mathrm{N}$

Longitude: $\quad 80037^{\circ} \mathrm{W}$

Site description: Chekika State Recreation Area

Site condition: dry at the time of sampling

Map quadrangle: USGS topographic map Grossman Hammock, Florida

Method of collection: plastic tube

Length of cote: $\quad 32.3 \mathrm{~cm}$

Date collected: l1 July 1991

Comments: The site is located approximately $15.4 \mathrm{~km}$ west of Krome Ave, and west of SW 237 Ave (Fig. 1). The sample was collected approximately 2 meters north of the northemmost turn of the rature trail in the tropical hammosk. Chekika had previously been the site of exploratory oil drilling operations. An lllegal dumping area is located approximately $2 \mathrm{~km}$ north of the area where SW 237 Ave ends. The sile was selected because of accessibility and depth of sediment. The plastic lube method was used because the site was dry at the time of sampling. 


\section{Macroscopic}

General:

$0+11.5 \mathrm{~cm}:$

$10.5-21 \mathrm{~cm}:$

$18.5-32.3 \mathrm{~cm}$

Consists of three visually identifiable layers. Roots present throughout the core (Plate 5).

Dusky brown (5YR 2/2) sof muck mixed with pale yellowish-orange (10YR 8/6) micrite aggregates and clumps of quartz sand. Gradational boundary whth layer two.

Predominately pale yellowish-orange (10YR 8/6) quartz sand interfingered with pale yellowish-brown (10YR 6/2) mani.

Mostly finely laminated (less than $2 \mathrm{~mm}$ ) soft, grayish-

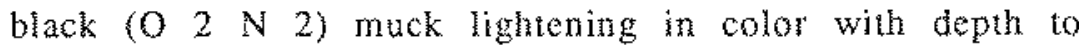
dasky brown (5YR 2/2). Also includes some yellowishgrey (5YR 8/1) clumped quartz and micrite aggregates.

\section{Microscopic}

1.2 cm: Mostly plant residue mixed with micrite and quartz with tiny unidentifable fragments of mollusk tests.

14-15 cm: Predominately quartz and some tiny fragments of reworked shells, some foraminifera; marine, shallow water benthic, assigned to Elphidium or cibicides, and little organic matter.

30-31 cm: Mostly quartz and humic material mixed with scant micrite. 


\section{Segmentation of core:}

The division of this core was based on the presence of its sedimentary features. The first two segments contained the upper layer of the core. The next two segments were comprised of the middle layer. The last two segments were the organic rich bottom layer.

$\begin{array}{lll}1 & \text { upper } 6 \mathrm{~cm} & 6 \mathrm{~cm} \\ 2 & 6-10.5 \mathrm{~cm} & 4.5 \mathrm{~cm} \\ 3 & 10.5-15.5 \mathrm{~cm} & 5 \mathrm{~cm} \\ 4 & 15.5-21.5 \mathrm{~cm} & 5 \mathrm{~cm} \\ 5 & 21.5-26.5 \mathrm{~cm} & 5 \mathrm{~cm} \\ 6 & 26.5-32.3 \mathrm{~cm} & 5.8 \mathrm{~cm}\end{array}$




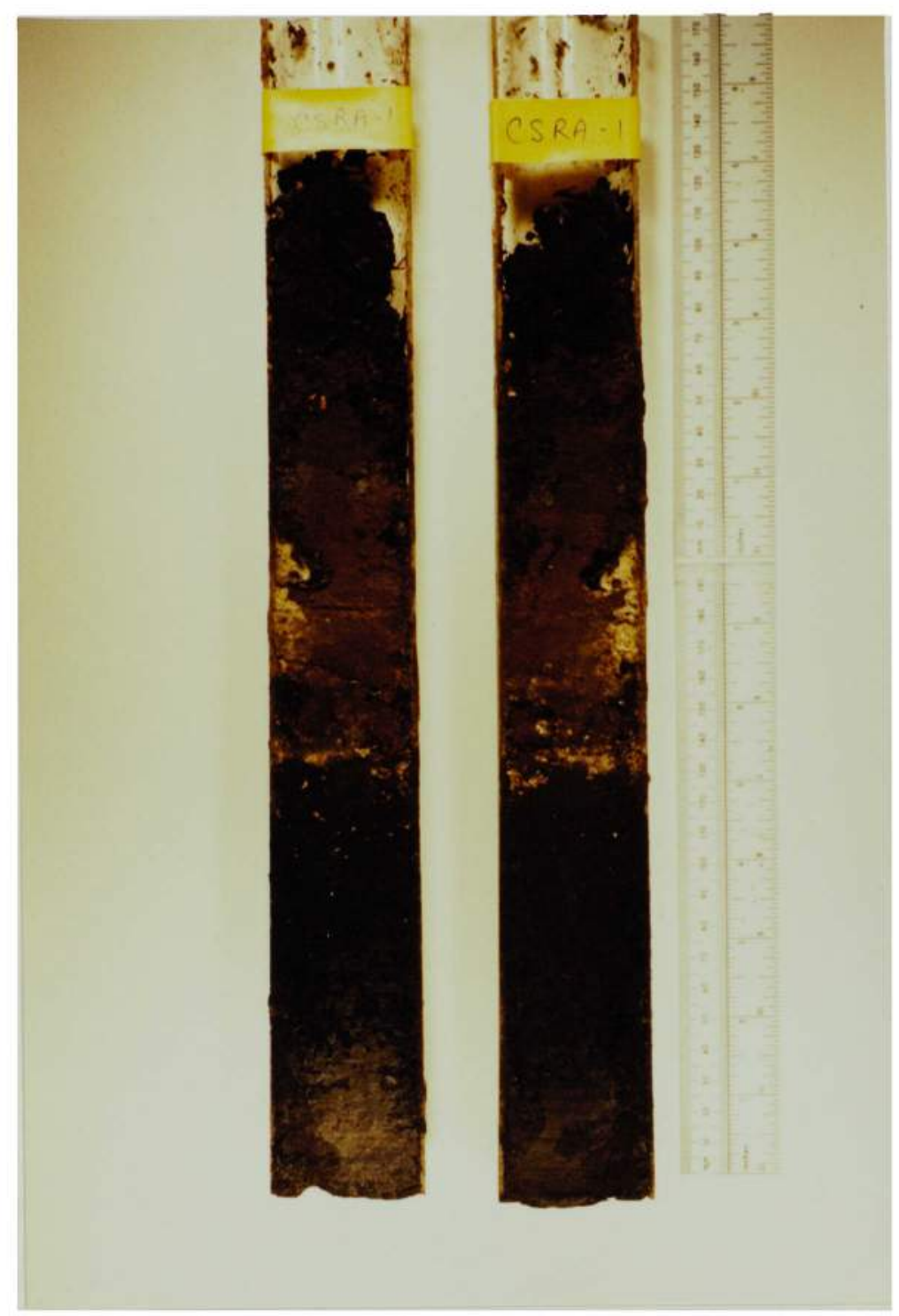

Plate five: Core from Chekika Recreation Area 


\section{CHAPTER FOUR}

\section{CHEMICAL ANALYSIS}

A flow chart conaining a summary of the steps involved in sample preparation is included after this section, and the detaled procedure is found in Appendix C. Brieny, each section of each core was dried at $1100 \mathrm{C}$, sieved and the samples of fine size fraction were split into 4 fractions: carbonate, organic (humic and fulvic acids) and residue. The carbonate and organic fractions were analyzed, the residue was reserved for future work. Each sample (except WCA3B2-1, 3 and 4) was also analyzed as a whole soil sample (not separated into the four fractional components). The four split fractions from eacl sample were analyzed by ICPES (Inductively Coupled Plasma Emission Spectrometer) for major elements Fe, Si, Al, Ca. $\mathrm{Mg}$ and trace elements $\mathrm{P}, \mathrm{Ni}, \mathrm{Ba}, \mathrm{Mn}, \mathrm{Cr}, \mathrm{Ti}, \mathrm{Sc}, \mathrm{Sr}, \mathrm{Sb}, \mathrm{Zn}, \mathrm{Pb}, \mathrm{Cd}, \mathrm{Co}, \mathrm{V}, \mathrm{Be}, \mathrm{Cu}$ and $Y$.

Since the relative proportions of organic and carbonate material from the samples could not be detemined during the separation, a separate evaluation was done using volatile loss palterns (Appendix D). The samples which had been previously heated to $1100 \mathrm{C}$, as noted above, were then heated to $550^{\circ} \mathrm{C}$ and $1000^{\circ} \mathrm{C}$ and weighed after each step. The percent weight lost at $5500 \mathrm{C}$ is proportional to the organic component. Mostly water bound in clays and hydroxides, and organic compounds are lost under $5500 \mathrm{C}$, whereas $1000^{\circ} \mathrm{C}$ is the temperature of decarbonation of carbonate, since the samples were clay and hydroxide poor. Therefore, the weight lost at each temperature interval is an estimate of the organic and carbonate fractions of the sample. 


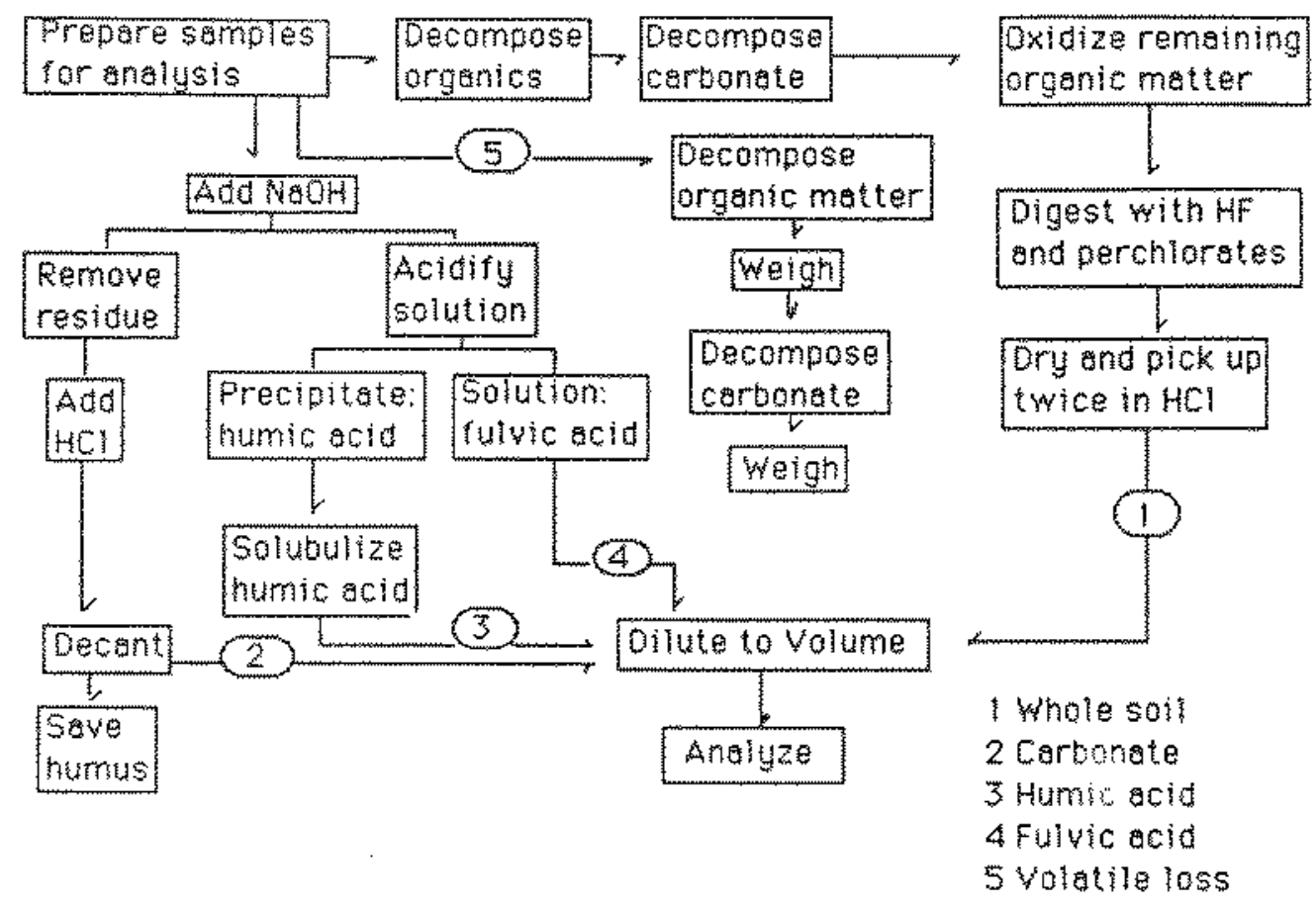

Fig. 3: Flowchart of chemical analysis procedure 


\section{RESULTS AND INTERPRETATIONS}

\section{Resuls}

The raw data with accompanying infomation on the reliability of the data may be found in Appendix E. Concentrations corrected for dilution are in Appendix $\mathrm{F}$.

\section{World and Florida Concentration Ranges}

Background concentrations of solls and sediments accepted as normal and presumably safe (toxic elemems) on a worldwide basis have becn assembled from various works and are compared to the elemental concentrations determined in this sudy for South Florida. This information is presented in Table 2, World and Florida Ranges. The concentrations presented are for whole soil measurements and have been corrected for dilution. Most of the concentrations are within the ranges accepted as nomal for soils on a world basis with the following exceptions: FCEG segments 1.4 enriched in cadmium, all FCEG segments enriched in phosphorus; CSRA segment 6 enriched in antimony, all CSRA segments enriched in phosphorus.

\section{Data Analysis}

I used several approaches to examine the data and assess the behavior of the clements:

1) whole soil element concentrations vs depth, 
2) element concentrations in each fraction vs depth.

3) affinity of elements for the various fractions,

4) cotrelation coefficients for element $v s$ etement, and for element vs volatite loss in the whole soil, and

5) principal component analysis.

\section{First Methodological Approach}

In the inst approach I constructed plots of the concentrations of the elements in the whole soil (not fractionated) in each segment vs the depths of the core segments. This indicates that elements are concentating at a particular depth, and although this approach is the most direct, it does not address possible changes in whole sont composition through the depth of the core. Because the cores and depth segments wete of different lengths, I developed a scale (Table 3) which allows the comparison between segmens from each cote based on their depths. I then recorded the segment in each cote where the peak abundances of each element occurred, and compared this information with lue depth scale from Table 3. Table 4 summarizes this approach by showing at what depth the peak abundances of each element occurs within each core. This permits a rough comparison between all the cores and highlights on the depths where the elements are concentrated. 


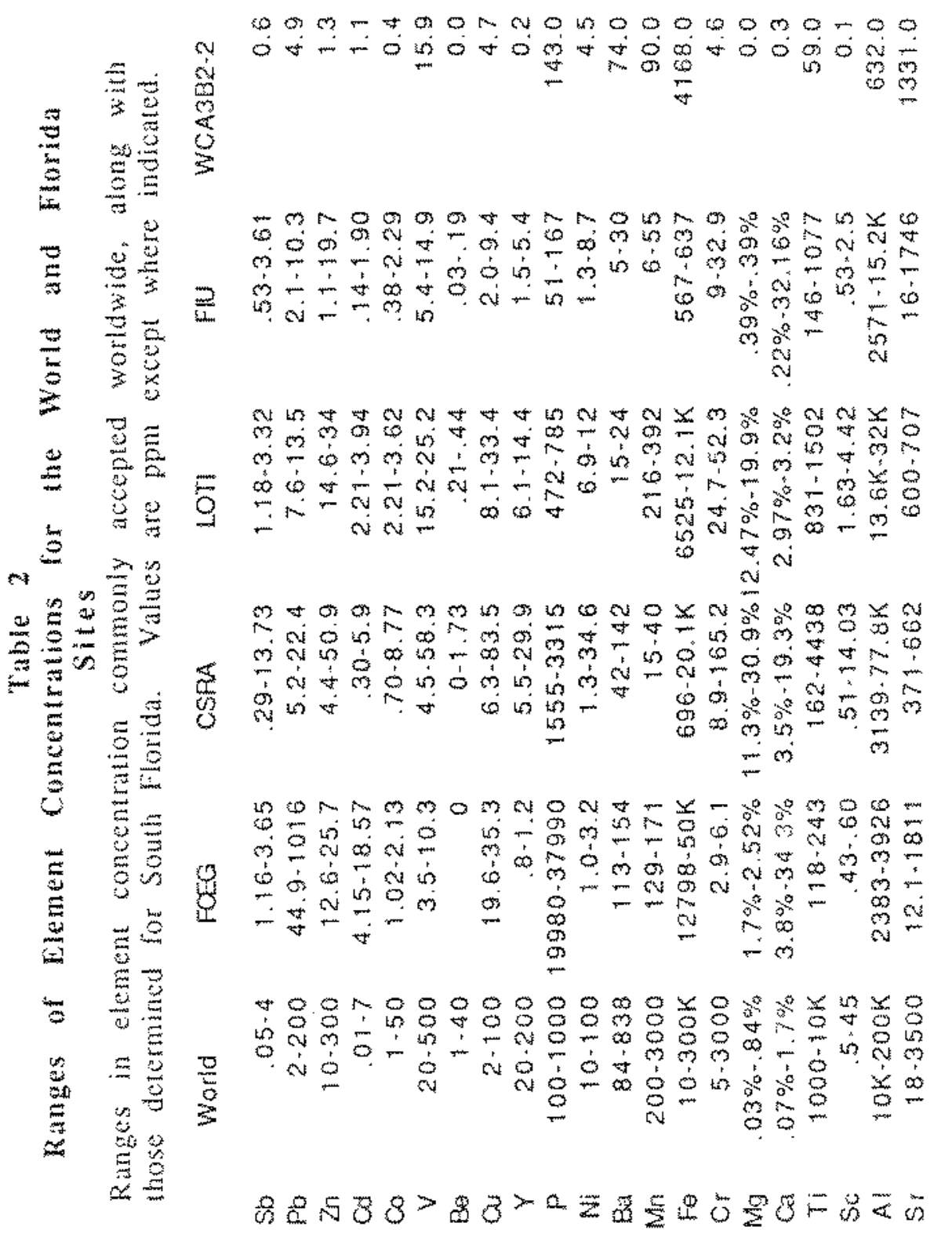


TABLE 3

\section{DEPTH COMPARISON BETWEEN CORES}

This scale provides a rough comparison between the depths at which the various segments from different cores are located. For example, any core segment which falls predominantly between 10 and $20 \mathrm{~cm}$ is included in the third segment.

$\begin{array}{lccccc}\text { Depth } & & \text { FIU LOT } & \text { FOEG CSRA } \\ <5 \mathrm{~cm} & \text { (1) } & 1 & 1 & 1 & 1 \\ 5-10 \mathrm{~cm} & (2) & 2 & 2 & 2 & 2 \\ 10-20 \mathrm{~cm} & (3) & 3,4 & 3 & 3 & 3,4 \\ 20-30 \mathrm{~cm} & \text { (4) } & 5,6 & 4 & 4,5 & 5,6 \\ 30-40 \mathrm{~cm} & \text { (5) } & 7,8 & & & \end{array}$


TALE 4

\section{Peak Abundances of Elements Within the Cores}

This table shows the depth at which the peak abundances of each element occurs within each core. Depth scale is from Table 3 . The greatest abundances of phosphorus is found in the first depth segment (upper 5 cm) in FIU, LOT, and CSRA. In the FCEG core the peak abundance of $\mathrm{P}$ is in the fourth depth segment $(20-30 \mathrm{~cm})$.

\begin{tabular}{|c|c|c|c|c|}
\hline Elements & Fu & LOTI & FOEO & CSRA \\
\hline$p$ & 1 & 1 & 4 & \\
\hline $\mathrm{Ni}$ & 2 & 4 & 2 & \\
\hline $\mathrm{Ba}$ & 2 & 1 & 2 & \\
\hline $\mathrm{Mn}$ & 1 & $\uparrow$ & 2 & \\
\hline$F_{\theta}$ & $t$ & 4 & 4 & \\
\hline $\mathrm{Cr}$ & 4 & 4 & 4 & \\
\hline $\mathrm{Mg}$ & 5 & 4 & 1 & \\
\hline $\mathrm{Ca}$ & 5 & 4 & 4 & \\
\hline $\mathrm{Ti}$ & 1 & 4 & 1 & \\
\hline So & 2 & 4 & 2 & \\
\hline $\mathrm{Al}$ & 2 & 4 & 1 & \\
\hline$S t$ & 5 & 1 & 4 & \\
\hline$S b$ & 2 & 2 & 2 & \\
\hline $\mathrm{Zn}$ & 1 & 1 & 4 & \\
\hline $\mathrm{PQ}$ & i & 1 & 1 & \\
\hline $\mathrm{cd}$ & 1 & 4 & 2 & \\
\hline$\infty$ & 1 & $A$ & 2 & \\
\hline V & 1 & 4 & 2 & \\
\hline Be & 3 & 4 & . & \\
\hline$a$ & 1 & 1 & 1 & \\
\hline$Y$ & 1 & 4 & 2 & \\
\hline
\end{tabular}


Certain pattems of behavior were noted in Table 4. The greatest concentrations of $\mathrm{Cu}$ always occurred near the top of the cores less than 5 $\mathrm{cm}$ depth. The greatest abundances of $\mathrm{Mn}$ were in the upper $10 \mathrm{~cm}$ of the cores. Conversely, Ni, Sc, Sb and Be never displayed a peak abundance in the upper $5 \mathrm{~cm}$ of the cores. Their greatest concentrations were always in the segments greater than $5 \mathrm{~cm}$. The peak concentrations of $\mathrm{Cr}$ were always greater than $20 \mathrm{~cm}$ depth.

These patterns do not necessarily reflect processes occurring at the site(s). Manganese is always found in the upper $10 \mathrm{~cm}$ of the cores. It is known to accumulate in top solis by complexing with orgatic matter, and may fixate on the surfaces of $\mathrm{CaCO}_{3}$. Its concentration in the upper $10 \mathrm{~cm}$ of the cores would likely be due to the abundance of organic matter associated with these depths. As detailed in the less than $550^{\circ} \mathrm{C}$ volatile loss study (Appendix D) these levels contain the highest percent estimates of surficial organic fraction. However, when the $\mathrm{Mn}$ from all five sites are ploted against both the less than $550^{\circ} \mathrm{C}$ and greater than $550^{\circ} \mathrm{C}$ volatile loss estimates, very little correlation is found. This indicates that concentrations are related to other factors, and highlights the need for pursuit of other avenues of investigation, as were discussed above.

The plots of element concentrations in the whole soil vs depth are included as part of figures 6 to 85 , (ref, p. 52-91) and when considered along with the peak element concentrations reveal trends which possibly Hllustrate the impact of changes in the bulk composition of the whole soil within a core. 


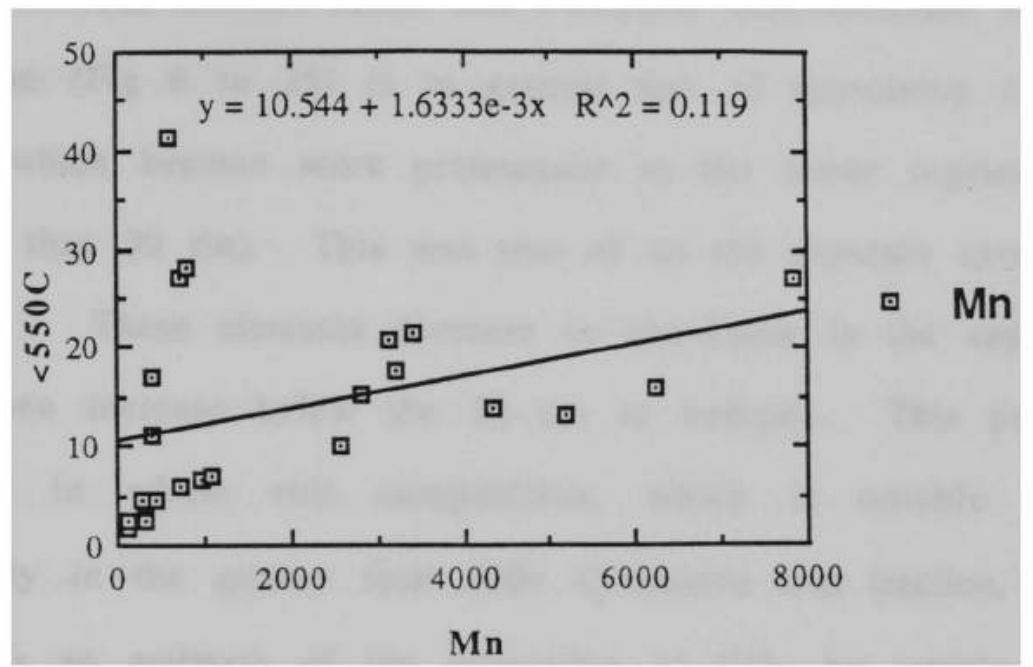

Fig. 4: $\mathrm{Mn}$ vs less than $550^{\circ} \mathrm{C}$ volatile loss

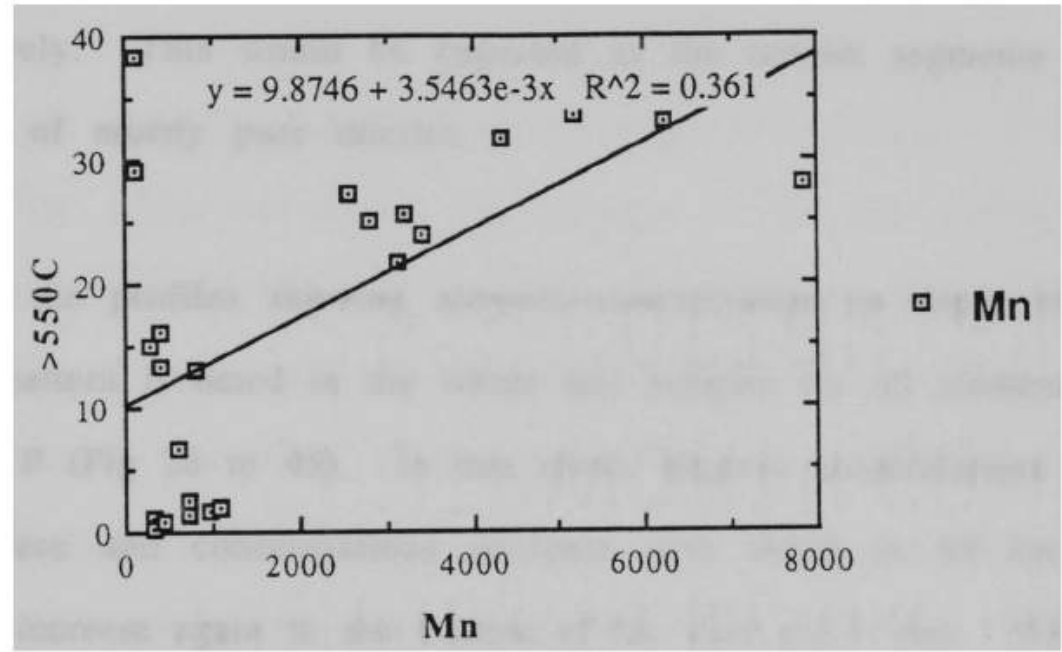

Fig. 5: Mn vs greater than $550^{\circ} \mathrm{C}$ volatile loss 
The trend of the whole soif elemental concentrations vs depth in the FIU core (Fig 6 10 25) is in general that of decreasing abundances with depth, which become more pronounced in the lower segment of the core (greater than $30 \mathrm{~cm}$ ). This was true of all the elements except $\mathrm{Ca}, \mathrm{Mg}, \mathrm{P}$, and $\mathrm{Sr}$. These elements decrease in abundance in the upper part of the core, then increase below the $30 \mathrm{~cm}$ to bedrock. This probably reflects changes in whole soil composition, which is notable in this core, especially in the greater than $550^{\circ} \mathrm{C}$ volatile loss fraction. This fraction, which is an estimate of the proporion of $\mathrm{CO}_{2}$ by sample, is $2 \%$ in the surface segment of the core, decreases to less than $.5 \%$ in the subsurface and then sharply increases in segments 7 and 8 to $29 \%$ and $38 \%$ respectively. This would be expected as the botom segments of this core consists of mostly pure micrite.

\section{CSRA}

In the profiles showing element concentration $v$ s depth for the CSRA core a pattern is noled in the whole soil samples for all elements except $\mathrm{Ca}$, Sr, and P (Fig 26 to 45). In this trend, element accumulations are noted at the surface and concentrations decrease with depth to $30 \mathrm{~cm}$ where they start to increase again to the bottom of the core $(32.3 \mathrm{~cm})$. When compared to the less than $5500 \mathrm{C}$ percent volatile loss (Appendix D) a similar pattern is seen where the percent volatile loss is $28 \%$ at the surface, decreases with depth $(17 \%, 5 \%, 11 \%$ respectively), and then demonstrates a large increase below $30 \mathrm{~cm}$ depth $(41 \%, 27 \%$ respectively). This is related to changes in composition, corresponding to the organic rich lower layer of the core. 
In the Lake Okeechobee core, little change is noted to occur in the whole soil in element abundance with depth (Fig 46 to 65). Most of the concentrations vary less than 1 ppm, witn the following exceptions: 1) $\mathrm{Al}$, $\mathrm{Ca}, \mathrm{Fe}, \mathrm{Mg}$, and $\mathrm{Ti}$, which vary by more than $10 \mathrm{ppm}$, 2) $\mathrm{P}$, which varies by 6 ppm, 3) Mn, which varies by $3.5 \mathrm{ppm}$, and 4) Sr which varies by 3 ppm. The less than $5500 \mathrm{C} \%$ volatile loss estimate indicates the greates proportion of organic matter $(28 \%)$ is in the upper segment of the core, followed by $16 \%, 13 \%$ and $14 \%$ respectively with depth. The greater than $550 \circ \mathrm{C} \%$ volatile loss varies litue, being $28 \%, 33 \%$ and $34 \%$ respectively with depth. No clear patterns are detected when comparing the changes in element concentrations with depth and volatile loss patterns.

\section{RCE:}

In the FCEG core (Fig 66-85) the major soll elements (Al, Ca, Fe, Mg) vary in the whole soll by at least 10 ppm. The trace elements show less variation. Strontium varies by $12.2 \mathrm{ppm}$ and phosphorus by $360 \mathrm{ppn}$. The other trace elements vary by less than 2 pprn through the core (Appendix E). When the variations of elemental abundances with deph are compared to the changes in the whole soil contents of the core as determined by the volatile loss study, no clear pattern emerges. In this core, there is a relatively small variation in the volatile loss for each segment. 


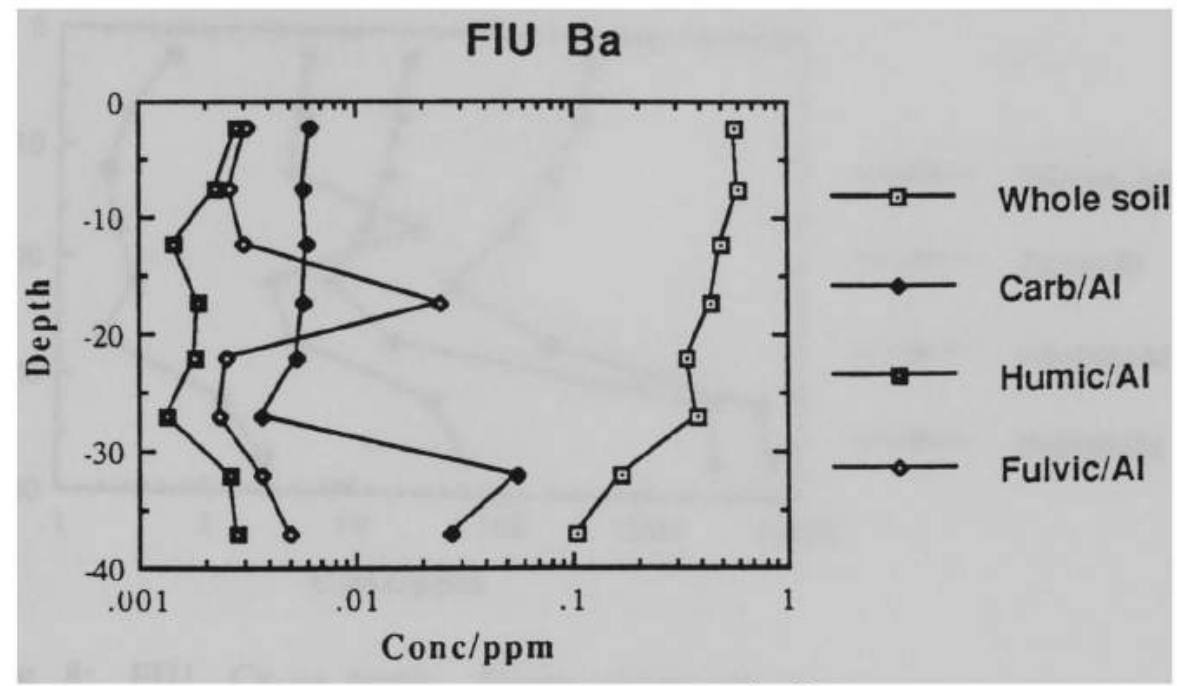

Fig. 6: FIU Ba vs depth. Average standard

deviations, sigma values, are: whole soil $2.7 \%$;

carbonate $1.7 \%$; humic acid $26 \%$; fulvic acid $8.3 \%$.

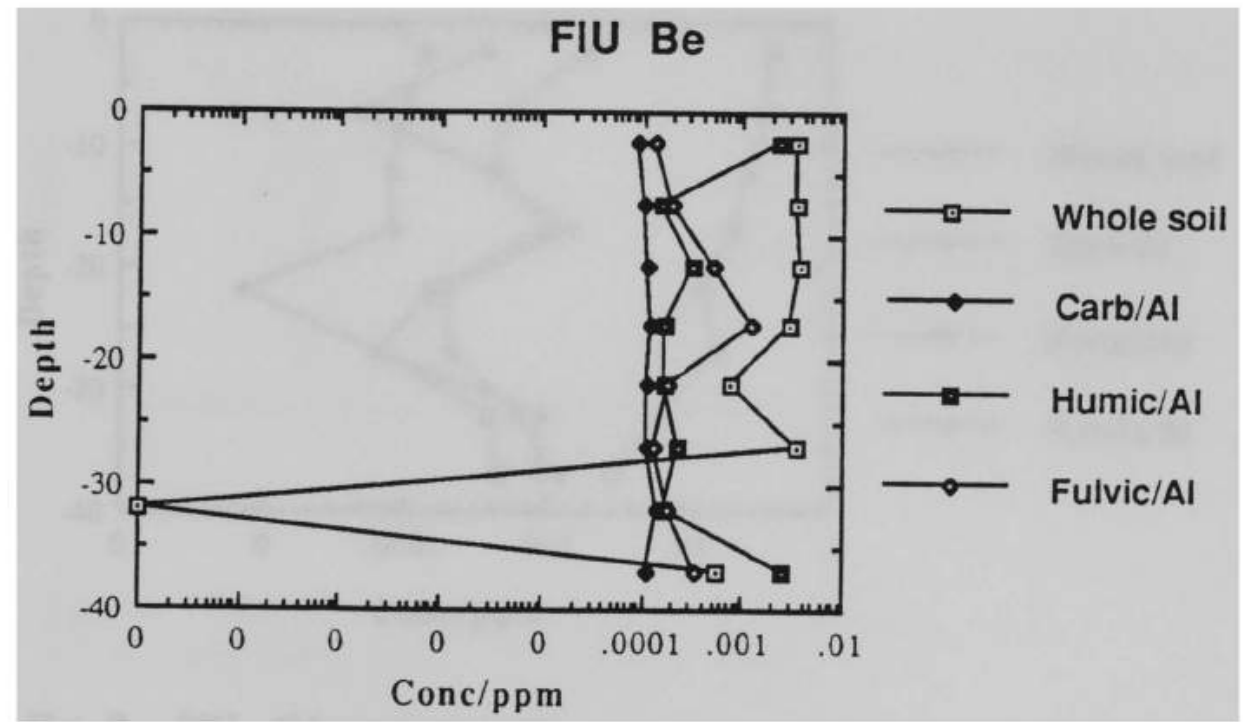

Fig. 7: FIU Be vs depth. Sigma values are w.s.

$4.1 \%$; carb $160 \%$; humic $310 \%$; fulvic $360 \%$. 


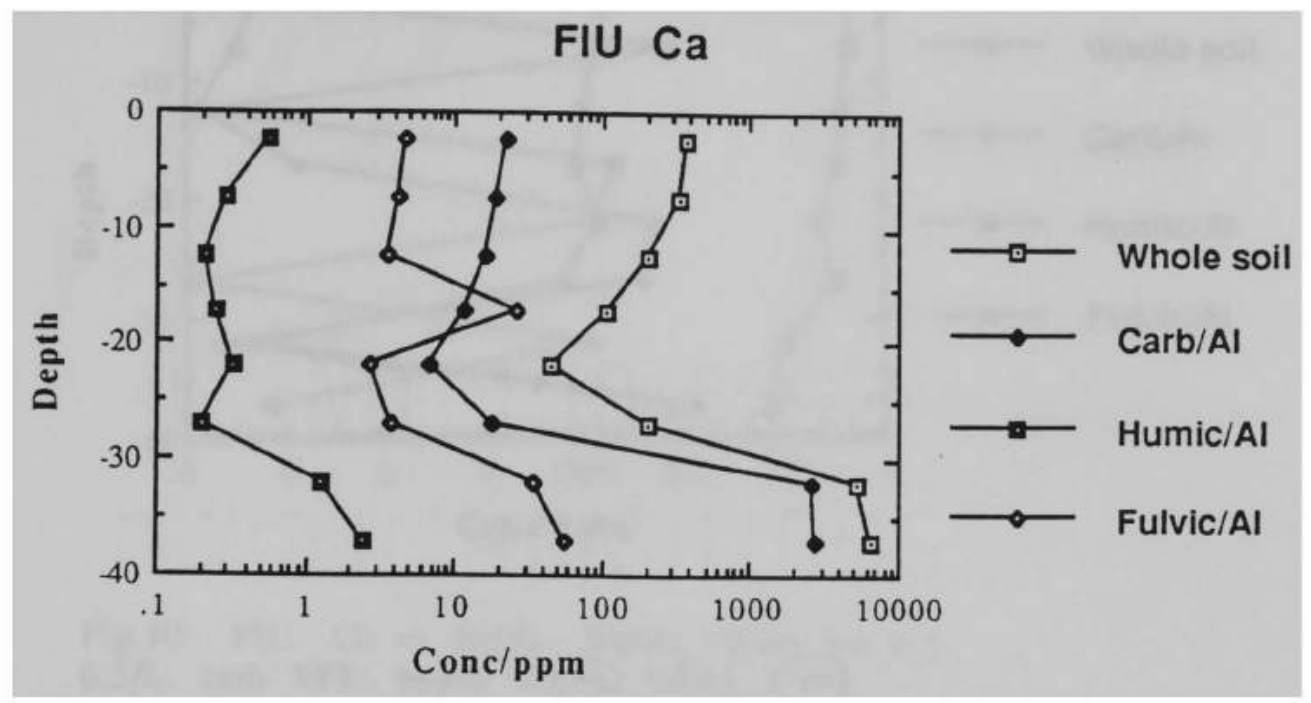

Fig. 8: FIU Ca vs depth. Sigma values are w.s.

$1.5 \%$; carb $2.3 \%$; humic $1.0 \%$; fulvic $1.1 \%$.

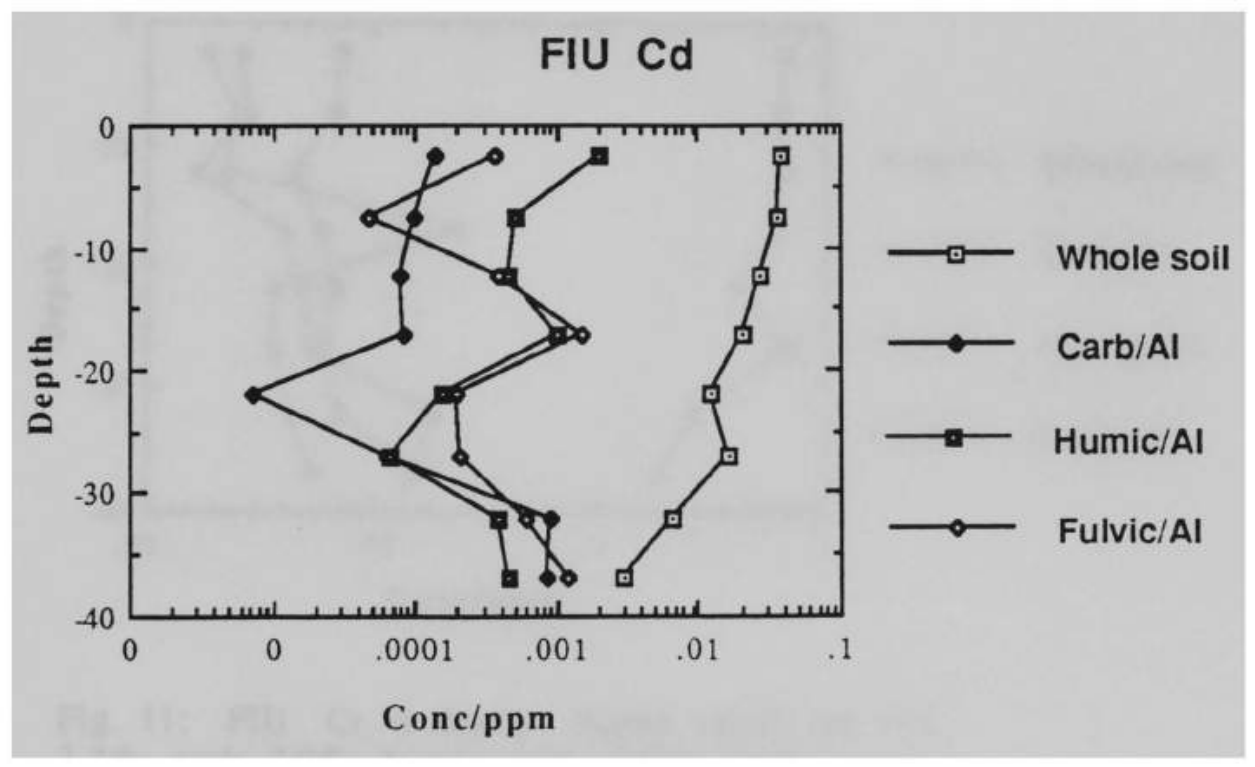

Fig. 9: FIU Cd vs depth. Sigma values are w.s.

$4.5 \%$; carb $82 \%$; humic $79 \%$; fulvic $130 \%$. 


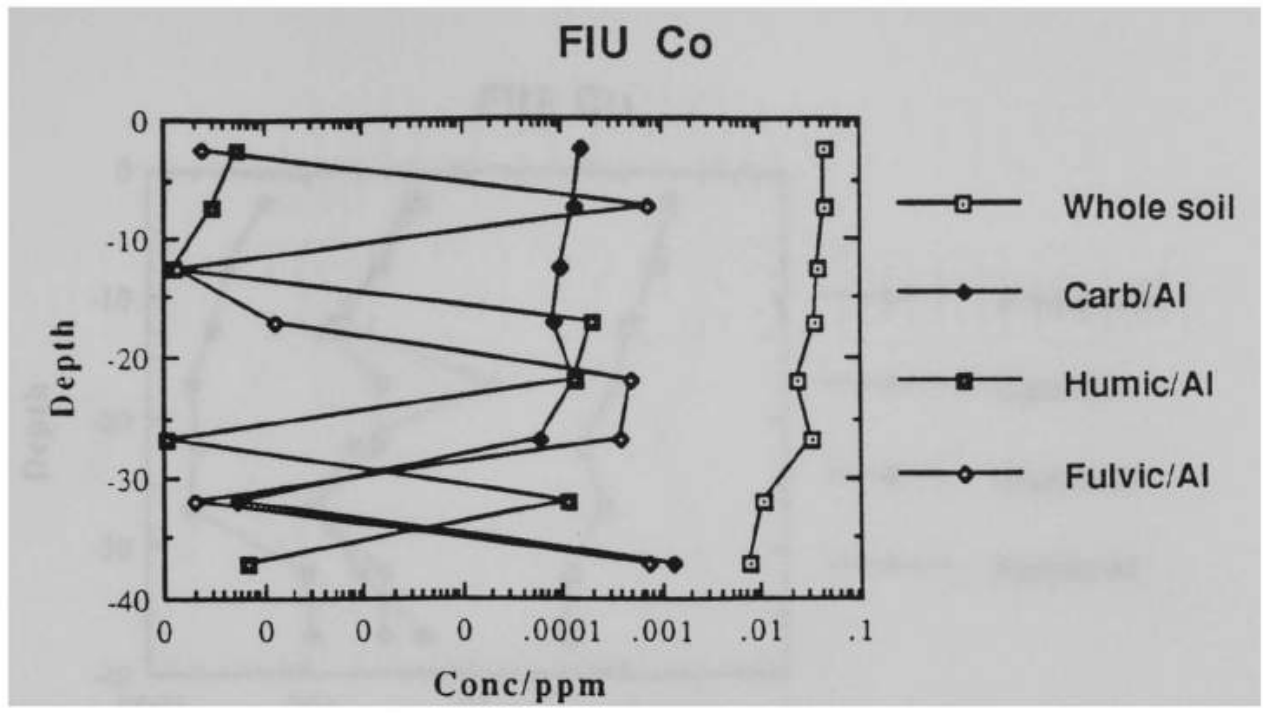

Fig.10: FIU Co vs depth. Sigma values are w.s.

$6.5 \%$; carb $59 \%$; humic $250 \%$; fulvic $170 \%$.

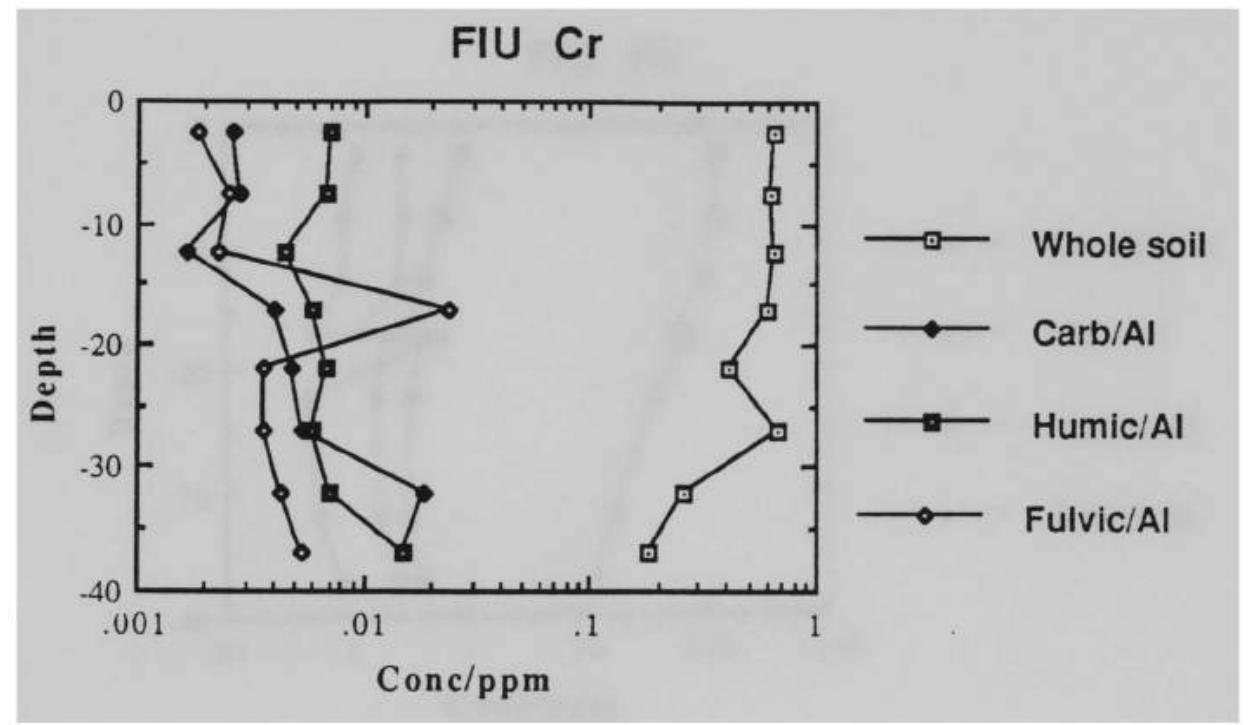

Fig. 11: FIU $\mathrm{Cr}$ vs depth. Sigma values are w.s. $3.4 \%$; carb $7.0 \%$; humic $16 \%$; fulvic $28 \%$. 


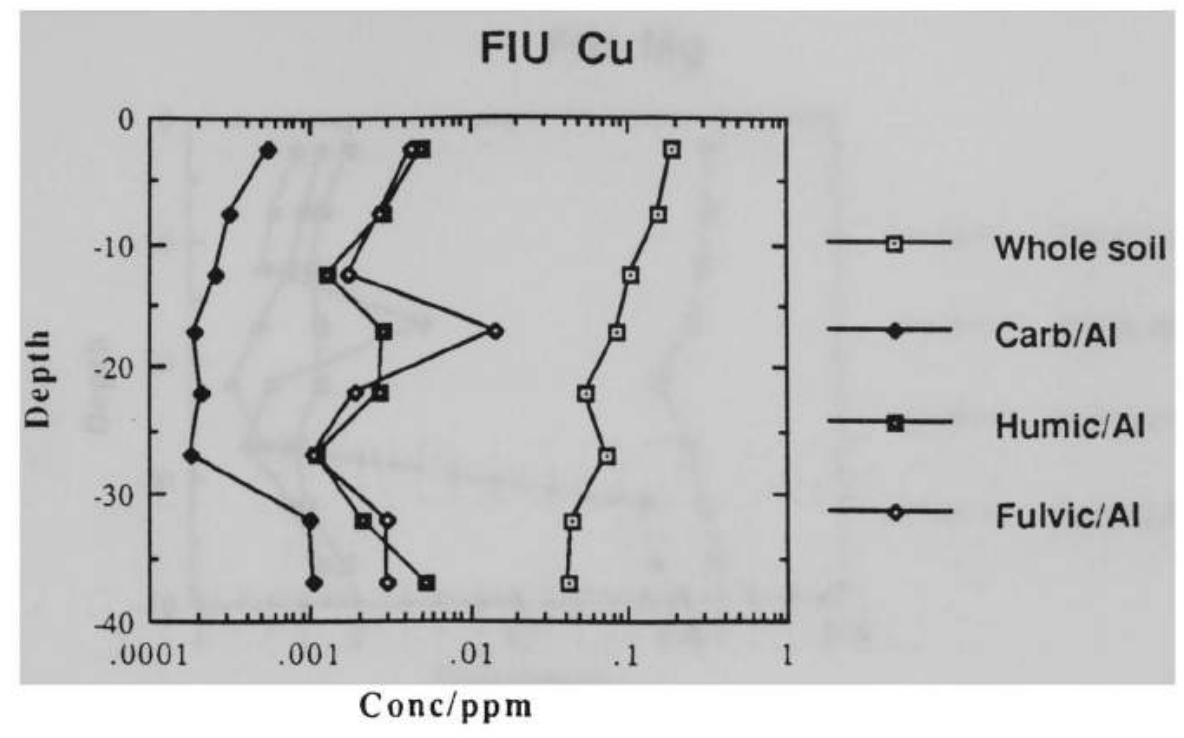

Fig. 12: FIU Cu vs depth. Sigma values are w.s. $2.8 \%$; carb $12 \%$; humic $16 \%$; fulvic $25 \%$.

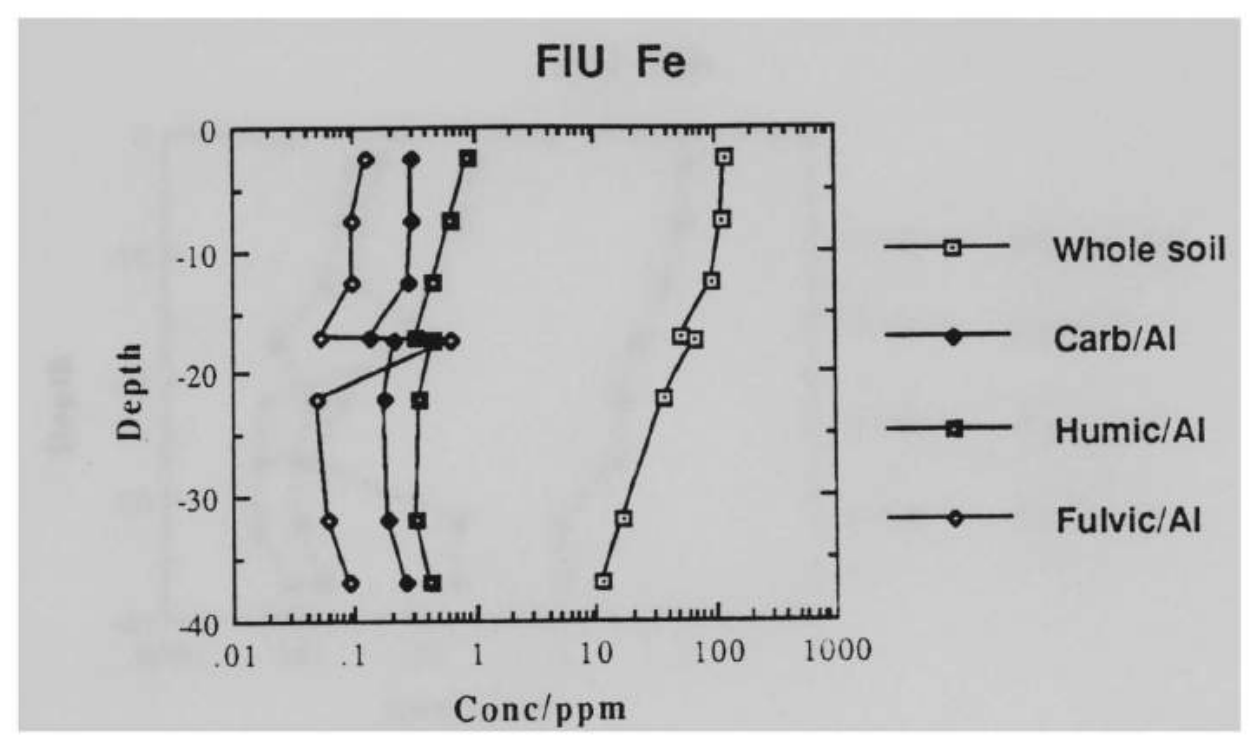

Fig. 13: FIU Fe vs depth. Sigma values are w.s. $1.7 \%$; carb $2.5 \%$; humic $1.1 \%$; fulvic $1.9 \%$. 


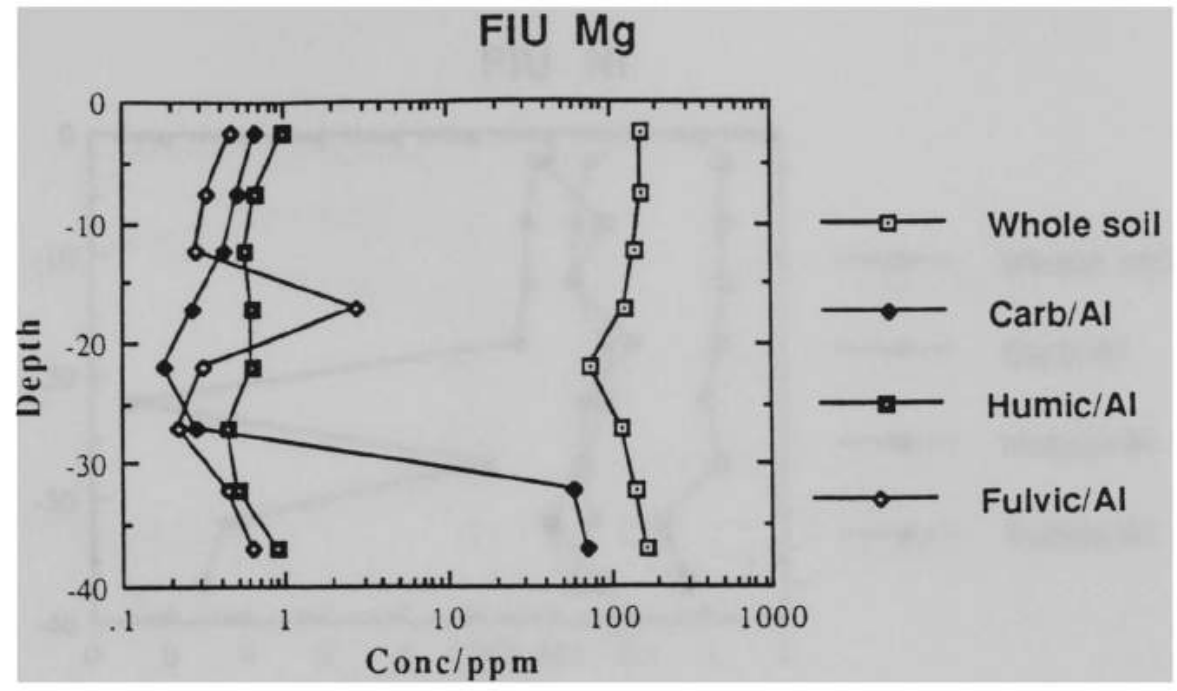

Fig. 14: FIU Mg vs depth. Sigma values are w.s.

$1.6 \%$; carb $1.3 \%$; humic $1.1 \%$; fulvic $1.2 \%$.

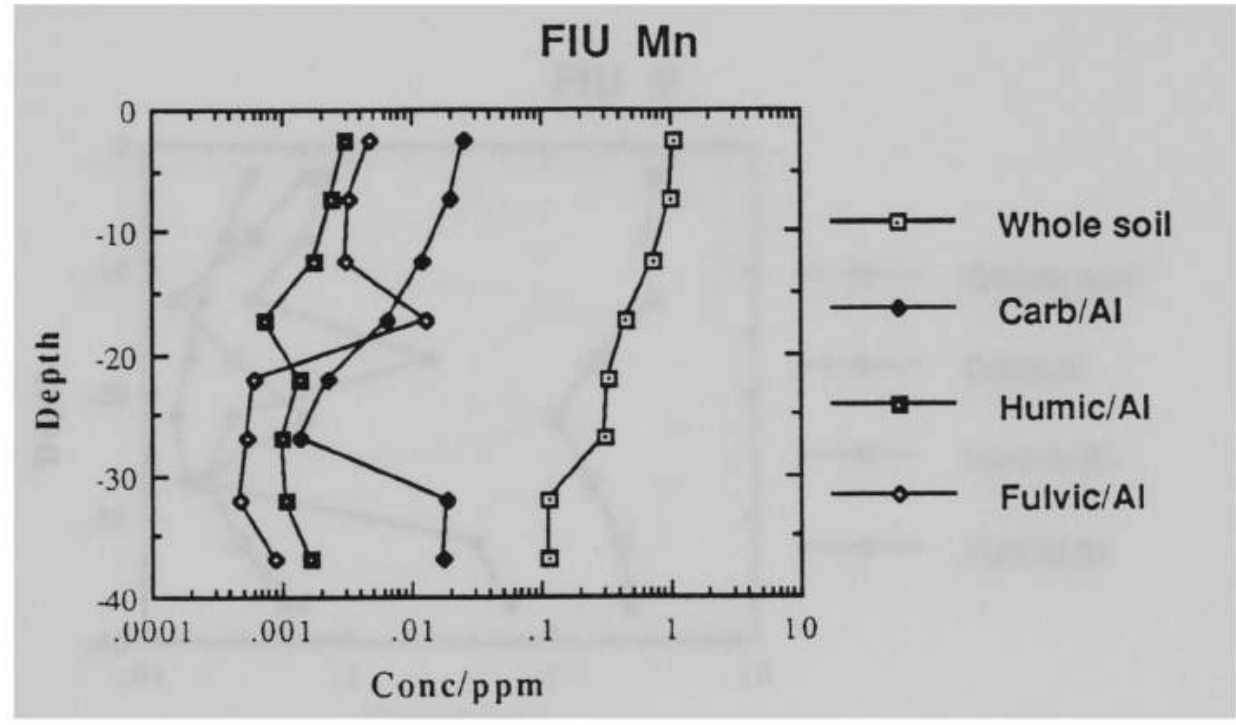

Fig. 15: FIU Mn vs depth. Sigma values are w.s. $2.2 \%$; carb $1.3 \%$; humic $4.2 \%$; fulvic $4.5 \%$. 


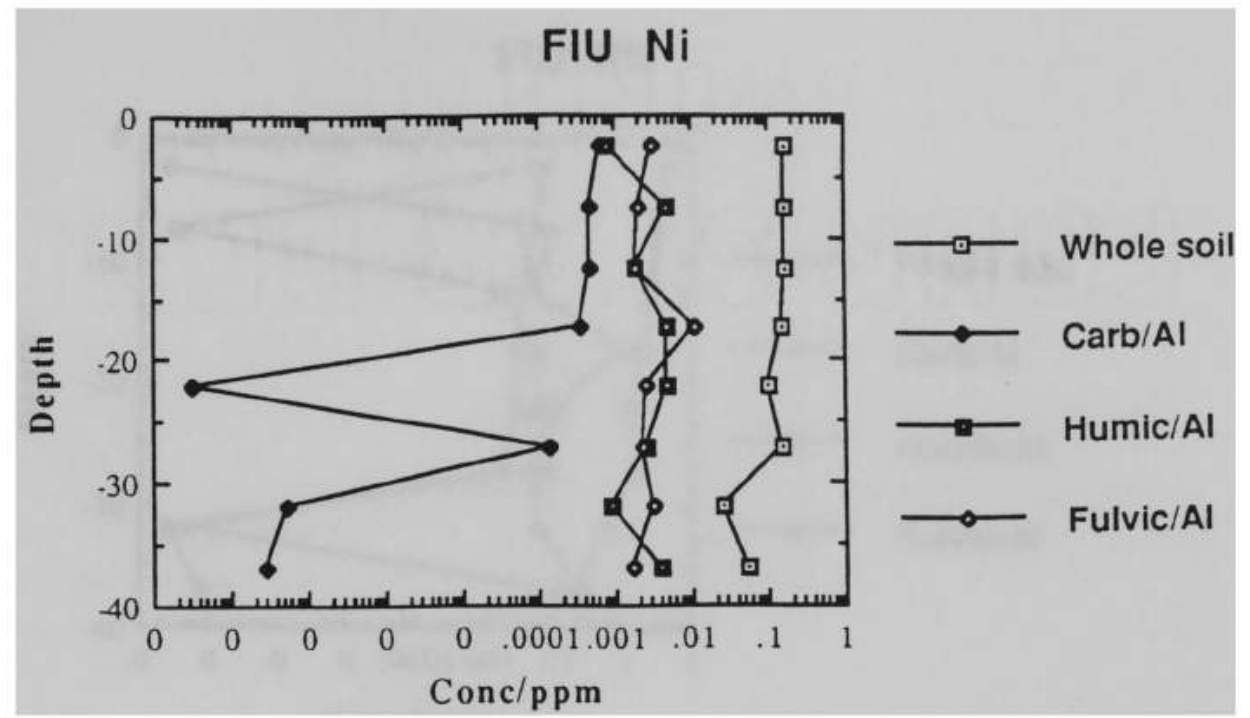

Fig. 16: FIU Ni vs depth. Sigma values are w.s. $13 \%$; carb $40 \%$; humic $96 \%$; fulvic $47 \%$.

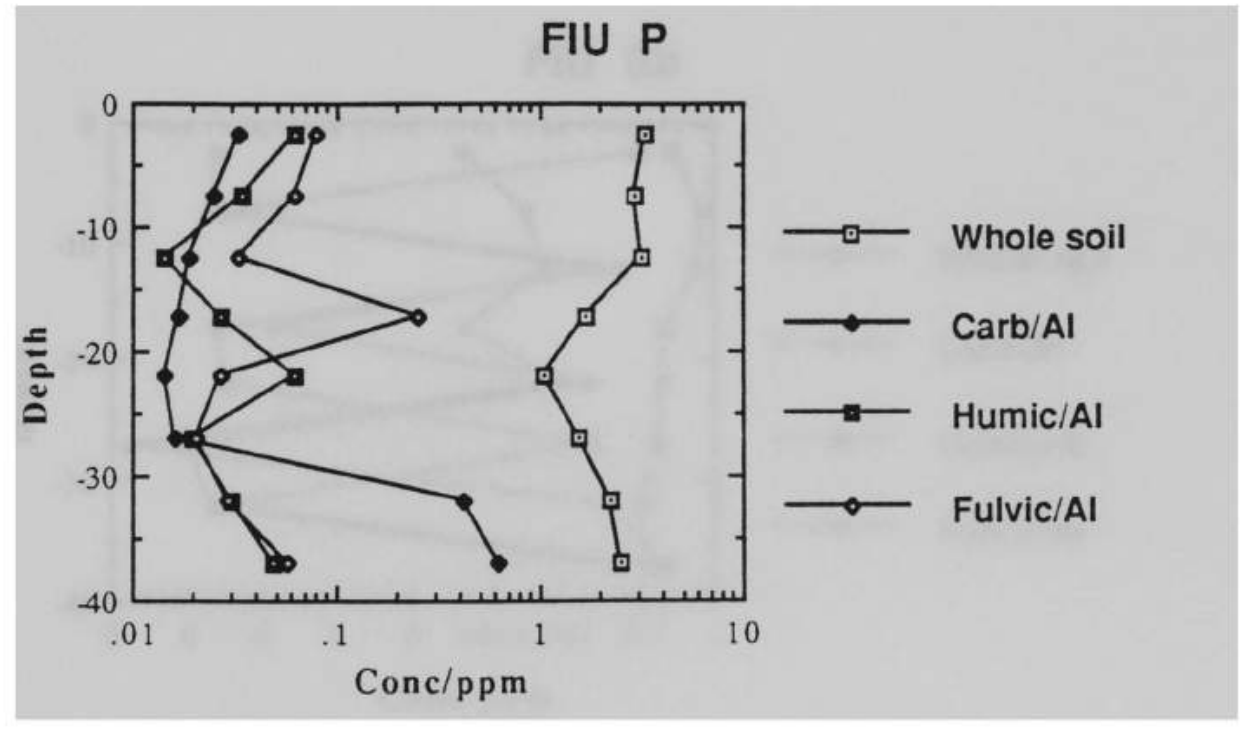

Fig. 17: FIU $\mathrm{P}$ vs depth. Sigma values are w.s.

$7.7 \%$; carb $8.2 \%$; humic $51 \%$; fulvic $34 \%$. 


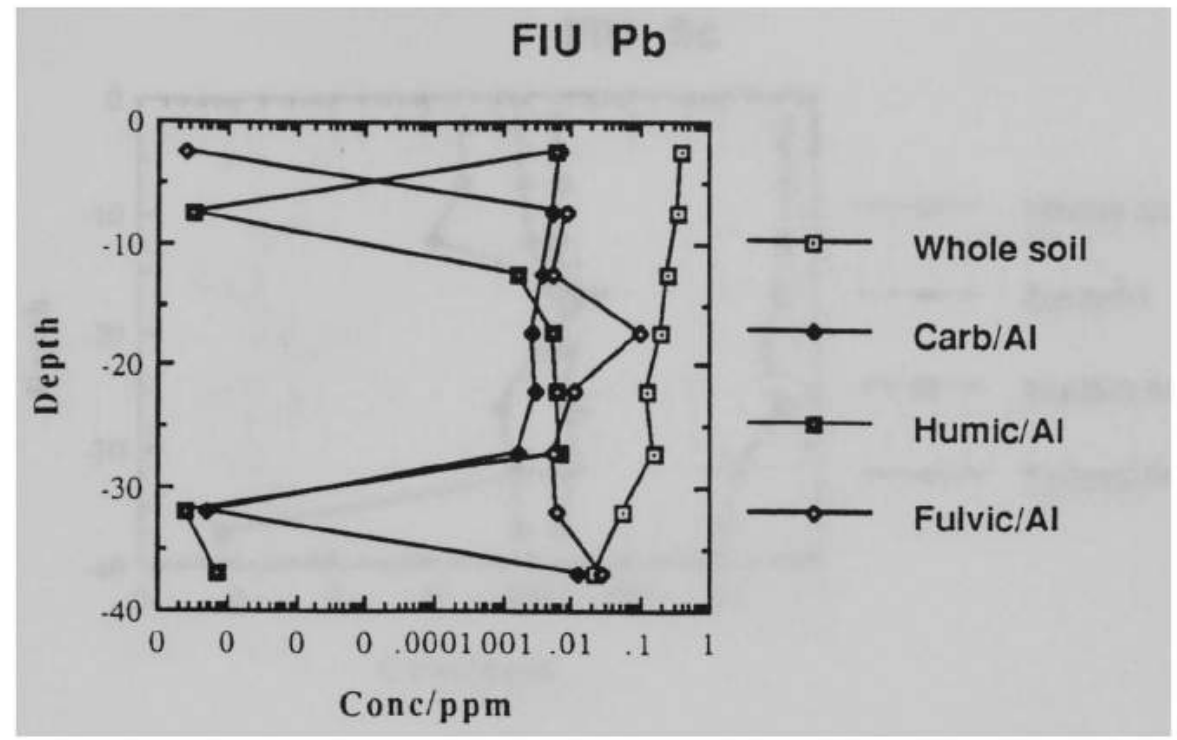

Fig. 18: FIU Pb vs depth. Sigma values are w.s. $8.8 \%$; carb $16 \%$; humic $120 \%$; fulvic $56 \%$.

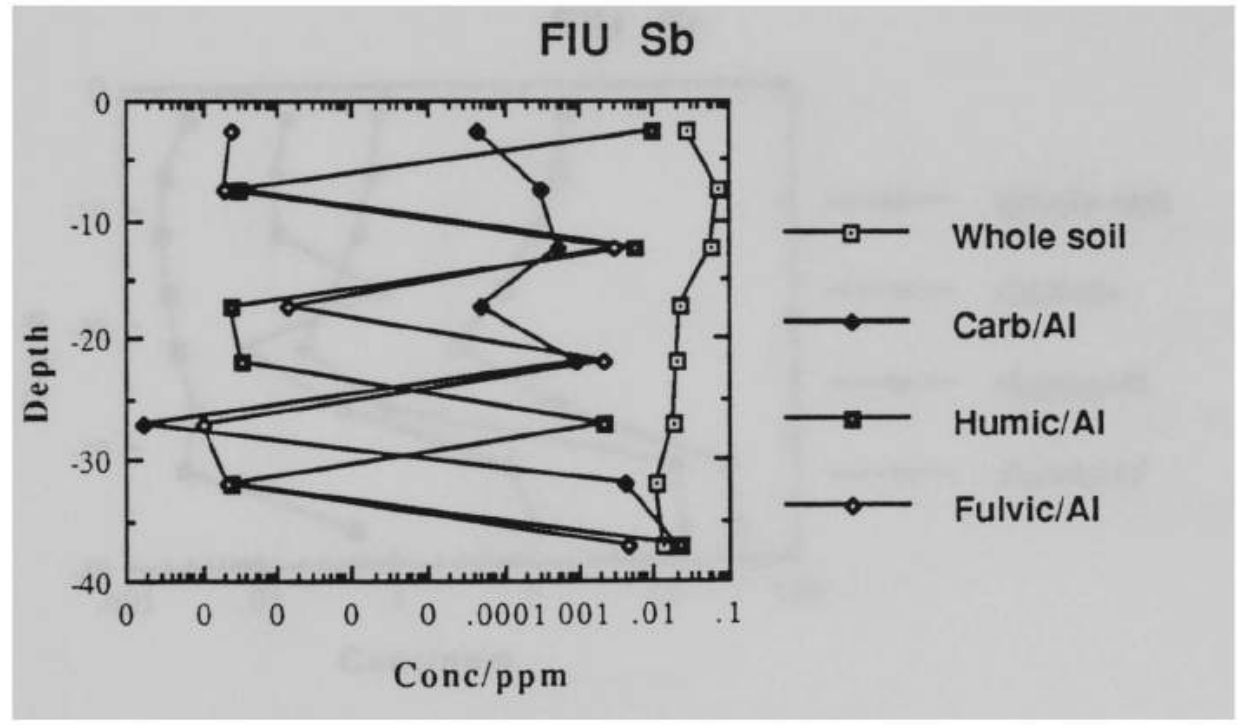

Fig. 19: FIU Sb vs depth. Sigma values are w.s. $56 \%$; carb $240 \%$; humic $94 \%$; fulvic $200 \%$. 


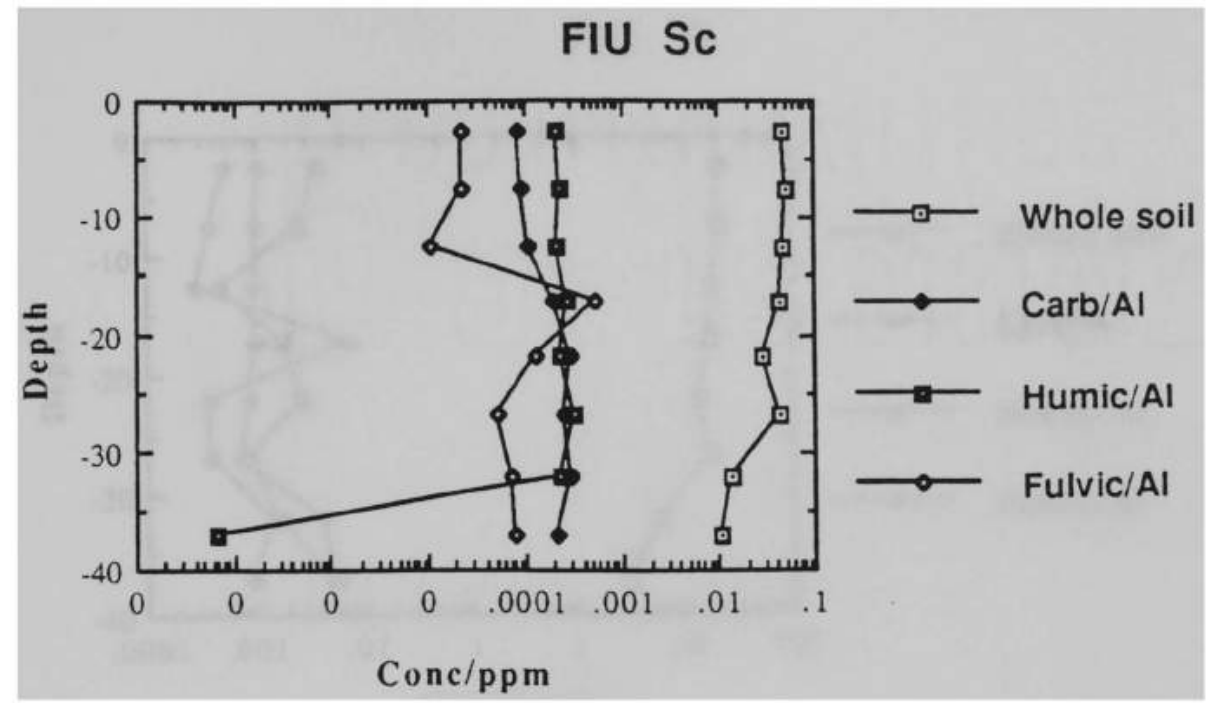

Fig. 20: FIU Sc vs depth. Sigma values are w.s. $2.2 \%$; carb $16 \%$; humic $23 \%$; fulvic $140 \%$.

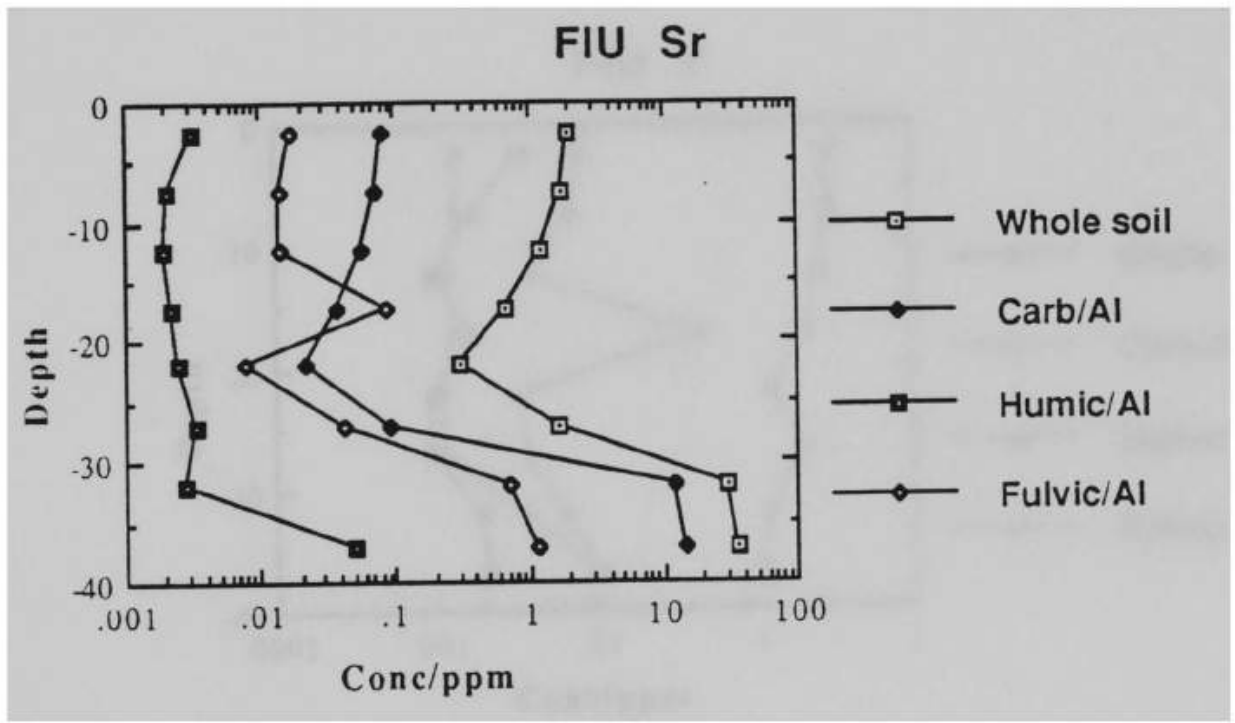

Fig. 21: FIU Sr vs depth. Sigma values are w.s.

$2.2 \%$; carb $1.3 \%$; humic $1.3 \%$; fulvic $1.2 \%$. 


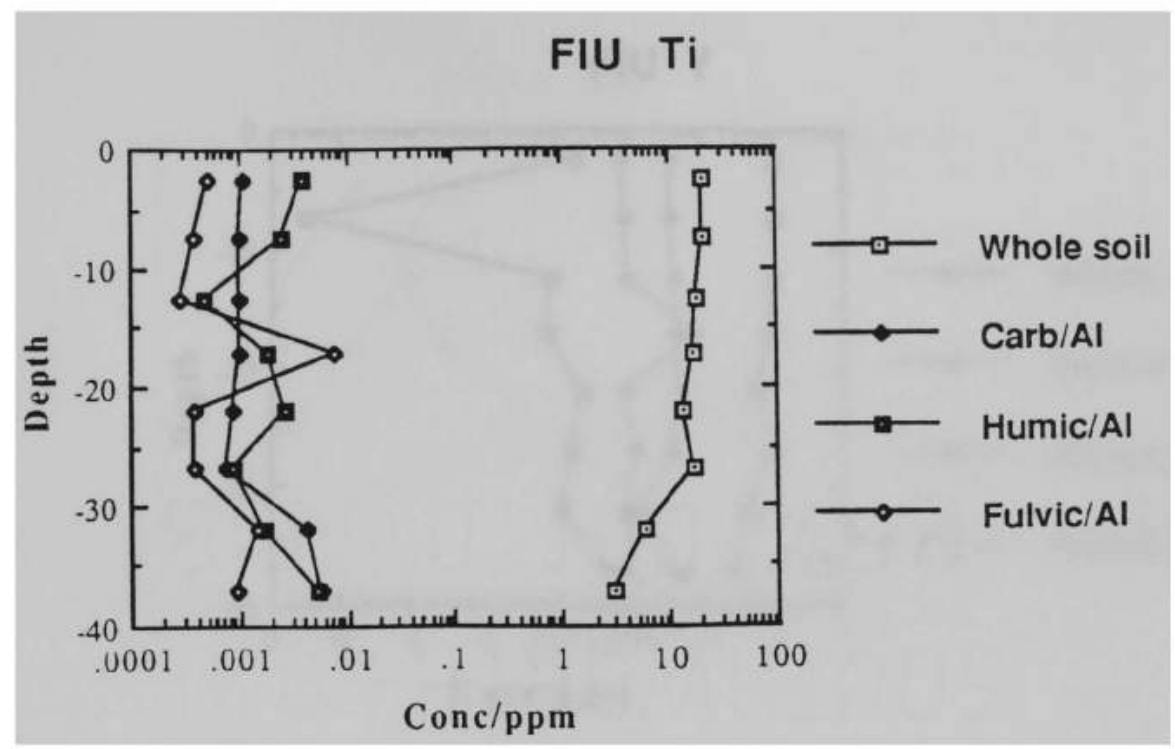

Fig. 22: FIU Ti vs depth. Sigma values are w.s. $2.0 \%$; carb $2.5 \%$; humic $13 \%$; fulvic $54 \%$.

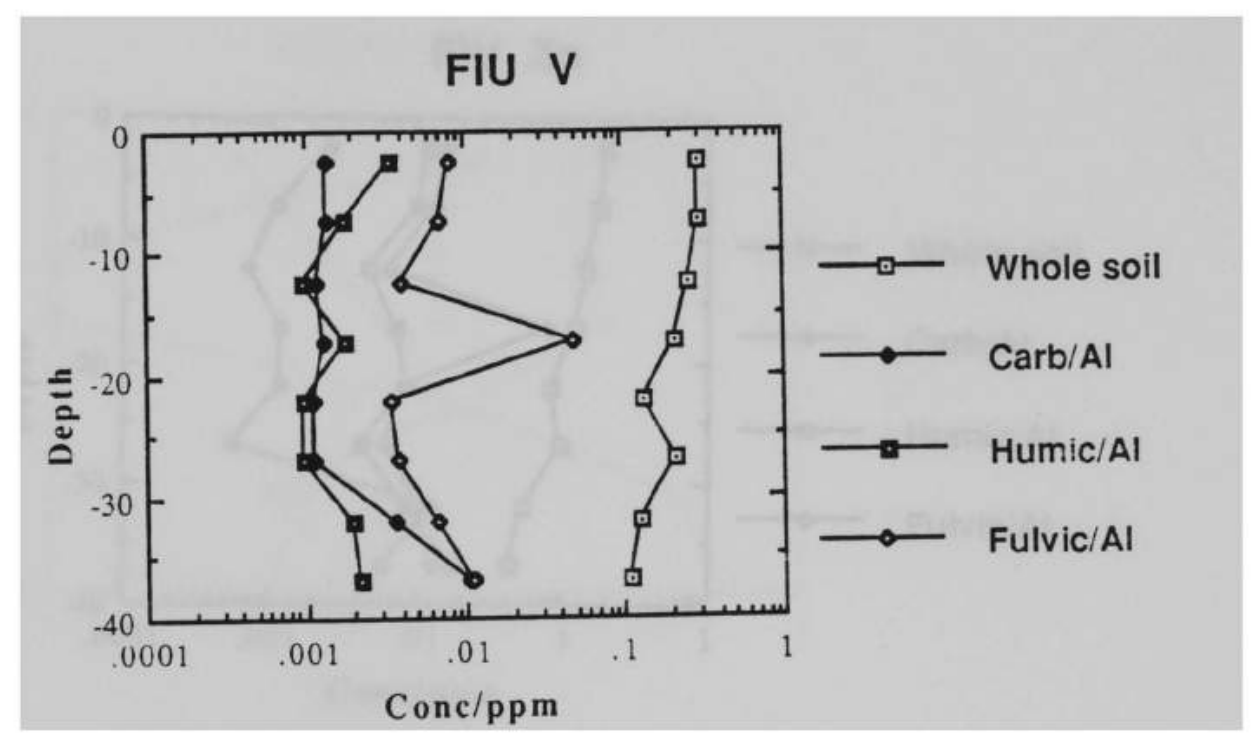

Fig. 23: FIU V vs depth. Sigma values are w.s. $1.5 \%$; carb $46 \%$; humic $32 \%$; fulvic $9.6 \%$. 


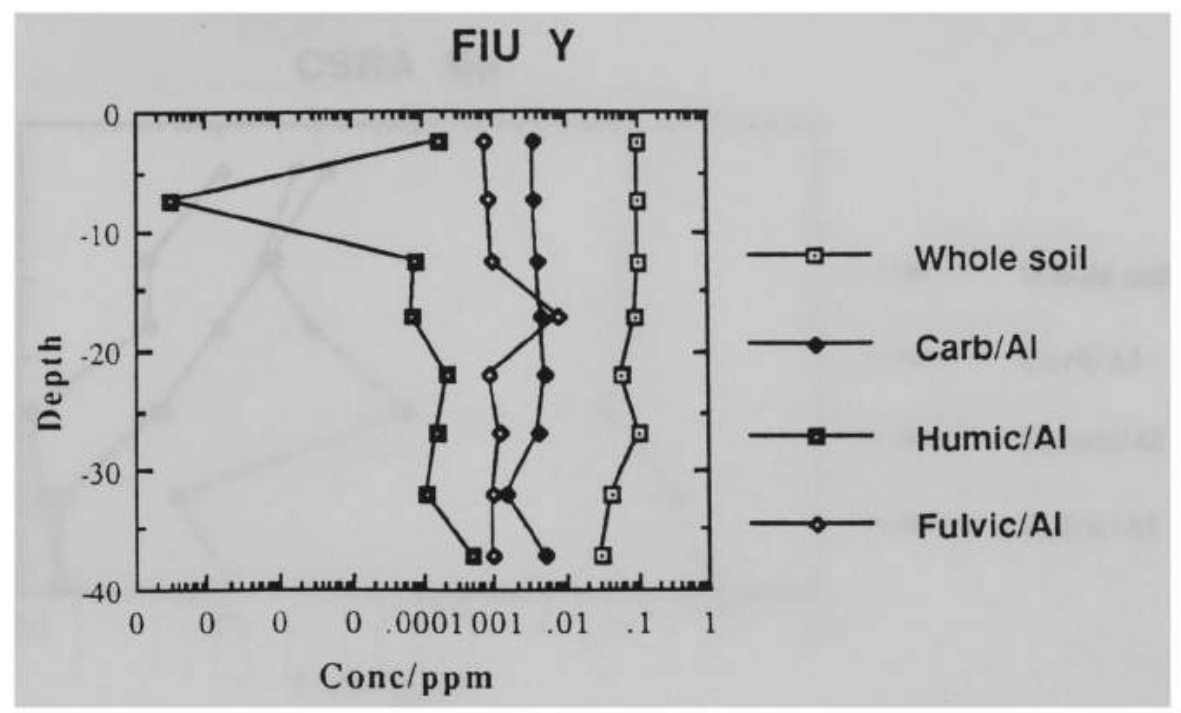

Fig. 24: FIU Y vs depth. Sigma values are w.s.

$1.6 \%$; carb $1.8 \%$; humic $130 \%$; fulvic $8.7 \%$.

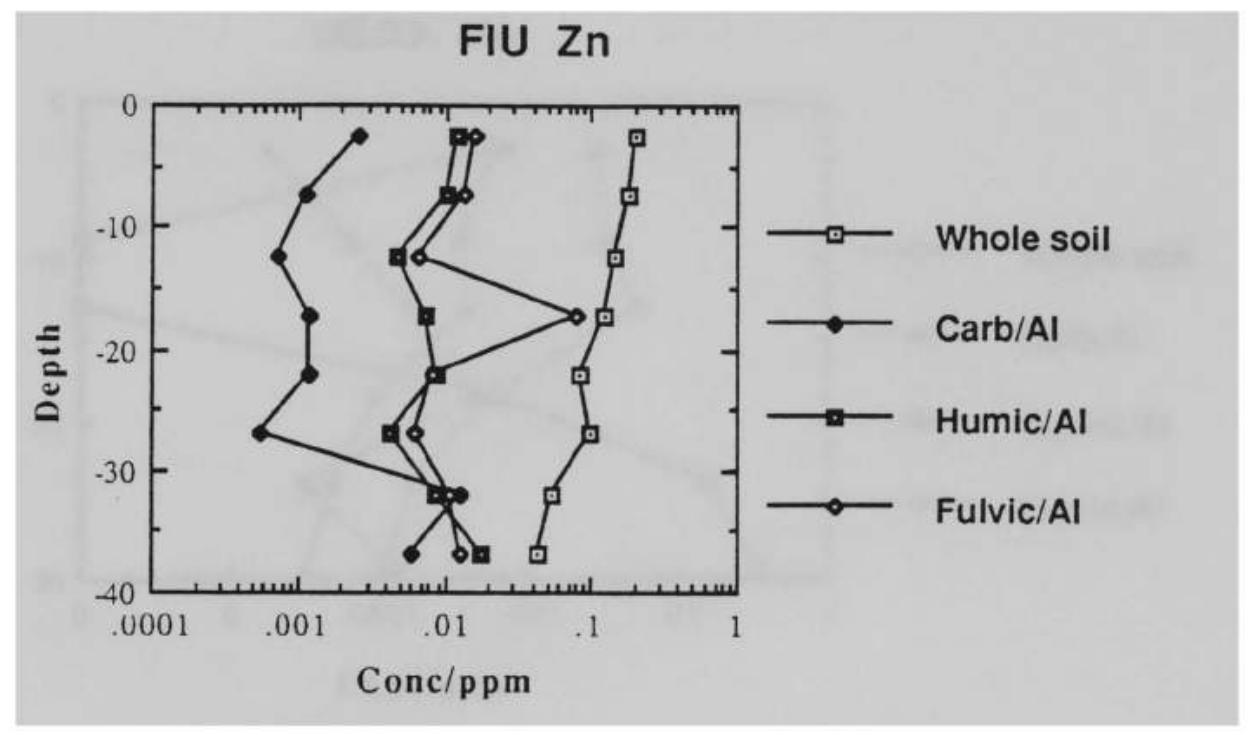

Fig. 25: FIU $\mathrm{Zn}$ vs depth. Sigma values are w.s.

$1.7 \%$; carb $3.5 \%$; humic $5.9 \%$; fulvic $5.8 \%$. 


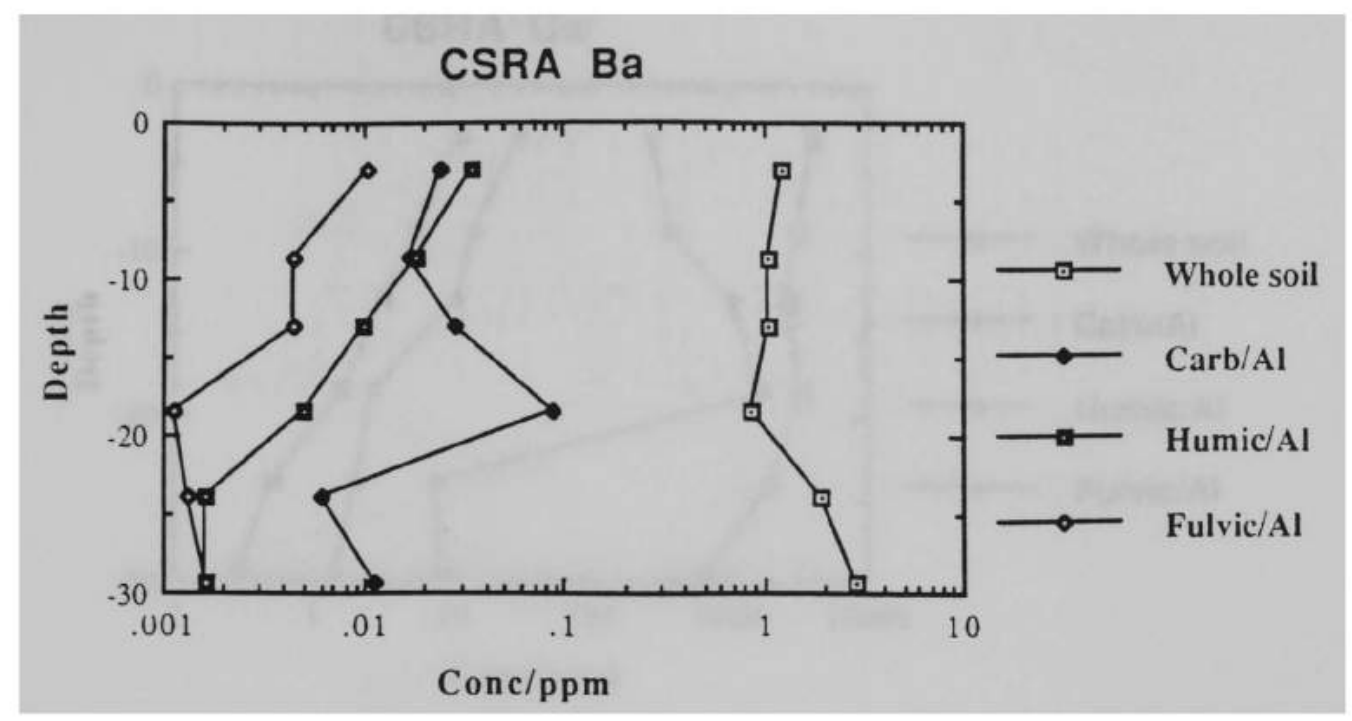

Fig. 26: CSRA $\mathrm{Ba}$ vs depth. Sigma values are w.s. $1.4 \%$; carb $1.8 \%$; humic $23 \%$; fulvic $12 \%$.

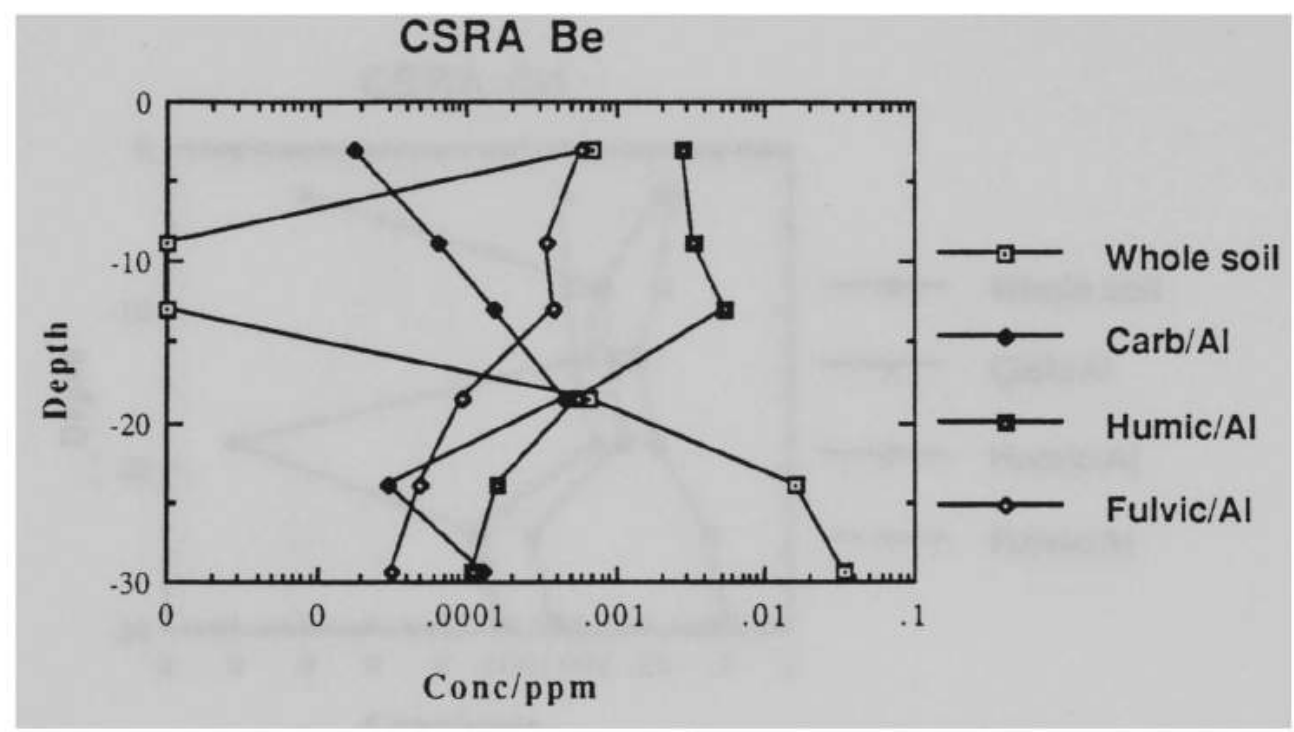

Fig. 27: CSRA Be vs depth. Sigma values are w.s. $3.3 \%$; carb $250 \%$; humic $190 \%$; fulvic $510 \%$. 


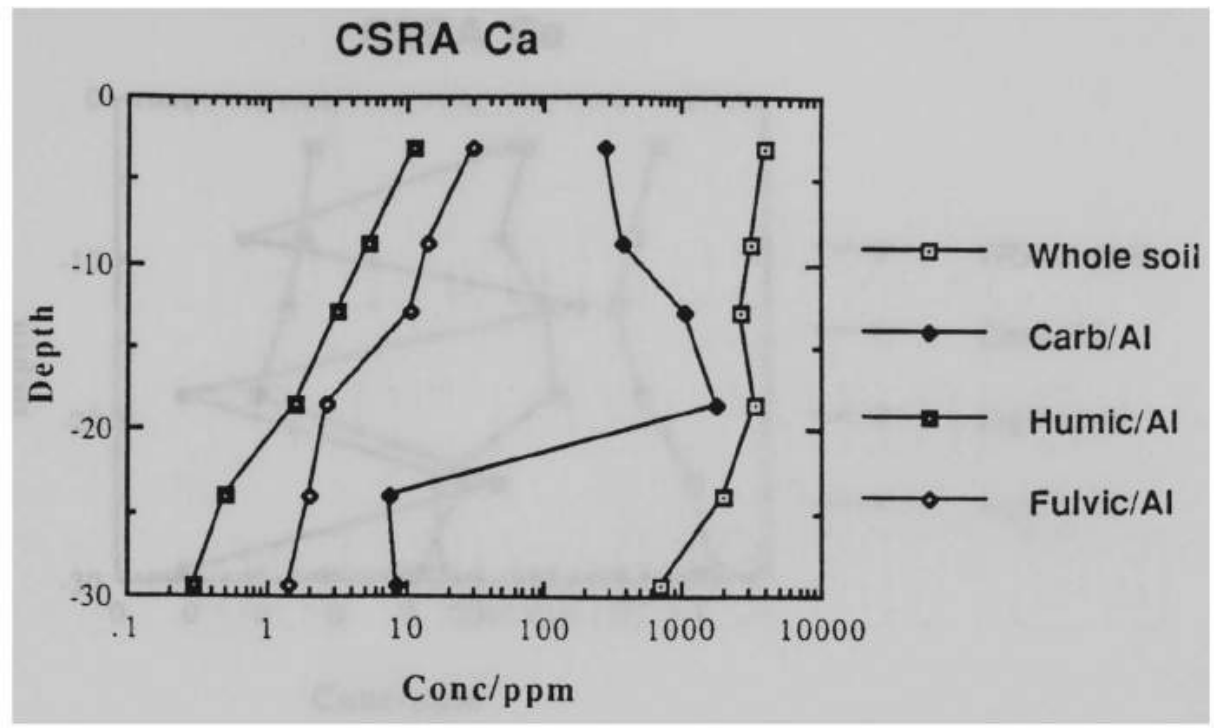

Fig. 28: CSRA Ca vs depth. Sigma values are w.s.

$1.1 \%$; carb $2.5 \%$; humic $1.5 \%$; fulvic $1.0 \%$.

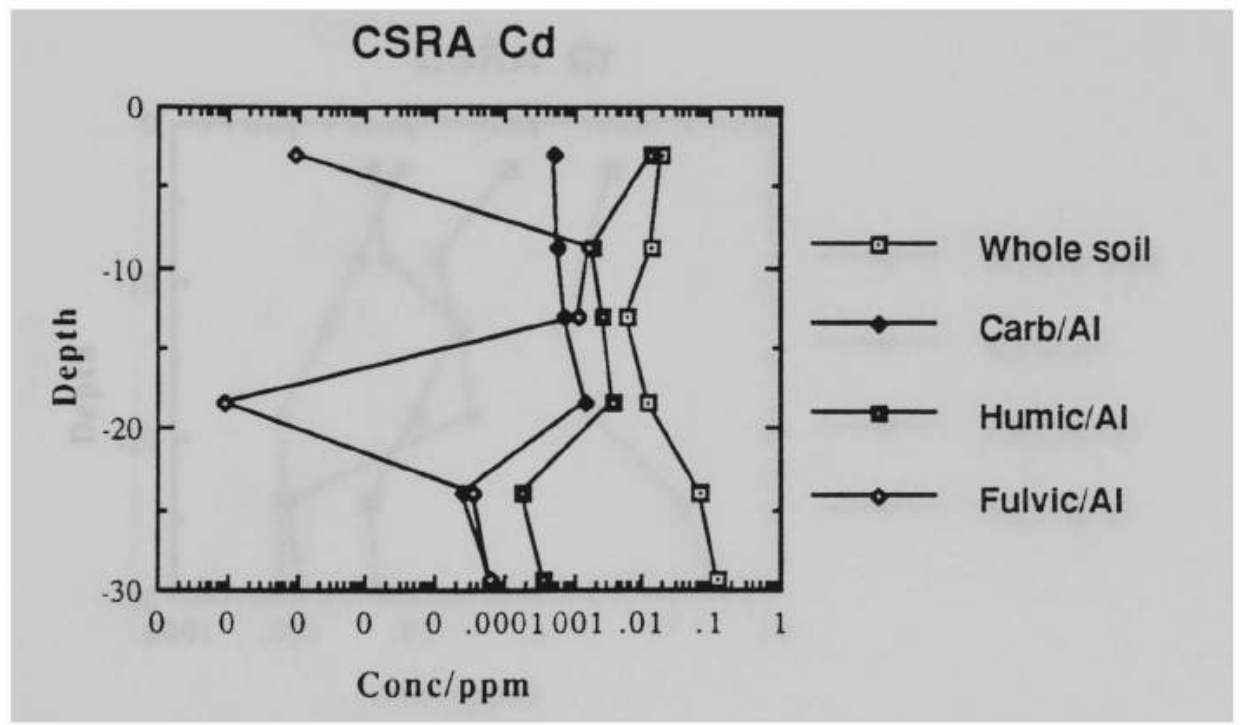

Fig. 29: CSRA Cd vs depth. Sigma values are w.s. $5.3 \%$; carb $21 \%$; humic $170 \%$; fulvic $100 \%$. 


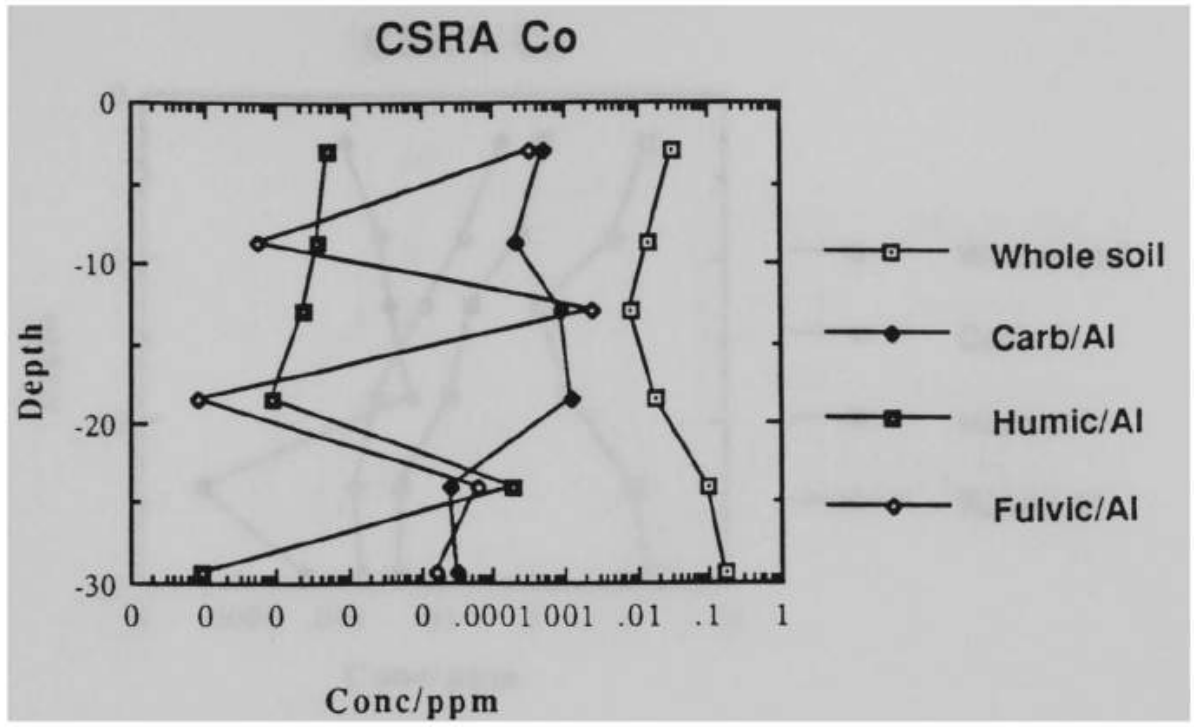

Fig. 30: CSRA Co vs depth. Sigma values are w.s. $4.8 \%$; carb $32 \%$; humic $210 \%$; fulvic $370 \%$.

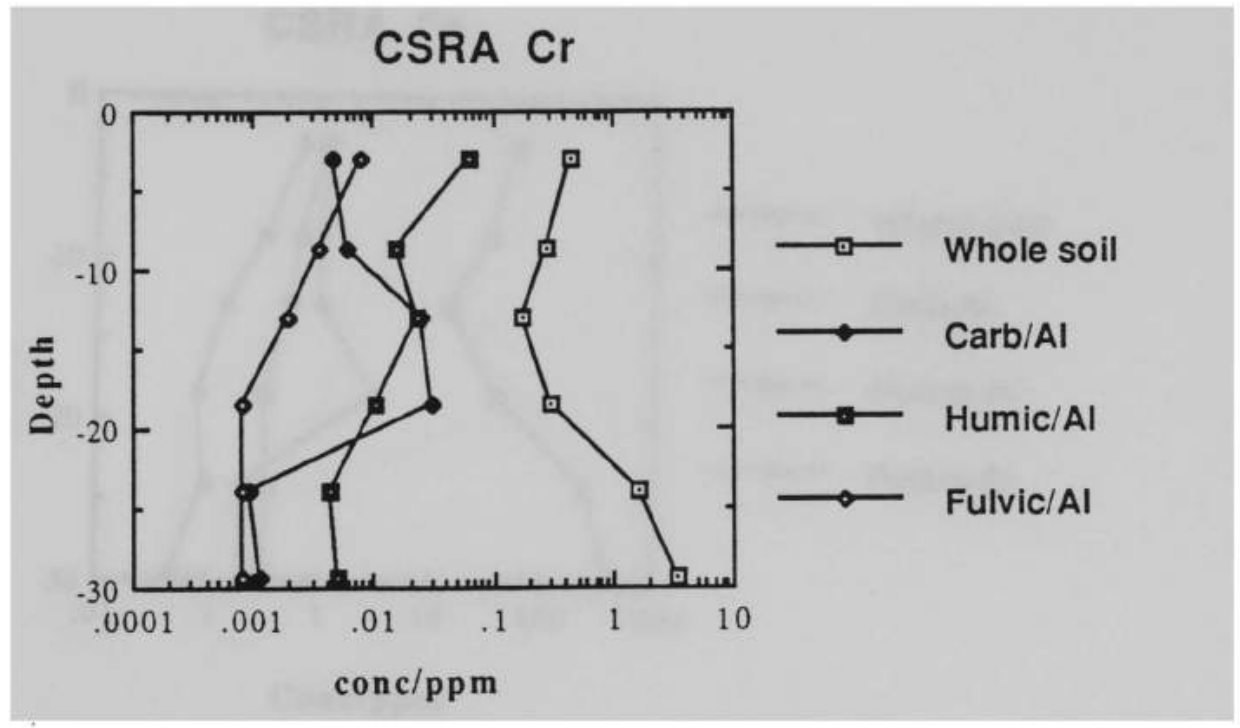

Fig. 31: CSRA Cr vs depth. Sigma values are w.s. $2.9 \%$; carb $2.8 \%$; humic $25 \%$; fulvic $63 \%$. 


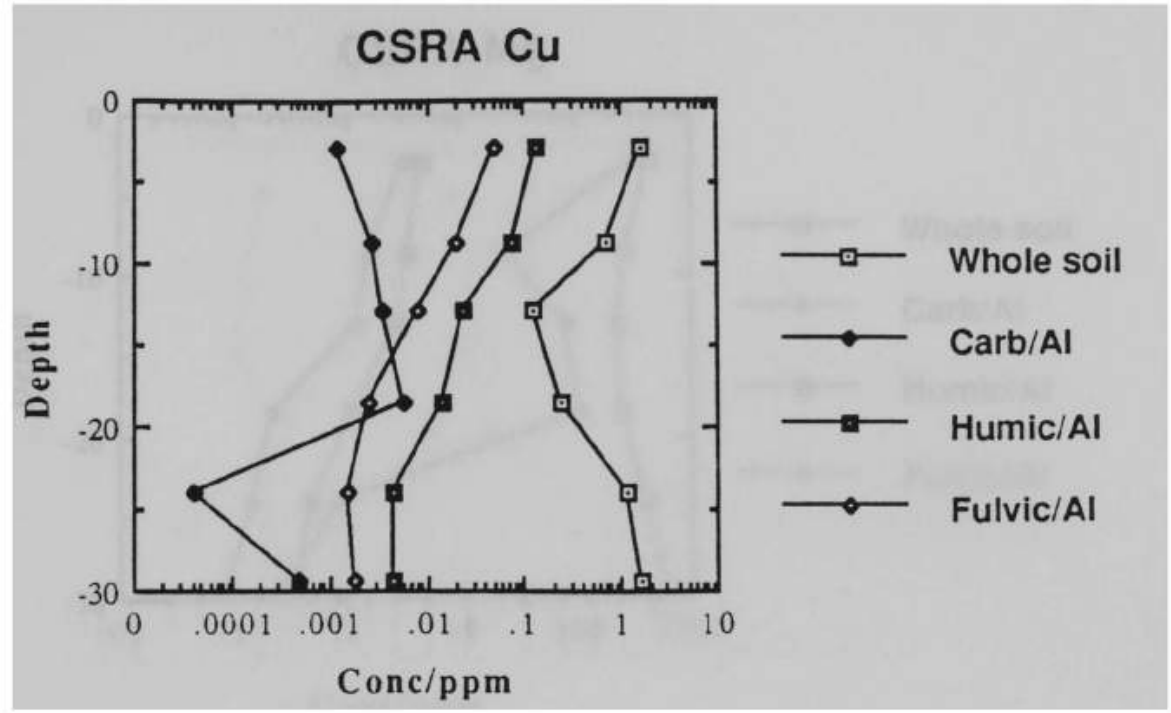

Fig. 32: CSRA Cu vs depth. Sigma values are w.s. $1.4 \%$; carb $7.4 \%$; humic $8.8 \%$; fulvic $4.0 \%$.

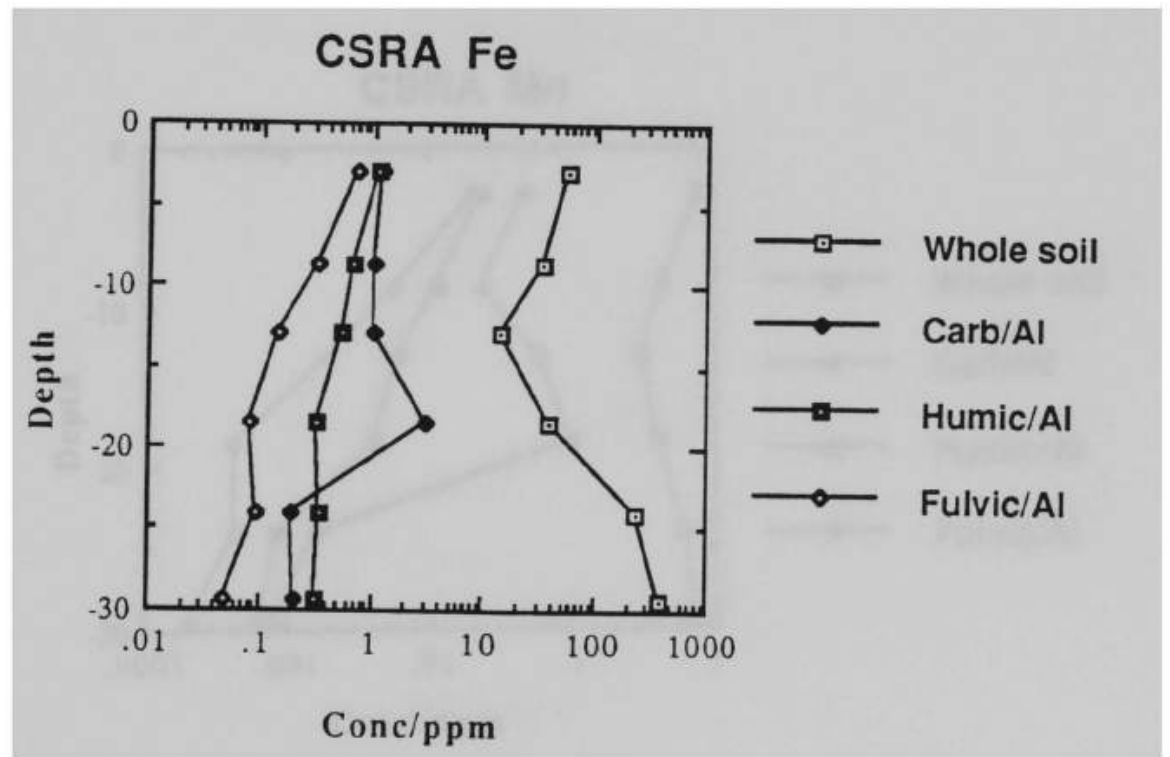

Fig. 33: CSRA Fe vs depth. Sigma values are w.s. $1.6 \%$; carb $1.5 \%$; humic $1.9 \%$; fulvic $1.1 \%$. 


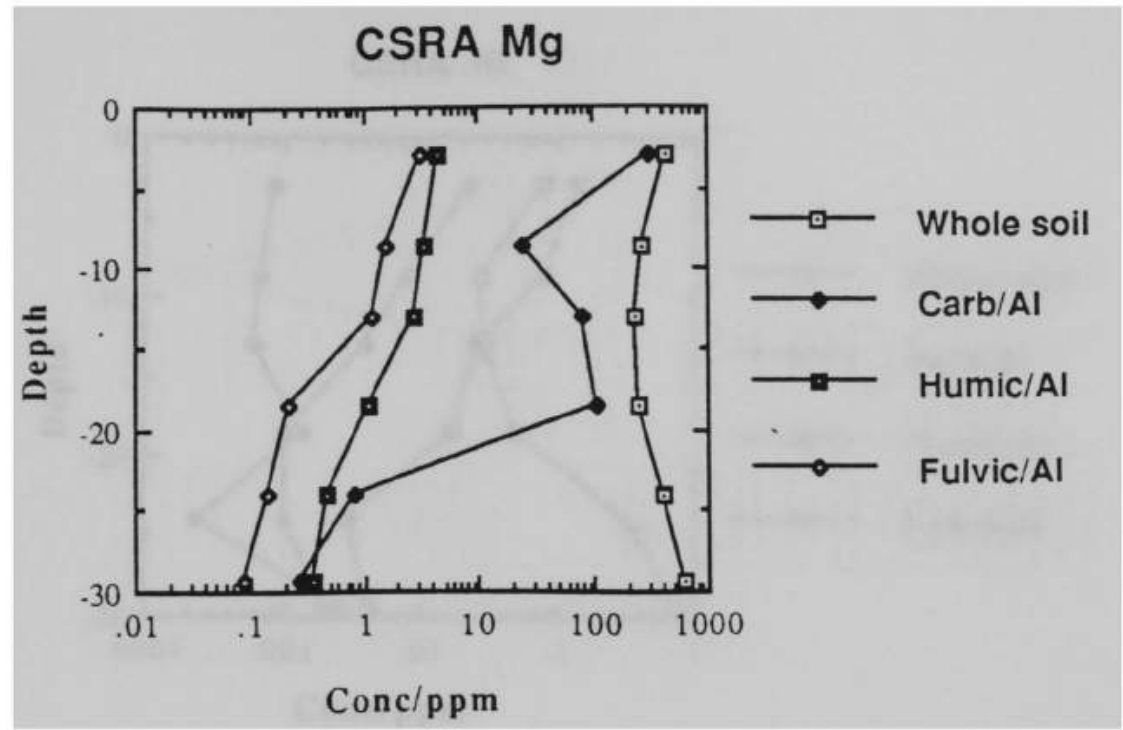

Fig. 34: CSRA Mg vs depth. Sigma values are w.s. $1.6 \%$; carb $1.4 \%$; humic $1.2 \%$; fulvic $1.1 \%$.

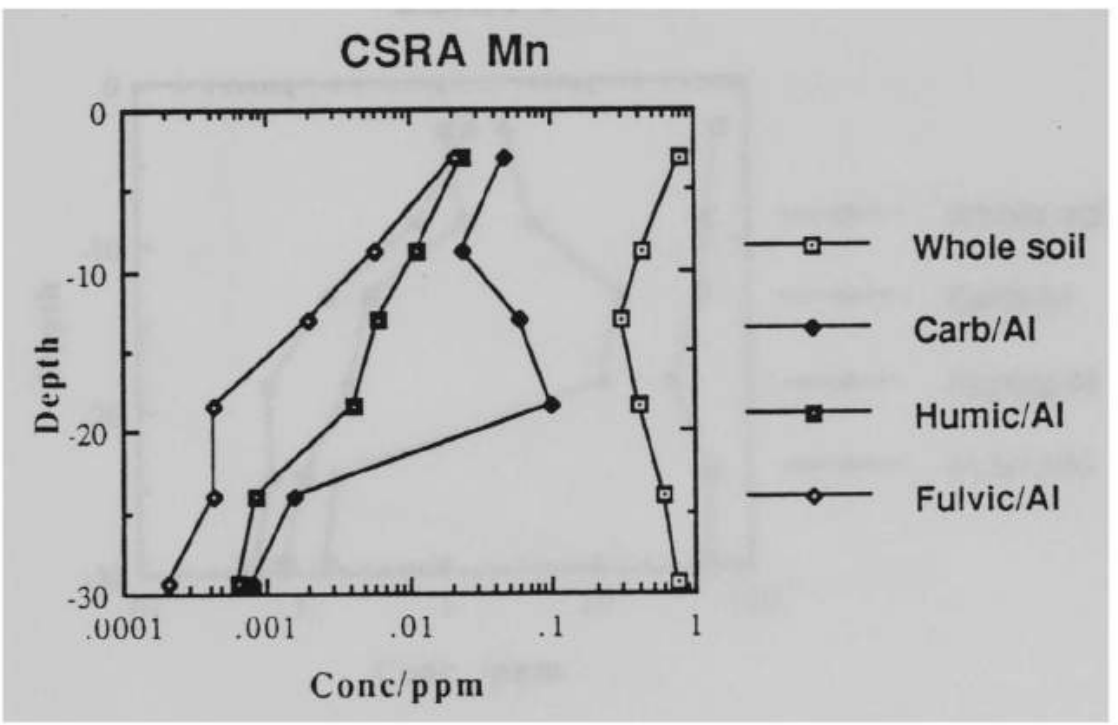

Fig. 35: CSRA Mn vs depth. Sigma values are w.s. $1.6 \%$; carb $1.4 \%$; humic $9.2 \%$; fulvic $11 \%$. 


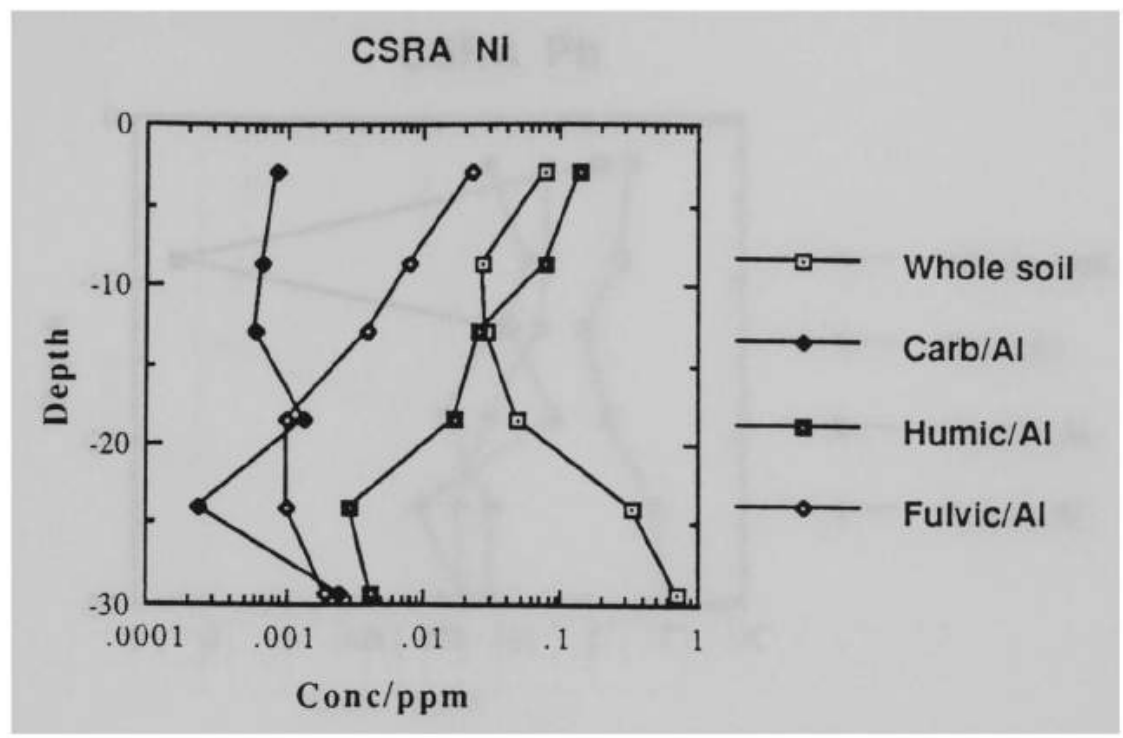

Fig. 36: CSRA Ni vs depth. Sigma values are w.s. $19 \%$; carb $36 \%$; humic $30 \%$; fulvic $71 \%$.

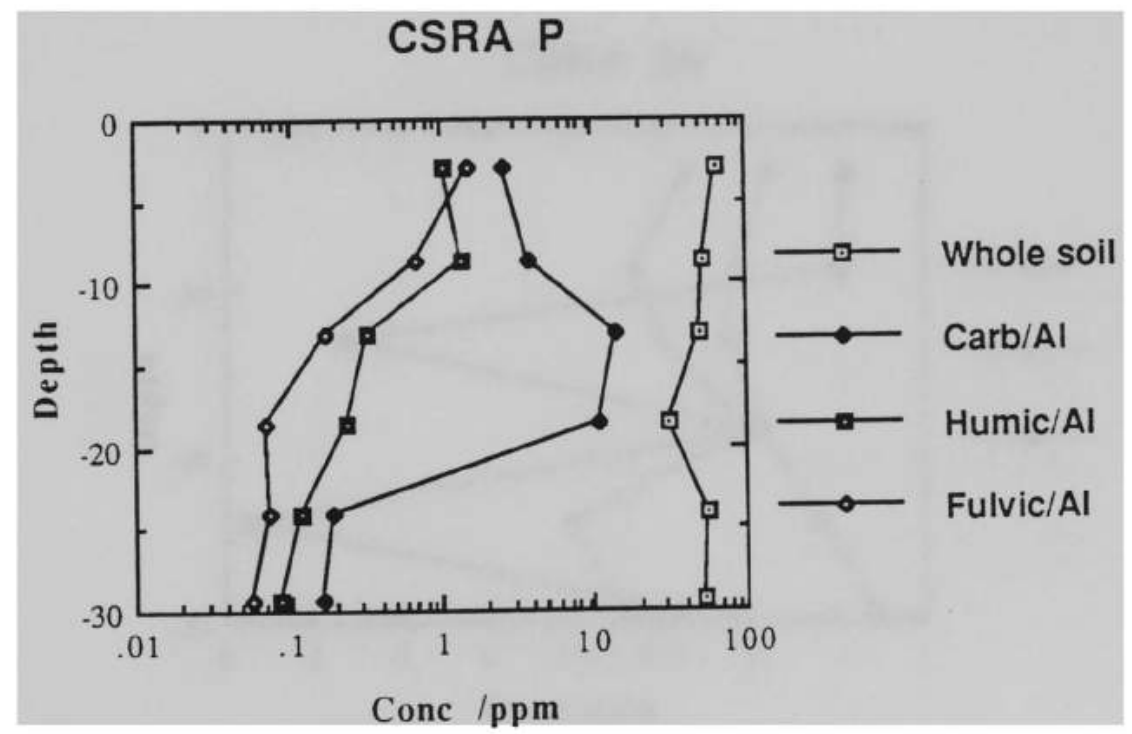

Fig. 37: CSRA P vs depth. Sigma values are w.s. $1.4 \%$; carb $1.8 \%$; humic $23 \%$; fulvic $8.6 \%$. 


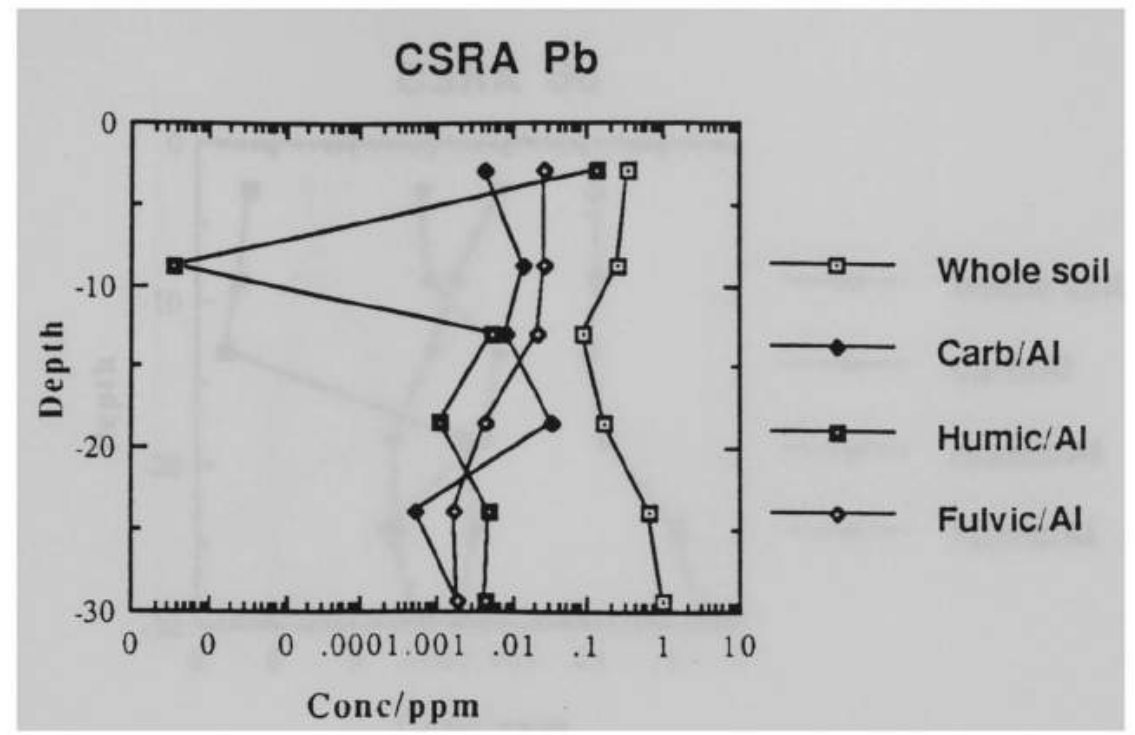

Fig. 38: CSRA Pb vs depth. Sigma values are w.s. $4.2 \%$; carb $2.8 \%$; humic $25 \%$; fulvic $60 \%$.

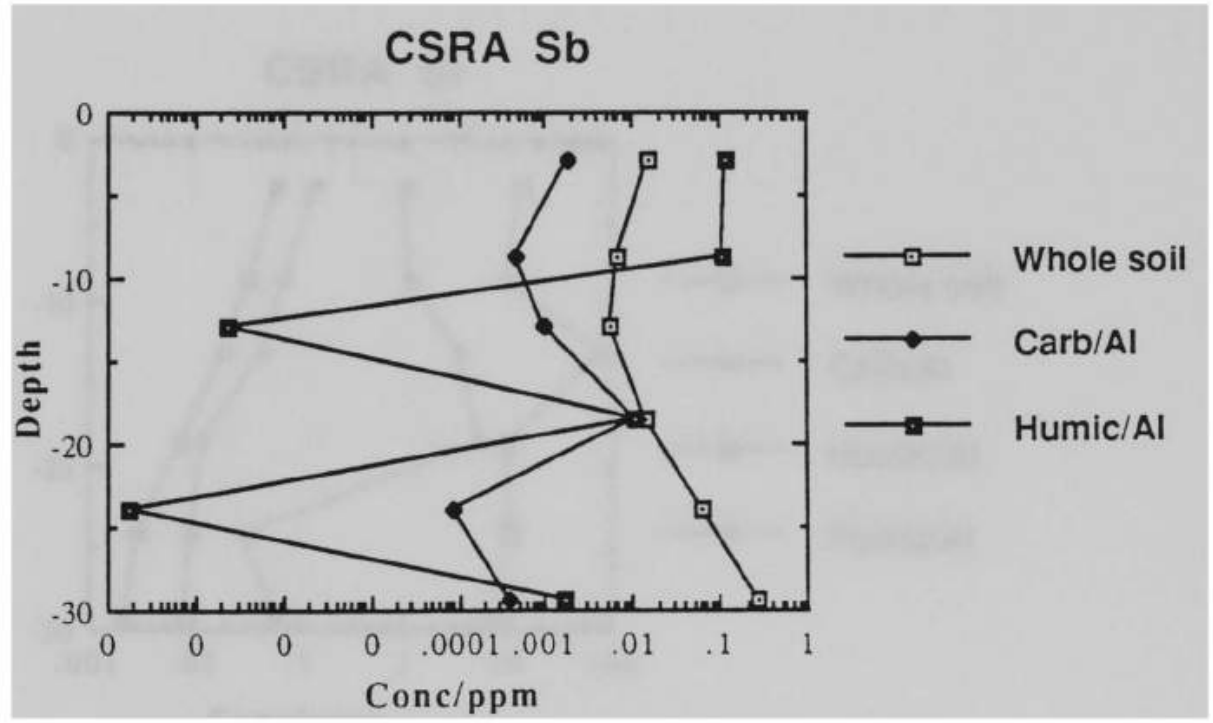

Fig. 39: CSRA Sb vs depth. Sigma values are w.s. $64 \%$; carb $110 \%$; humic $81 \%$. Sb not detected in the fulvic acid. 


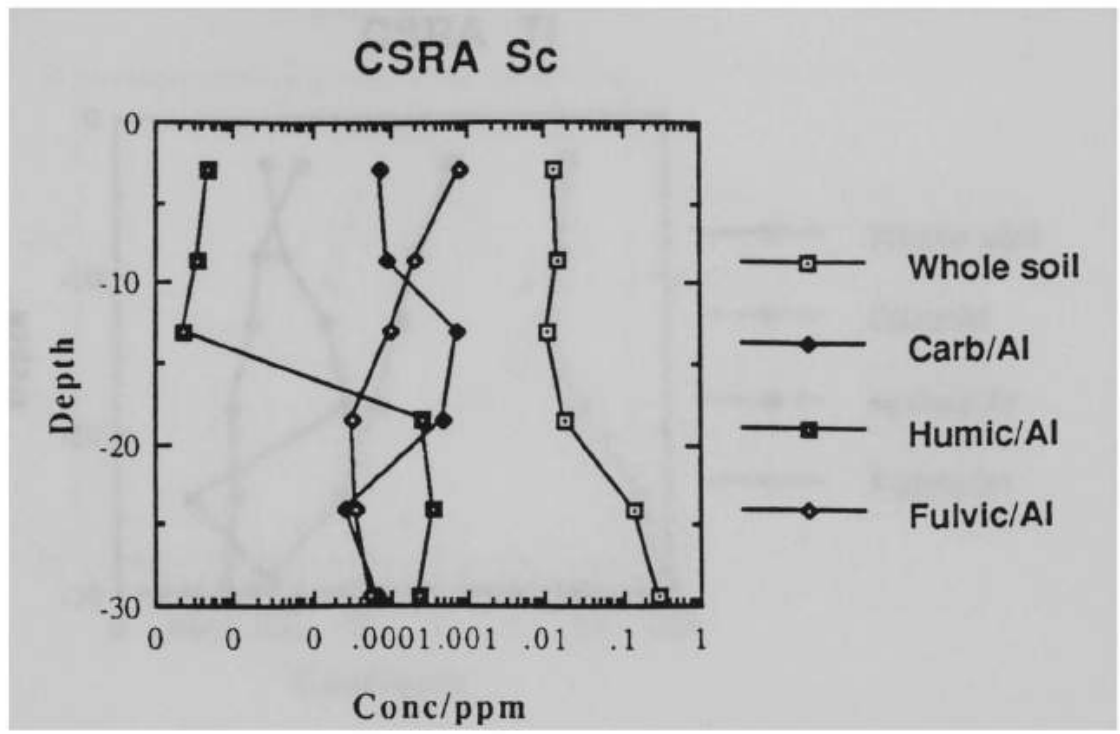

Fig. 40: CSRA Sc vs depth. Sigma. values are w.s. $2.7 \%$; carb $6.9 \%$; humic $18 \%$; fulvic $59 \%$.

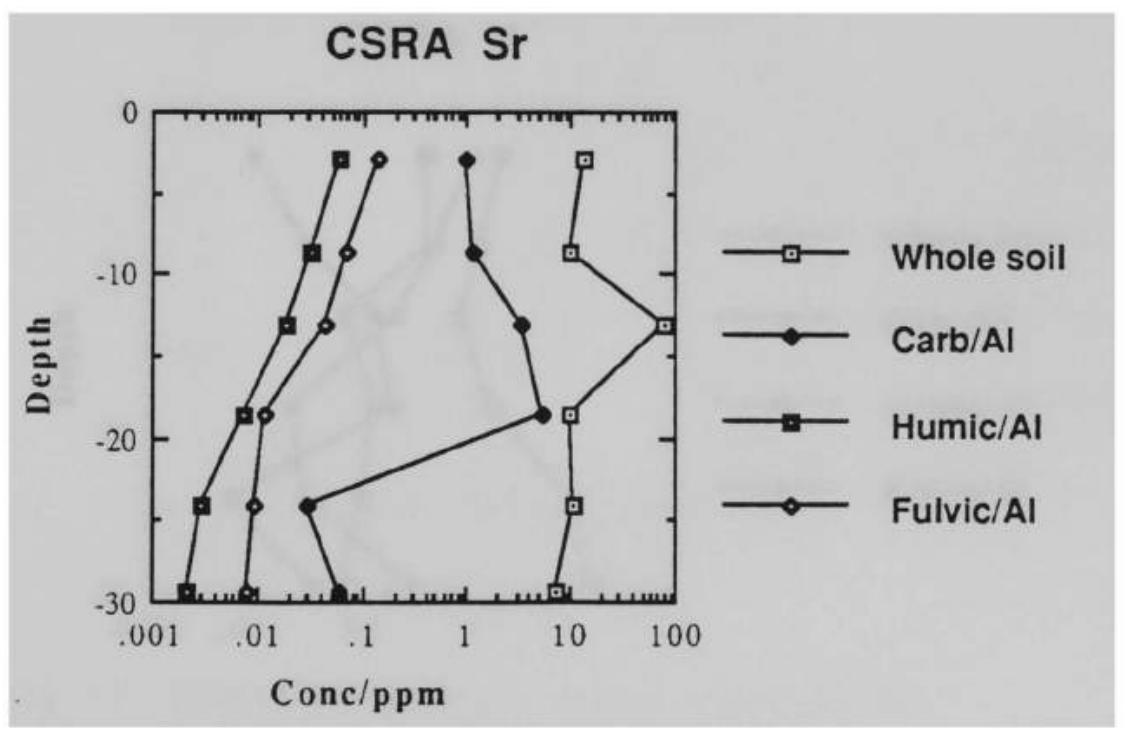

Fig. 41: CSRA Sr vs depth. Sigma values are w.s. $2.5 \%$; carb $1.4 \%$; humic $1.0 \%$; fulvic $1.1 \%$. 


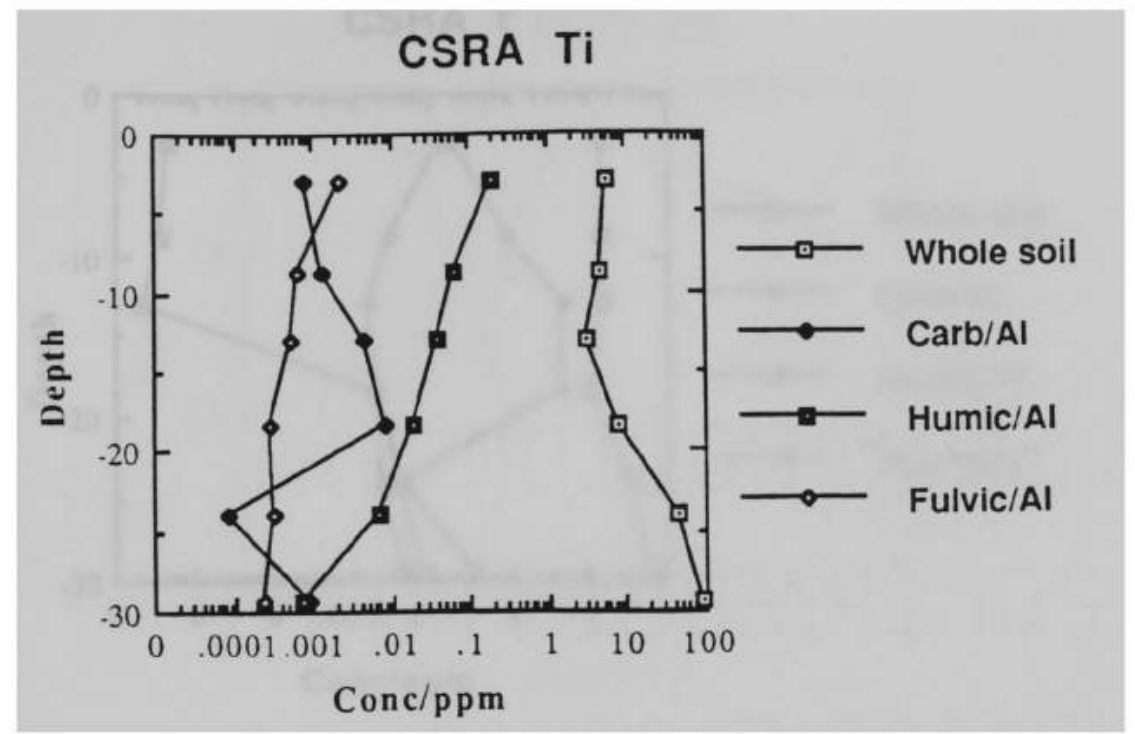

Fig. 42: CSRA Ti vs depth. Sigma values are w.s. $2.2 \%$; carb $1.7 \%$; humic $8.8 \%$; fulvic $30 \%$.

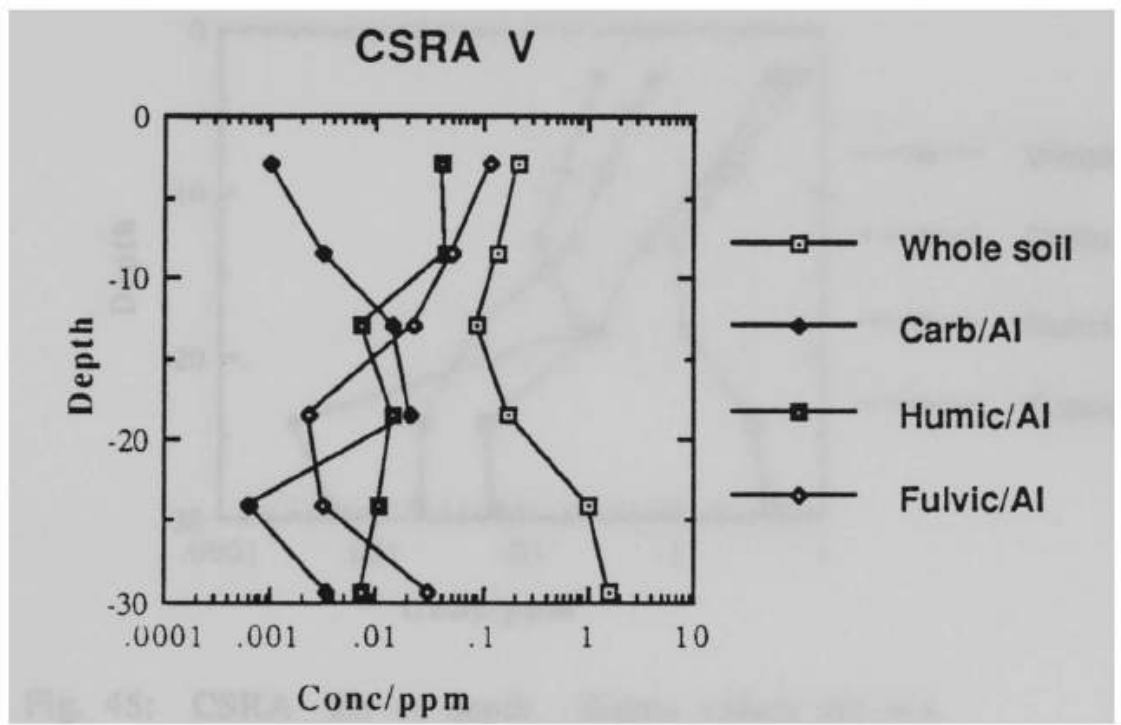

Fig. 43: CSRA V vs depth. Sigma values are w.s.

$2.1 \%$; carb $80 \%$; humic $22 \%$; fulvic $2.5 \%$. 


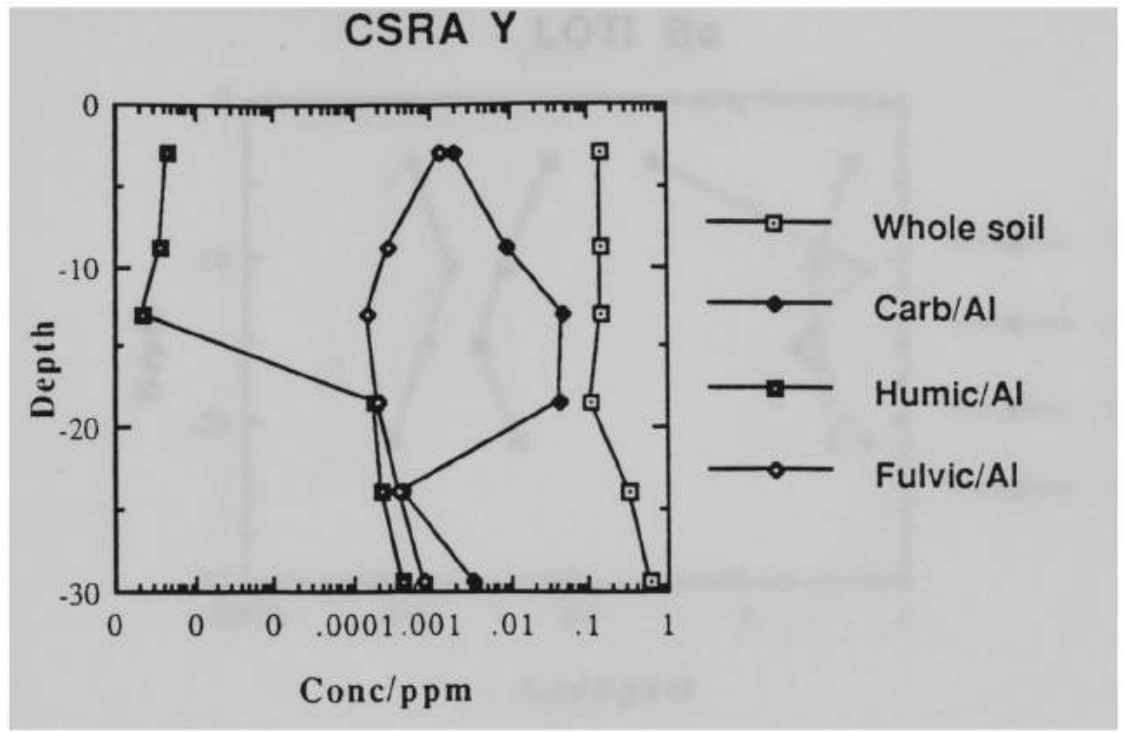

Fig. 44: CSRA Y vs depth. Sigma values are w.s. $1.2 \%$; carb $3.1 \%$; humic $10 \%$; fulvic $3.6 \%$.

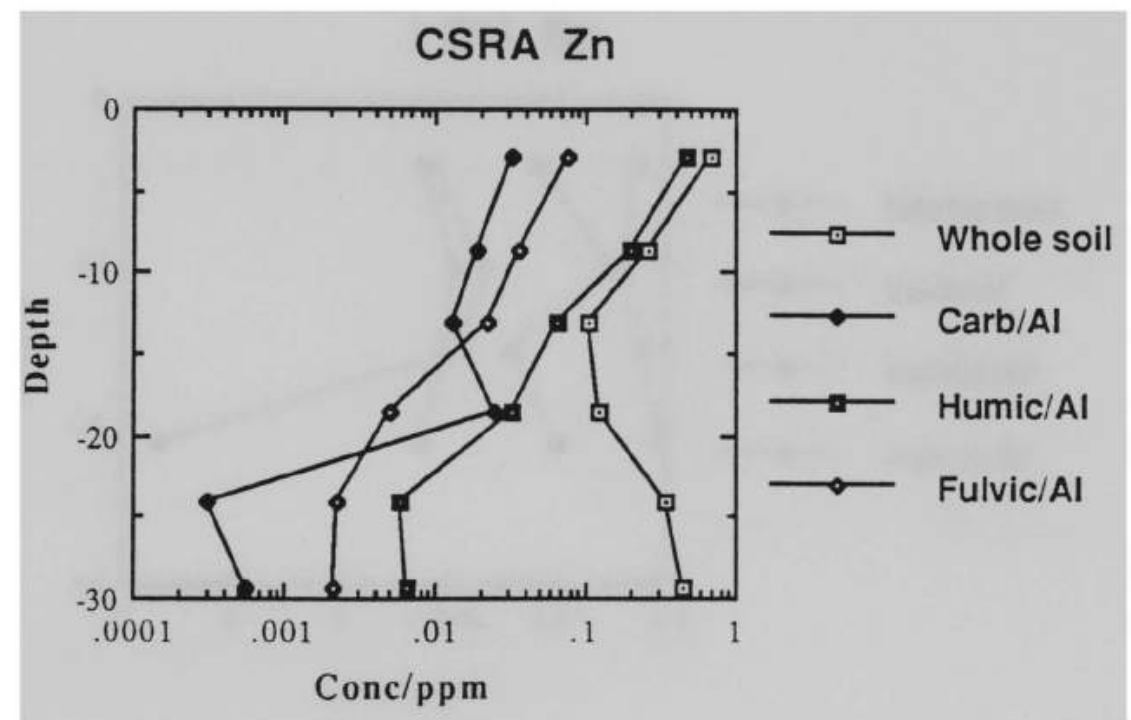

Fig. 45: CSRA Zn vs depth. Sigma values are w.s. $1.8 \%$; carb $2.0 \%$; humic $5.1 \%$; fulvic $4.3 \%$. 


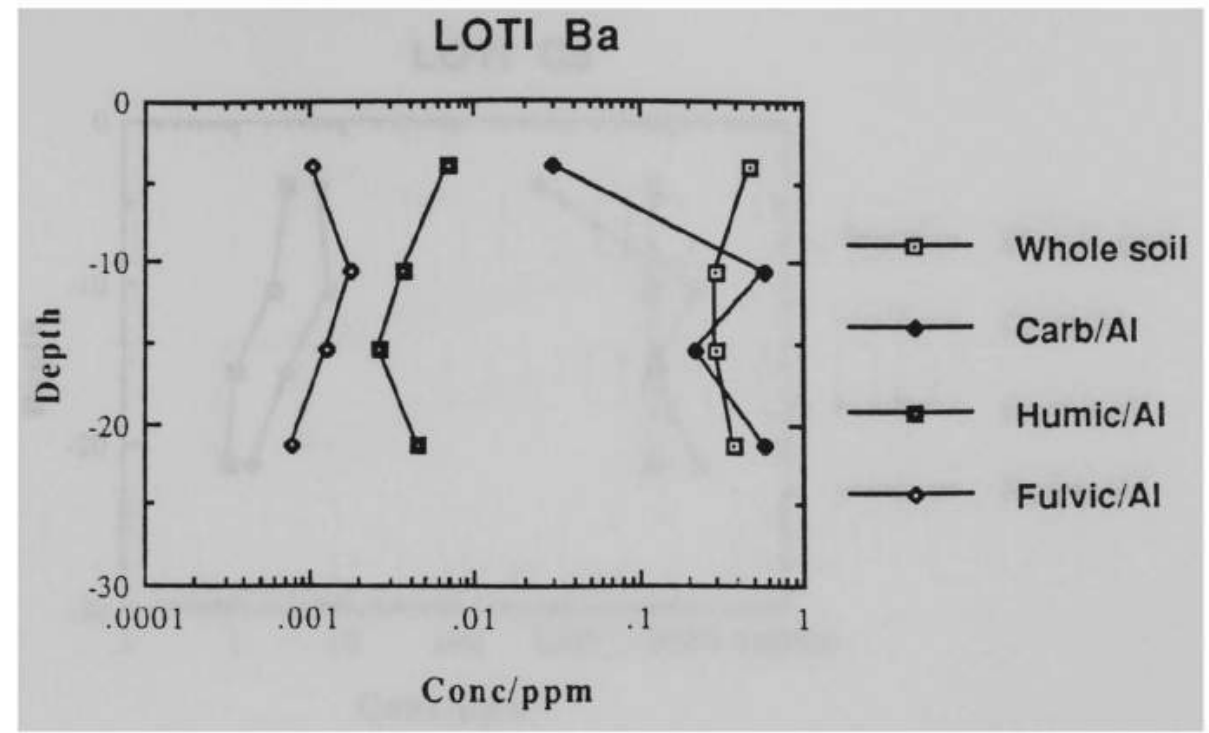

Fig. 46: LOTI Ba vs depth. Sigma values are w.s. $2.5 \%$; carb $1.3 \%$; humic $47 \%$; fulvic $27 \%$.

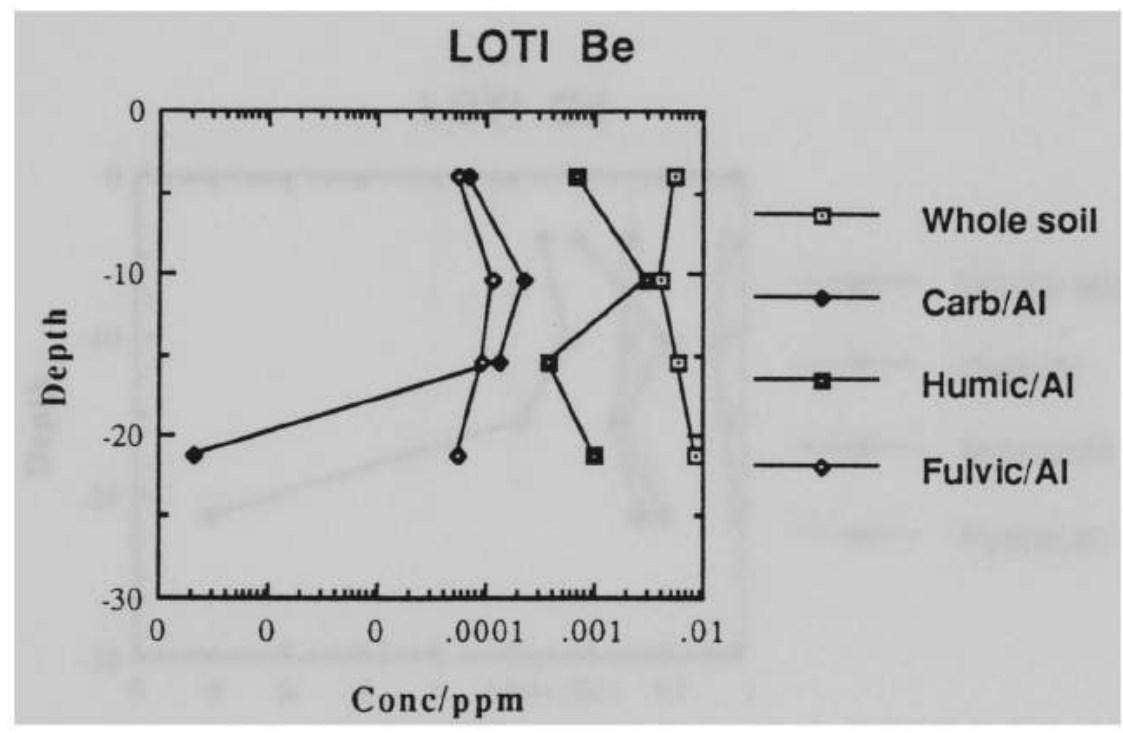

Fig. 47: LOTI Be vs depth. Sigma values are w.s. $2.9 \%$; carb $88 \%$; humic $260 \%$; fulvic $590 \%$. 


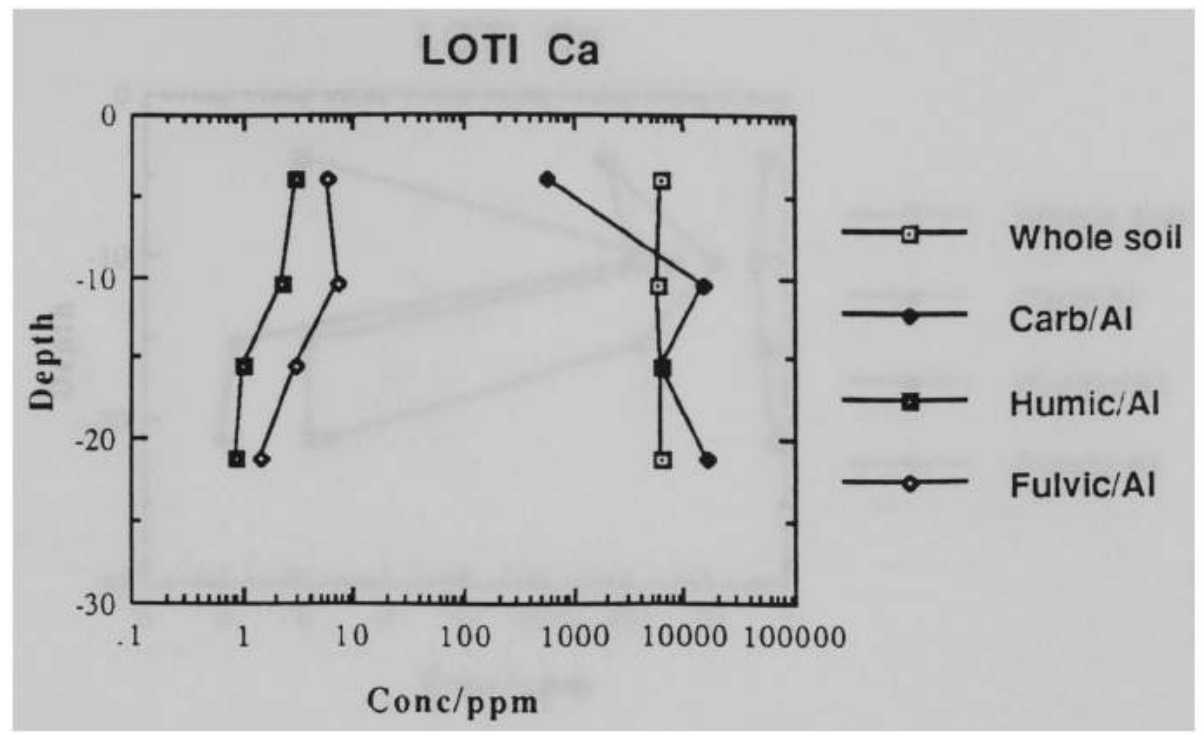

Fig. 48: LOTI Ca vs depth. Sigma values are w.s. $1.3 \%$; carb $2.0 \%$; humic $2.7 \%$; fulvic $1.5 \%$.

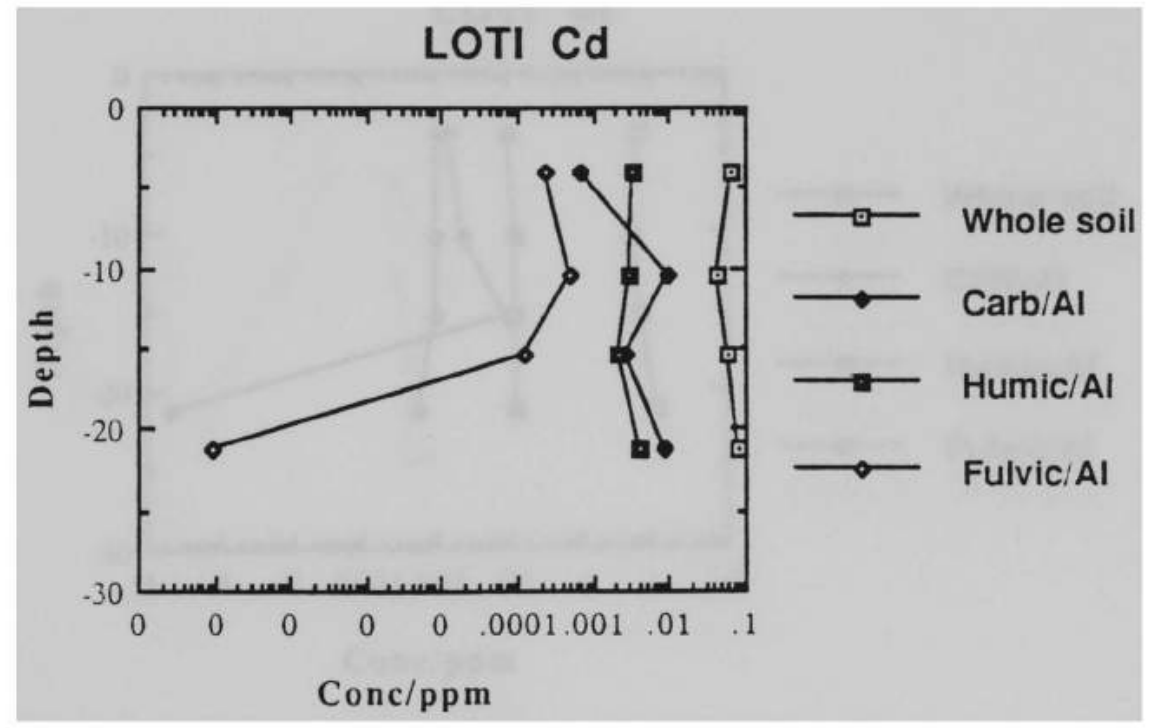

Fig. 49: LOTI Cd vs depth. Sigma values are w.s. $2.0 \%$; carb $35 \%$; humic $68 \%$; fulvic $85 \%$. 


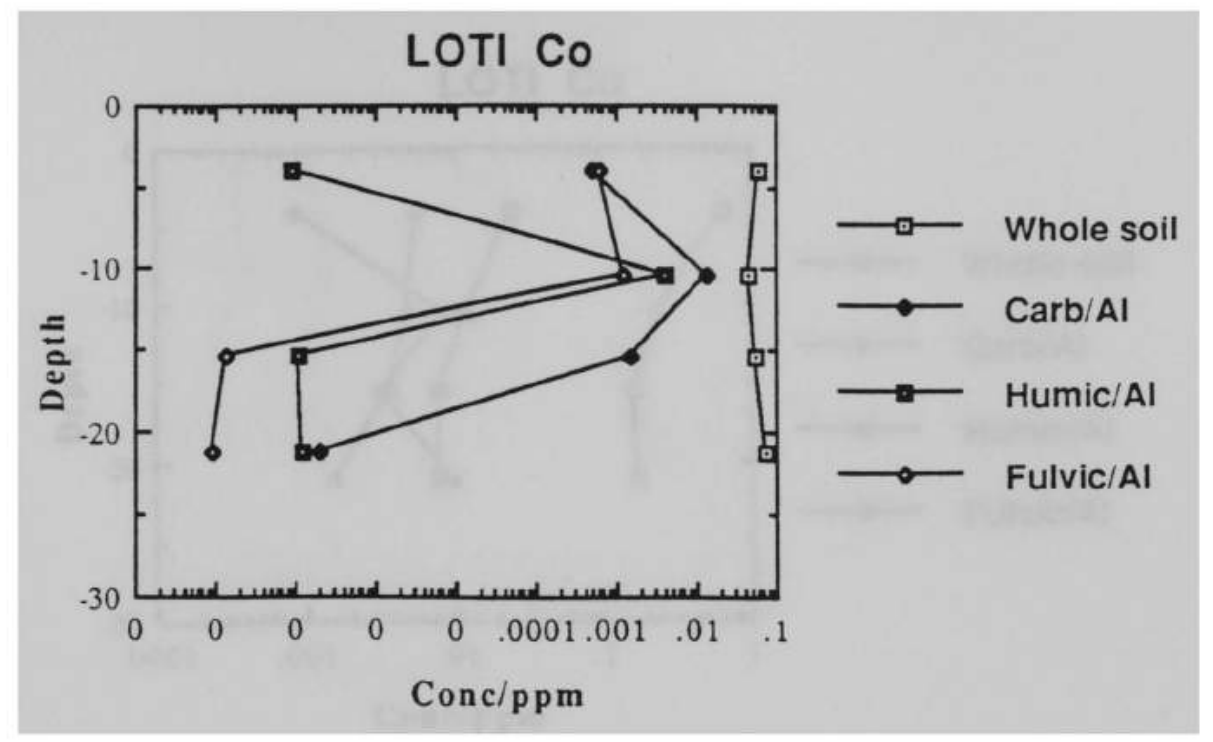

Fig. 50: LOTI Co vs depth. Sigma values are w.s. $2.9 \%$; carb $47 \%$; humic $66 \%$; fulvic $69 \%$.

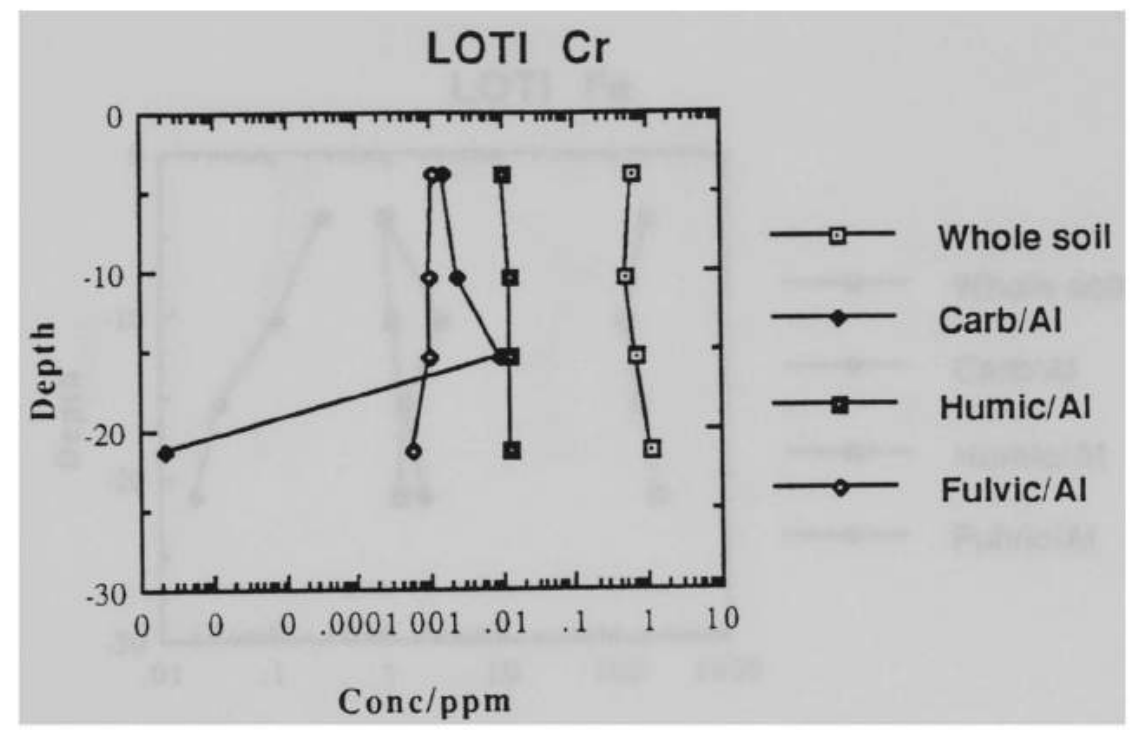

Fig. 51: LOTI Cr vs depth. Sigma values are w.s. $4.0 \%$; carb $190 \%$; humic $28 \%$; fulvic $71 \%$. 


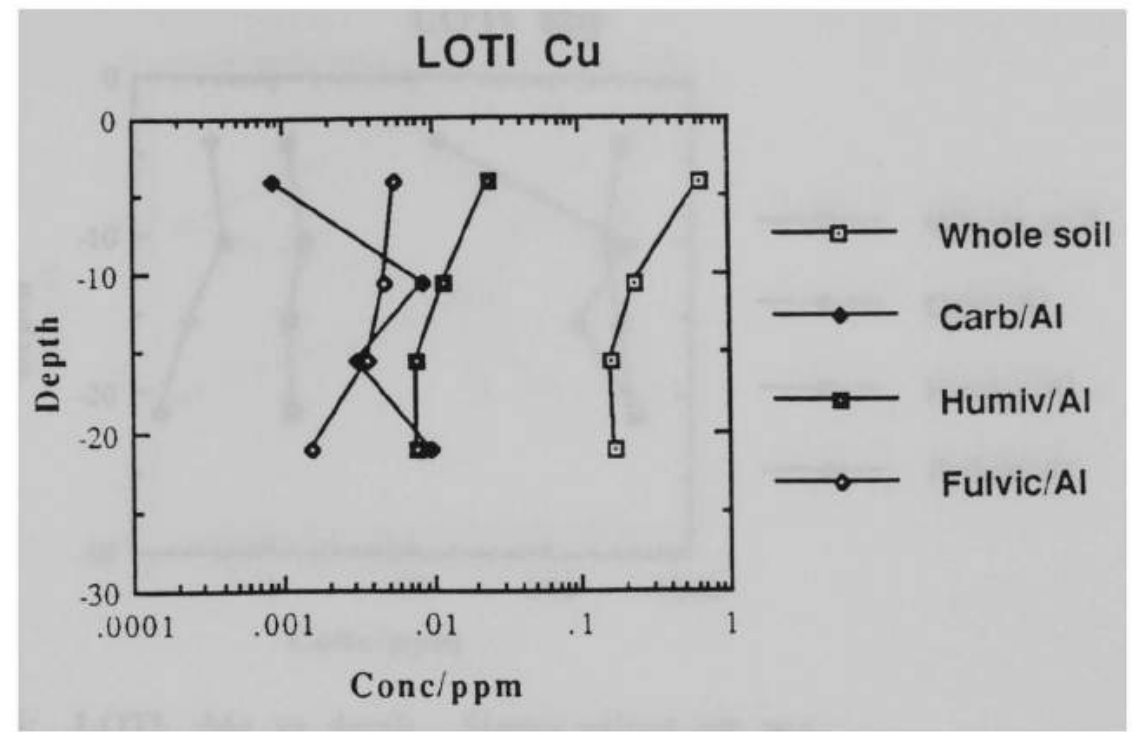

Fig. 52: LOTI Cu vs depth. Sigma values are w.s. $1.8 \%$; carb $28 \%$; humic $15 \%$; fulvic $7.8 \%$.

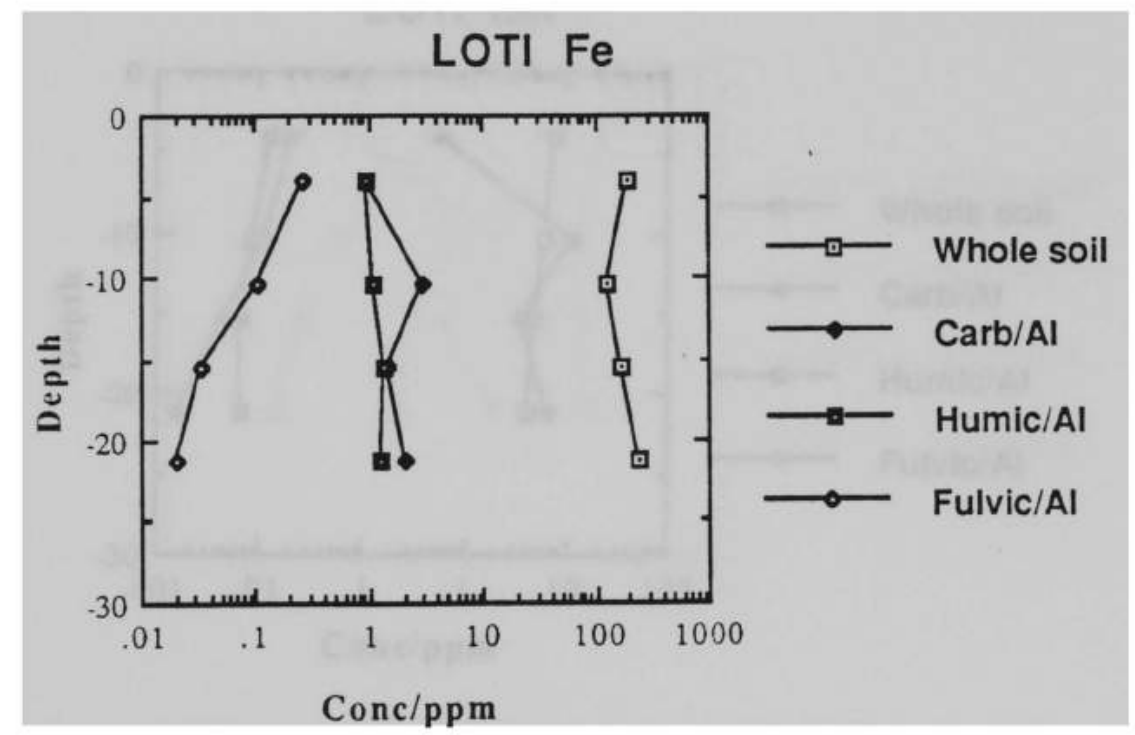

Fig. 53: LOTI Fe vs depth. Sigma values are w.s. $1.4 \%$; carb $1.8 \%$; humic $2.1 \%$; fulvic $2.5 \%$. 


\section{LOTI Mg}

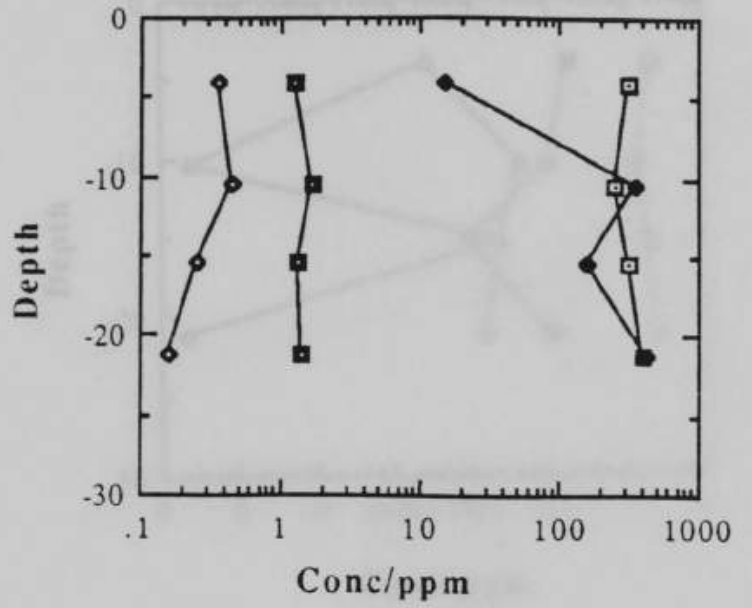

$\longrightarrow$ Whole soil

$\longrightarrow$ Carb/Al

$\longrightarrow$ Humic/Al

$\longrightarrow$ Fulvic/Al

Fig. 54: LOTI Mg vs depth. Sigma values are w.s.

$1.3 \%$; carb $1.0 \%$; humic $2.3 \%$; fulvic $1.6 \%$.

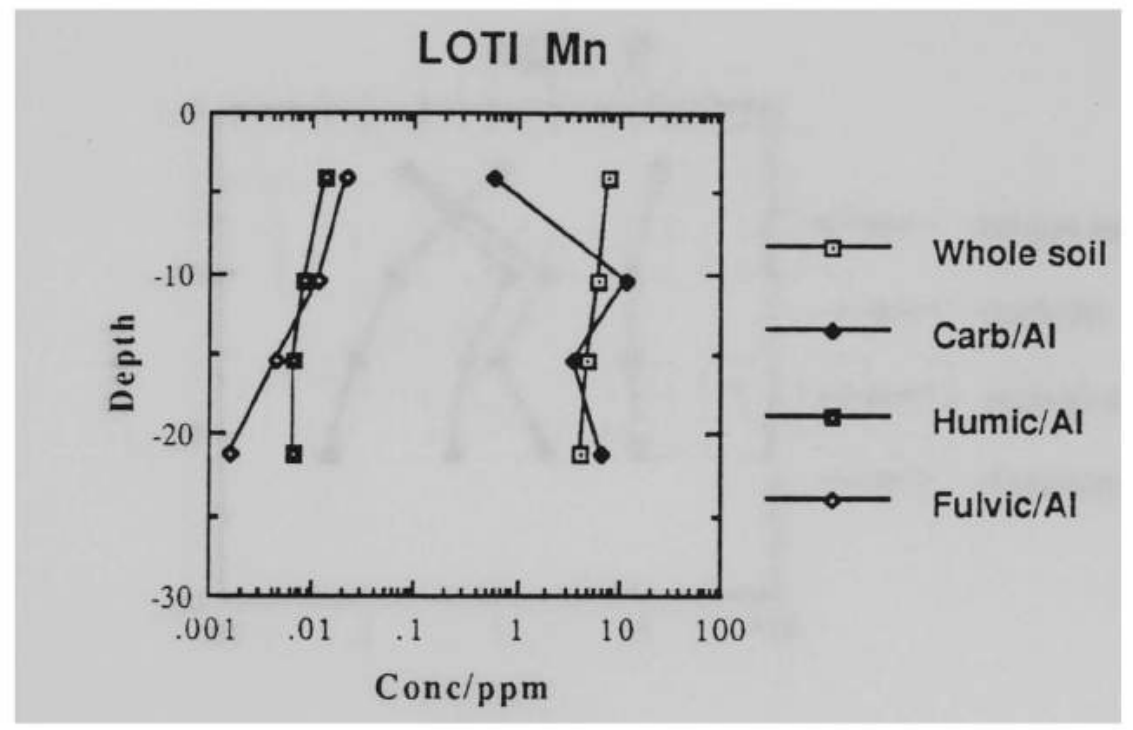

Fig. 55: LOTI Mn vs depth. Sigma values are w.s. $1.7 \%$; carb $1.1 \%$; humic $7.9 \%$; fulvic $2.2 \%$. 


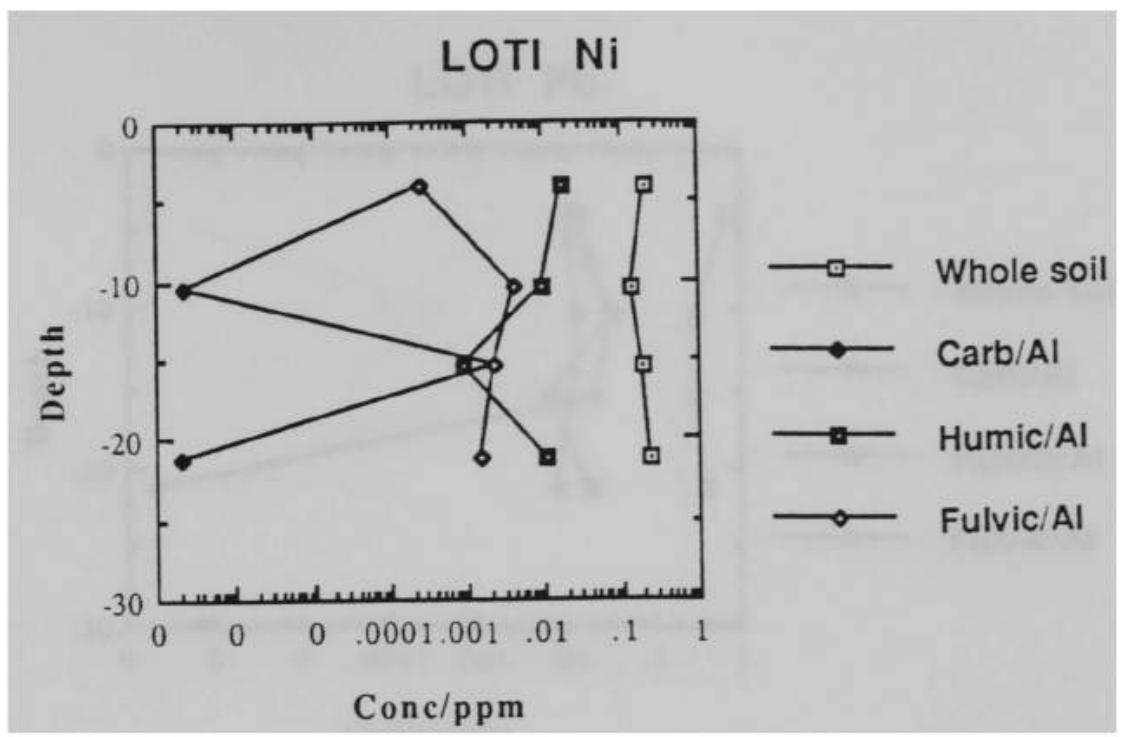

Fig. 56: LOTI Ni vs depth. Sigma values are w.s. $5.7 \%$; carb $170 \%$; humic $52 \%$; fulvic $210 \%$.

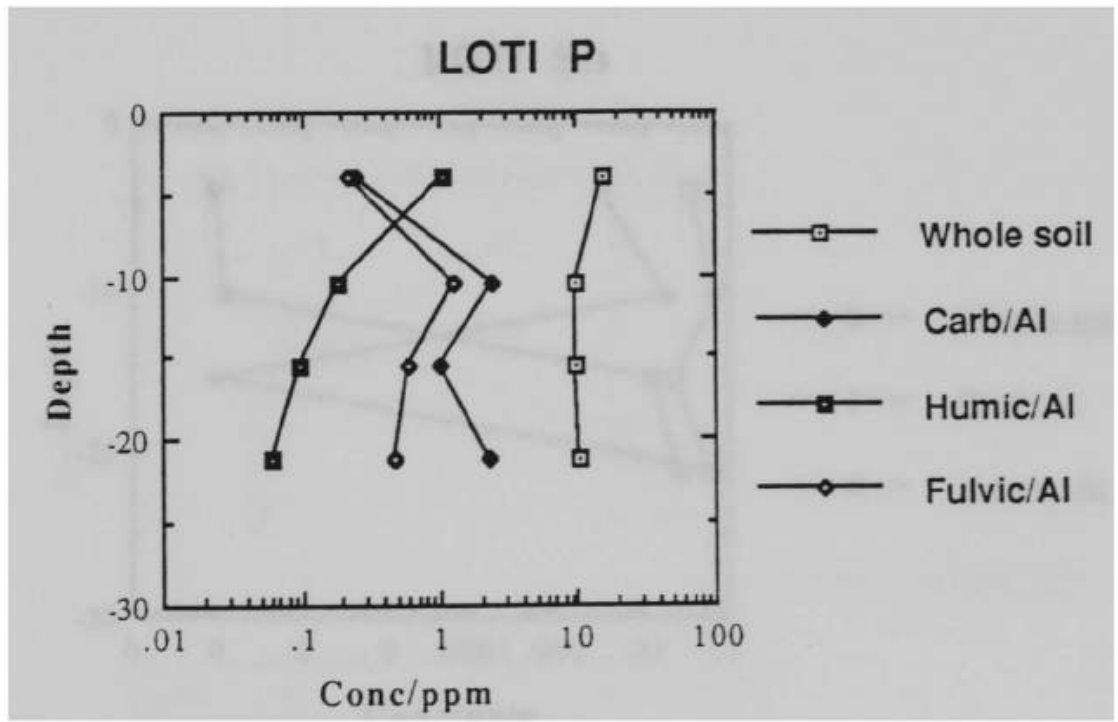

Fig. 57: LOTI P vs depth. Sigma values are w.s. $2.5 \%$; carb $9.7 \%$; humic $40 \%$; fulvic $5.5 \%$. 


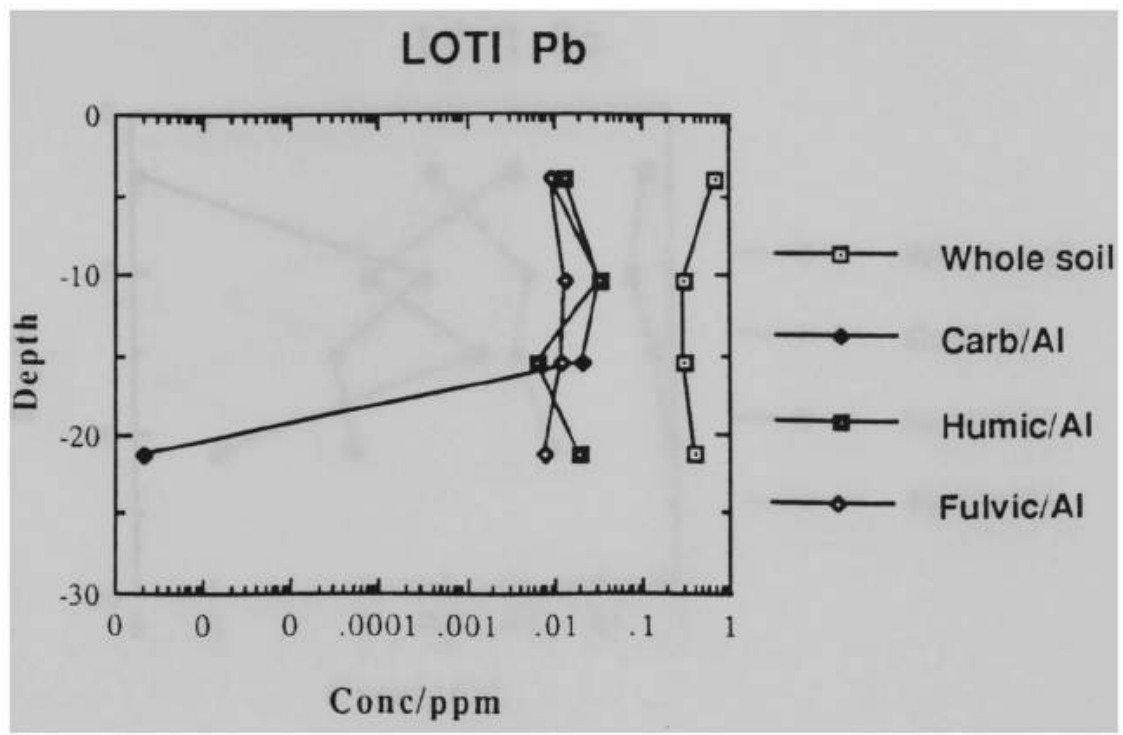

Fig. 58: LOTI $\mathrm{Pb}$ vs depth. Sigma values are w.s. $3.5 \%$; carb $98 \%$; humic $200 \%$; fulvic $32 \%$.

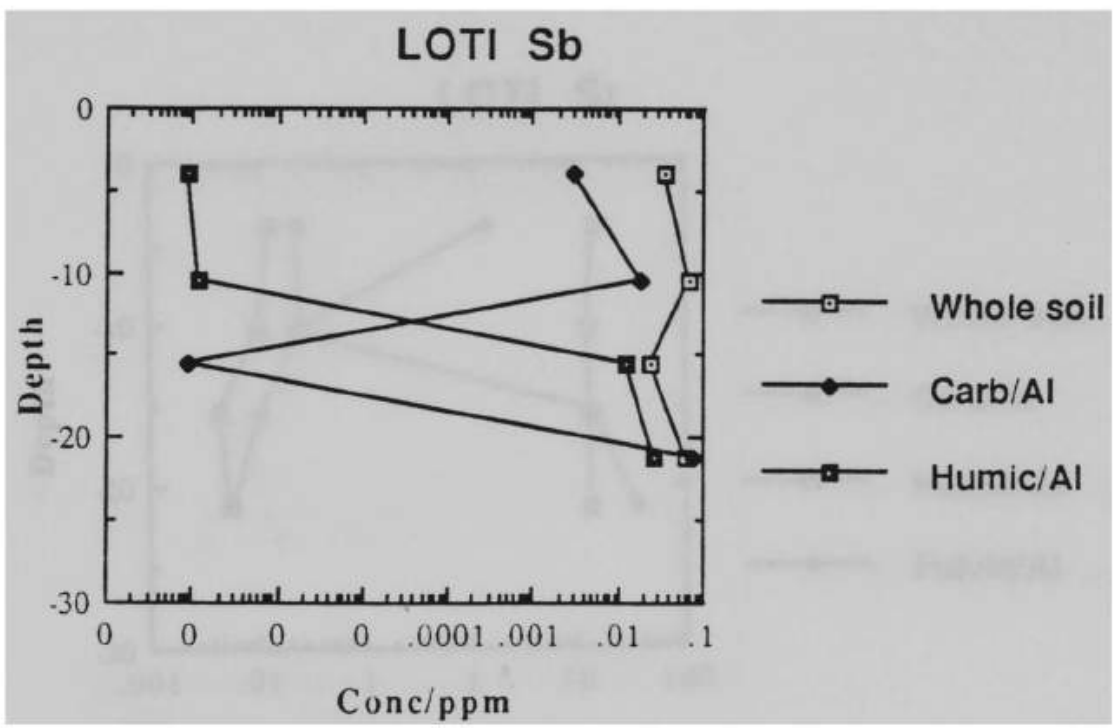

Fig. 59: LOTI Sb vs depth. Sigma values are w.s. $30 \%$; carb 130\%; humic $77 \%$. Sb not detected in the fulvic acid. 


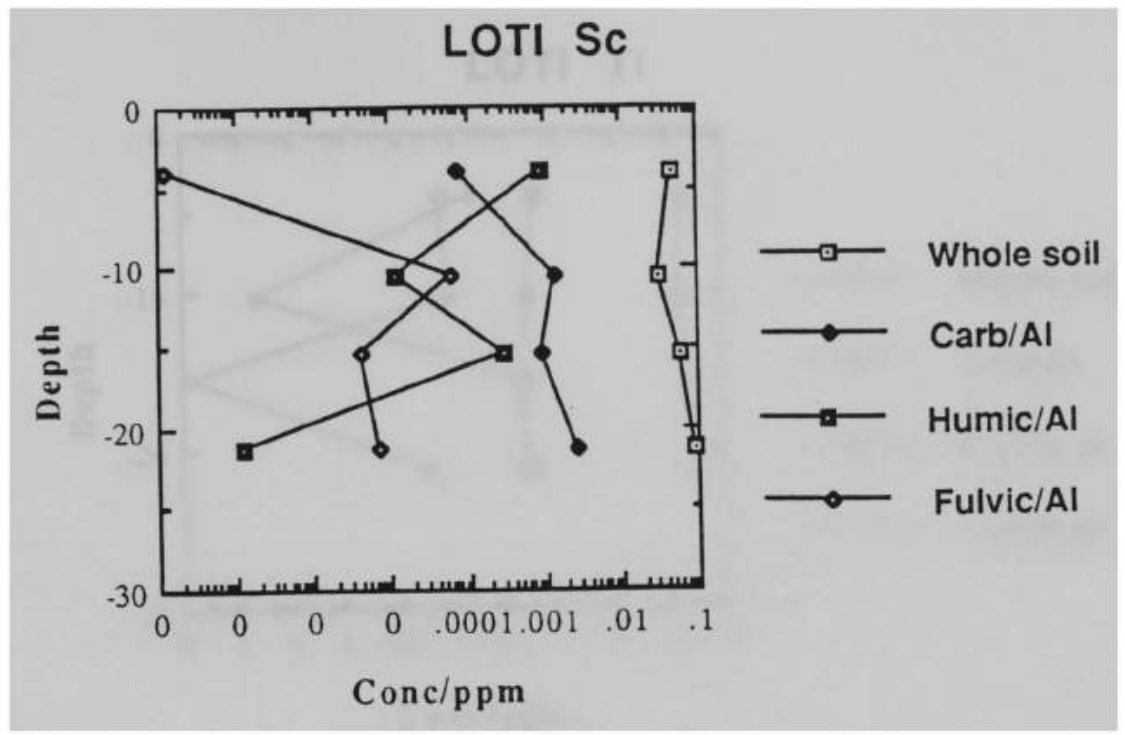

Fig. 60: LOTI Sc vs depth. Sigma values are w.s. $1.9 \%$; carb $35 \%$; humic $180 \%$; fulvic $220 \%$.

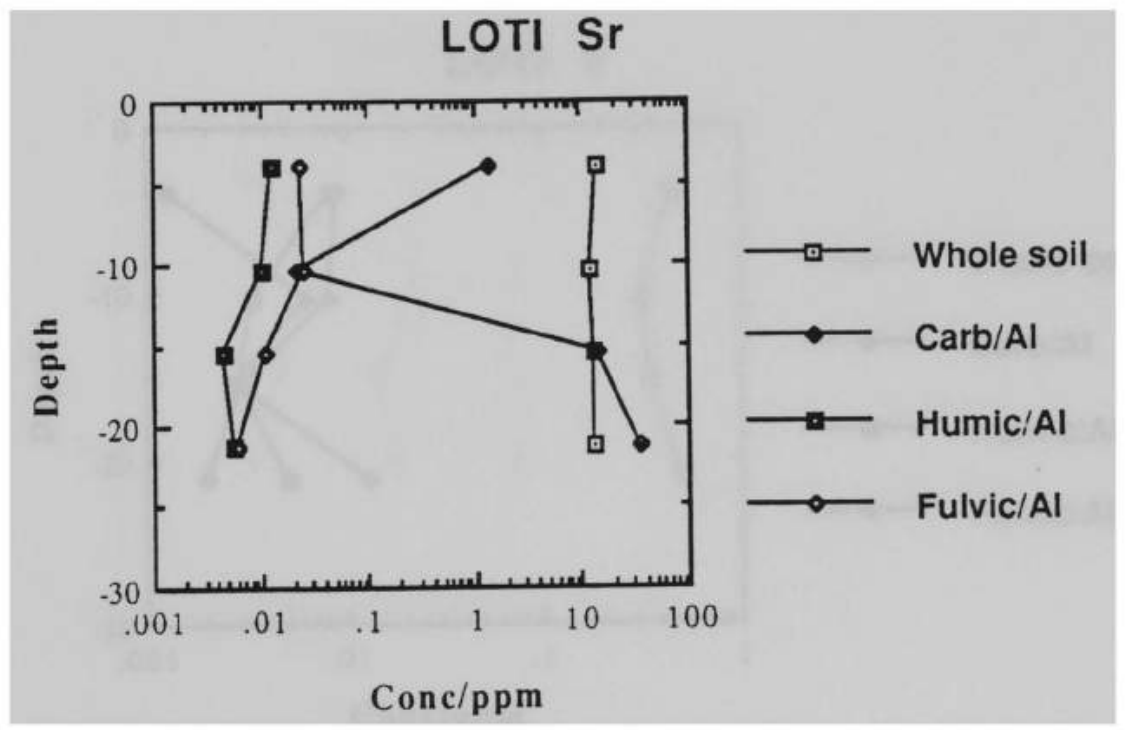

Fig. 61: LOTI Sr vs depth. Sigma values are w.s. $2.0 \%$; carb $5.2 \%$; humic $2.5 \%$; fulvic $1.5 \%$. 


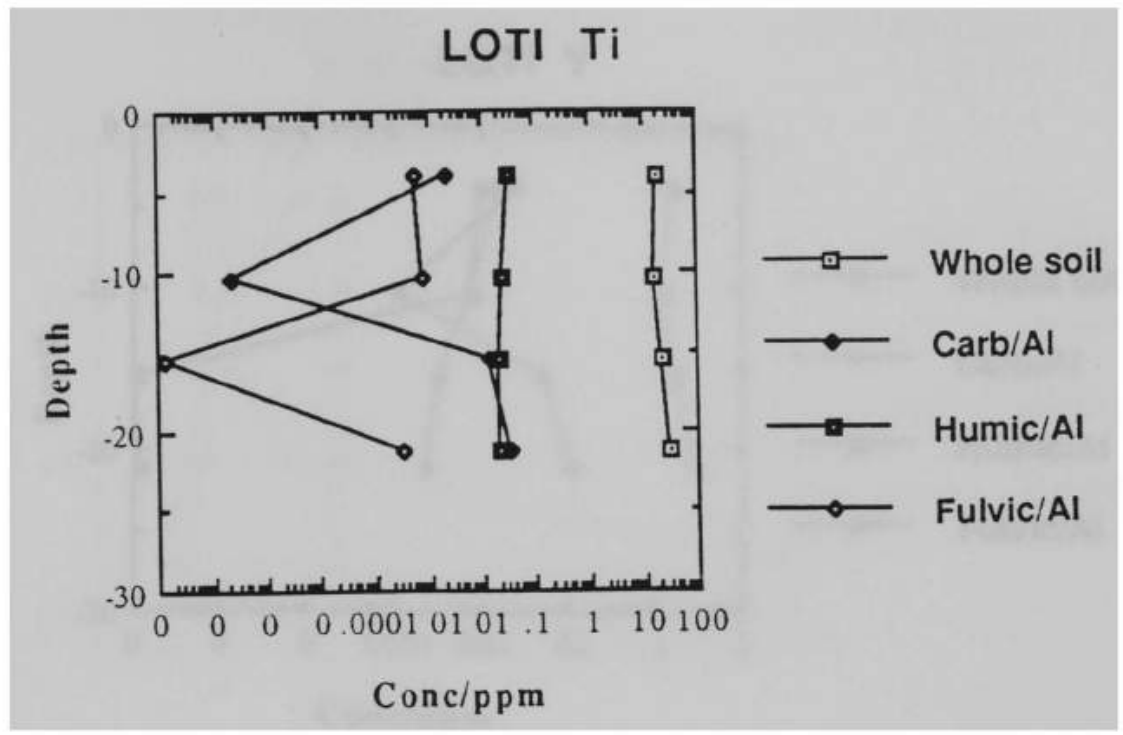

Fig. 62: LOTI Ti vs depth. Sigma values are w.s. $1.7 \%$; carb $3.2 \%$; humic $4.4 \%$; fulvic $50 \%$.

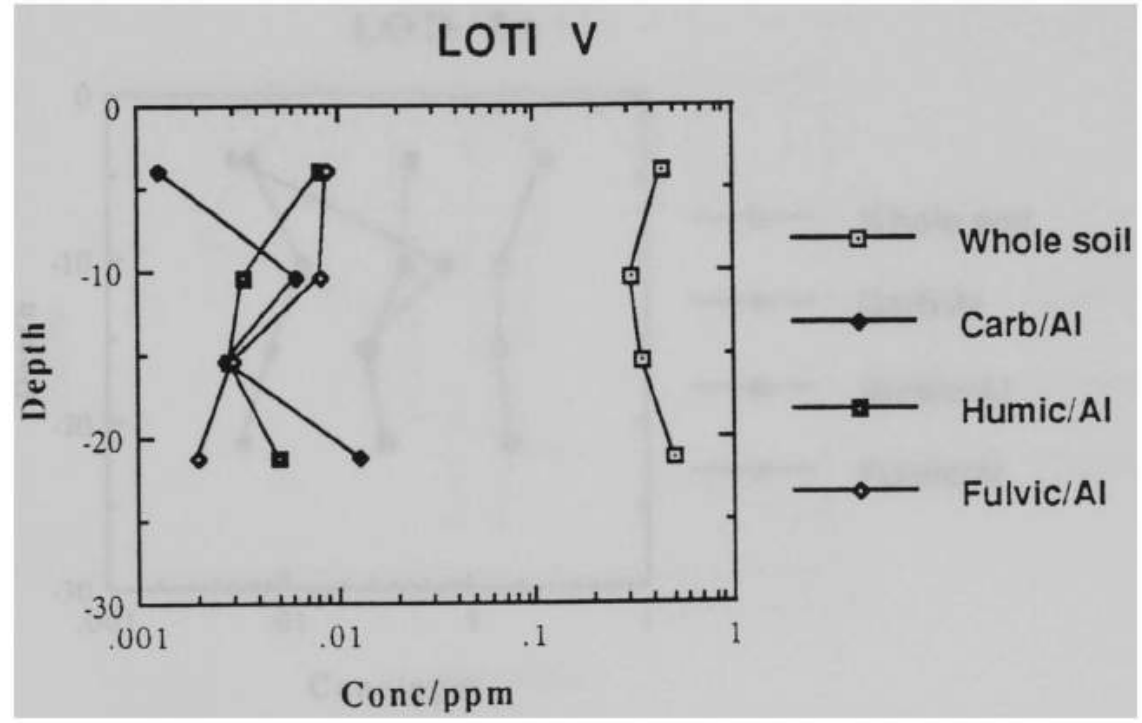

Fig. 63: LOTI V vs depth. Sigma values are w.s. $1.8 \%$; carb $23 \%$; humic $44 \%$; fulvic $11 \%$. 


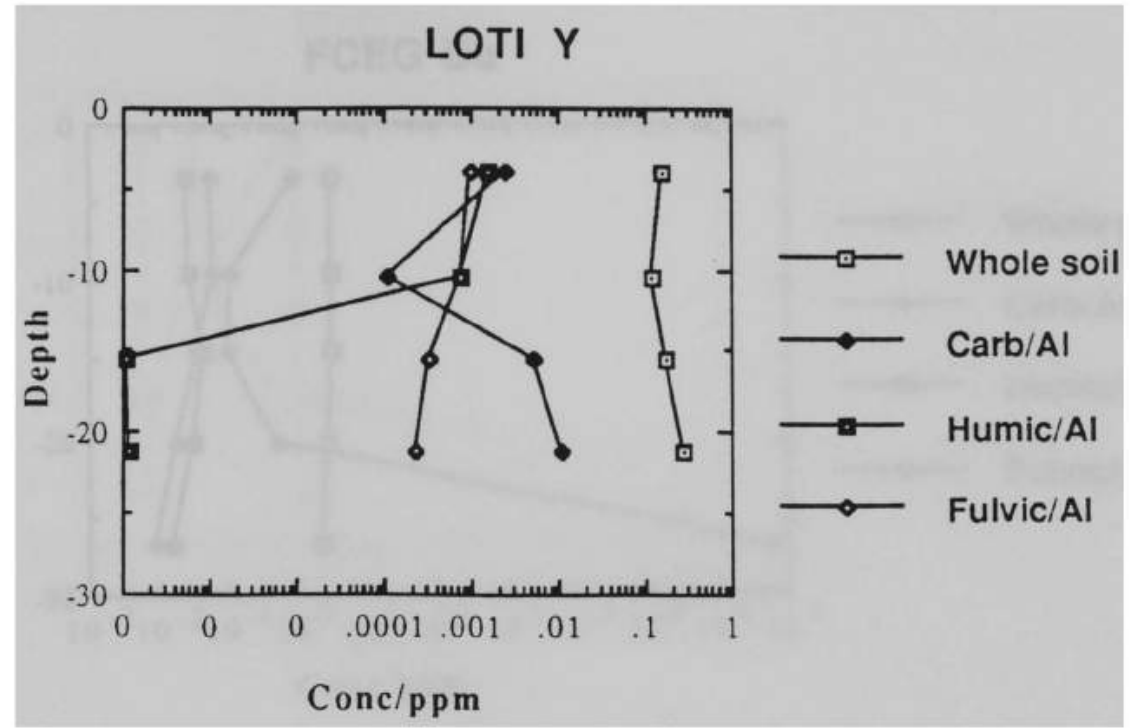

Fig. 64: LOTI Y vs depth. Sigma values are w.s. $2.1 \%$; carb $9.2 \%$; humic $170 \%$; fulvic $12 \%$.

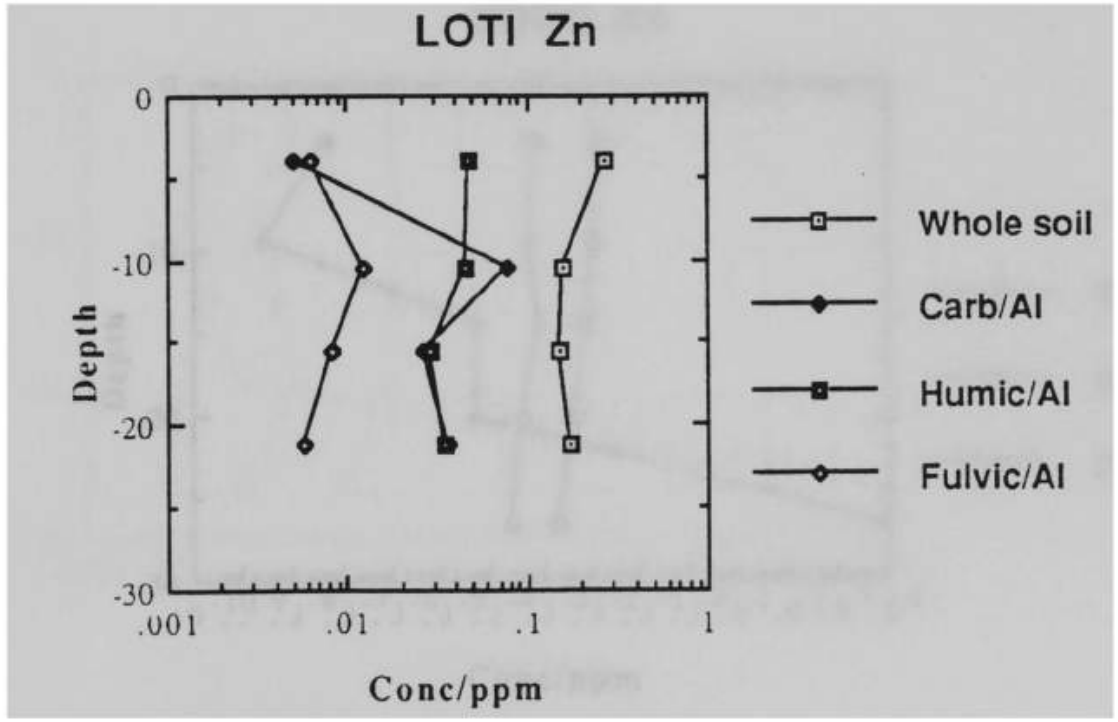

Fig. 65: LOTI $\mathrm{Zn}$ vs depth. Sigma values are w.s. $1.8 \%$; carb $2.7 \%$; humic $6.9 \%$; fulvic $4.3 \%$. 


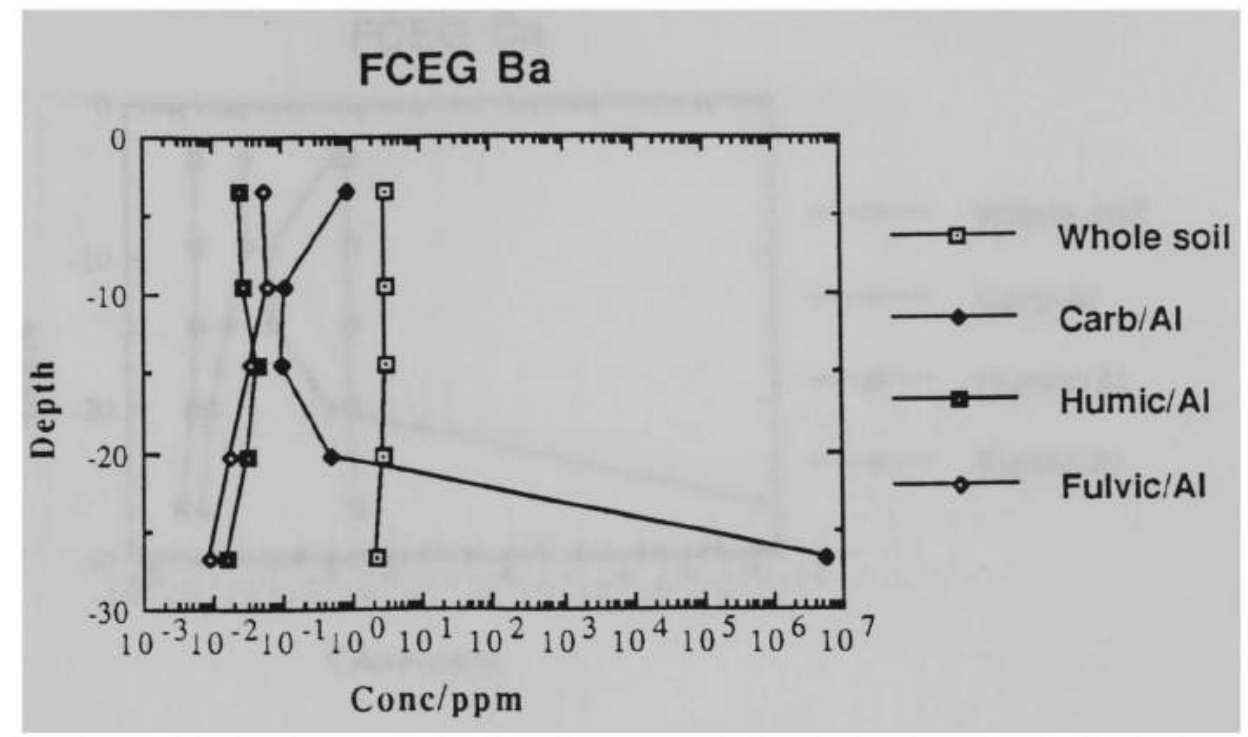

Fig. 66: FCEG Ba vs depth. Sigma values are w.s. $2.3 \%$; carb $3.3 \%$; humic $22 \%$; fulvic $4.6 \%$.

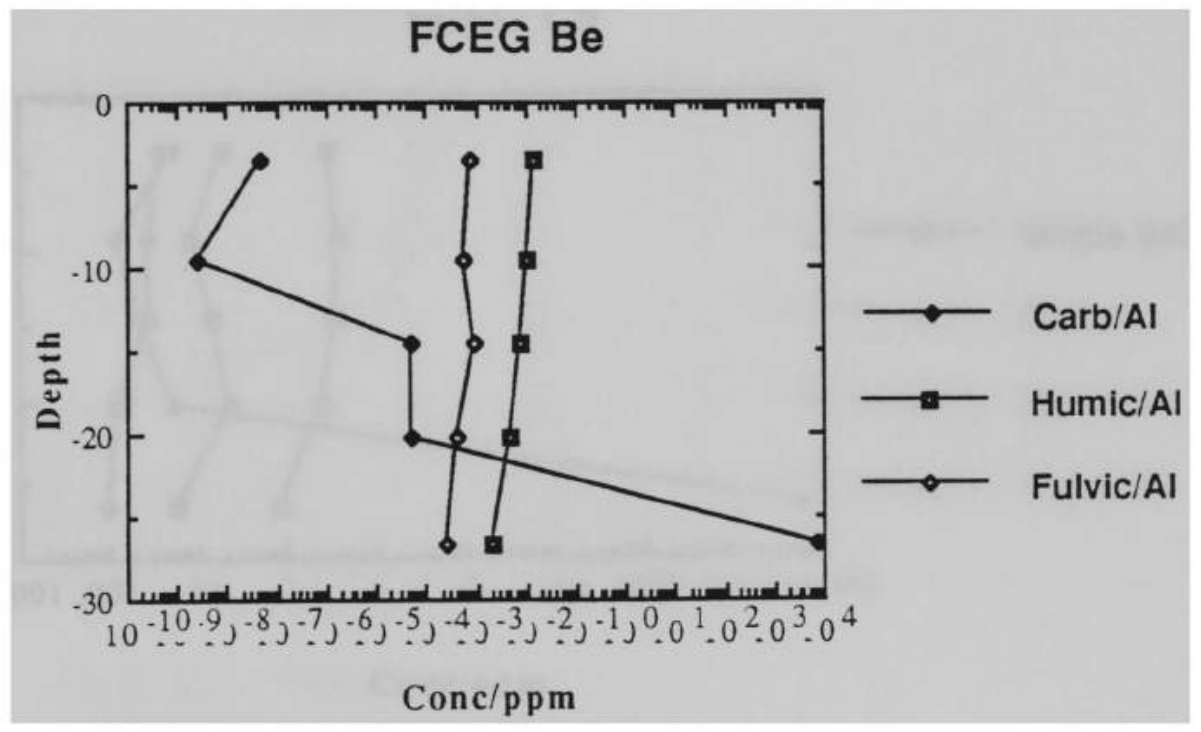

Fig. 67: FCEG Be vs depth. Sigma values are carb $88 \%$; humic $320 \%$; fulvic $570 \%$. Be not detected in the whole soil. 


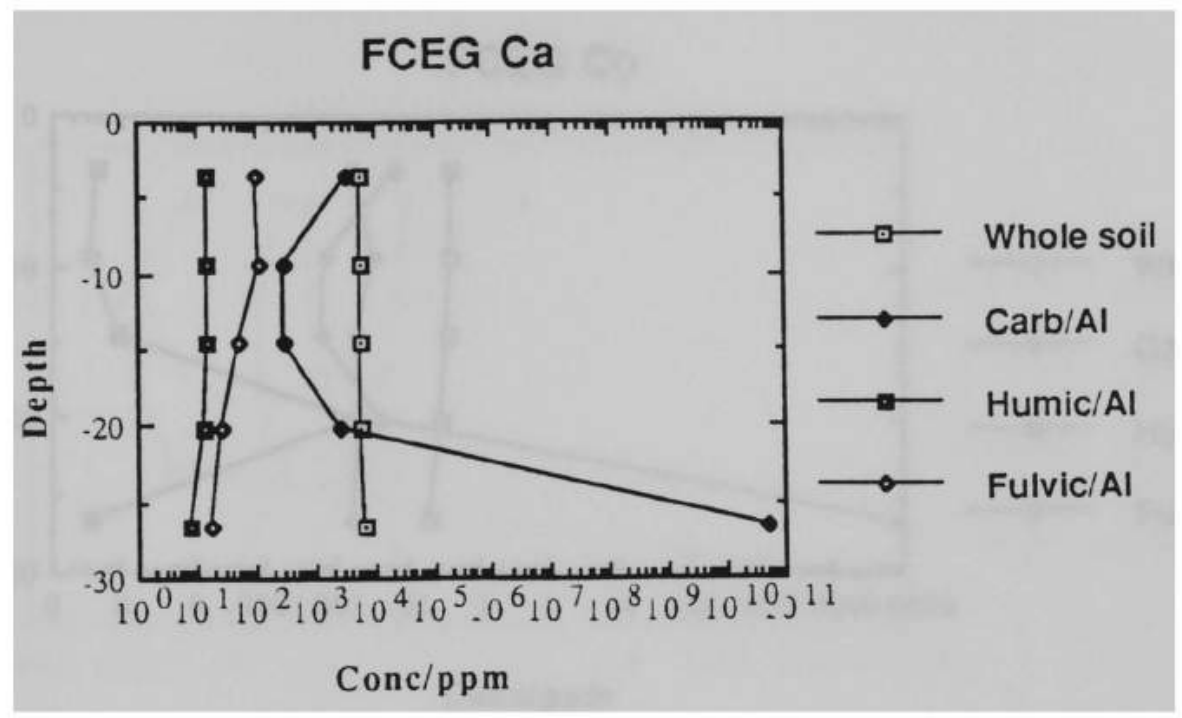

Fig. 68: FCEG Ca vs depth. Sigma values are w.s. $1.4 \%$; carb $2.5 \%$; humic $2.7 \%$; fulvic $1.5 \%$.

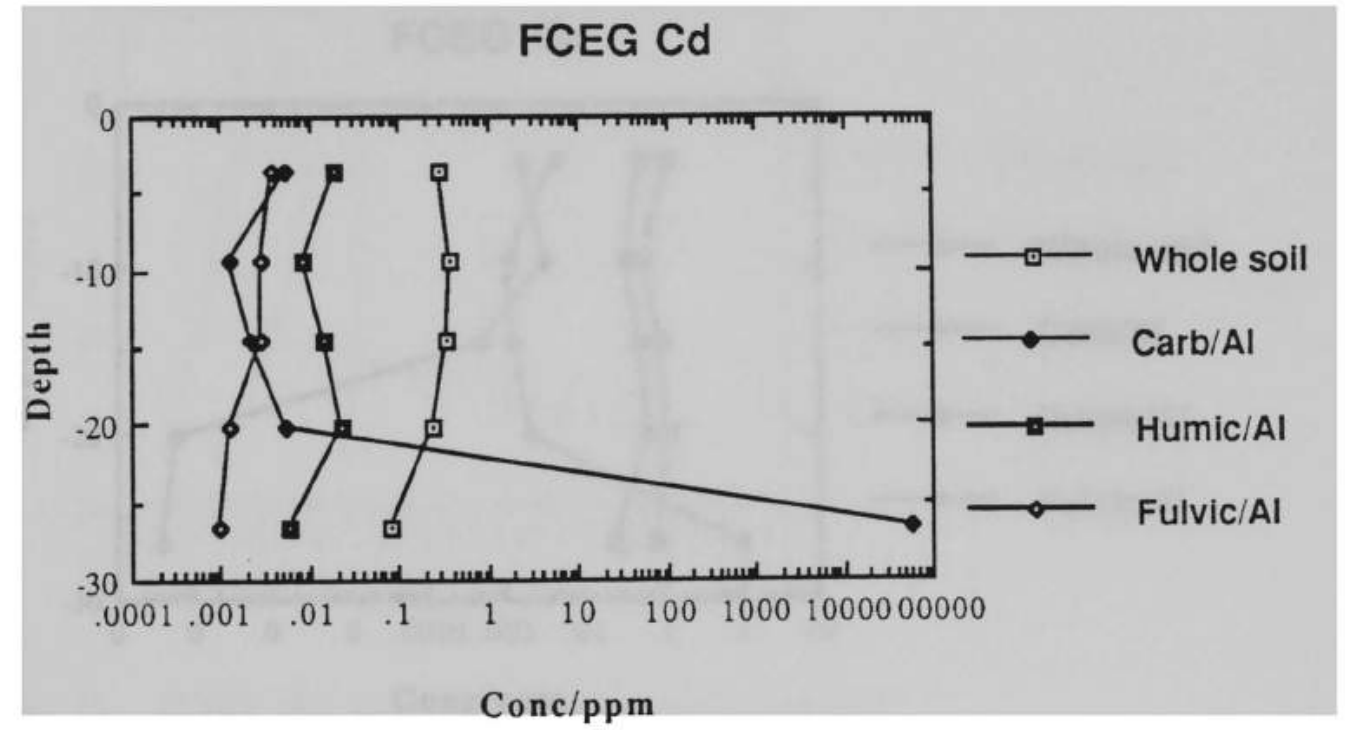

Fig. 69: FCEG Cd vs depth. Sigma values are w.s. $1.7 \%$; carb $14 \%$; humic $90 \%$; fulvic $63 \%$. 


\section{FCEG Co}

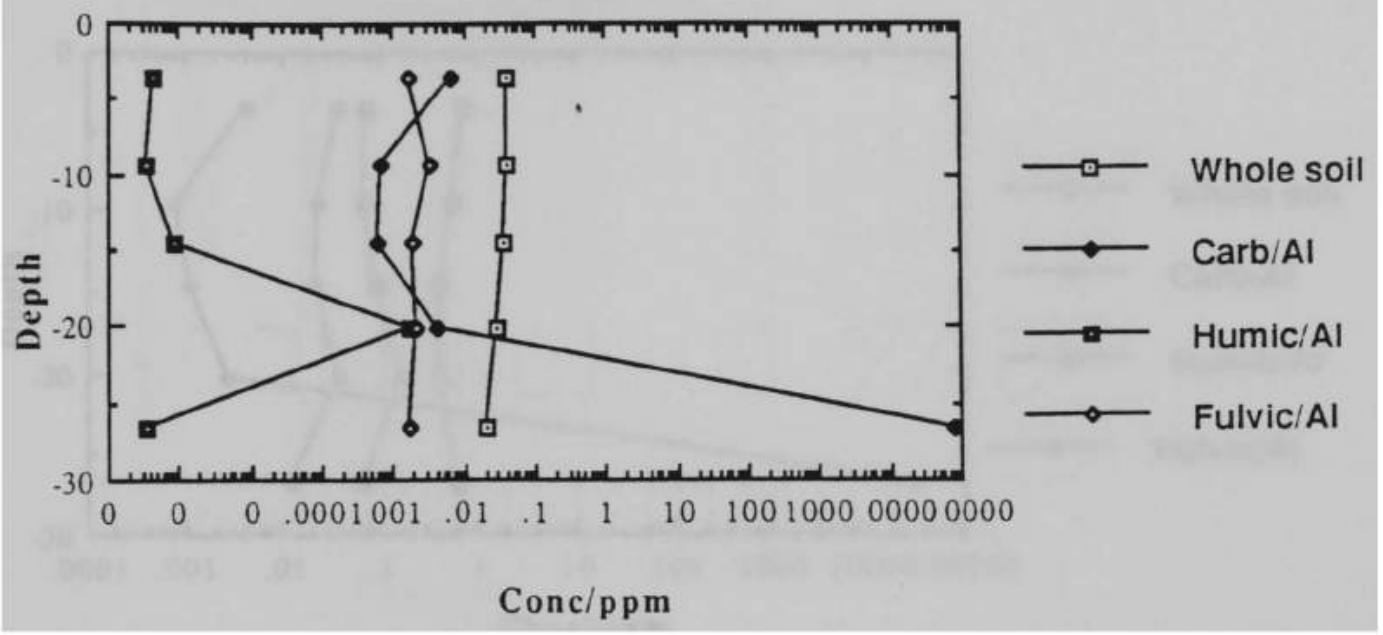

Fig. 70: FCEG Co vs depth. Sigma values are w.s.

$5.8 \%$; carb $30 \%$; humic $520 \%$; fulvic $100 \%$.

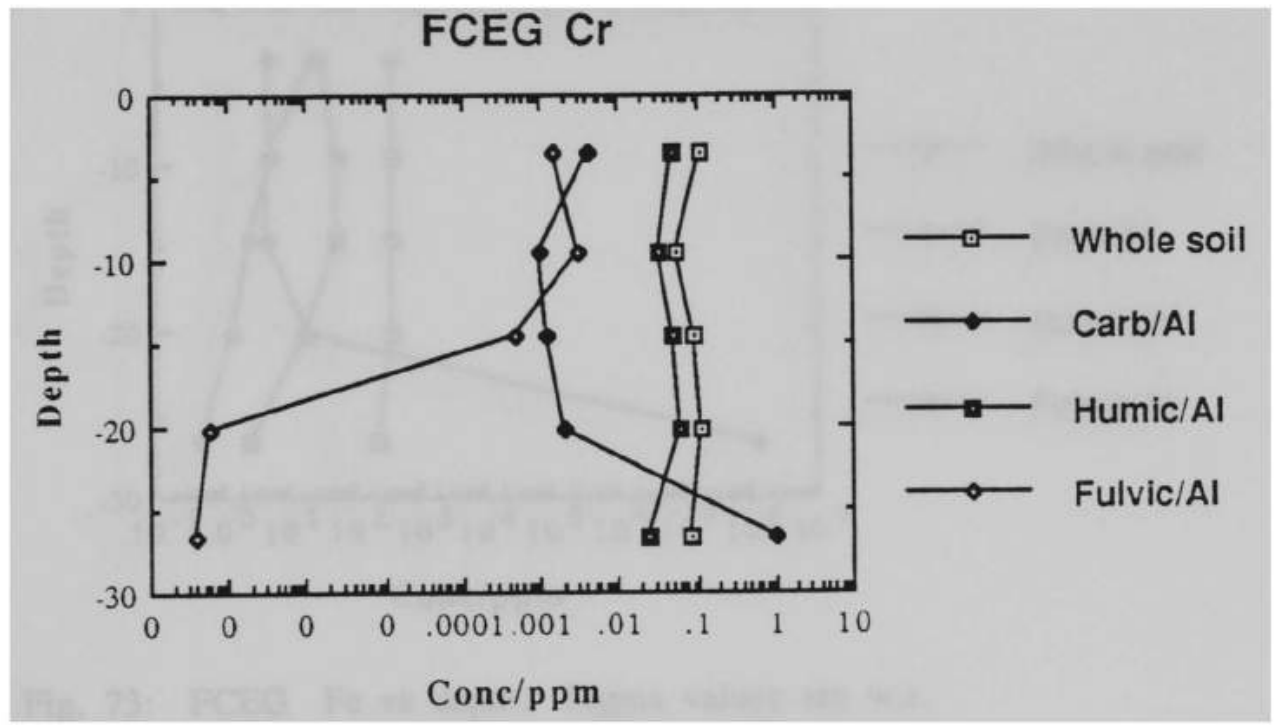

Fig. 71: FCEG Cr vs depth. Sigma values are w.s. $18 \%$; carb $46 \%$; humic $49 \%$; fulvic $100 \%$. 


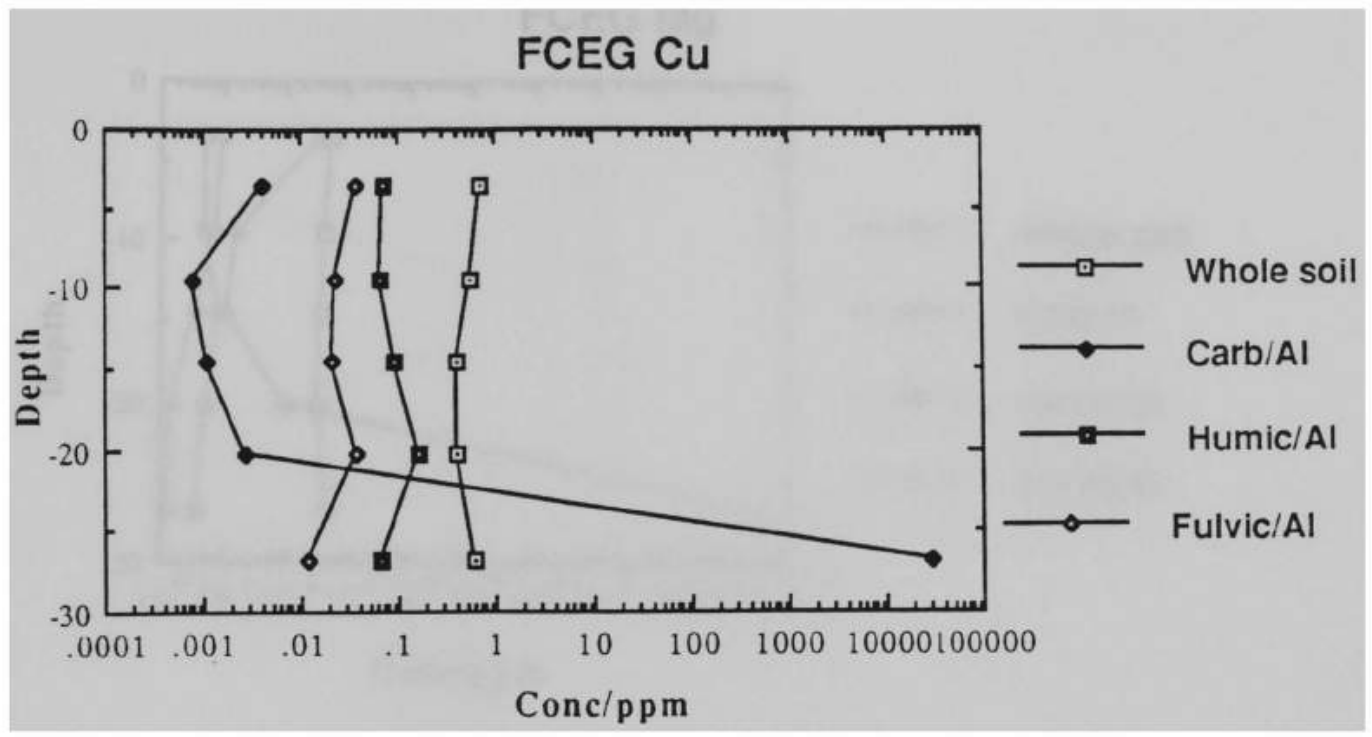

Fig. 72: FCEG $\mathrm{Cu}$ vs depth. Sigma values are w.s. $1.4 \%$; carb $24 \%$; humic $7.2 \%$; fulvic $10 \%$.

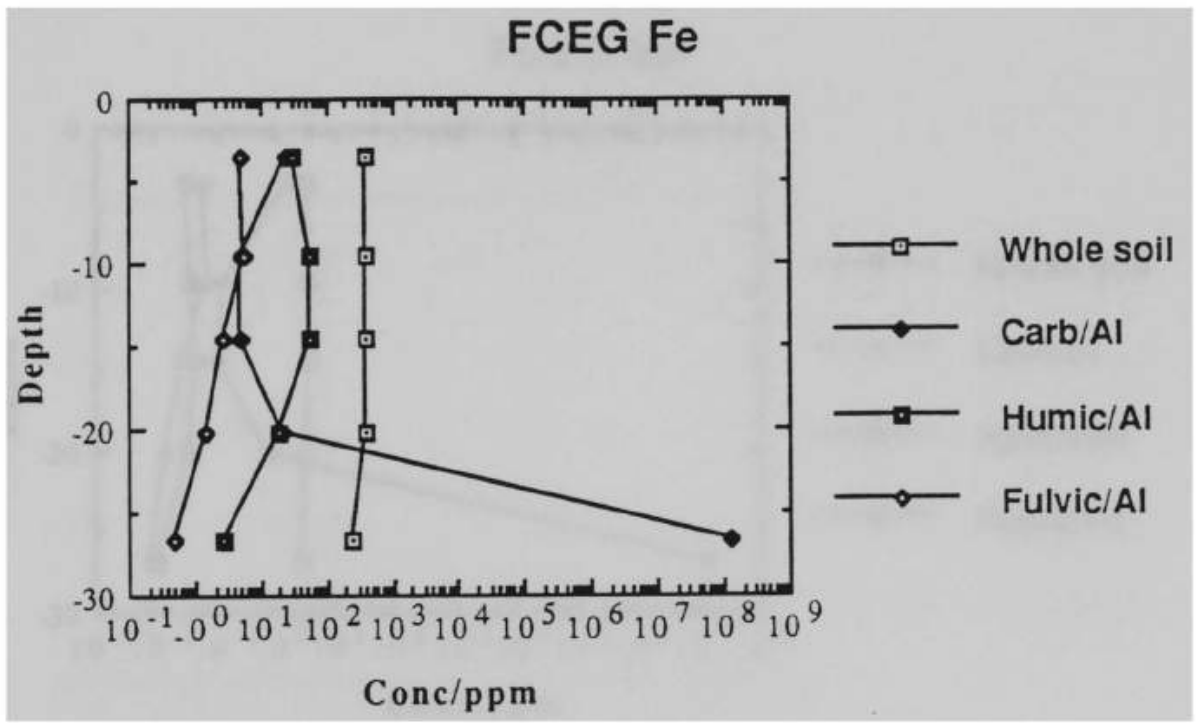

Fig. 73: FCEG Fe vs depth. Sigma values are w.s. $0.3 \%$; carb $2.3 \%$; humic $1.5 \%$; fulvic $1.0 \%$. 


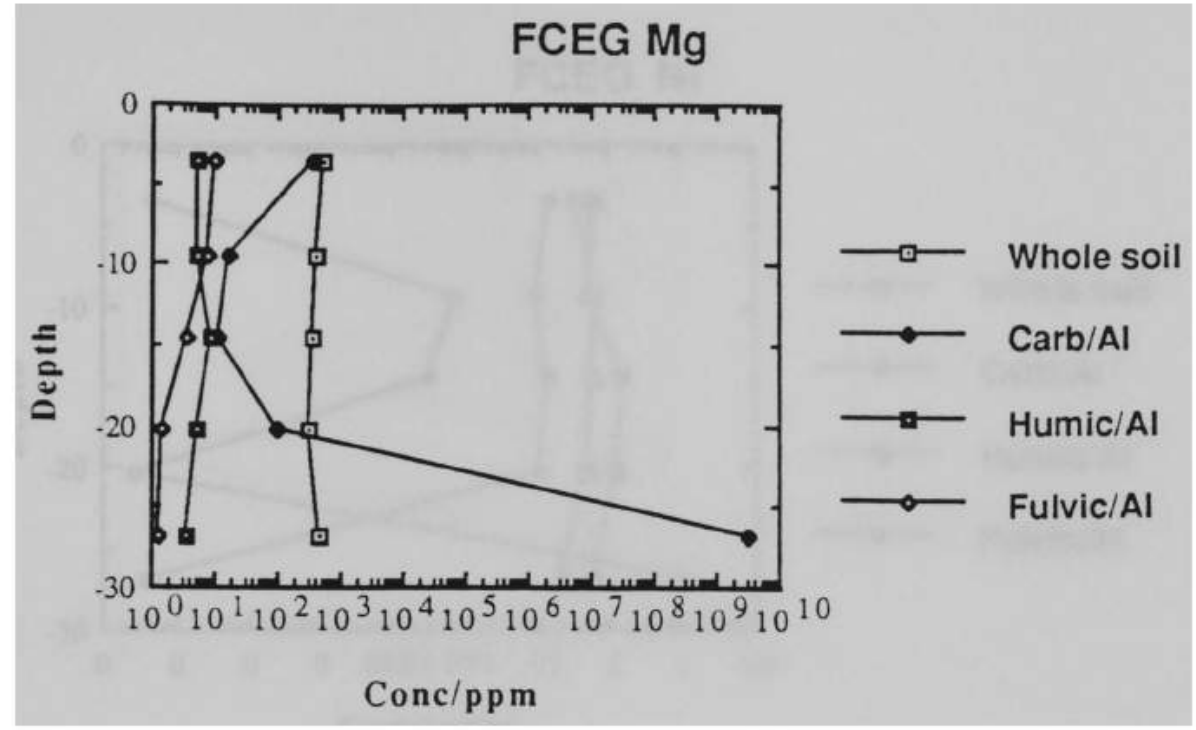

Fig. 74: FCEG Mg vs depth. Sigma values are w.s. $1.3 \%$; carb $1.5 \%$; humic $1.4 \%$; fulvic $0.7 \%$.

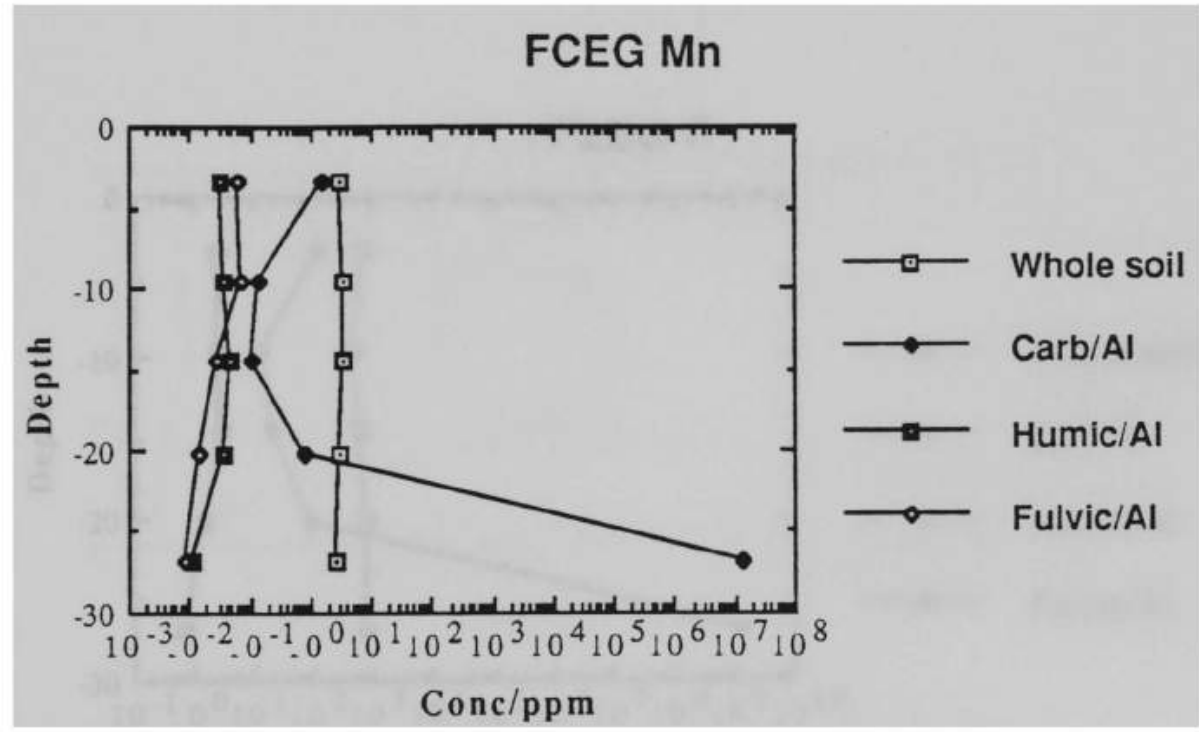

Fig. 75: FCEG Mn vs depth. Sigma values are w.s. $1.8 \%$; carb $1.6 \%$; humic $4.3 \%$; fulvic $1.6 \%$. 


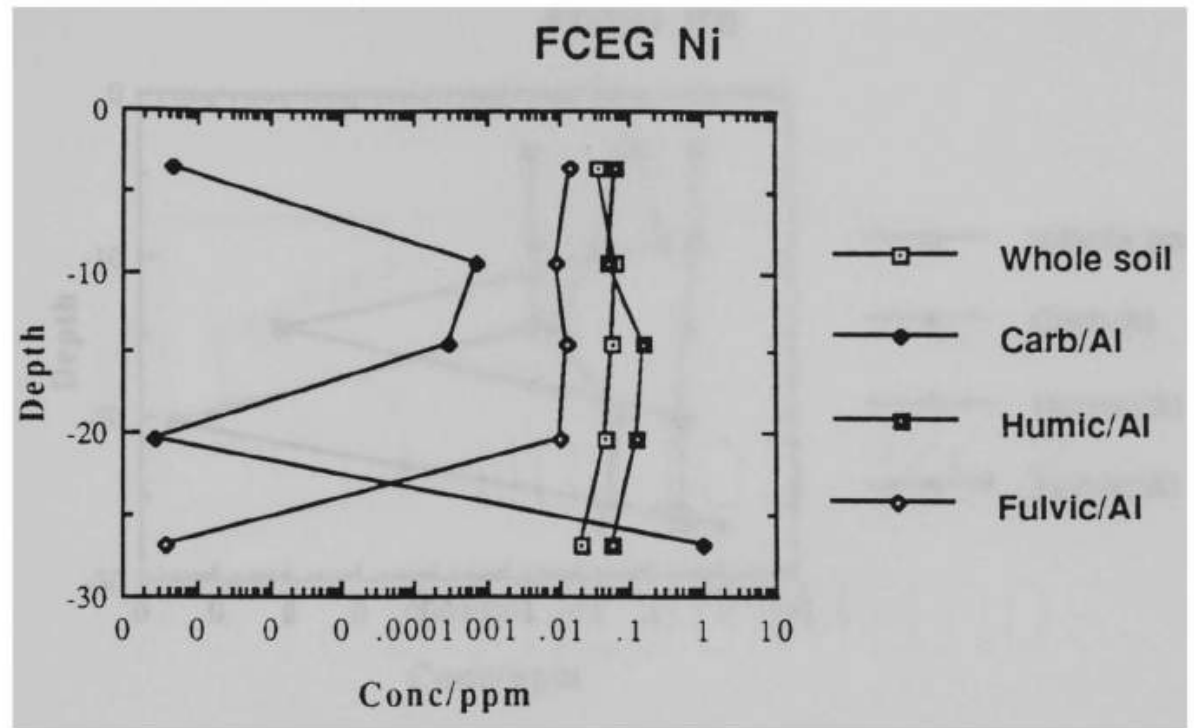

Fig. 76: FCEG Ni vs depth. Sigma values are w.s. $46 \%$; carb $36 \%$; humic $40 \%$; fulvic $88 \%$.

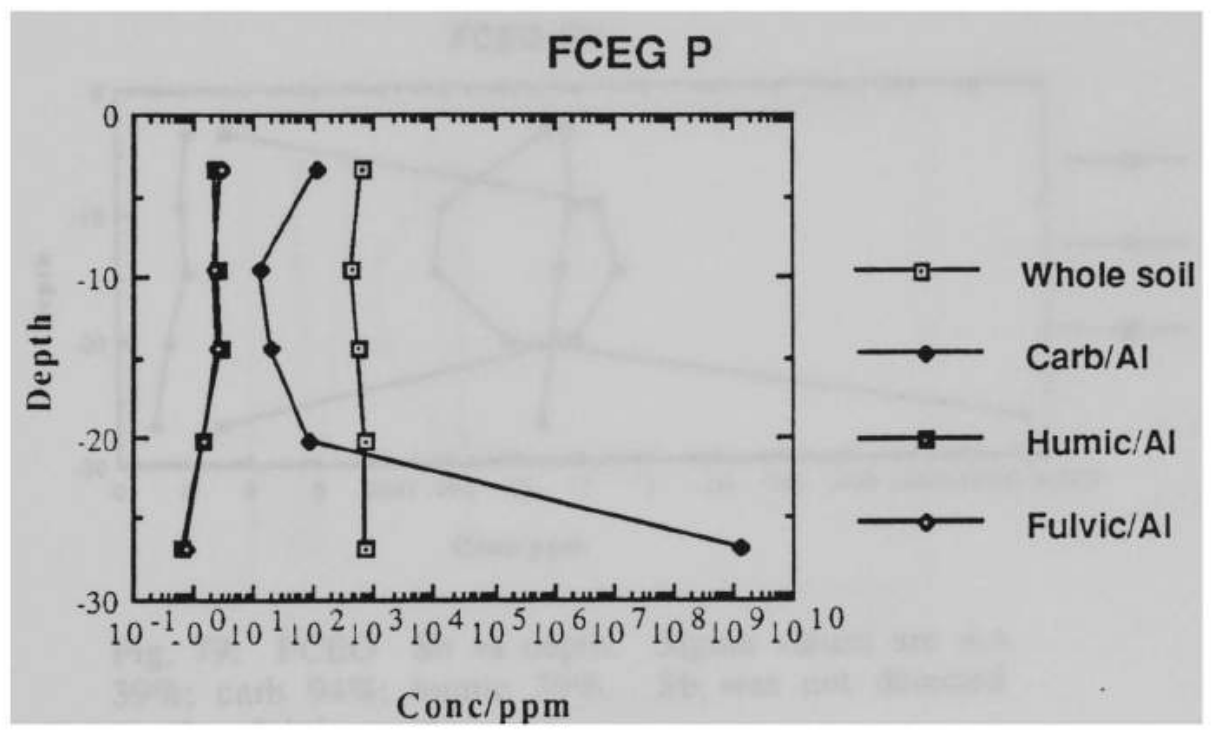

Fig. 77: FCEG $\mathrm{P}$ vs depth. Sigma values are w.s.

$1.5 \%$; carb $1.9 \%$; humic $26 \%$; fulvic $37 \%$. 


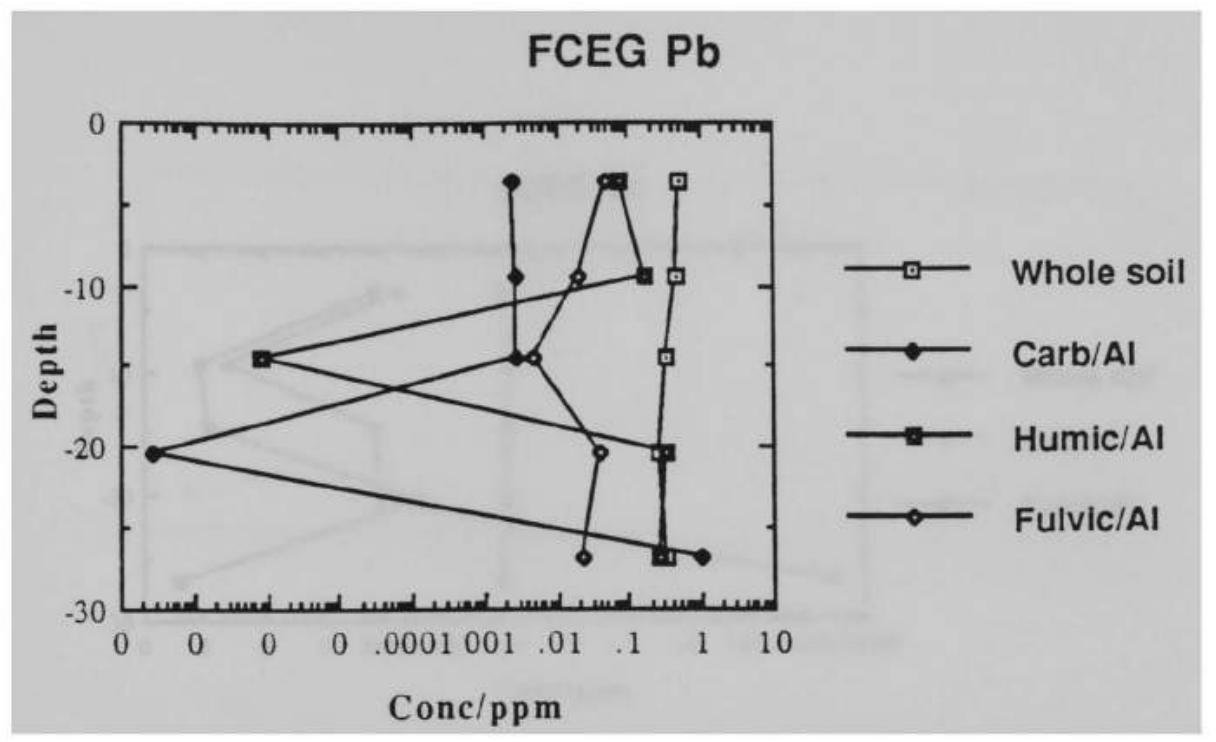

Fig. 78: FCEG $\mathrm{Pb}$ vs depth. Sigma values are w.s.

$3.5 \%$; carb $120 \%$; humic $84 \%$; fulvic $160 \%$.

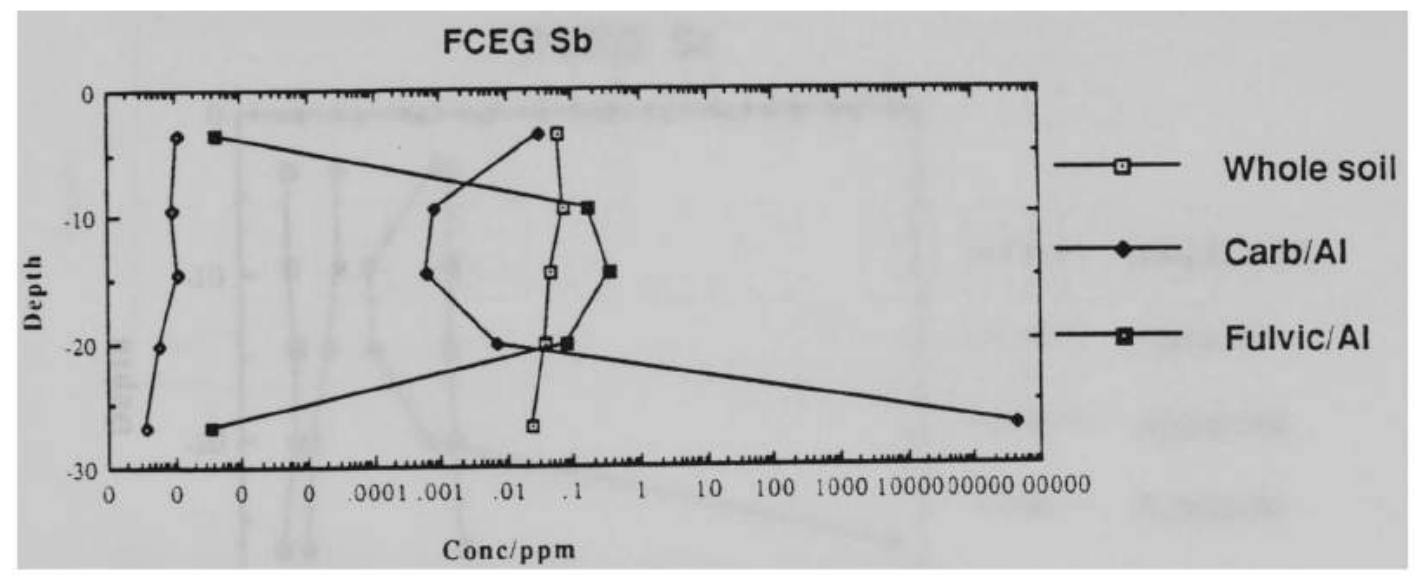

Fig. 79: FCEG Sb vs depth. Sigma values are w.s. $39 \%$; carb $94 \%$; humic $79 \%$. Sb was not detected in the fulvic acid. 


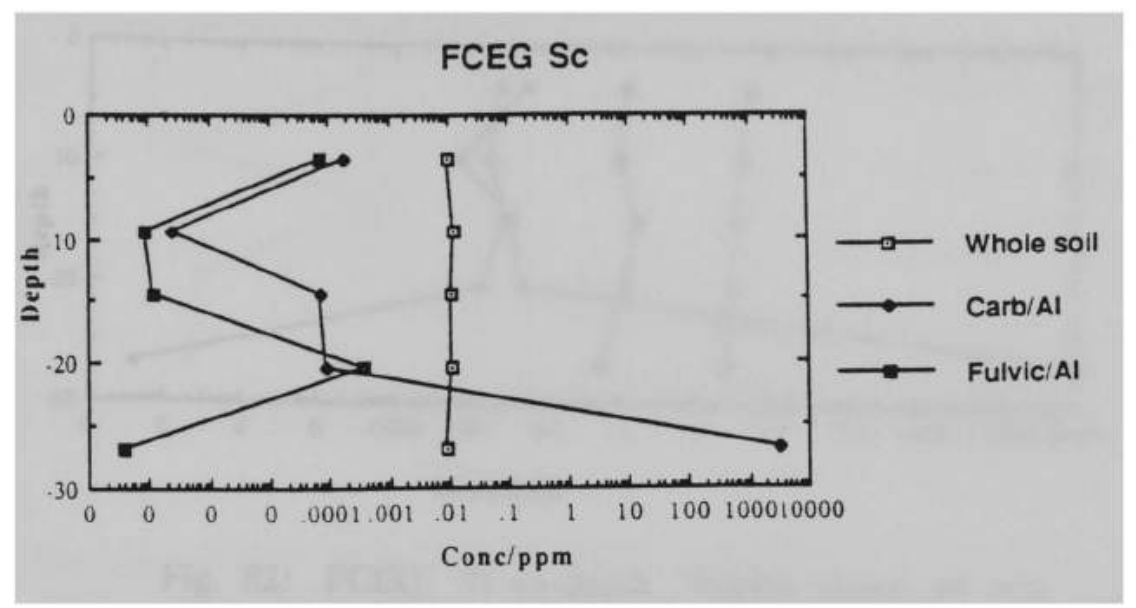

Fig. 80: FCEG Sc vs depth. Sigma values are w.s. $4.9 \%$; carb $77 \%$; fulvic $245 \%$. Sc was not detected in the humic acid.

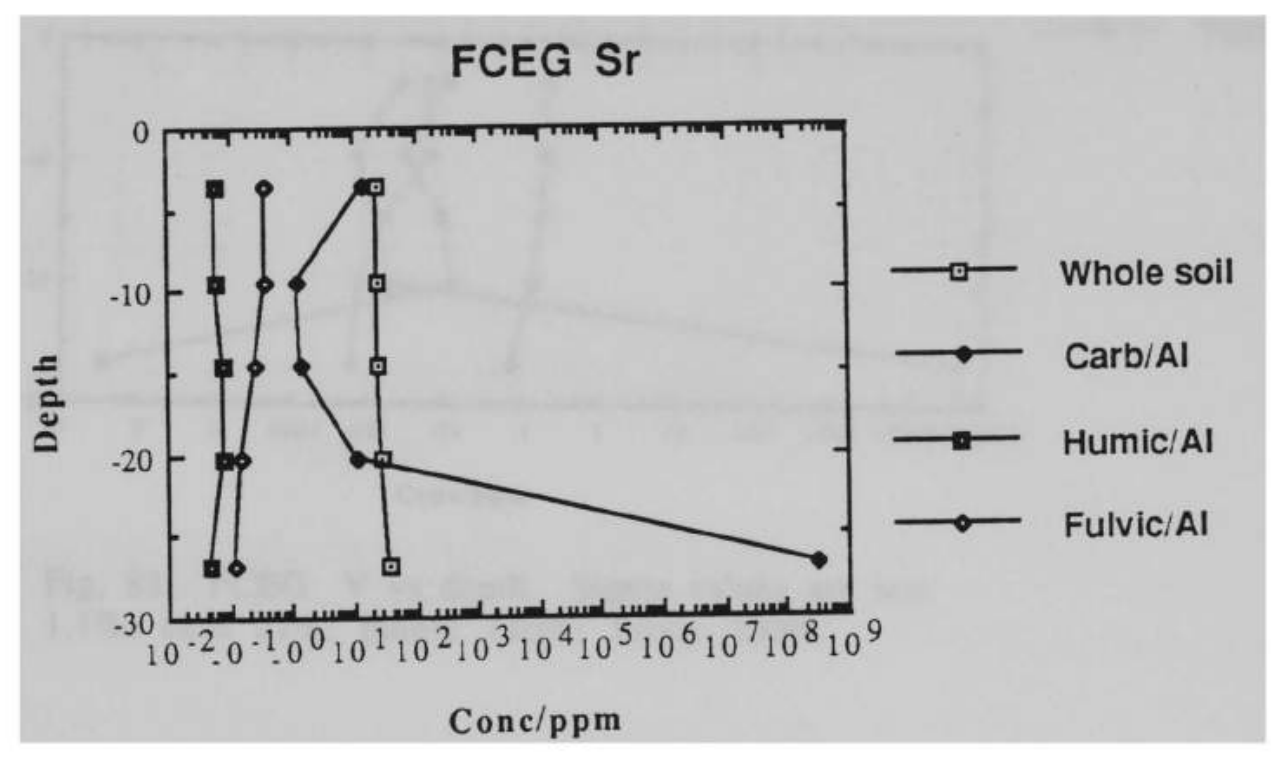

Fig. 81: FCEG Sr vs depth. Sigma values are w.s. $1.5 \%$; carb $1.3 \%$; humic $1.6 \%$; fulvic $0.8 \%$. 


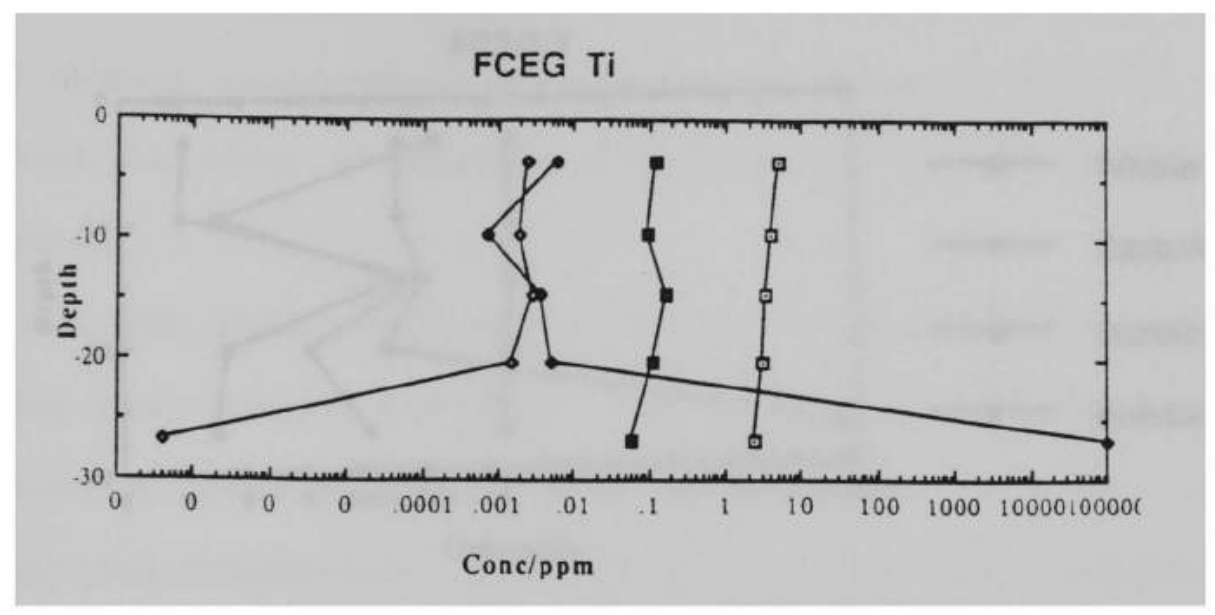

Fig. 82: FCEG Ti vs depth. Sigma values are w.s. $1.5 \%$; carb $5.2 \%$; humic $4.1 \%$; fulvic $56 \%$.
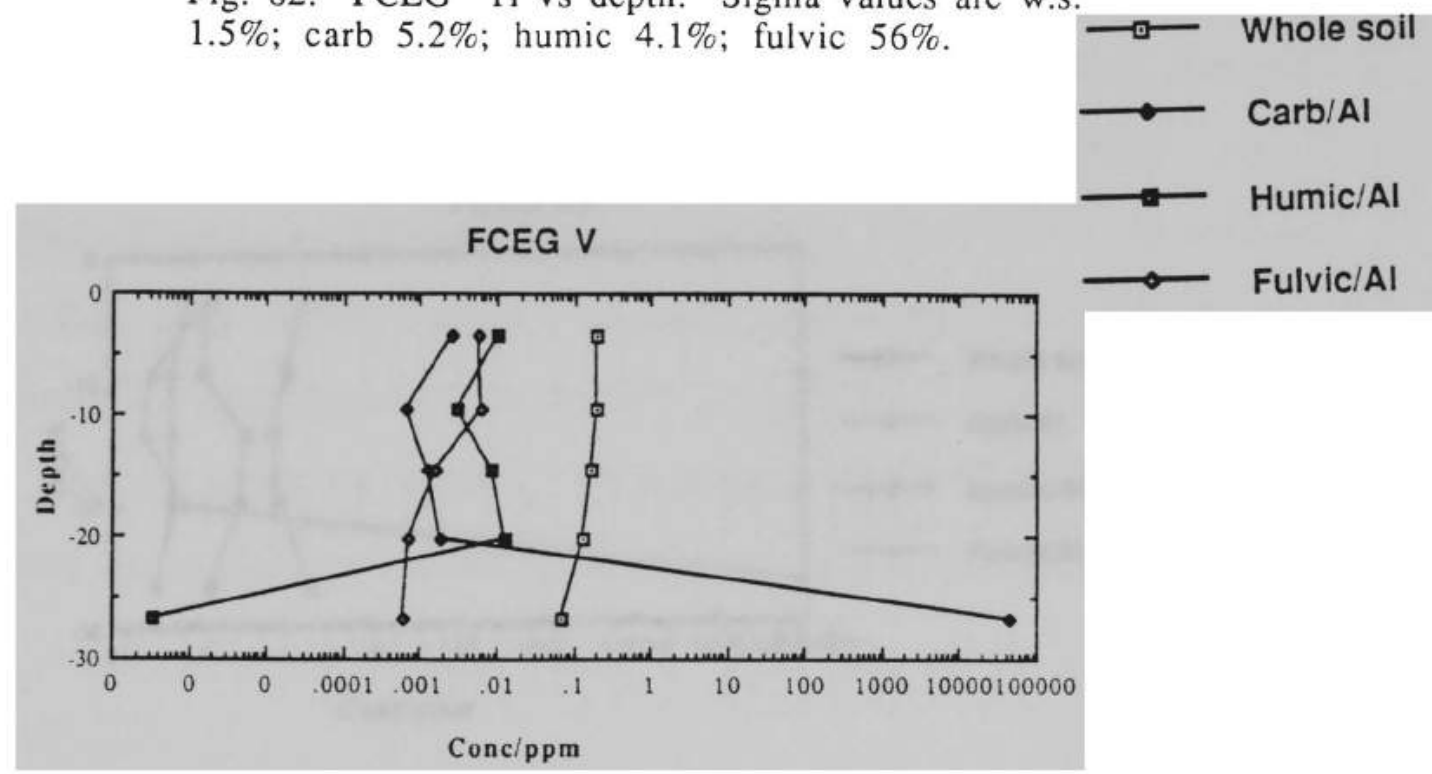

Fulvic/Al

Fig. 83: FCEG V vs depth. Sigma values are w.s. $1.1 \%$; carb $21 \%$; humic $210 \%$; fulvic $180 \%$. 


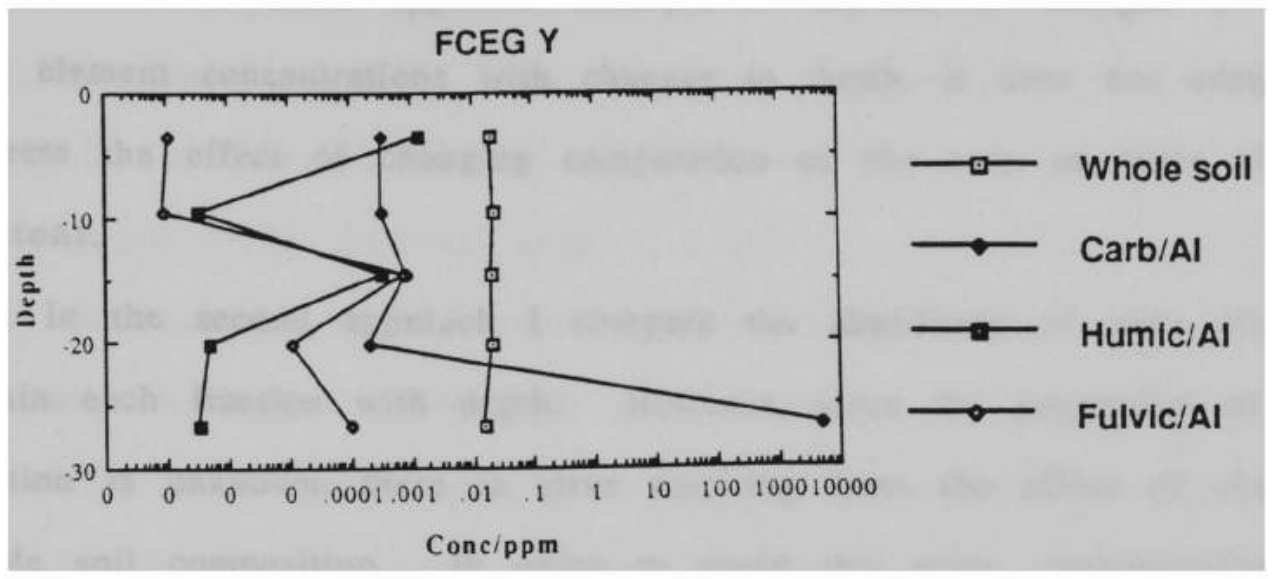

Fig. 84: FCEG Y vs depth. Sigma values are w.s. $1.8 \%$; carb $120 \%$; humic $1000 \%$; fulvic $332 \%$.

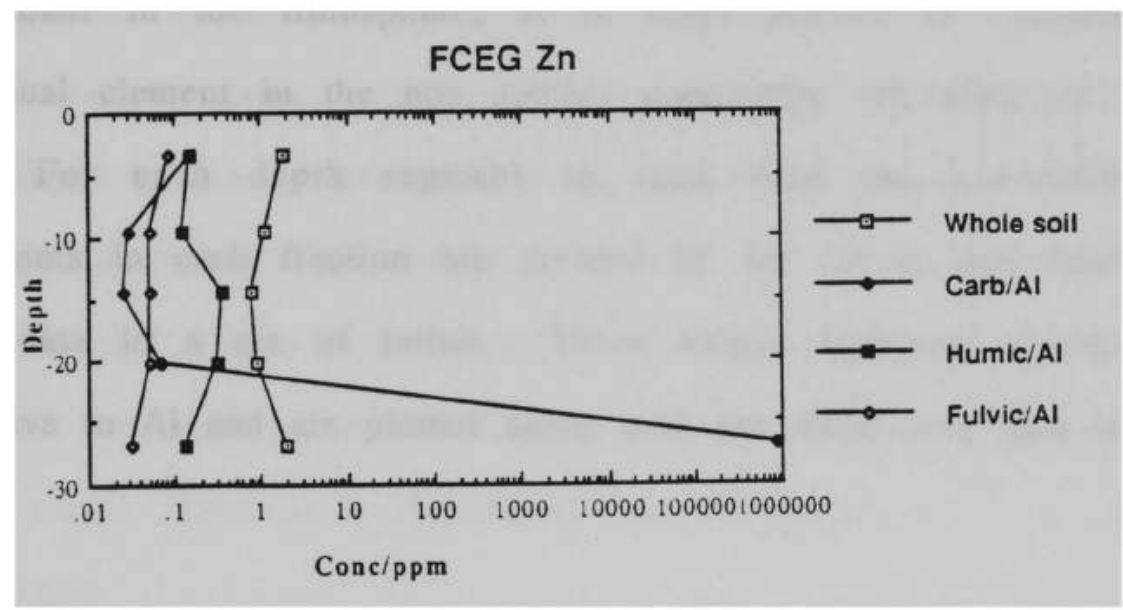

Fig. 85: FCEG Zn vs depth. Sigma values are w.s. $1.8 \%$; carb $2.0 \%$; humic $4.7 \%$; fulvic $3.9 \%$. 
Second Methodological Approach

While the above approach attempts to characterize changes in whole soil element concentrations with changes in depth, it does not adequately address the effect of changing composition of the core on trace element content.

In the second approach I compare the abundance of trace elements within each fraction with depth. However, since the proportion of each fraction is unknown, there is arror resulting from the effect of changing whole soil composition. In order to avoid this error, concentrations are normalized to a single element within each fraction. The single element chosen is Al because it is one of the major soil forming elements, is abundant in the lithosphere, is in clay, present in limestone and is a residual element in the non soluble component left after its weathering.

For each depth segment in each core the concentrations of the elements in each fraction are divided by the $A$ in that fraction, reducing the data to a set of ratios. These values represent element abundances relative to Al and are plotted along with the whole soil data in figures 6 to 85.

\section{Third Methodological Approach}

In the third approach, I attempt to assess the affinity of elements for the different fractions, regardless of the depth. I divide the normalized carbonate and organic fractions by the ratio of the whole soil to Al (whole soil/Al) and plot the elements against the log of the normalized concenurations (Fig 86 to 112). The approach for WCA3B2 is slightly 
different. Whole soil was available only for segment wo of that core, so all depths are normalized to that soil/Al ratio.

The patterns of these plots show that the abundances of Ba, Ca, Moy and $P$ in the carbonate fraction display values always greater than 1 (with the exception of the WCA3B2 plots, 1, 3 and 4). These values indicate that these elements are relatively more abundant when compared to the Al in the carbonate fraction. None of the elements in the carbonate fraction in any of the cores studied had a value consistently less than 1 , In the FCEG core the apparent increased carbonate abundances for segment 5 plotred in the figures is an artifact resulting from the nomalization to Al, which was essentially not detected in that segment of the core.

In the humic acid fraction the elements $\mathrm{Be}, \mathrm{Cd}, \mathrm{Cr}, \mathrm{Cn}$ and $\mathrm{Zn}$ always show values greater than 1 , indicating a greater relative abundance compared to Al, None of the elements in the humic acid fraction have values consistently less than 1.

In the fulvic acid fraction, Be always shows values greater than 1 , and Ti consistenty shows values less llan 1 , indicating relatively greater and lesser abundances respectively as compared with the abundances of aluminum.

Although these patterns represent the general affinity of elements for a particular fraction il needs to be further quantified, I define values for enrichment and depletion of the elements as greater than $10 x$ and less than $0.1 \mathrm{X}$ respectively as compared to Al, look at the concentrations of each element compared to the $\mathrm{Al}$ in each fraction and note the frequency of occurrence divided by the possible number of occurrences. This 
information is included in Table 5. Elements which were enriched or depleted in a particular fraction in at least 12 of the 24 segments were:

\section{Carbonate fraction}

Enriched: $\mathrm{Ba}, \mathrm{Ca}, \mathrm{Sr}, \mathrm{Mg}$ and $\mathrm{Sb}$

Depleted: Ty

Humic raction

Enriched: $\mathrm{Be}, \mathrm{Ni}$ and $\mathrm{Zn}$

Depleted: Co and $\mathrm{Sc}$

Fulvic fraction

Enriched: Be and Zn

Depleted: $\quad S b$ and $T i$

Fourth Methodological Approach

In the fourth approach, correlation coefficients in the whole soil are deteruined for element $v$ s element (Table 6, Fig 113, 114) and the element concentrations in the whole soils are ploted against the less than $5500 \mathrm{C}$ and the greater than $5500 \mathrm{C} \%$ volatile loss. The correlation coefficients for these plots are detemined (Table 7). This approach highlights simitar behavior between the major and trace elements which indicates that the trace elements are sited in predictable minerals or phases (i.e. Al and Ti;

Fe and Co and demonstrates the correlations between changes in the composition of the whole soil and element concentrations (Fig 115 and 116). 


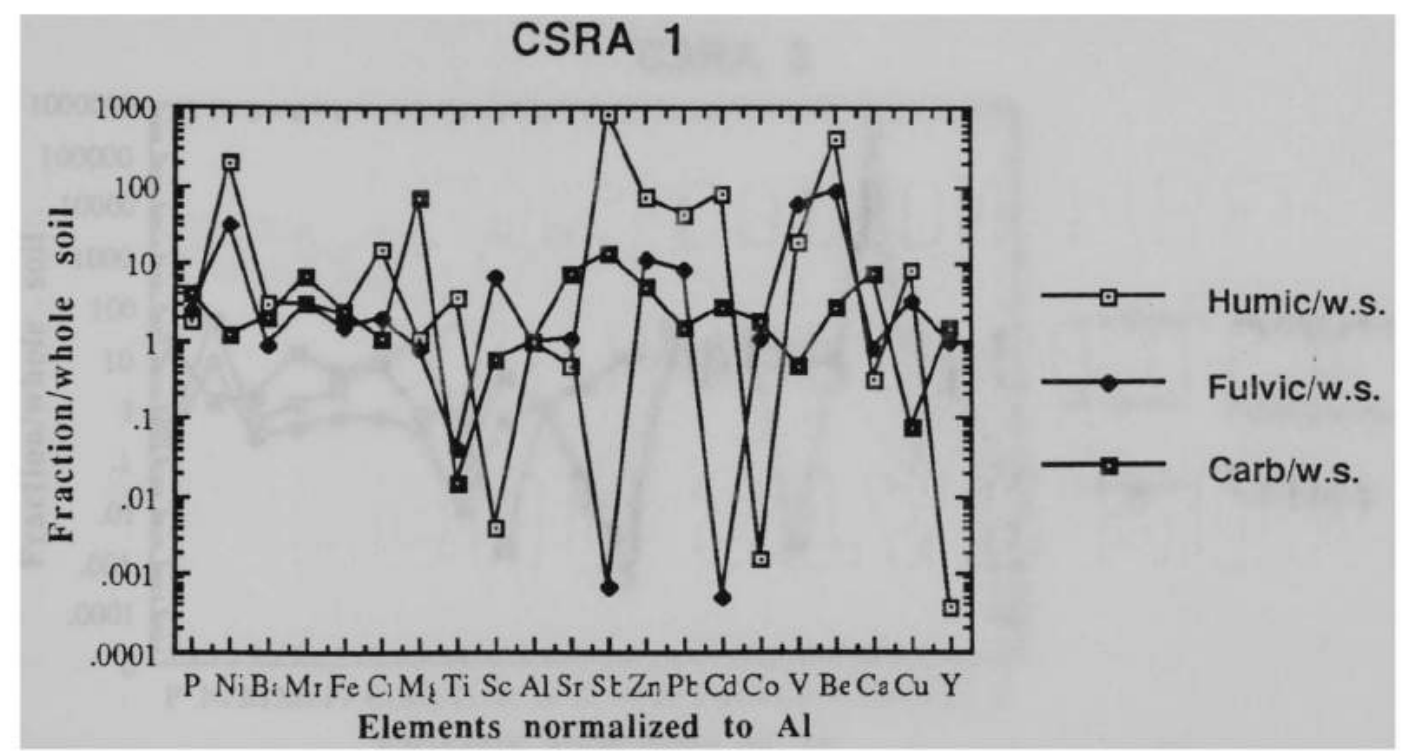

Fig. 86: CSRA 1: Enrichment/depletion of organic and carbonate fractions relative to Al.

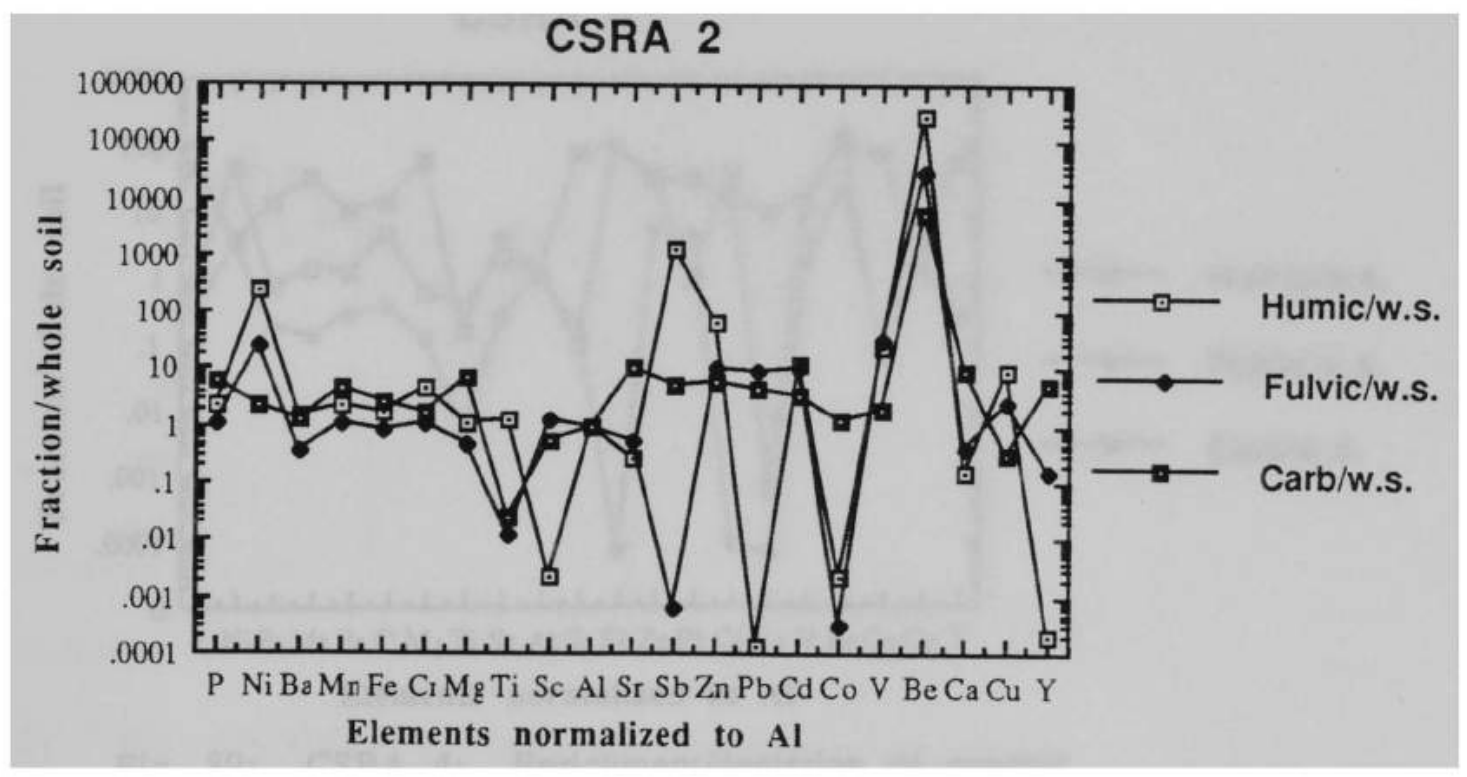

Fig. 87: CSRA 2: Enrichment/depletion of organic and carbonate fractions relative to $\mathrm{Al}$. 


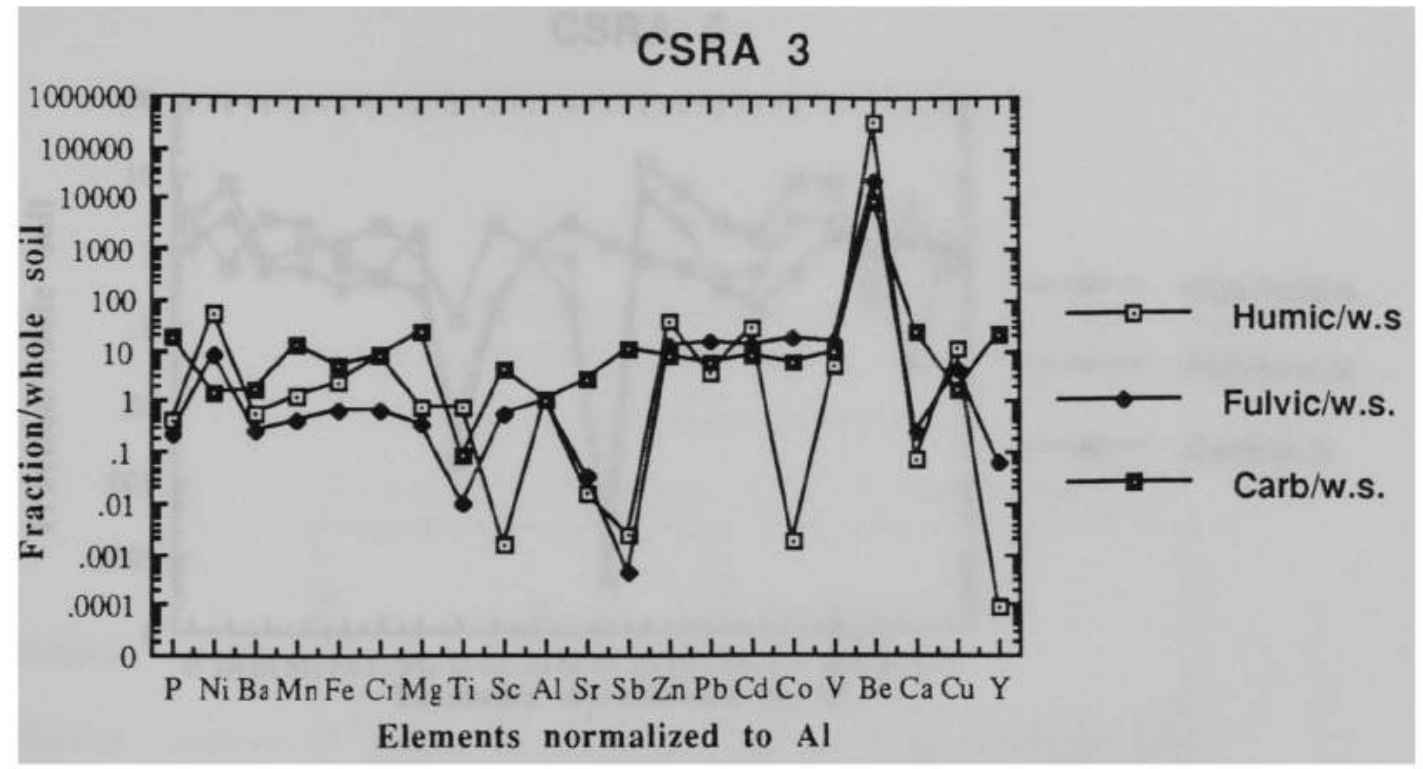

Fig. 88: CSRA 3: Enrichment/depletion of organic and carbonate fractions relative to $\mathrm{Al}$.

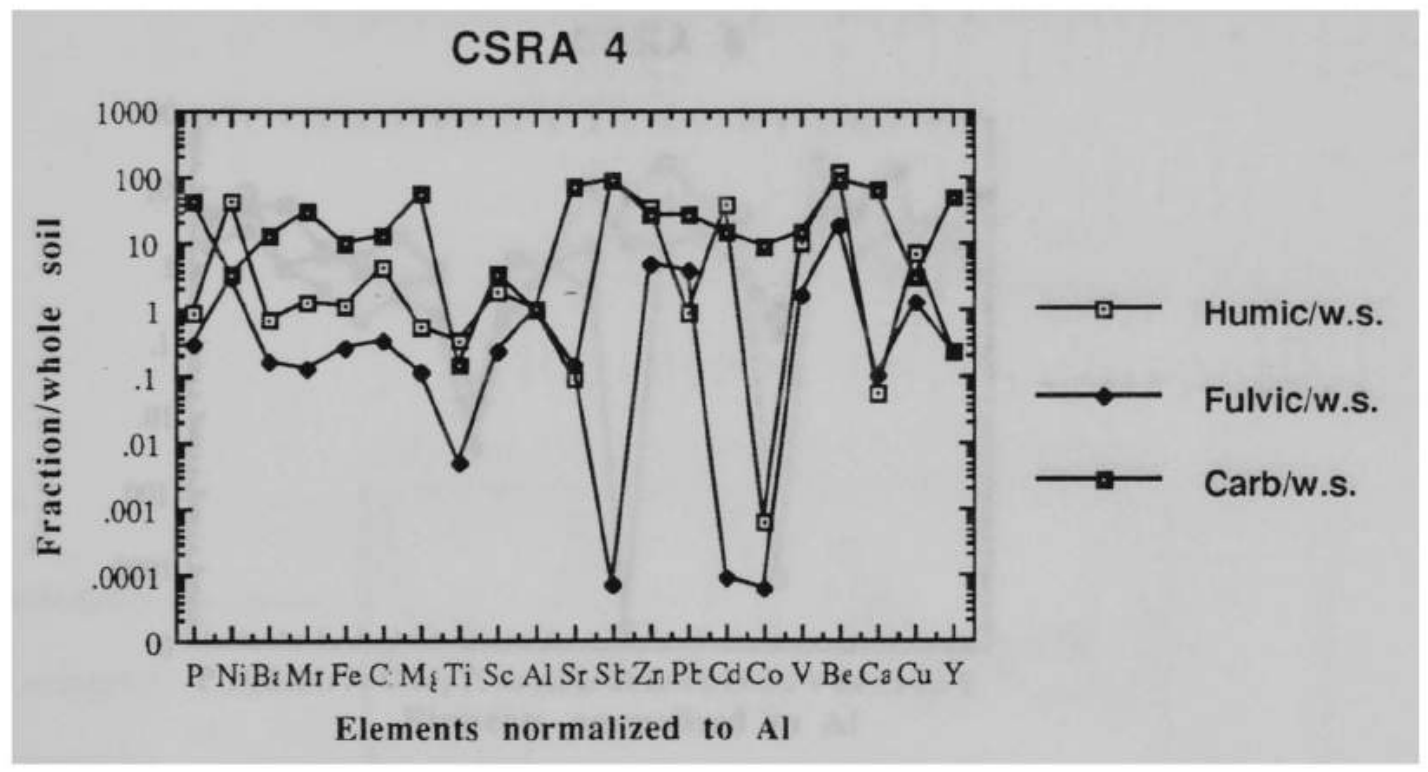

Fig. 89: CSRA 4: Enrichment/depletion of organic and carbonate fractions relative to Al. 


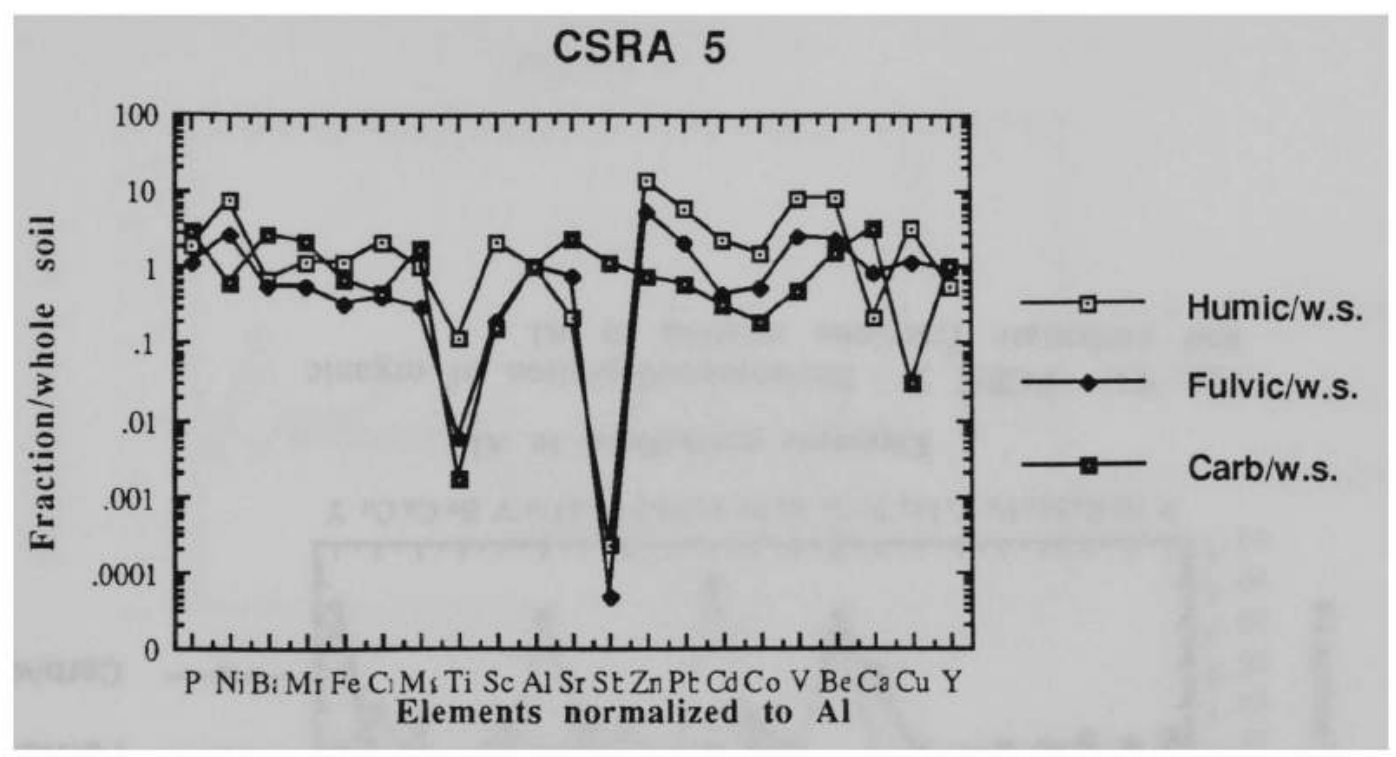

Fig. 90: CSRA 5: Enrichment/depletion of organic and carbonate fractions relative to $\mathrm{Al}$.

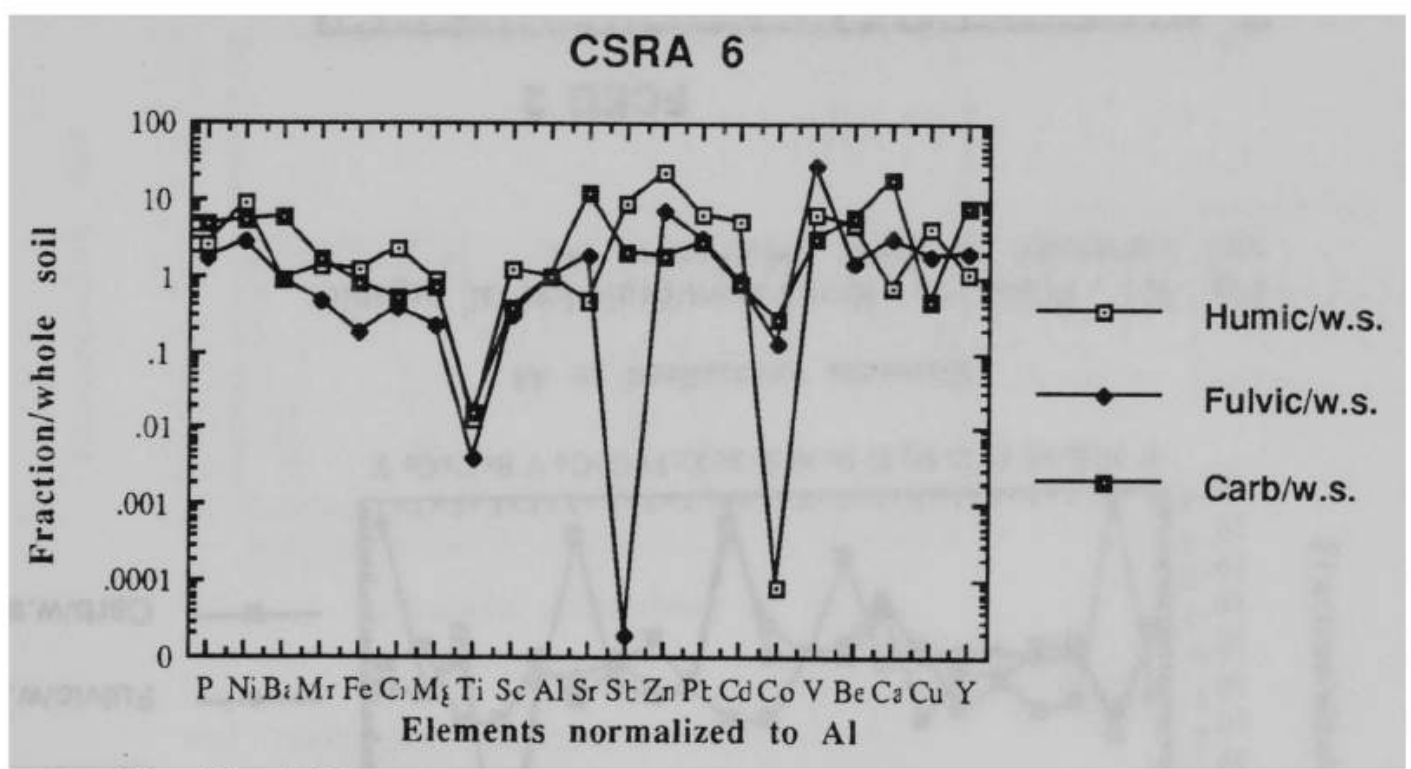

Fig. 91: CSRA 6: Enrichment/depletion of organic

and carbonate fractions relative to $\mathrm{Al}$. 


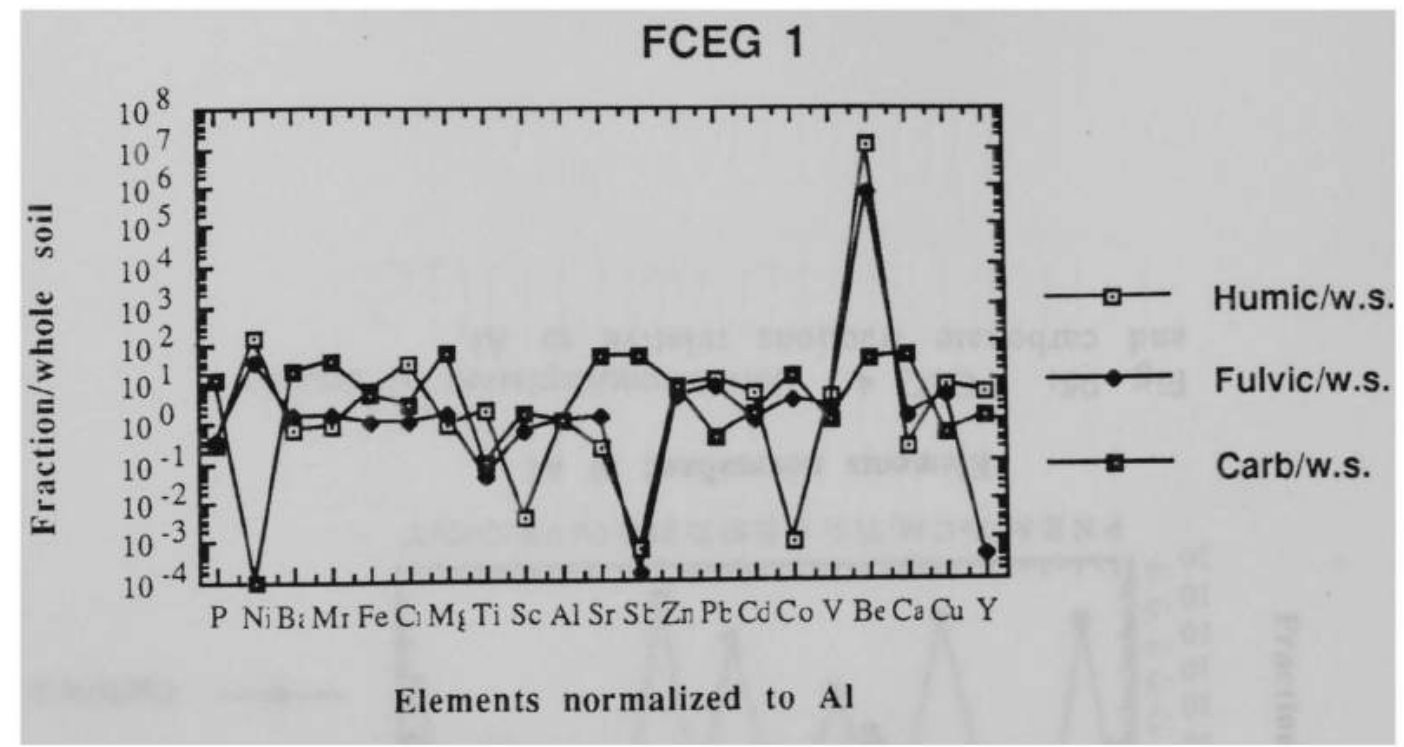

Fig. 92: FCEG 1: Enrichment/depletion of organic and carbonate fractions relative to $\mathrm{Al}$.

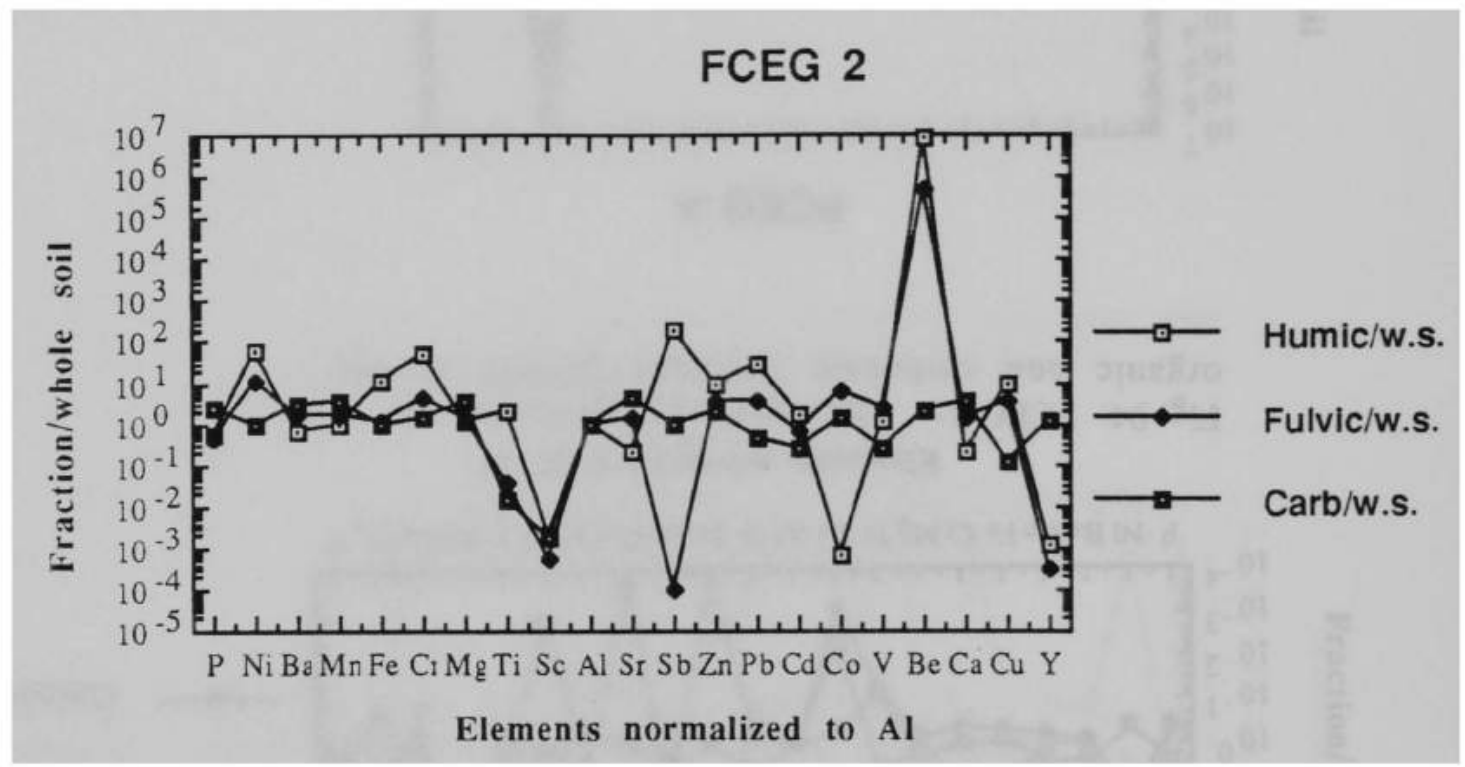

Fig. 93: FCEG 2: Enrichment/depletion of organic and carbonate fractions relative to $\mathrm{Al}$. 


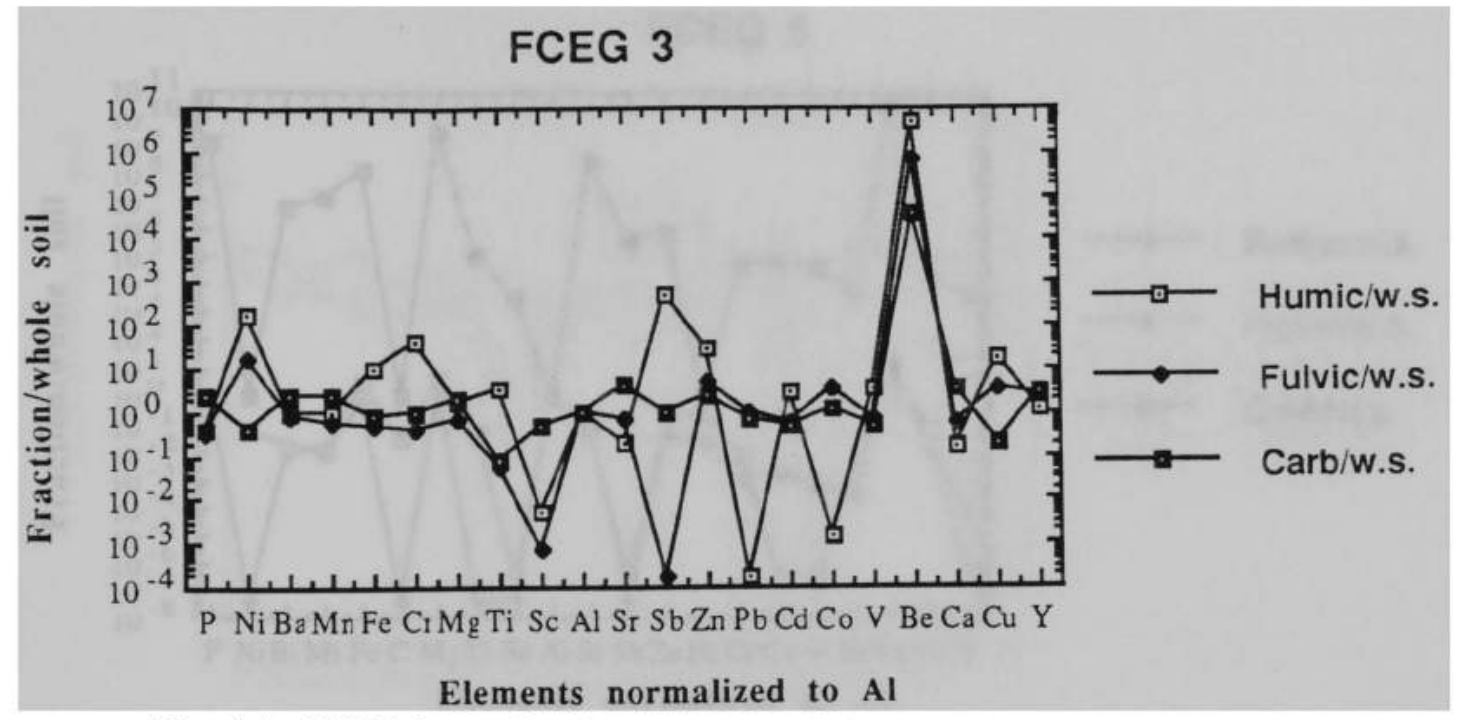

Fig. 94: FCEG 3: Enrichment/depletion of organic and carbonate fractions relative to $\mathrm{Al}$.

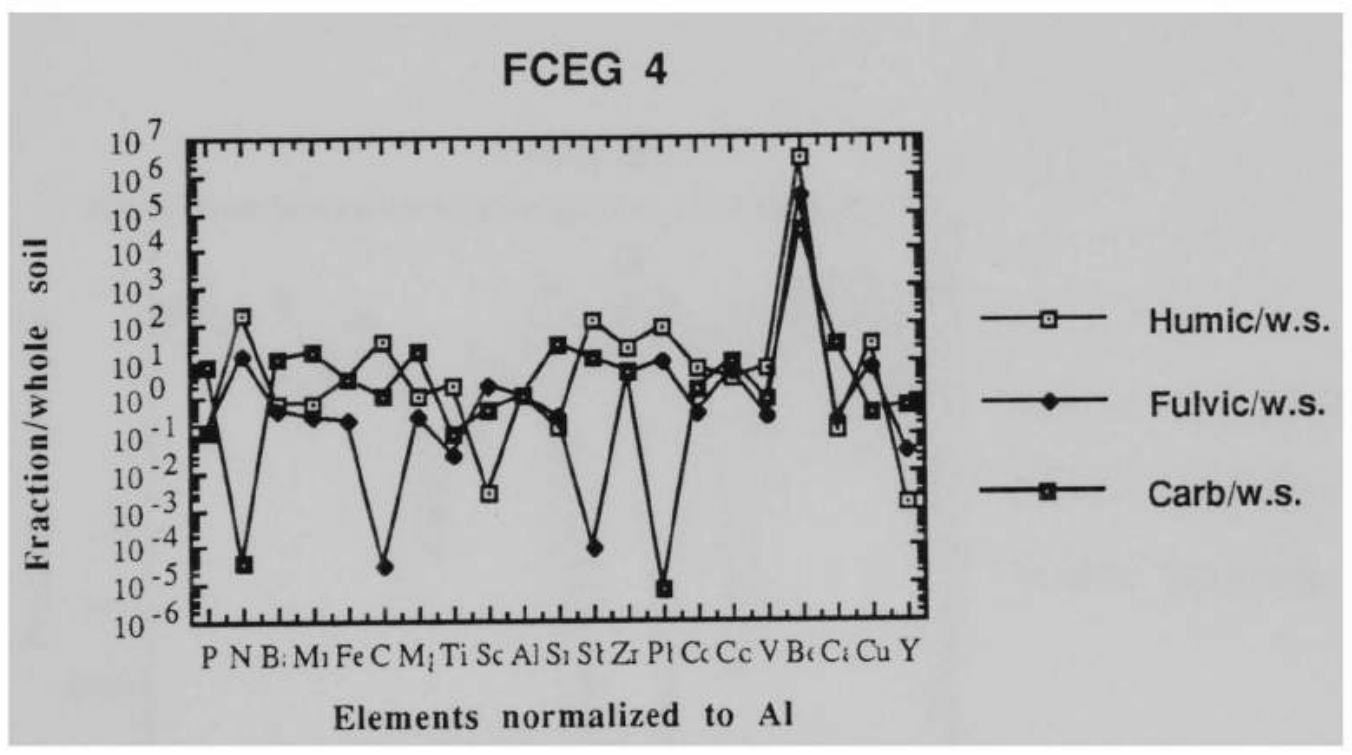

Fig. 95: FCEG 4: Enrichment/depletion of organic and carbonate fractions relative to $\mathrm{Al}$. 


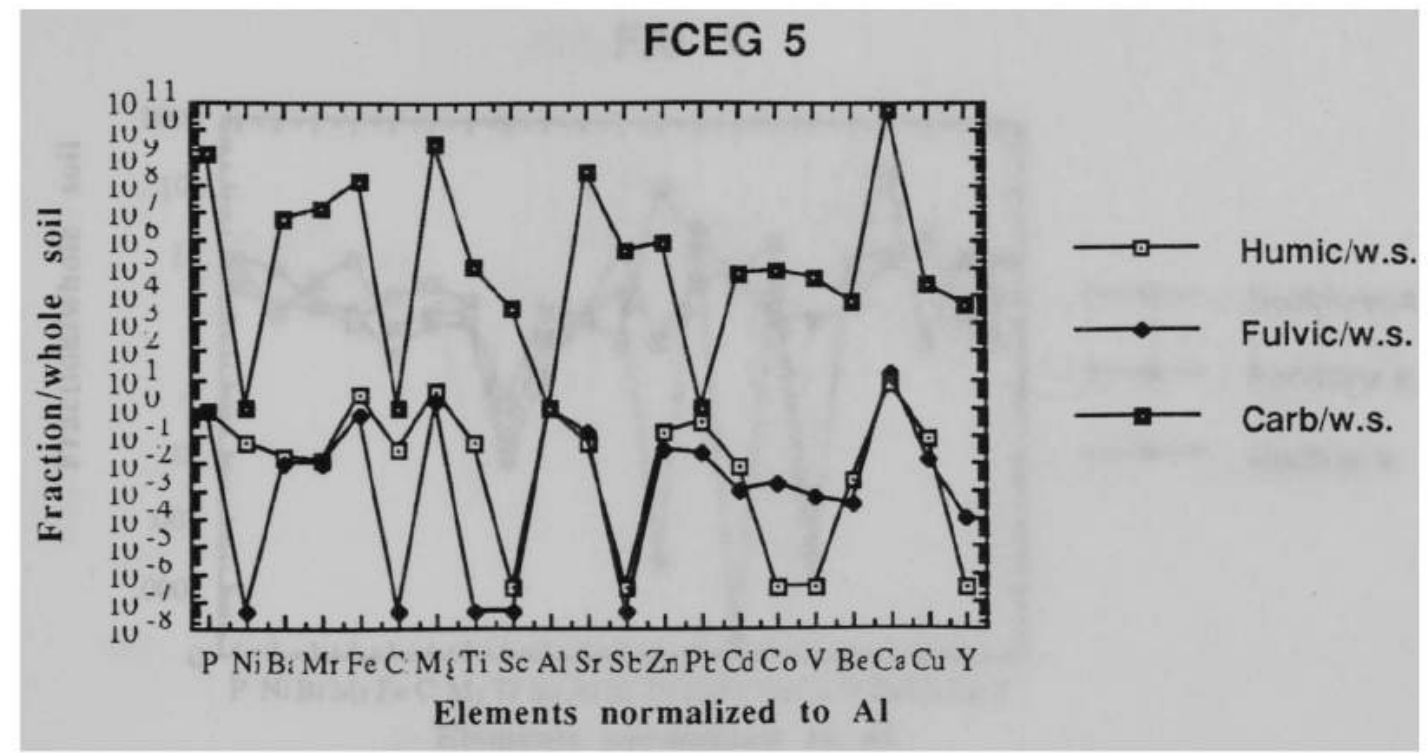

Fig. 96: FCEG 5: Enrichment/depletion of organic and carbonate fractions relative to $\mathrm{Al}$. 


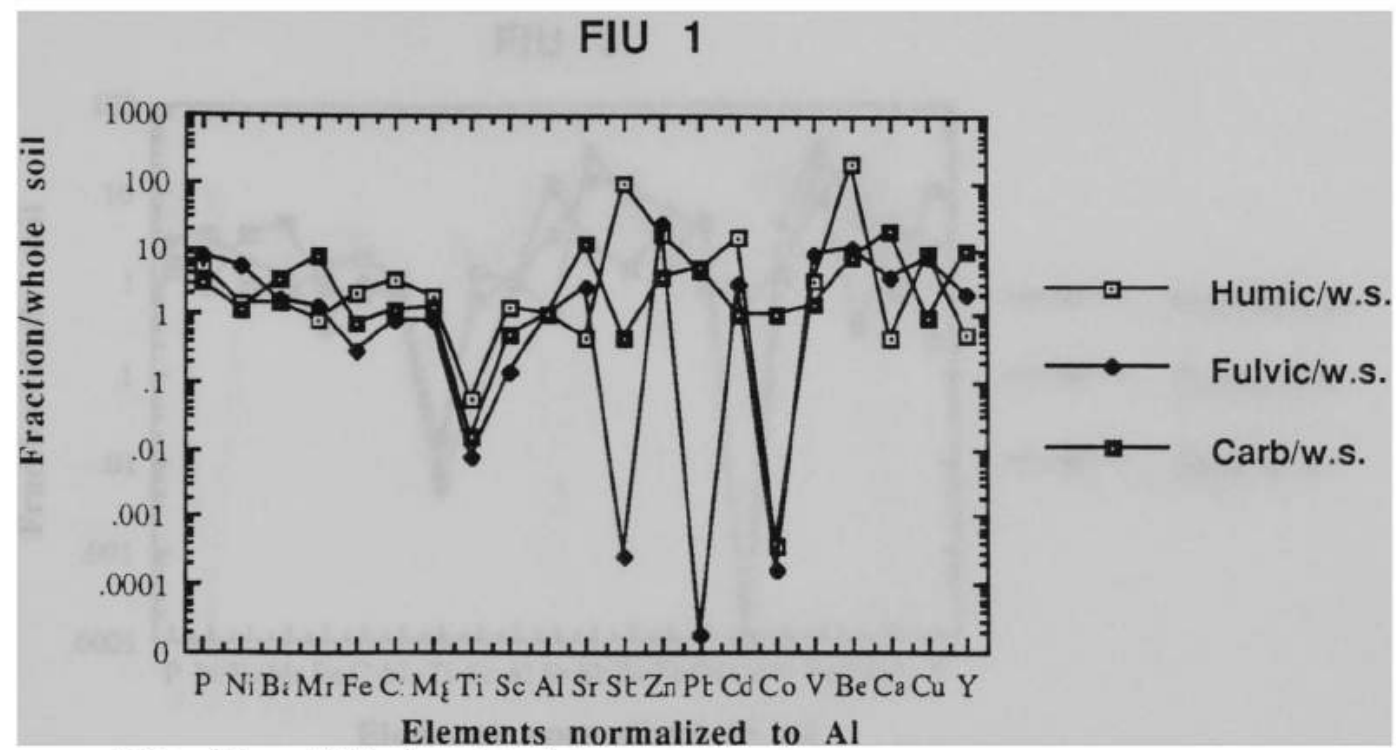

Fig. 97: FIU 1: Enrichment/depletion of organic and carbonate fractions relative to $\mathrm{Al}$.

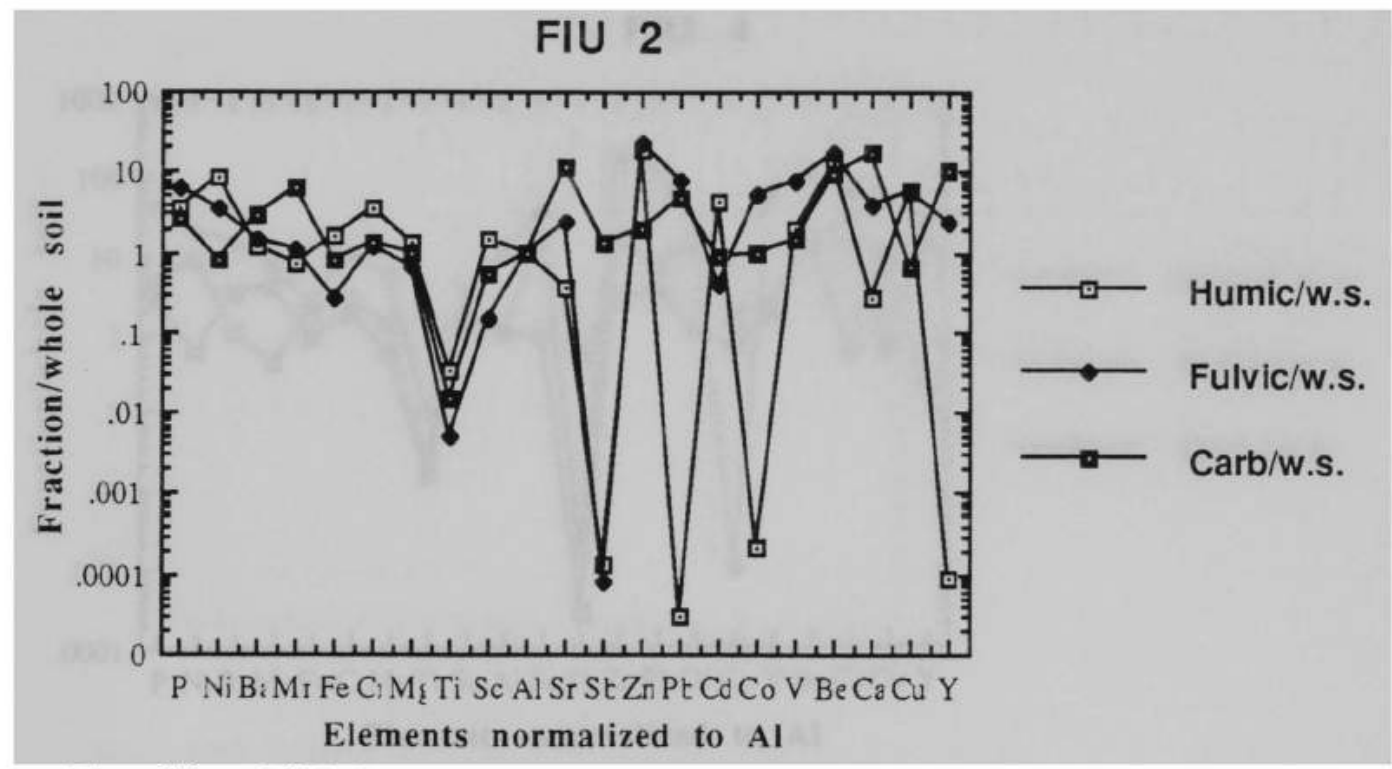

Fig. 98: FIU 2: Enrichment/depletion of organic and carbonate fractions relative to $\mathrm{Al}$. 


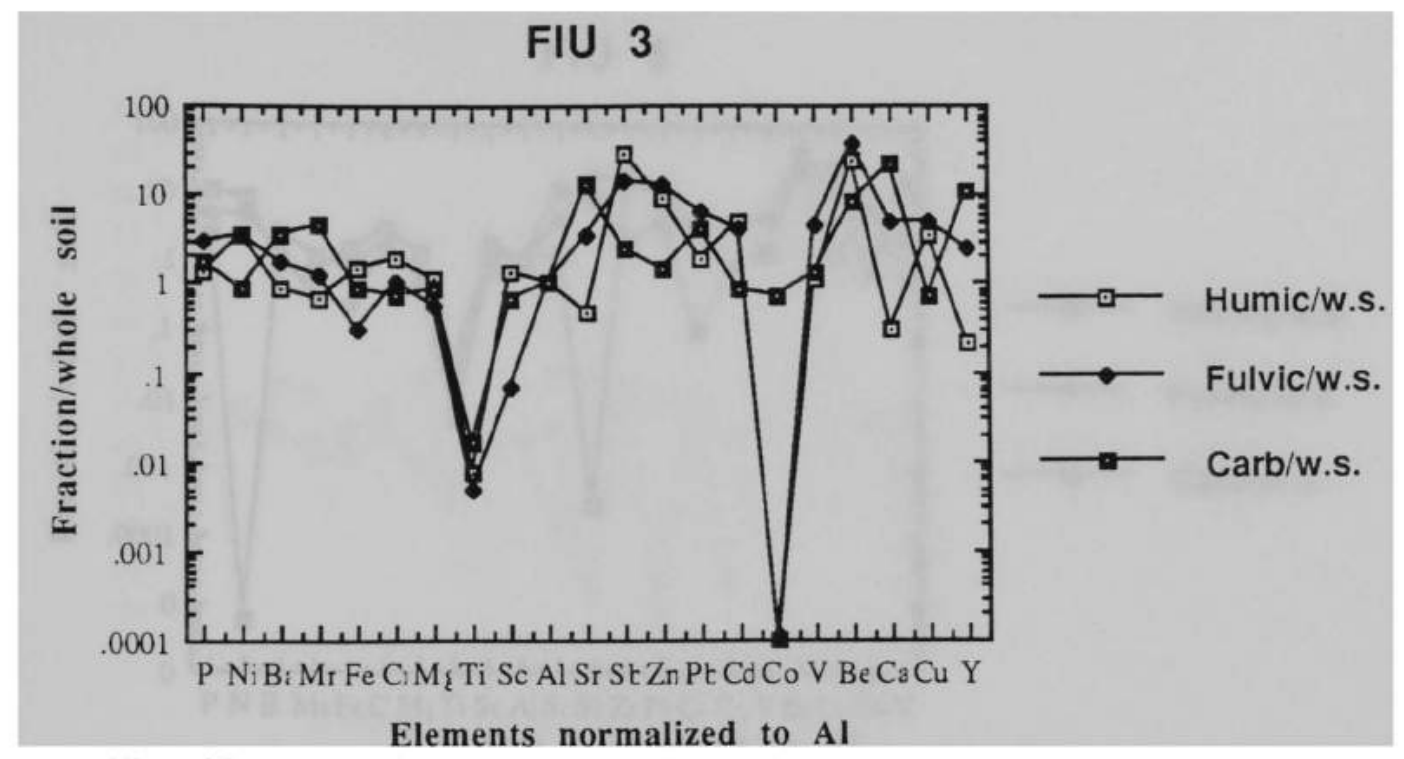

Fig. 99: FIU 3: Enrichment/depletion of organic and carbonate fractions relative to $\mathrm{Al}$.

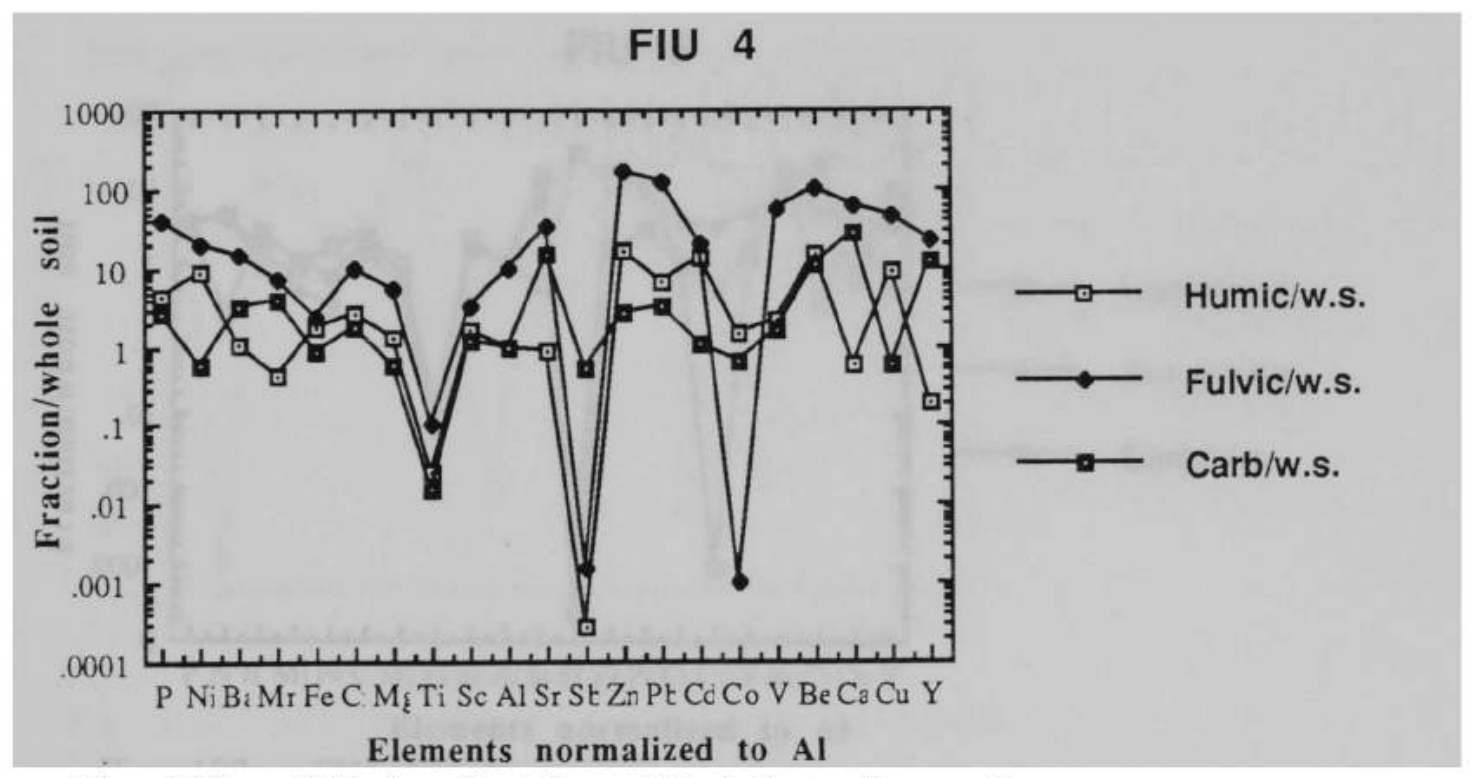

Fig. 100: FIU 4: Enrichment/depletion of organic and carbonate fractions relative to $\mathrm{Al}$. 


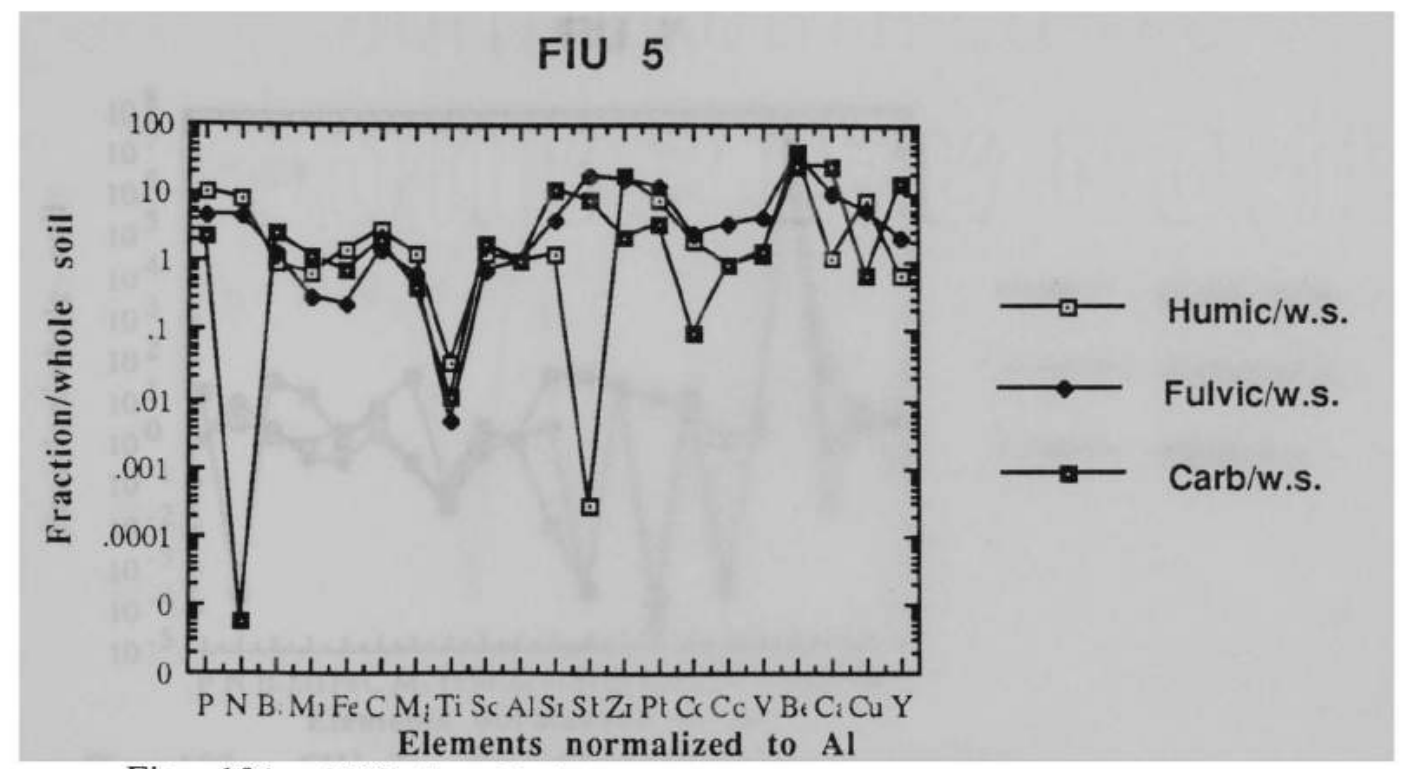

Fig. 101 FIU 5: Enrichment/depletion of organic and carbonate fractions relative to $\mathrm{Al}$.

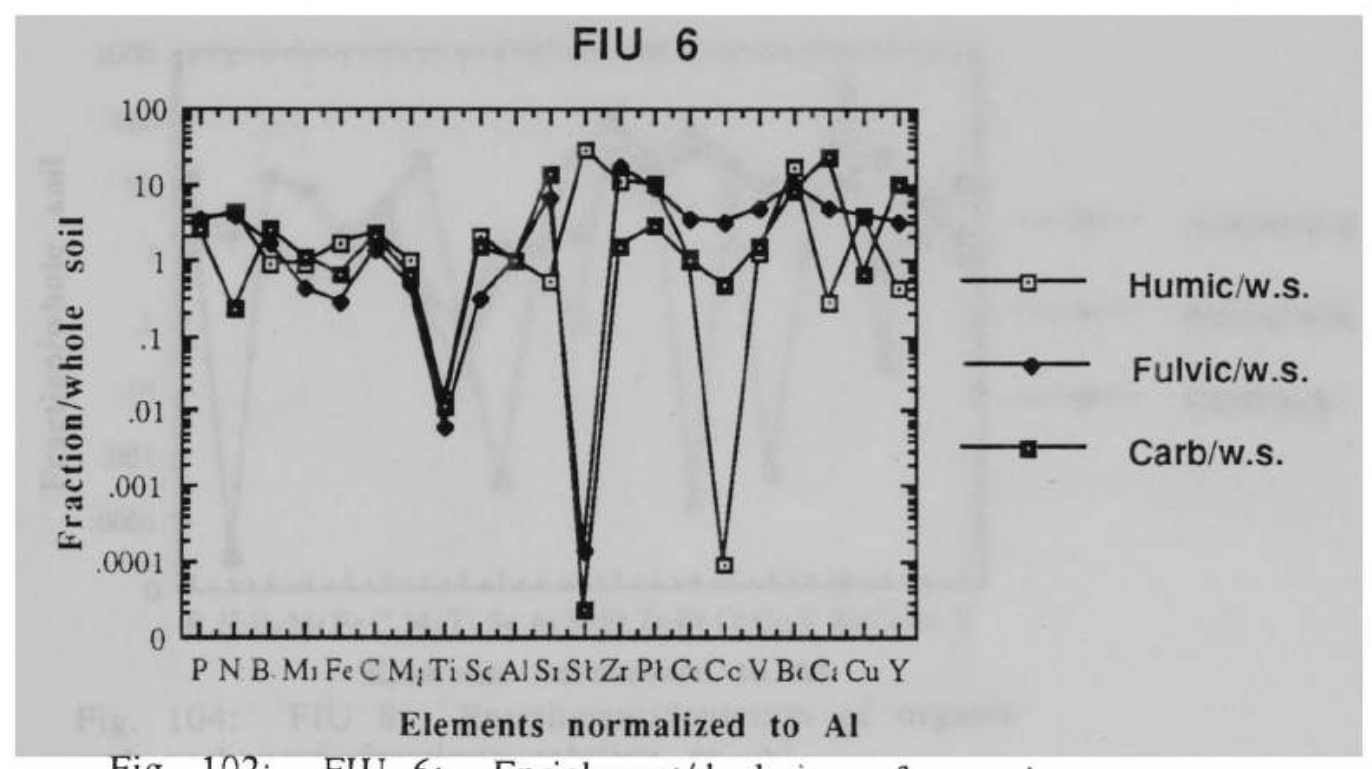

Fig. 102: FIU 6: Enrichment/depletion of organic and carbonate fractions relative to $\mathrm{Al}$. 


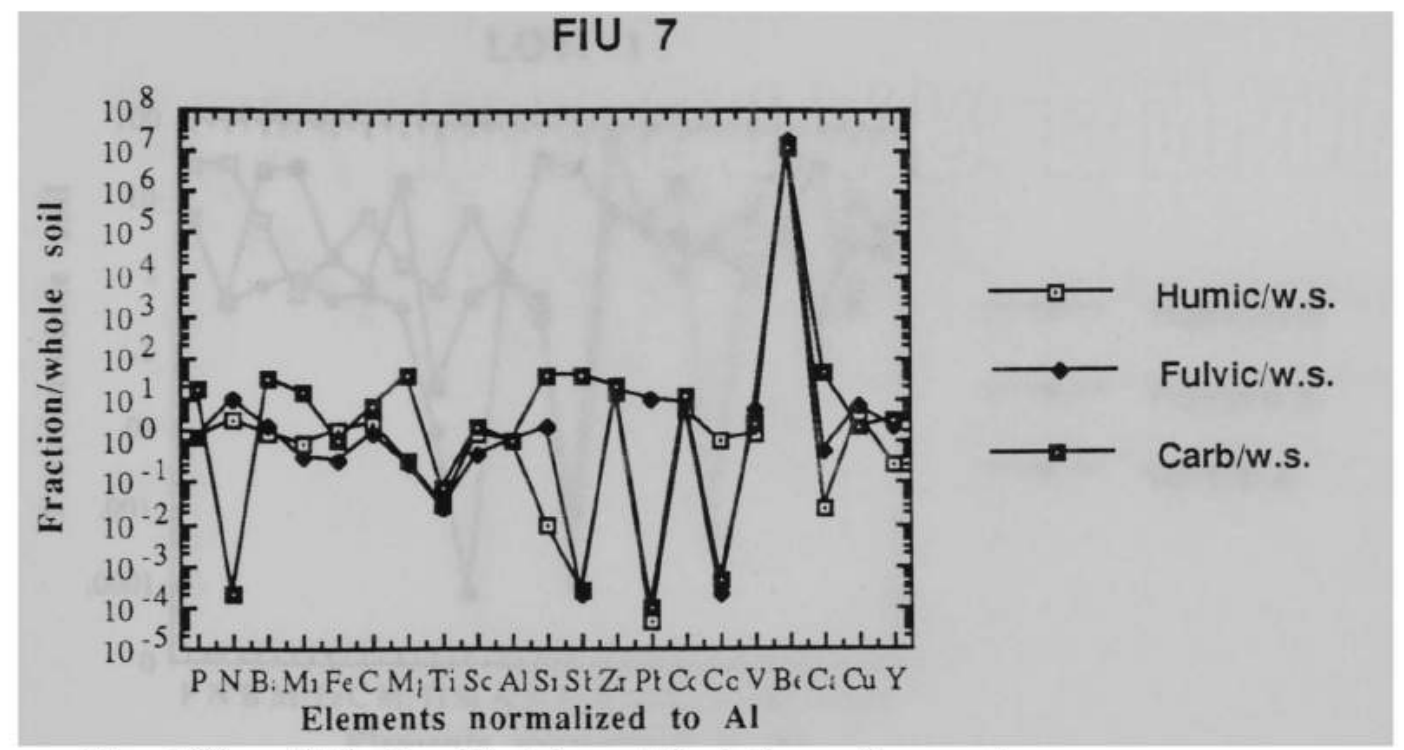

Fig. 103: FIU 7: Enrichment/depletion of organic and carbonate fractions relative to $\mathrm{Al}$.

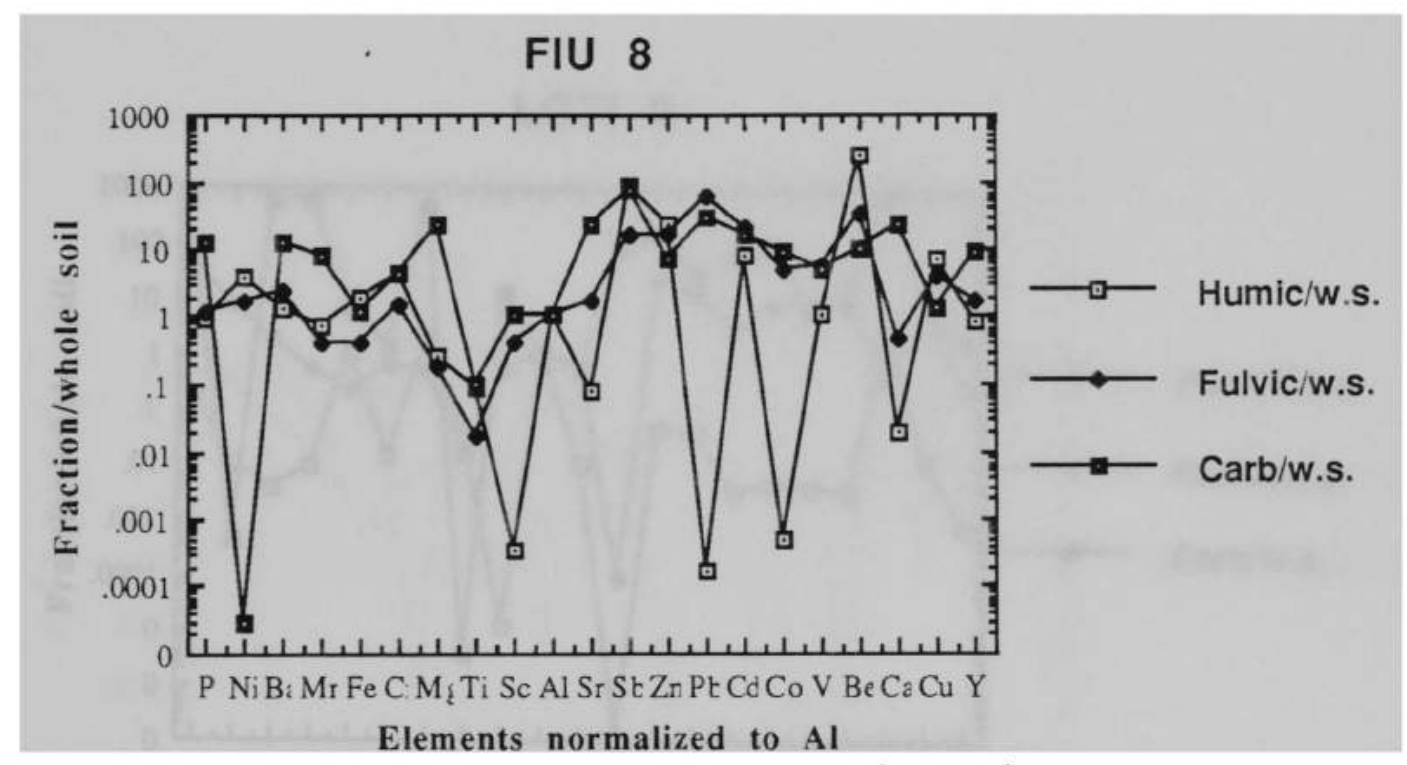

Fig. 104: FIU 8: Enrichment/depletion of organic and carbonate fractions relative to $\mathrm{Al}$. 


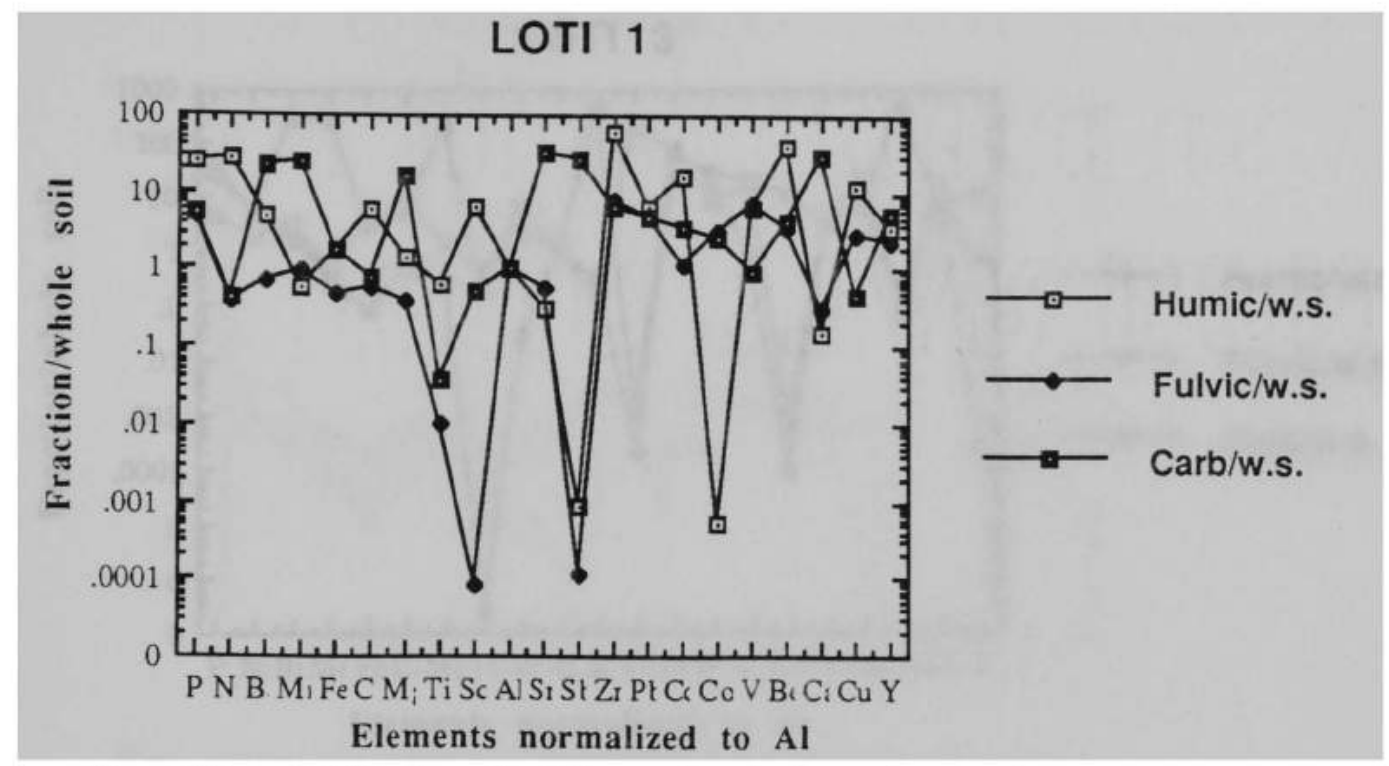

Fig. 105: LOTI 1: Enrichment/depletion of organic and carbonate fractions relative to $\mathrm{Al}$.

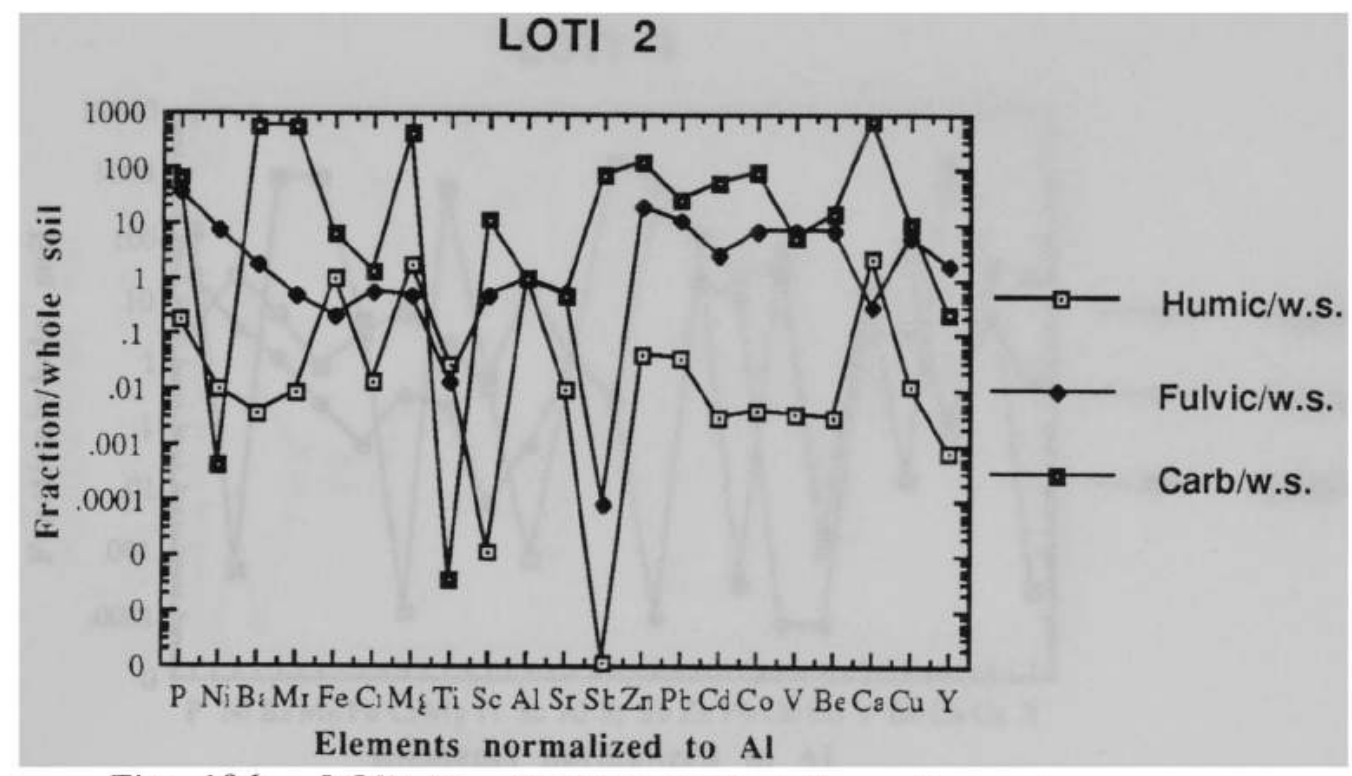

Fig. 106: LOTI 2: Enrichment/depletion of organic and carbonate fractions relative to $\mathrm{Al}$. 


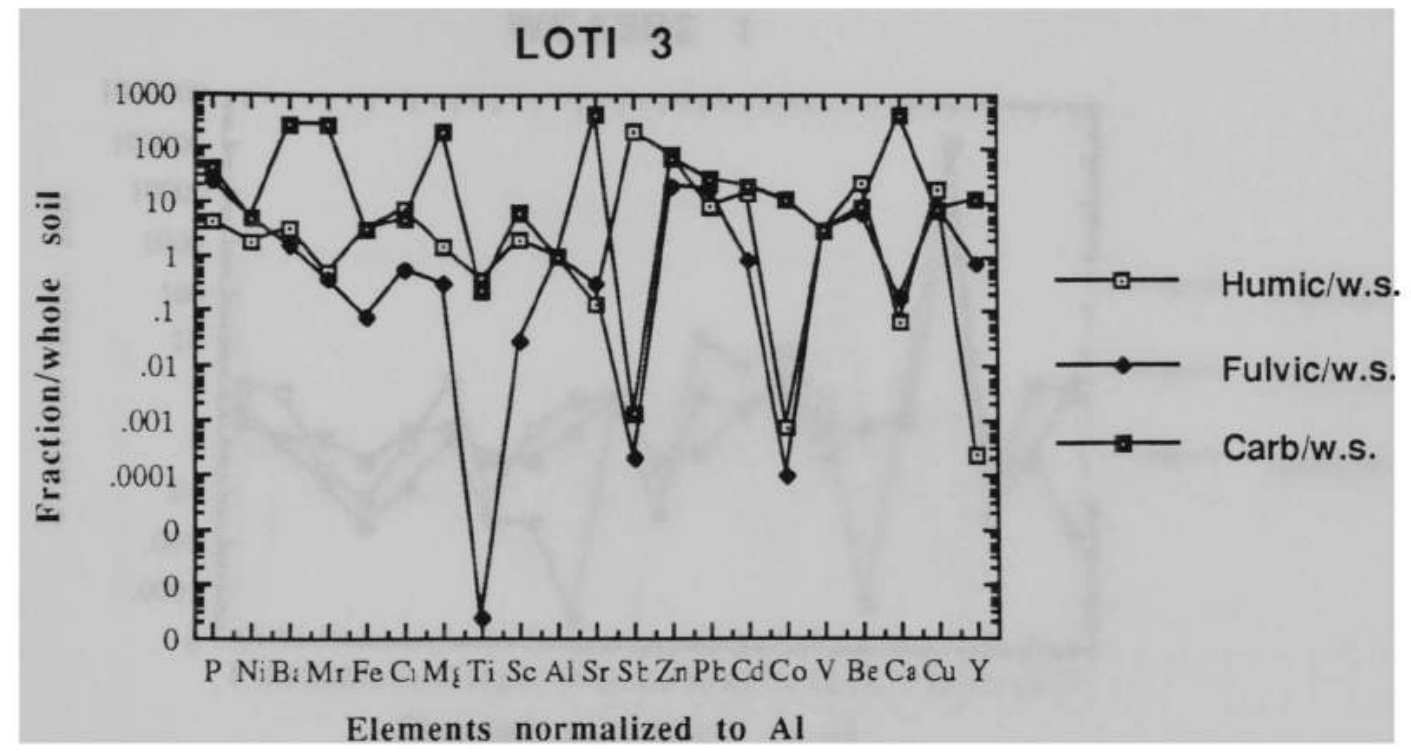

Fig. 107: LOTI 3: Enrichment/depletion of organic and carbonate fractions relative to $\mathrm{Al}$.

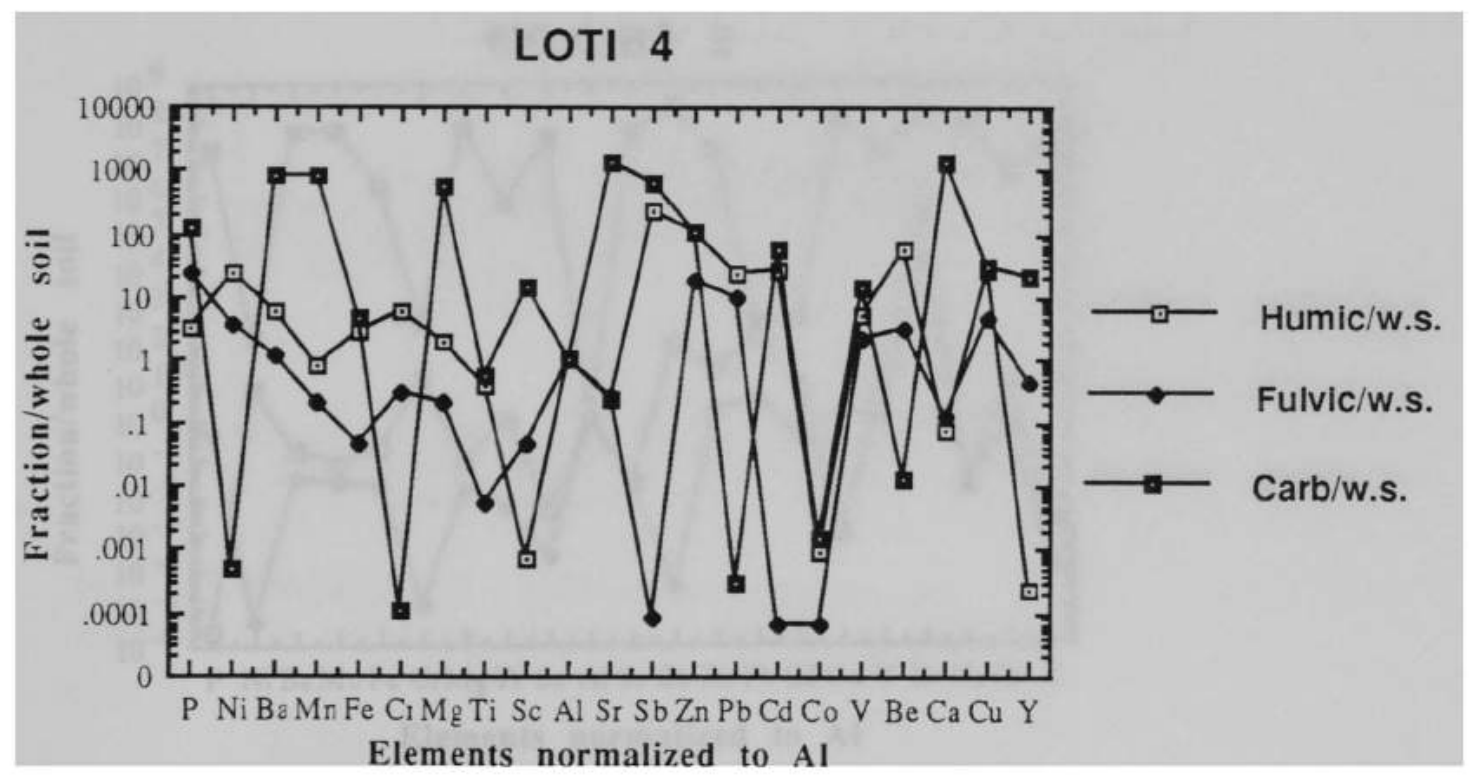

Fig. 108: LOTI 4: Enrichment/depletion of organic and carbonate fractions relative to $\mathrm{Al}$. 


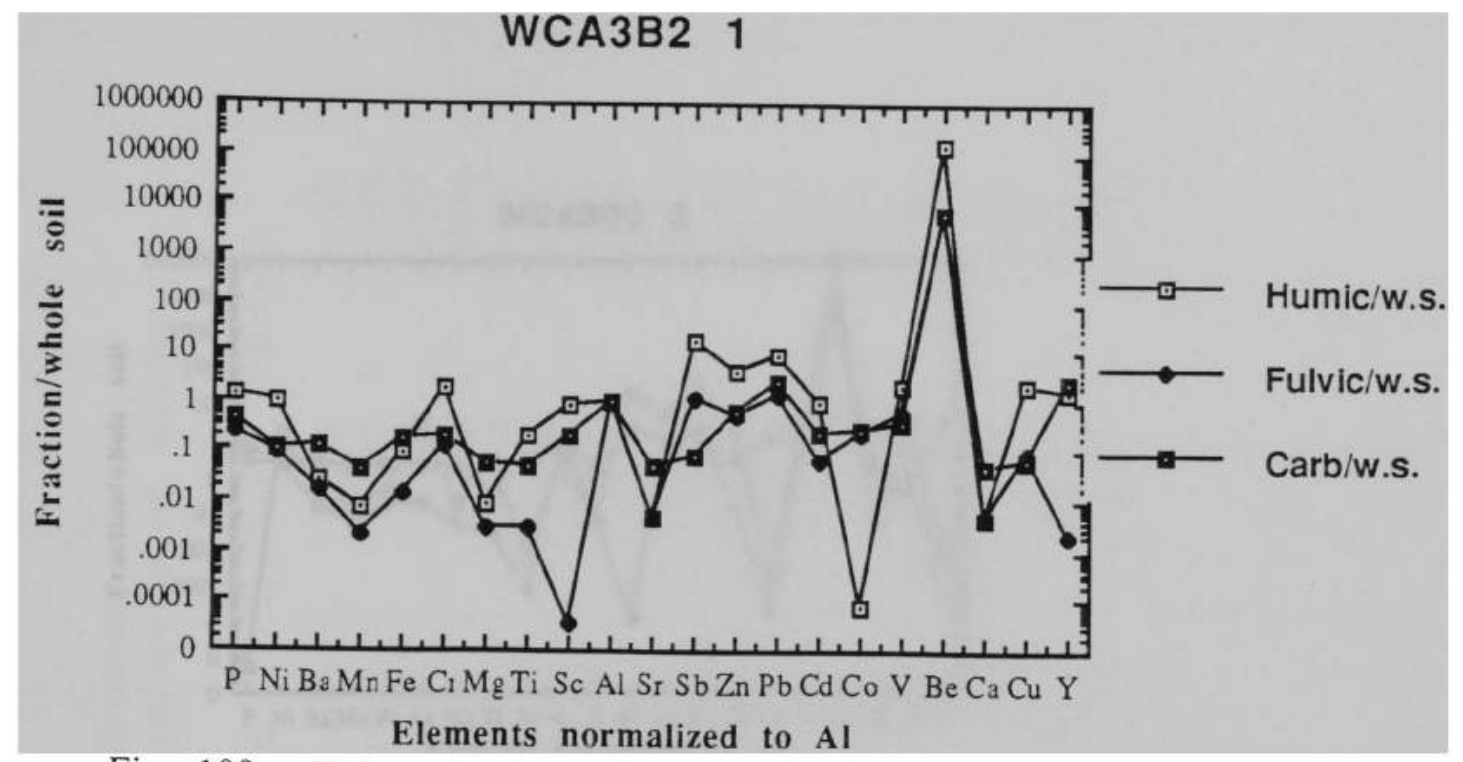

Fig. 109: WCA3B2 1: Enrichment/depletion of organic and carbonate fractions relative to $\mathrm{Al}$.

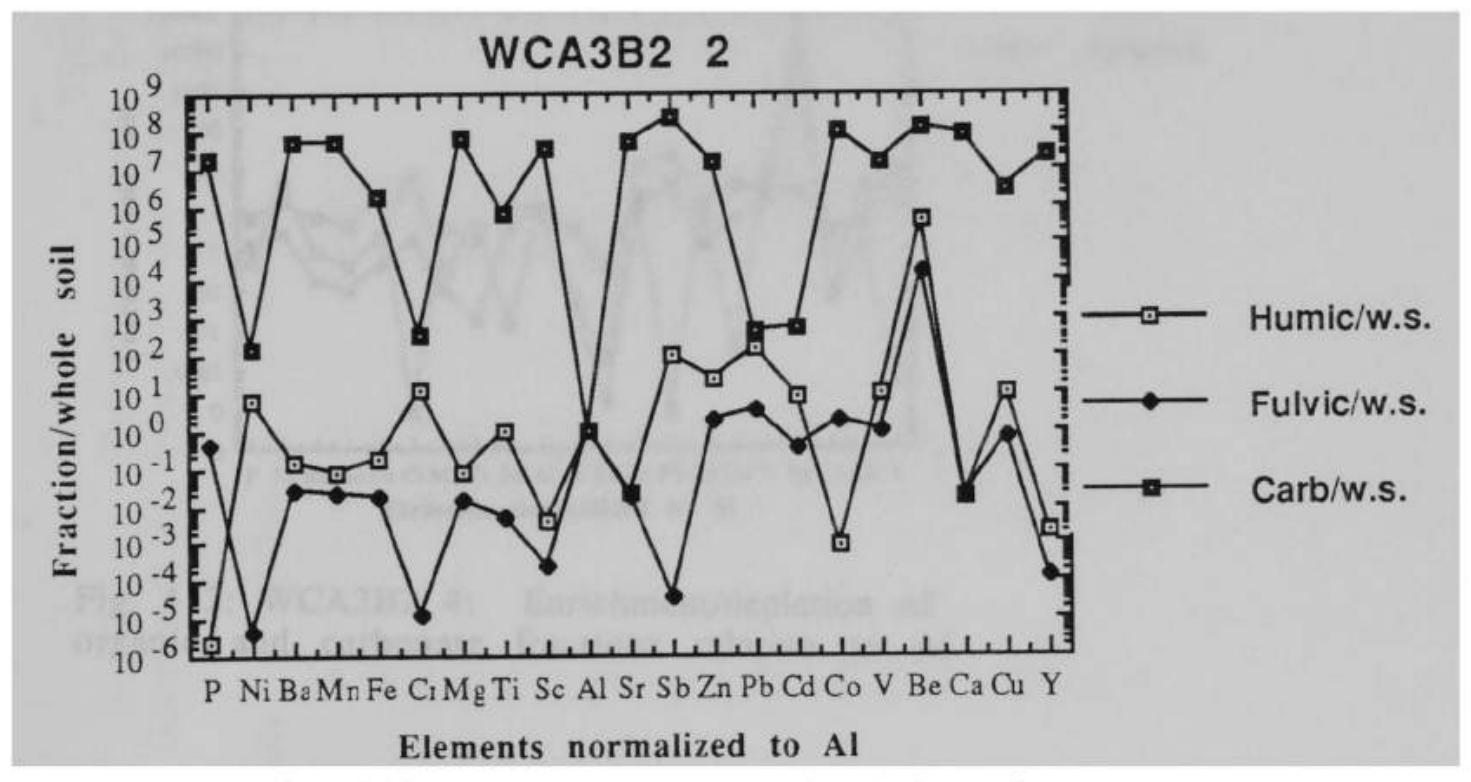

Fig. 110: WCA3B2 2: Enrichment/depletion of organic and carbonate fractions relative to Al. 


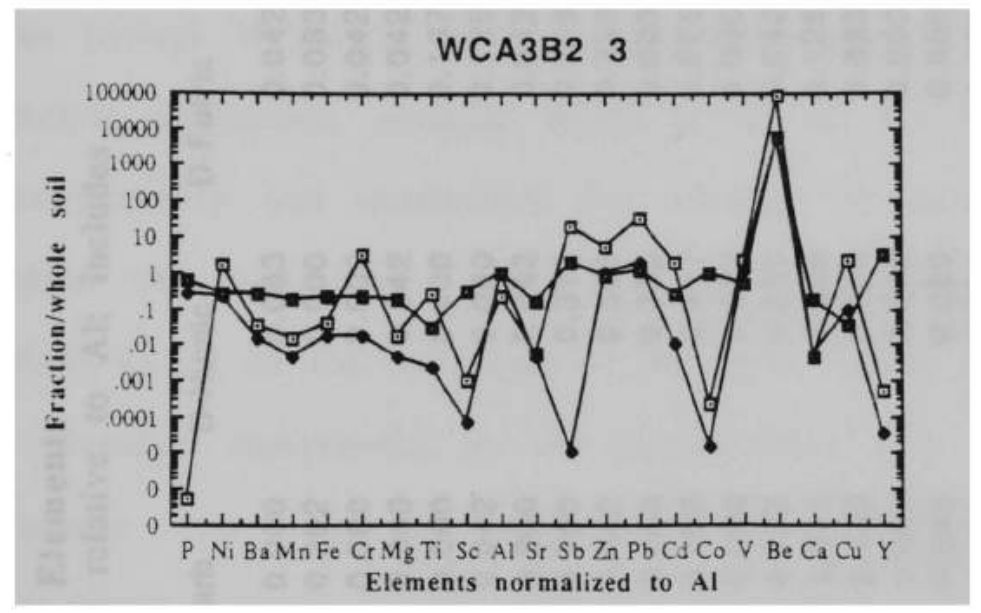

Fig. 111 WCA3B2 3: Enrichment/depletion of organic and carbonate fractions relative to $\mathrm{Al}$.

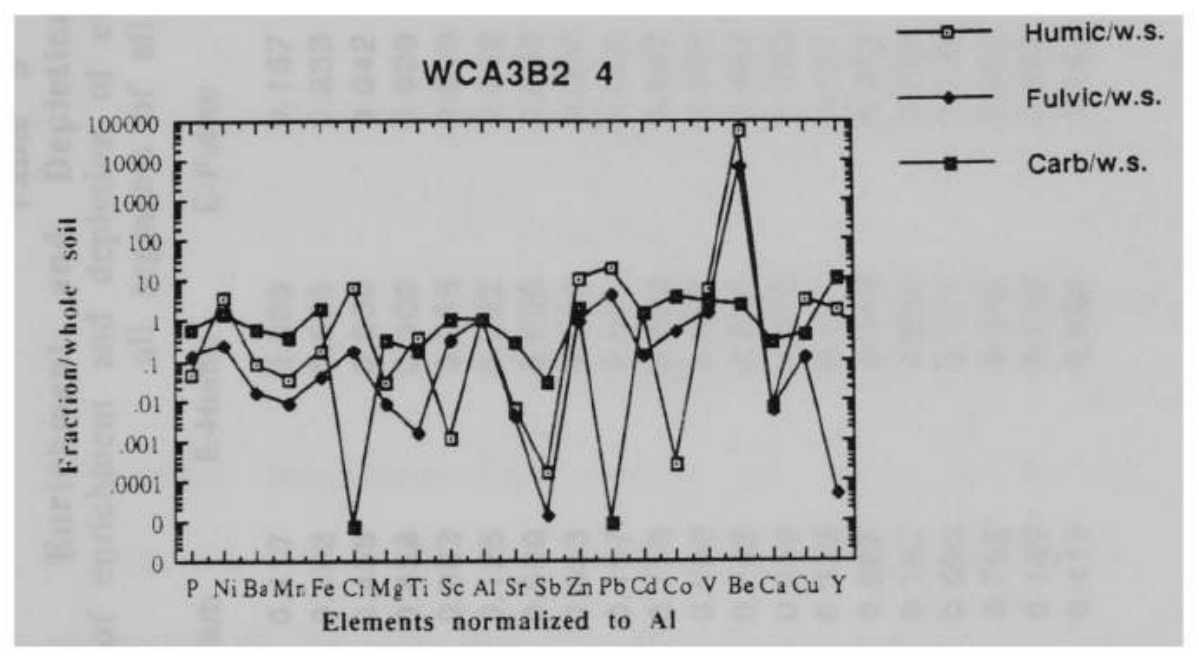

Fig. 112: WCA3B2 4: Enrichment/depletion of organic and carbonate fractions relative to $\mathrm{Al}$. 


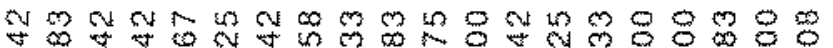

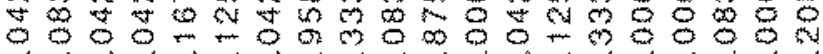

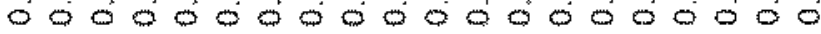

mogno n n

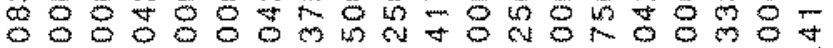
0́0 尊点

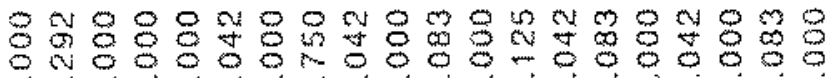

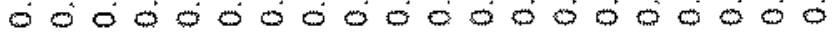

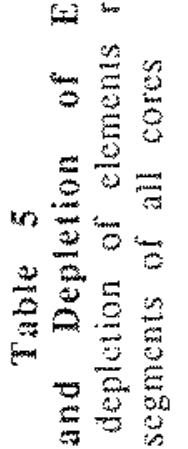

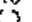

Nल0

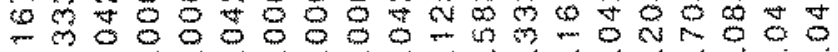
í 总要

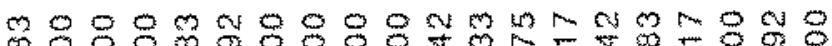
$98880 \% 8989$ \%

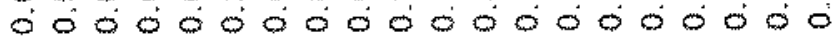

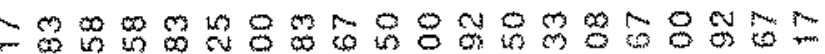
76 क

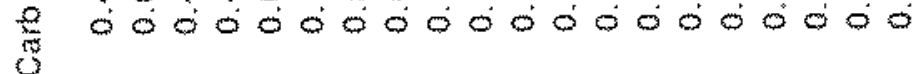
0

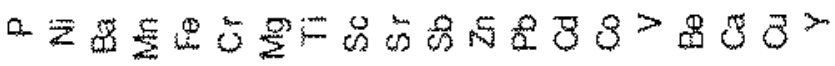


Fifith Methodological Approach:

\section{Principal Component Analysis}

A correlation matrix is constructed for all the elements in all the cores (except WCA3B2), and a principal component analysis is done. The principal component analysis looks at all of the variations in the data simultaneously and determines the number of endmembers necessary to explain the variations. Five principal components are found which explain $92.2 \%$ of the variations in the data. It is possible to characterize the principal components by the Eigenvectors, that is to determine which elements are strongly associated with the individual principal components.

Principal component

I

2

3

4

5
Eigenvector

.517368

.258928

.066811

.053429

.032599
Total

.517368

.776296

.843108

.896536

.929135

Principal component one reflects the variations in the behavior of $\mathrm{Al}, \mathrm{Be}, \mathrm{Co}, \mathrm{Cr}, \mathrm{Ni}, \mathrm{Pb}, \mathrm{Sb}, \mathrm{Sc}, \mathrm{Ti}, \mathrm{V}$ and $\mathrm{Y}$. Principal component two reflects the variations of $\mathrm{Ba}, \mathrm{Ca}, \mathrm{Cd}, \mathrm{Fe}, \mathrm{Mg}, \mathrm{P}, \mathrm{Sr}$ and $\mathrm{Zn}$. Principal component three reflects $\mathrm{Mn}$ and the variations of $\mathrm{Ca}$ and $\mathrm{Mg}$ not previously accounted for in primcipal component two. Principal component four; $\mathrm{Cu}$ and the variations of $\mathrm{Mg}$ and $\mathrm{Sr}$ not previously accounted for in principal component two. 


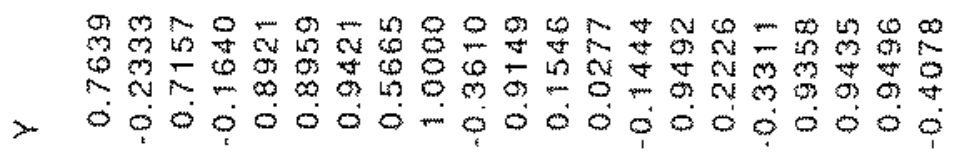

จ

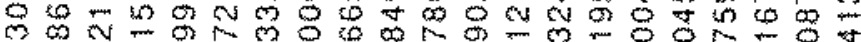

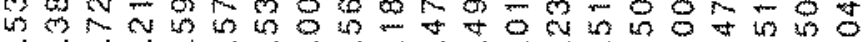
8

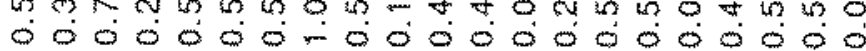

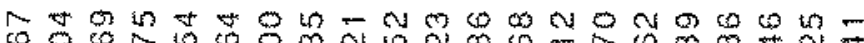

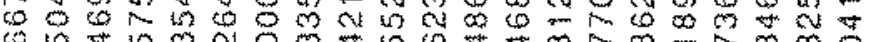

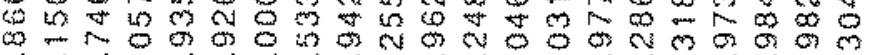
S -

9

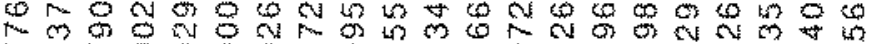

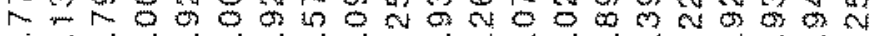

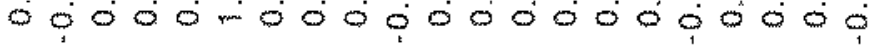

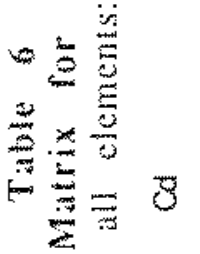

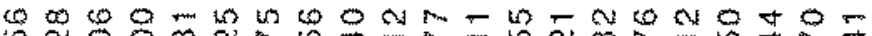

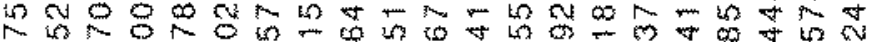
तब

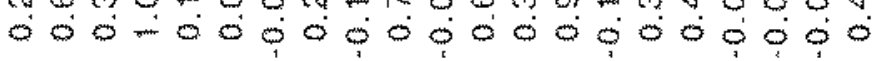

TN8 के

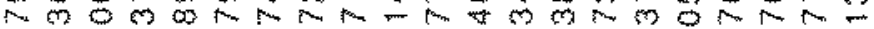
-0. 00000000000000000

O O N M

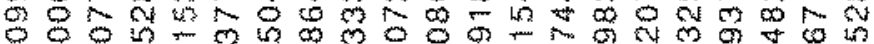
- -0 o

O 0 क O D W

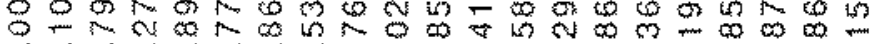

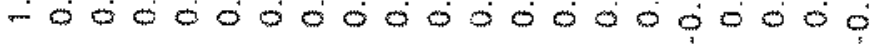

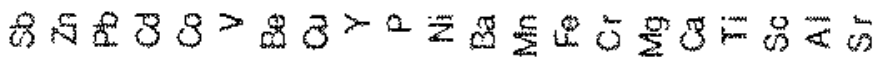




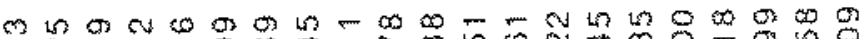

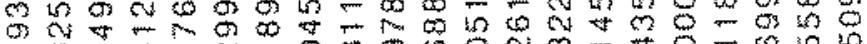
$\theta$ स

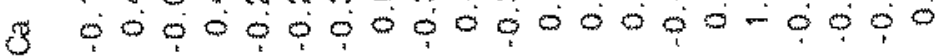

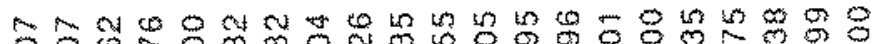

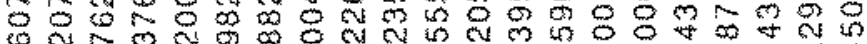

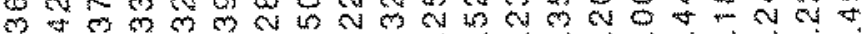

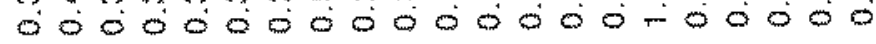

0 m a $00=0$ का

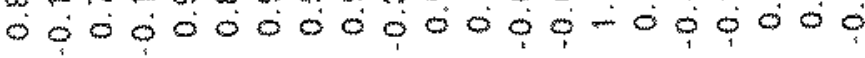

\% m. यूm

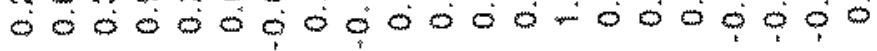

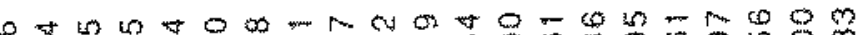

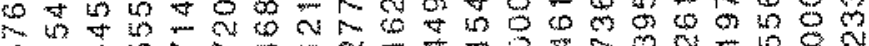

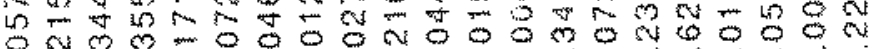
$\sum_{2}^{\infty}$

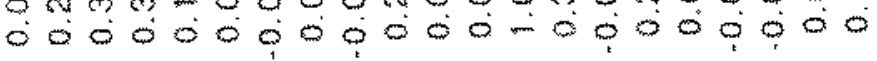

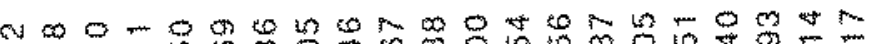

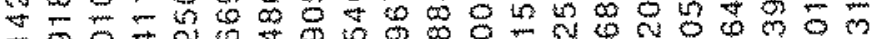

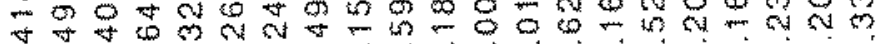

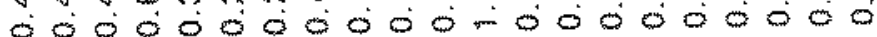

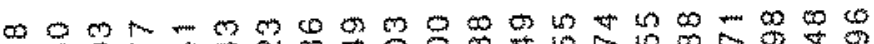

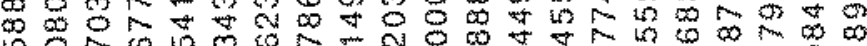
nO

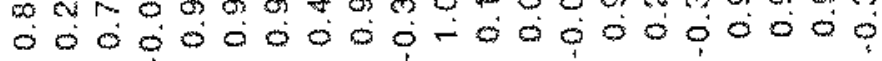

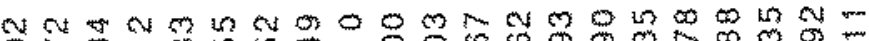
D伤 ब a. 000 की की




$T$

\begin{tabular}{|c|c|}
\hline Sb & 0.8597 \\
\hline Zn & .0 .1937 \\
\hline $\mathrm{Pb}$ & 0.7632 \\
\hline Cd & -0.0850 \\
\hline Co & 0.9531 \\
\hline V & 0.9264 \\
\hline Be & 0.9736 \\
\hline Ou & 0.4759 \\
\hline$Y$ & 0.9358 \\
\hline P & .0 .3088 \\
\hline $\mathrm{Ni}$ & 0.9871 \\
\hline $\mathrm{Bz}$ & 0.1640 \\
\hline $\mathrm{Mn}$ & -0.0197 \\
\hline $\mathrm{Fe}$ & .0 .0590 \\
\hline $\mathrm{Cr}$ & 0.9884 \\
\hline $\mathrm{Mg}$ & $0.18^{-15}$ \\
\hline $\mathrm{Ca}$ & $-0.41 \cdot 3$ \\
\hline$T$ & $: 0000$ \\
\hline Sc & 0.9928 \\
\hline Al & 0.9965 \\
\hline$S p$ & -0.414 \\
\hline
\end{tabular}

So

$$
0.8721
$$

$-0.1482$

0.7645

.0 .0444

0.9545

0.9356

0.9846

0.5167

0.9435

0.2535

0.9798

0.2393

- $0 . \quad 556$

$-0.0180$

0.9880

0.2438

$-0.3693$

0.9928

1.0000

0.9970

$-0.3436$
A.

0.8646

.0 .1671

0.7762

$-0.0370$

0.9617

0.9403

0.9825

0.5087

0.9496

$-0.2792$

0.9848

0.2014

0.0000

.0 .0316

0.9881

0.2299

$-0.35 £ 3$

0.9965

0.9970

1.0000

.0 .3642
$S$

$-0.1539$

0.5528

.0 .3351

0.4241

$-0.2713$

$-0.2565$

$-0.3041$

0.0413

.0 .4078

0.6211

$-0.3896$

0.3317

0.2233

0.4286

.0 .4013

0.4500

0.8509

$-0.4146$

$-0.3436$

$-0.3642$

1.0000 
NNA Noक 0

$\frac{5}{4}$

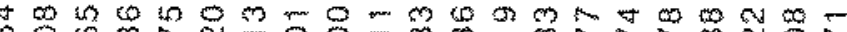

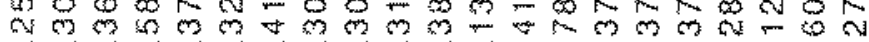

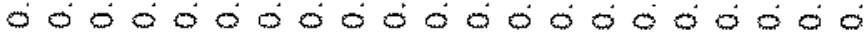

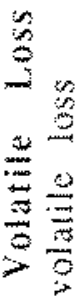

$<$

(1)

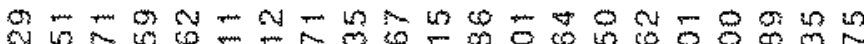

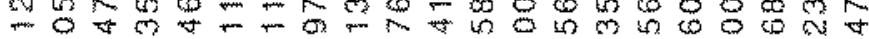
бо

$x$ is

G

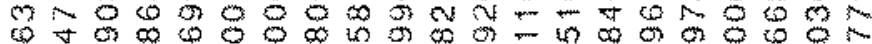

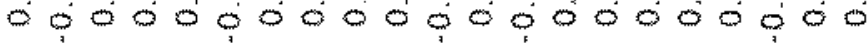

or

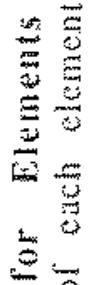

1

(1)

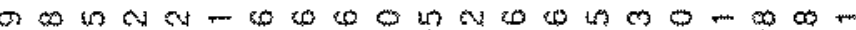

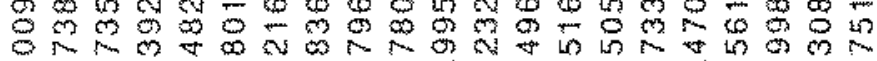

=

क m

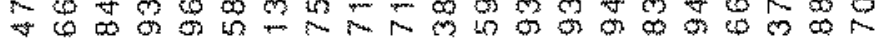

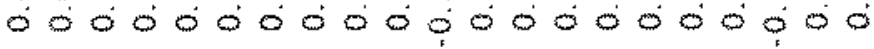

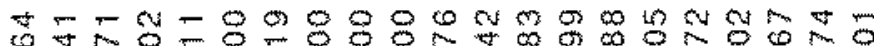

足

क

0.

F

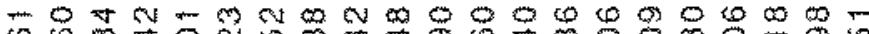
tक

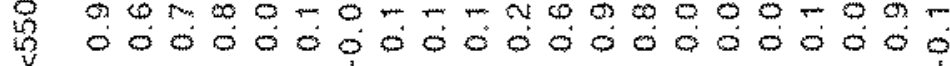

0

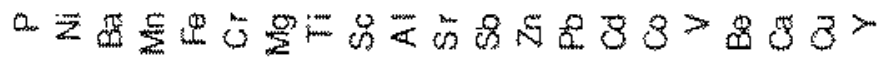




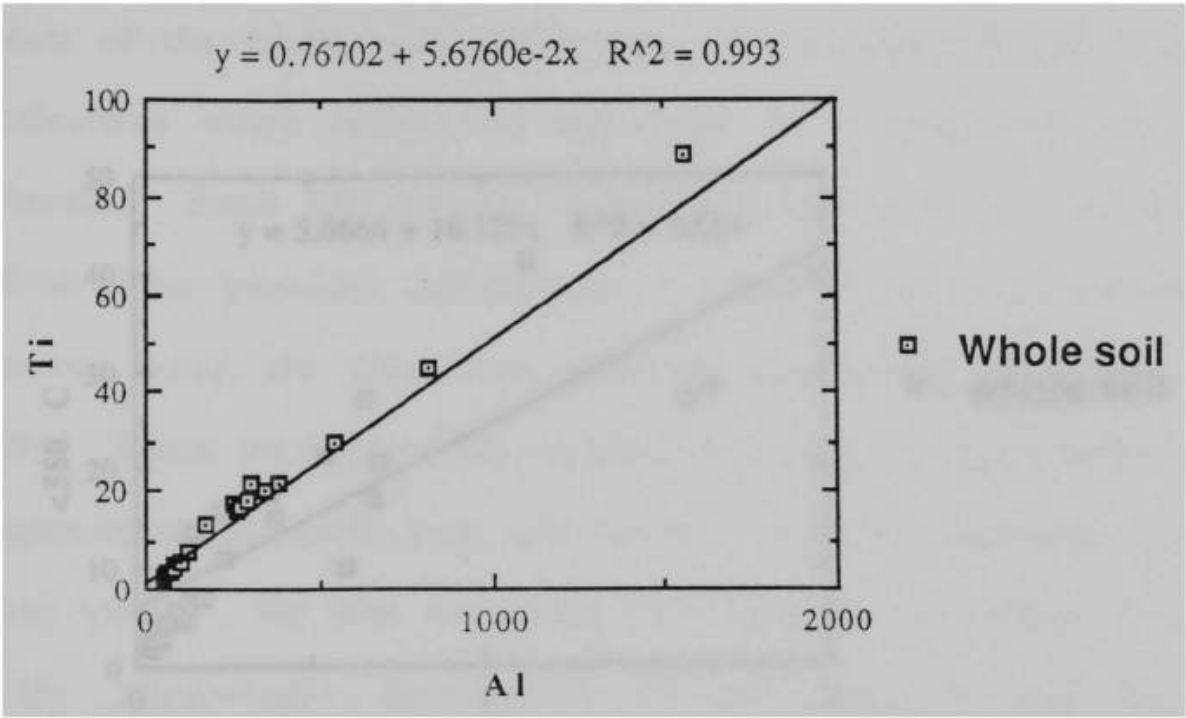

Fig. 113: Al vs Ti from all core segments whole soil.

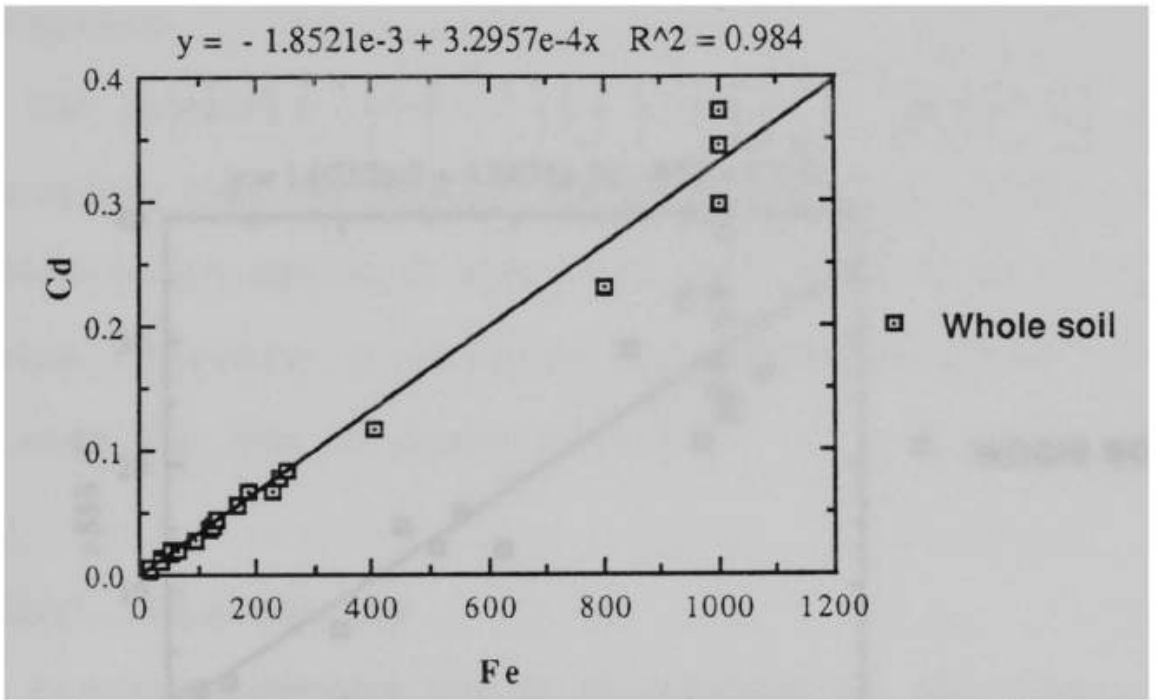

Fig. 114: $\mathrm{Fe}$ vs $\mathrm{Cd}$ from all core segments whole soil. 


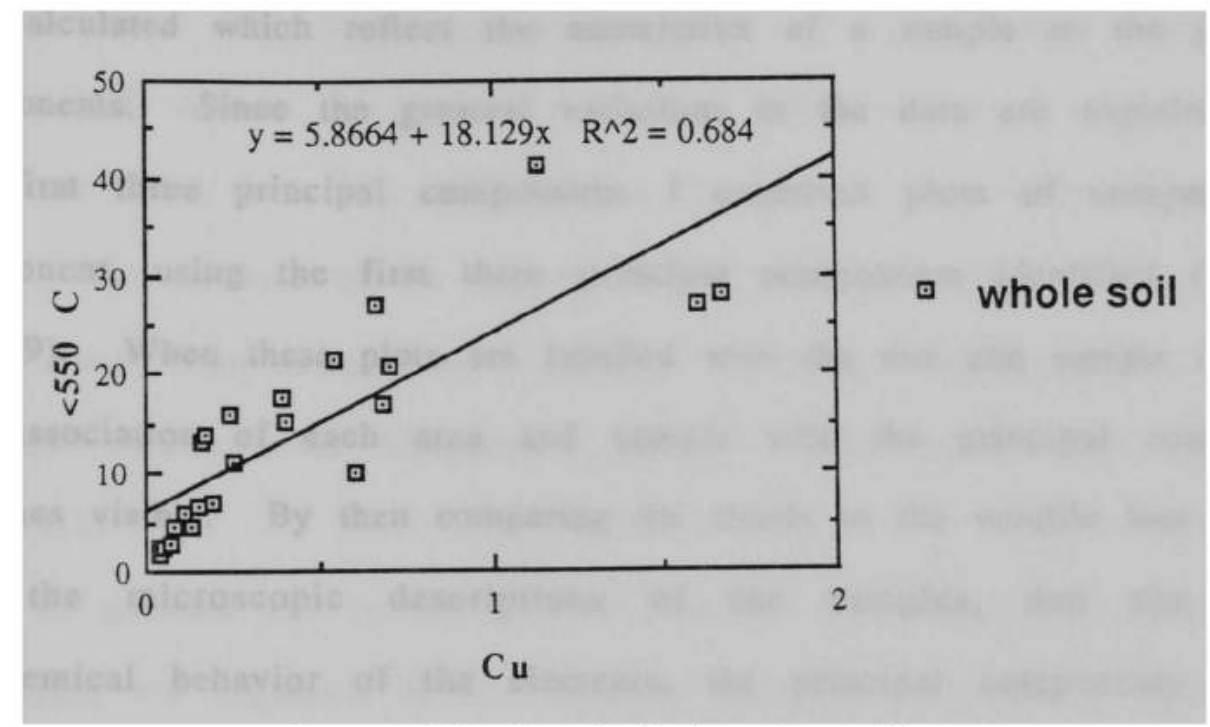

Fig. 115: $\mathrm{Cu}$ vs $<550^{\circ} \mathrm{C}$ volatile loss from all core segments whole soil.

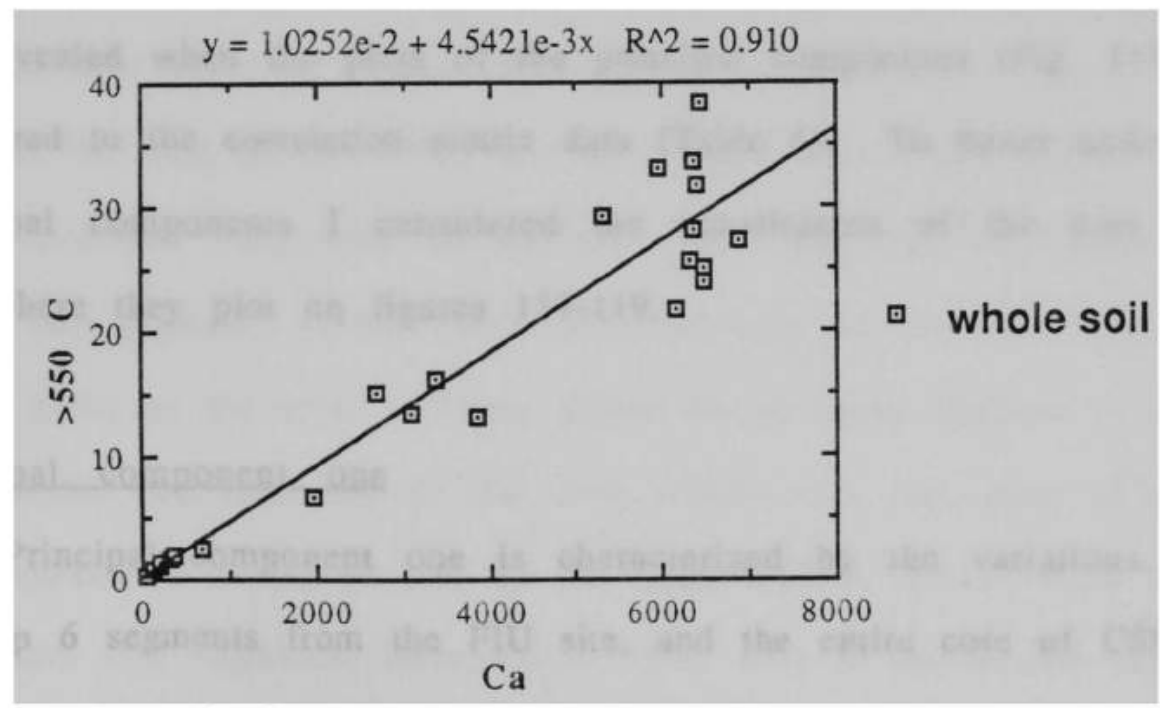

Fig. 116: $\mathrm{Ca}$ vs $>550^{\circ} \mathrm{C}$ volatile loss from all core segments whole soil. 
The variations are then applied specifically to the samples (the depth segments of the whole soil) rather than to the elements and Eigenvectors are calculated which reflect the association of a sample to the principal components. Since the greatest variations in the data are explained with the first three principal components, I construct plots of component vs component, using the first three principal components identified (fig 117 to 119). When these plots are labelled with the site and sample numbers, the association of each area and sample with the principal components becomes visible. By then comparing the trends to the volatile loss pattems and the microscopic descriptions of the samples, and the known geochemical behavior of the elements, the principal components can be described and identified with actual constituents of the soils.

\section{Discussion}

The association between each principal component and the samples are revealed when the plots of the principal components (Fig. 117-119) are compared to the correlation matrix data (Table 6). To better understand the principal components $I$ considered the constituents of the core segments and where they plot on figures $117+119$.

\section{Principal component one}

Principal component one is characterized by the vatiations found in the top 6 segments from the Fu site, and the emire core of CSRA. One endmember is composed of the variations of FIU 1 to 6 and CSRA 1 to 4 , and the other endmember is composed of CSRA 5 and 6 (Fig. 117 and 119 ). 
The FIU core shows distinct differences between the lithologic data from the upper six segments and those from the two lower most segments in the core. The upper segments consisl of quartz mixed with organic matter and minute spicules, and contain relatively small proportions of carbonate (less than $2 \%$ ) according to the greater than $5500 \mathrm{C}$ volatile loss study. The estimate of the organic conten (less than 5500 C) shows values which range from about 2 to 7 percent. In contrast, the lower two sections include anweathered limestone bedrock, and have high carbonate contents.

As pointed out in the site description the stratigraphy displayed in the upper six segments of this core is probably not natural, because the area sampled is located in the nature preserve of university grounds which was previously the site of an airport. It is likely that as such the site cond have been subjected to windblown grains from construction, as well as from the liftoffs and landings of aifcraft. The weathered material sampled also could be wholly or in part quaried fill.

In the case of the CSRA site the volatile loss studies show a relatively high estimated proportion of organic (less than $550^{\circ}$ C) material in the upper two segments $(28 \%, 17 \%)$, and especially in the lower two segments $(41 \%, 27 \%)$ of the core. These values are in sharp contrast to those from the middle two segments of the core which have less than $11 \%$ organic. The estimate of carbonate loss by the same method shows values of $13 \%$ in the upper two segments, increased to $15 \%, 17 \%$ in the middle segments, 10 lowest percentages $(7 \%, 3 \%)$ in the botom two segments. These volatile loss 


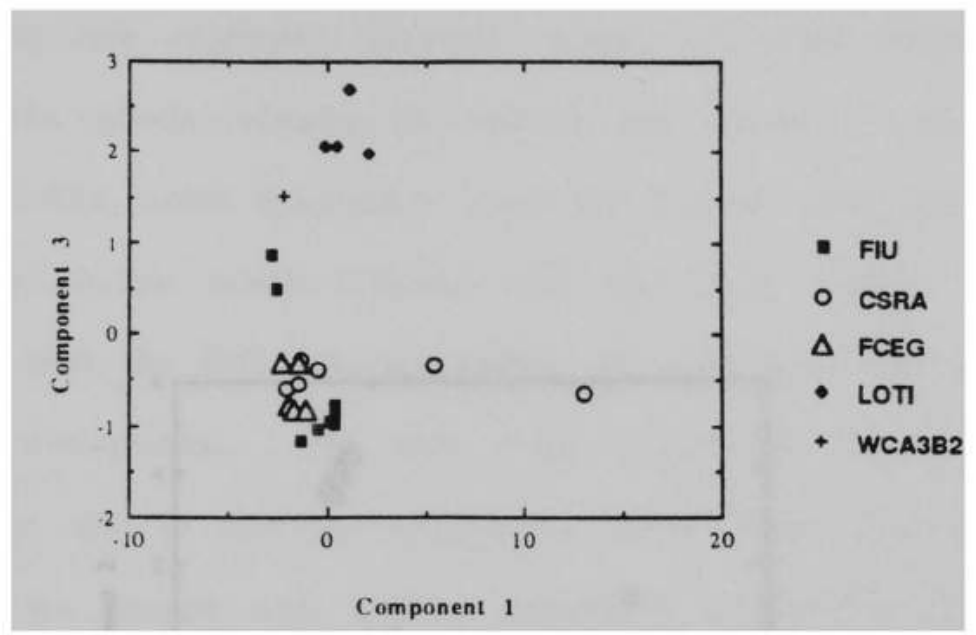

Fig. 117: Principal components 1 vs 3 .

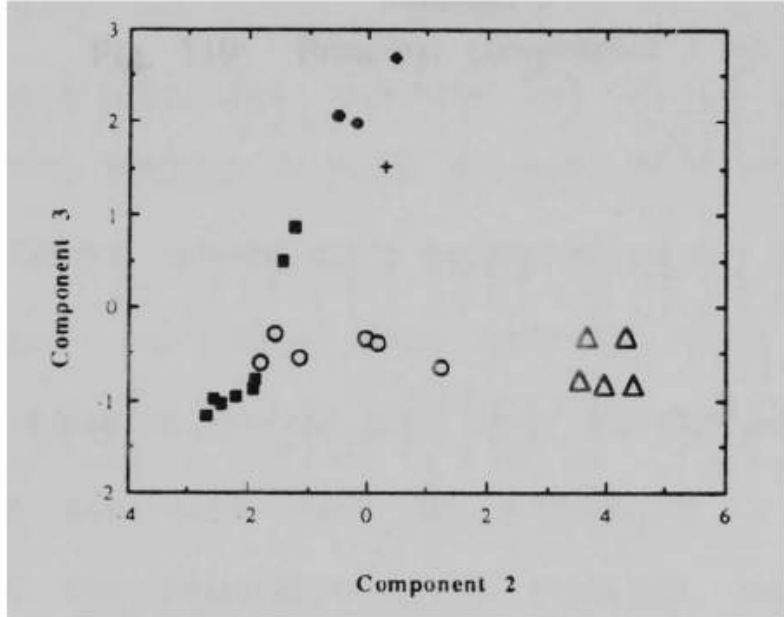

Fig. 118: Principal components 2 vs 3. 


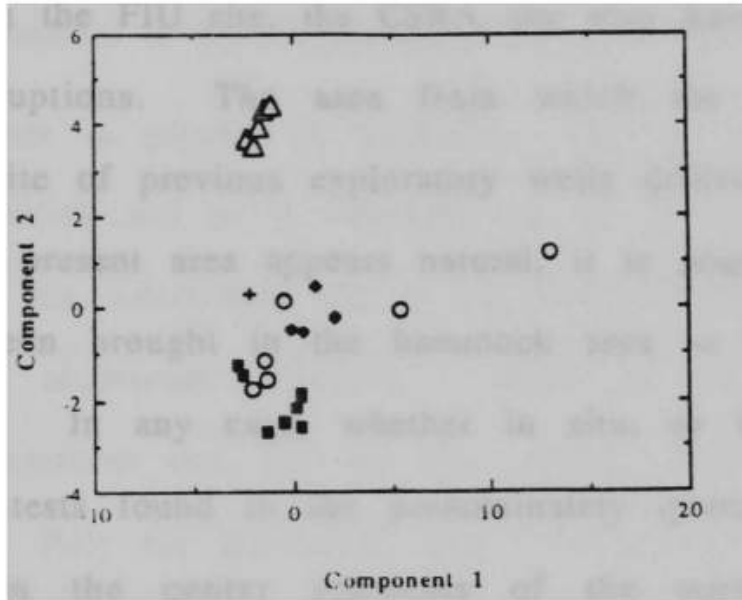

Fig. 119: Principal components 1 vs 2 . 
estimates are consistent with the physical description of the core, where the upper two segments consists mostly of plant residues mixed with micrite and quarti, whereas the middle two segments contain mostly quartz and reworked shell fragnents, and the botom two layers include only quartz and humic matter coupled with very lithle micrite.

As with the FIU site, the CSRA site may have been affected by manm induced distuptions. The area from which the core was recovered is nearby the site of previous exploratory wells drilled for oil (1947). Thus, although the present area appears natural, it is possible that some sand fill may have been brought in the hammock area 10 install pathways for the nature trails. In any case, whether in situ, or brought in the site, the foraminifera tests found in the predominately quartz content of the coarse fraction from the center segments of the core can be assigned to Elphidizm or Cibicides, indicating that the material had a shallow marine origin. It is difficult to make an exact determination of the origin of the material withoul conducting a systematic survey of the surrounding arca.

Because the cores were collected from an area underlain by limestone, which is also the most likely fill material, it is necessary to look at factors associated with the weathering of carbonate in order to understand the characteristics of principal component one. Calcium carbonate in limestone does not exist in a pure form, but carries trace elements whthin the rock. The weathering of $\mathrm{CaCO}_{3}$ usually produces soils or insoluble residues of clay minerals with quartz and iron oxides that were incorporated in the rock matrix. The insolube residues become concentrated as soil because the calcite is highly soluble and is effectively 
removed from the weathering site through dissolution. Weathering progresses at a faster pace in soils where organic decay produces abundant carbon dioxide which becomes dissolved in water and leads to carbonate dissolution by these reactions:

$$
\mathrm{H}_{2} \mathrm{O}+\mathrm{CO}_{2} \text { (gaseous carbon dioxide) }
$$

$\mathrm{CaCO}_{3}$ (calcite) $+\mathrm{H}_{2} \mathrm{CO}_{3}$ (dissolved carbon dioxide) $=2=\mathrm{Ca}^{2}+2 \mathrm{HCO}_{3}$

Aluminum is presen in carbonate rock as aluminum hydroxides and silicate impurities and as it weathers oul of the carbonate, has a tendency to remain at the weathering site in the form of clay mimerals, all of which are hydrous aluminum silicates. Many of the elements reflected in principal component one are the less soluble trace elements of carbonates (Ni, Co, Pb, Be); are associated with aluminum and could be incorporated into clay minerals or oxides (Be, V, Y, Sc, Cr, $\mathrm{Pb}, \mathrm{Sb}, \mathrm{Co}, \mathrm{Ti}$ ); or are known to have an affinity for organic materials (Be, $\mathrm{Sb}, \mathrm{Pb}$ ).

Therefore, in considering the geochemical behavior of the above elements and the volatile loss study coupled with the core descriptions, conclude that principal component one is best described as being a mixture of residues from the weathering of carbonate bectock and organic matter, with CSRA 5 and 6 being an organic rich endmember. Quartz sand observed in the cores, either of natural or human sources, probably is also a participant in this component, but contains small quantities of arace elements.

The concentrations of phosphorus it the CSRA core exced the worldwide range, 100 to $1000 \mathrm{ppm}$. (Table 2) for the length of the core, and So exceds the reported worldwide range, .05 to 4 ppm, (Table 2) in the 
bollom segment (CSRA 6). The other demental abundances fall within the worldwide ranges. The core has a small association with principal component two (Fig 118) but it is not an endmember of principal component two.

\section{Principal component we}

A comparison of the correlation matrix with the plots of the three dominant principal components (Fig 118 and 119) show that principal component two is associated with the trend that is dominated by variations of Fe, $\mathrm{Zn}, \mathrm{Cd}, \mathrm{P}, \mathrm{Ba}$ and $\mathrm{Mg}, \mathrm{Ca}$ and $\mathrm{Sr}$ variations not otherwise accounted for in principal components three of four. The samples which most strongly characterize principal component two are clearly associated with the five FCEG samples as one andmember. The lower segments of the CSRA core (5 and 6) are intermediate between these samples and those dominated by principal component one (Fig 117 and 118).

The stratigraphy of the FCEG core consists of thin laminae (less than $1 \mathrm{~mm})$ throughout the length of the core. Although the area was a campground (ref, p. 33) the presence of the laminae may indicate that the natural sedimentation pattern is undisturbed. The laminae may have been induced by short term periodic environmenal changes. One known instance in which similar periodic enviromenal changes are recorded in is varves, which result from the rhythmic changes in patterns of sediment distribution due to ammal or seasonal varations. A similar process may have occurred here. Since the area is subject to a seasonal dry period, and historic water levels were higher before drainage systems were built, the rhythmic change in wet to dry environmental conditions 
could account for the presence of lamination. The Everglades is a unique system characterized by the slow movement of water which would allow slow setting out of particulates from the water as it flowed sonthward.

The volatile loss estimate for organic material in the FCEG core (less than 5500 C) shows a steady decrease in organic material through the core (21\% to $10 \%$ ) as the carbonate estimate (greater than $550^{\circ}$ C) shows increasing proportions (22\% $102 \%$.

Groupings based on geochemical behavior as previously discussed can be useful in identifying principal component wo. Gon, zinc and cadmin may be grouped logether based on theit behavior and characteristics as ferroalloy metals. Calcium is grouped with $\mathrm{Mg}, \mathrm{Fe}, \mathrm{Ba}, \mathrm{Cd}$, Sr and $Z_{n}$ as trace elements in carbonates. Barim is known to concentrate in phosphorus concretions, and phosphorus in the form of phosphates forms complex mixtures of iron and calcium phosphates. Cadmium and zinc are associated with phosphates, both naturally occuring and as fertilizers. The bulk composition of FCEG samples are not unusual compared with other areas. Organic contents are comparable with CSRA samples associated with principal component one (weathered bedrock and organic matter) and carbonate contents are comparable with FIU segments 7 and 8 and LOTI which are dominated by unweathered $\mathrm{CaCO}_{3}$ (principal component three, see below). Therefore, alhough the present physical conditions of site FCEG shows limited evidence of prior human activities at the hammock, (ref, p. 33) it is possible that principal component two is a foreign material introduced by anthropogenic activities, and not related to changing proportions of the soil constiuents or lithology. Possible sources are: amospheric inpu (particulate matter, arbome dusts) and 
land based input (refuse dumping, leaching, other solid wastes, fertilizer aplication).

1) Aerial fallout of trace metals from sources suct as coal combustion and metal smelting industries is reported (Adriano, 1986; Kabala-Pondias and Pendias, 1984) as being widely dispersed over considerable distances, and impacts on natural areas. In the present case it is less likely that the deposition of general atmospheric fallout would impact so strongly on this one site, well within the Everglades, while the other sites analyzed were not. This mode cannot be ruted out entrely, because air currents forming narrow plames could accomplish this. However, it is also possible that a more localized event (a fire at an illegal dumpsite) could have strongly impacted this site, but not necessarily the other sites. In addition to the direct effects of anthropogenic activities at this site, other effects related to agriculfural activities may be involved as well.

2) Land based sources of trace elements are subject to movement through ground water (as leachates), and in the case of the Everglades through surface water movements south from hake Okeechobec, It is possible that some of the variations in principal component two are due to impact from application of phosphatic fertilizers. Some phosphatic fertilizers contain significant amounts of cadmium, zinc and/or barim depending upon their source rock, conversely other phosphatic fertilizers are lacking in these trace elements because they are retrieved from different source rocks. Phosphate ores from the western United States contain higher concentrations of these elements than ores recovered from the southeastem states (Adriano, 1986). 
3) Sewage sludge or raw sewage disposal is another possible source of trace metals which could account for some of the element variations at this sice. Cadmium and zinc generally are enriched in sewage sludge and raw sewage, and variations in $\mathrm{Cd}$ and $\mathrm{Zn}$ in part characterize principal component two. However, sludge and raw sewage also usually contain concentrations of $\mathrm{Ni}, \mathrm{Pb}$ and $\mathrm{Cu}$; and these element variations are not found to characterize principal component two. Sewage may not have been used in agriculure practices here, but its presence cannot be entirely ruled out (unsanitary refuse disposan).

4) Animal wastes may also be involved in increased trace element concentrations. However, there is great variability in the elements excreted and the amounts excreted, depending upon factors such as the type and age of the animal(s), as well as the type of foodstuff and dietary supplements the animals might receive. Element enrichment in animal wastes is generally associated with livestock, and are rarely enriched in potentially toxic trace elements (Adriano, 1986). Although the possibility of impact from this source is not strong, (lack of livestock herds) it camnot be ruled out altogether (unpenned animal intabitants).

5) Irrigation water runoff from distant sources is another possible source of elements at this site, bat is unlikely to have strongly impacted only this site.

Samples from the lower portion of CSRA (5 and 6) and LOTl show a slight association with principal component two. These samples have a wide range of carbonate contents $(2 \%$ to $33 \%$ ), including some very low values, so it is unlikely that this component is related to $\mathrm{CaCO}_{3}$. Like FCEG, all these samples have relatively high organic contents $(13 \%$ to $2.6 \%)$, and 
CSRA 5 and 6 form the organic rich andmember of component one. Therefore, it is likely that there is a relationship between principal component two and organic mater, although one that is distinct from the vatiation described by principal component one. The association of component wo and organic matter suggests that it originates from phosphate fertilizers or refuse (human or animal) of fertilized plants.

Overall, it is difficult to clearly describe the nature of the material represented by principal component two based on the available information. It does show some variations associated with carbonates; Ca, Sr. Mg, and to a lesser extent $F \mathrm{C}, \mathrm{Ba}, \mathrm{Cd}$, $\mathrm{Zn}$ and $\mathrm{P}$. However, the variations in $\mathrm{Cd}$ and $\mathrm{P}$ are likely to be associated with an anthropogenic source, most probably phosphatic material such as fertilizer.

\section{Principal componcnt three}

Principal component three reflects the behavior of three elements, Mn, ard the variations of $\mathrm{Ca}$ and $\mathrm{Mg}$ not accounted for in principal components two or four.

The plots of the principal components (Fig 117 and 118) show that principal component three is described by the vartations in the LOTI core, the WCA3B2 sample and FIU segments 7 and 8.

The volatile loss sudy for estimated proportion of carbonale (greater than $550^{\circ}$ C) show the samples 10 contain a high proportion of carbonate (L.OT 28-34\%; WCA.3B2 39\%; FIU 7 and $830 \%, 38 \%$ ). The organic estimate (less than $550^{\circ} \mathrm{C}$ ) is more variable, from 2 to 28 percent (Appendix D).

The LOTI core is composed of mostly pure micrite with rare quartz, ostracod, mollusk and gastropod fragments. It is thinly laminated 
throughout which may be natural structures indicating thythmic environmental changes. As discussed for the FCEG site, the lamination here conld have also been the result of subtle seasonal changes like diferences in rainfall or temperature which affect sediment dismribution. or biogenic or chemical preciptation within the lake.

The wo lower segments of the Fu core which are included in principal component three are amost pure micrite, mixed with little decayed organic matter and quartz. These two segments are most likely upper bedrock.

The WCA3B2 core lacked idemifiable sedimentary structures and only one segment was available for whole soil analysis and nclusion in the principal component analysis (the other segments were consumed during the volatile loss study).

The most notable characteristic of principal component three are that only the variations of three elements (Ca, Mg, Mn) are described. The variations in the principal component are also described by samples which show high estimated proportions of carbonate. In contrast to the trace elements associated wich principal component one, these are the most soluble elements in carbonates. The common link between the samples is the high estimated proportion of carbonate, and the key to the principal component is the direct observation of relatively unweathered carbonate of the FIU samples. I conclude, therefore, that principal component three reflects the presence of relatively unweathered carbonale. 


\section{Summary and Conclusions}

FIU

In the FIU core the upper six segments contain mostly quartz cemened with some organic material, sponge spicules and very linte carbonate $(.3$ to $1.9 \%)$ while the two lower segments, the bedrock, are composed of mostly pure micrite (29 and $33 \%$ carbonate).

None of the whole soil element concentrations are found to exceed the reported bulk worldwide ranges (Appendix F). The site shows a patern of general decreasing whole soil elemental abundances with depth, with the exceptions of $\mathrm{Ca}, \mathrm{Sr}, \mathrm{Mg}$, and $\mathrm{P}$. The concentrations of calcium and strontum increase in the lower segments reflecting the change in bulk composition of the core.

The correlation matrix and principal component analysis indicates that the variations encountered in the soils and sediments at this site are associated with two principal components. The segments which are above the bedrock are included in principal component one, which describes mixing of organic matter, weathered carbonate and quartz sand. The two bedrock segments are included in principal component three which describes the large fresh carbonate component.

\section{CSRA}

The upper two segments of the CSRA core contain mostly organic matter (28 and 17\%) in the form of plant residue mixed with micrite (13\% carbonate each), quarz and some mollusk tests. The middle segments are predominately quart with a few reworked shell fragments and foraminifera with litle organic mater $(4$ and $1 \%$. The two lower 
segmenss are mostly quartz and organic material (4) and $27 \%$ respectivety).

The majority of the element abundances fall within the worldwide ranges with the exception of antimony which exceeds its range in CSRA 6 , and phosphorus which shows excessive concentrations throughout the length of the core.

Chemical variations in the CSRA core are best described by principal component one: the elemental variations resulting from the mixing of residual material from carbonate weathering, organic matter and quartz. The core is also associated with principal component two, in that some samples are unusually coriched in phosphorus.

\section{RCQ}

The FCEG core displays lamination consisting of mictite and organic matter mixed with some quatz and shell fragments. Most of the elemental abunances for this core fall within the worldwide ranges with the exception of $\mathrm{Cd}$ and $\mathrm{P}$ concentrations which exced the ranges throughout the length of the core. When the clement concentrations are compared to changes in the soil constituents in the core as determined by the volatile loss study, no clear pattern emerges.

The principal component andysis indicates that the FCEG samples are most strongly associated with principal component two, which is possibly a foreign material introduced by anthropogenic activines. This is consistent with entichment of $C d$ and $P$, and is apparently not related to changing proportions of the soil constituents or lithology of the core. 
The core from Lake Okeechobee is composed of mostly micrite, some organic matter, quartz and very rare freshwater molluscan fragmenis. The volatile loss study for estimated proportion of carbonate (greater than 5500 C) shows the samples in this core to contain a high proportion of carbonate $(28 \cdot 34 \%)$

This core conatas whole soil trace element concentrations consistent with worldwide ranges and show little variation in abundances win depth with the exception of $\mathrm{Al}, \mathrm{Ca}, \mathrm{Fe}, \mathrm{Mg}$ and $\mathrm{Tr}$, and to a lesser extent $\mathrm{P}$ and $\mathrm{Sr}$. It is primarly associated wht principal component three, characteristic of the large unweathered carbonate content, but also shows a sligh association with principal component two. This association is probably related to organic matter, yet in a different relationship than described by principal component one.

\section{WCA $3 B 2$}

This core consists of mosuly decayed to partly decayed organic material cemented witl micrite, with some spicules and carbonized plant remains. Only one segment is available for whole soil analysis, and the element abundances determined for this core segment are mot elevated above the worldwide ranges. The greater than $5500 \mathrm{C}$ volatile loss procedure determined a high carbonate conent for this core sample (38\%). When plotted (Fig 118 and 119) it lies between the Lot samples and the lower two samples from the FIU core, and as such is associated with principal component three, characteristic of its large unweathered catoonale content. 
In conclusion, analysis of principal components of South Florida soils and sediments revealed that $84 \%$ of the element variations in the samples are described by three principal components.

Principal component one is characterized by the variations of $\mathrm{Al}$, Be, $\mathrm{Co}, \mathrm{Cr}, \mathrm{Ni}, \mathrm{Pb}, \mathrm{Sb}, \mathrm{Sc}, \mathrm{Ti}, \mathrm{V}$, and $\mathrm{Y}$ and is best described as being a mixture of residues from the weathering of carbonate bedrock or fill and organic matter with CSRA 5 and 6 comprising an organic rich endmember.

The CSRA core and the upper 6 segments of the FIU core are associated with principal component one, with CSRA 5 and 6 comprising an organic rich endmember of that componem.

Principal component two is characterized by the variations in $\mathrm{Ba}, \mathrm{Ca}$, $\mathrm{Cd}, \mathrm{Fe}, \mathrm{Mg}, \mathrm{P}, \mathrm{Sr}$, and $\mathrm{Zn}$. It is not associated with any one bulk constituent of the soils. Based on its composition it is probably the residne of phosphatic fertilizer or fertilized plant material. The CSRA core shows elemental abundances of $P$ and $S b$ elevated above ranges which are generally accepted as nomal and presumably safe worldwide. These elevated concentrations are related to principal component two, and may result from the application of phosphatic fertilizer (P) and/or pesticides (Sb) in the past.

The FCEG core shows the strongest association with principal component two, and clearly comprises an endmember of this component. This core has elevated levels of phosphorus and cadmium which is probably related to the application of phosphatic fertilizer.

Principal component three represents the variations of $\mathrm{Mn}$, and the variations of $\mathrm{Ca}$ and $\mathrm{Mg}$ not accounted for in principal components two or four and reflecis the presence of relatively unweathered carbonate. 
The lake Okechobee core (LOT1), the WCA3B2 sample, and the FlU 7 and 8 segments show elcment concentrations within the generally accepted ranges of background levels worldwide. These samples are associated strongly with principal component three, relatively umwathered carbonate.

Most vertical changes in soil major and trace element conents are related to variations in lue proportions of bulk soil constiuents: unweathered carbonate, the residue of carbonate weathering, organic malter and quart\% sand. These changes are comparable to those seen between different sites. Unusual abundances of $\mathrm{P}, \mathrm{Cd}$ and $\mathrm{Sb}$ are found at some sites and levels, but are not telated to changing proportions of bulk constituents. It is probable that this chemical signature indicates input from anthropogenic sources. The trace element contents of the bulk soil constituents can be used as a baseline against which to identify anthropogenic infuence.

\section{Areas for Fuure Research:}

Further research on arace metal abundances and their variations with depth is warranted in South florida. The resuls presented in this thesis can be tested and built upon in several ways.

One way to extend this study and to sest the methodologicat approaches 10 data analysis is to sample a larger number of different environmens where soils will have different proportions of bulk constiuents and possibly new bulk constituents not encountered here. This could be accomplished by selecting areas based on their characteristics, as done here, of by working on a grid and using random sampling. Such 
research will help 10 determine if the three principal components identined in this thesis aro widely applicable to Souh Florida.

A second way to extend this research would be 10 choose areas that show fine-scale sedimentological features, for example, the laminated woTI cores, and perform trace element analyses on the small layers. In order to do this properly, a better sampling technique must be used so that the layes are not disrupted and so they are large enough to analyze. A box corer may be more appropriate. because of the increased area sampled and the lesser disnution of layering near the center of the box. Since the laminae are formed by varying proportions of bulk constituens, this approach could help to test whether the trace element concentations in the bulk constituents are consistent in single area, of whether they change with time and/or depth.

A thind area for future research is to continue sampling the same areas sampled in this study. All these samples were taken at the cnd of a severe drought, and many areas, such as WCA3B, LOTI and FCEC are nomally under water at least part of the year. Therefore, it would be interesting to see whether the increased water flow changes the elemental abundances in the whole soils and buik constituents over the next few years ano over longer periods of time. This is especially imporant since restoring water flow through the Everglades has recently been mandated by law. 


\section{REFERENCES CITED}

Adriano, D.C. 1986. Trace elements in the terrestrial enviromment. Springer-Verlag, New York. 533 pp.

Bohn, H. L. McNeal, B. L. and G. A. O'Connor. 1985. Soil chemistry. J. Wiley and Sons, New York, Second Edition. 341 pp.

Brownlow, A. 1979. Geochemistry. Prentice-Hall Inc. Englewood Cliffs, New Jersey. $498 \mathrm{pp}$.

Deluxe Map of Forida. Rand McNally Corp., Chicago, Illinois, 1991.

Evans, L. J. 1989. Enviton. Sei. Technol. 23: 9; pp. 1046-1056. Chemistry of Metal Retention by Soils.

FitzPatrick, E. A. 1980, Soils: their formation, classification, and distribution. Longman, London, 353 pp.

Hoffmeister, J. E. 1974, Land from the Sea; the Geologic History of South Florida. University of Miami Press, Coral Gables, Florida. 143 pp.

Kabata-Pendias A. K, and H. Pendias, 1984. Trace elements in soils and plants. CRC Press, Boca Raton, Florida. $315 \mathrm{pp}$.

Sposito, G. 1989, The chemistry of sols, Oxford University Press, New York. $277 \mathrm{pp}$ 


\section{APPENDIX A}

\section{SITES SAMPLED BUT NOT ANALYZED}

A. Cores were oblained from these sites, however, they were not used in the present study.

WCA3BI core was collecied from the francis 8 . Taylor Preserve. The approximate latitude was $25045^{\circ} 45^{\prime \prime} \mathrm{N}$ and the longitude was $80030^{\prime} \mathrm{W}$ and is found on the Coopertown, Florida quadrangle. The core was recovered from the shallow muddy nats next to the boat ramp for canal $C+4$, using the rigid plastic tube method.

WCA3B3 core was collected from the Francis B. Taylor preserve at approximately latitude $2504730^{\circ} \mathrm{N}$ and longitude $80030^{\circ} \mathrm{W}$ and is on the Coopertown, Flonida quadrangle. The sample was collected approximately 2 $\mathrm{km}$ north of canal C-4, using the rigid plastic tube.

CAL67A core (Conservation Levy 67A). The site is located at approximately latitude $2504530^{\prime \prime} \mathrm{N}$ and longitude $80040^{\circ} \mathrm{W}$ and is on the Long Island, Florida quadrangle map. The site is north of the Tamiami Trail $19.2 \mathrm{~km}$ west of US 27, approximately 3 meters north of the parking area between levy $67 \mathrm{~A}$ and $67 \mathrm{C}$, and 5 meters east of levy $67 \mathrm{~A}$ and was collected using the hand held piston corer.

TP-1 core (Turkey point). The site is located at approximately latitude $25027^{\circ} \mathrm{N}$ and longitude $80021^{\circ} \mathrm{W}$ and is on the Arsenicker Keys, Florida quadrangle map. The site is in a hammock 10 meters south of SW 344 th $\mathrm{St}$ and $1.8 \mathrm{~km}$ east from $117 \mathrm{th} \mathrm{St}$. The core was recovered with the rigid plastic tube.

BFP-1 core (Homestead Bayfrom park). The site is located at approximately latitude $25028^{\circ} \mathrm{N}$ and longitude $80021^{\prime} 15^{\prime \prime} \mathrm{W}$ and is on the 
Arsenicker Keys, Florida quadrangle. The site is in a hammock 5 meters south of SW $328 \mathrm{th} \mathrm{St}$, approximately $.66 \mathrm{~km}$ west of the entrance to Homestead Bayfront Park. The rigid plastic fube was used.

CSR +1 core (Card Sound Road). The site is located at approximately latitude $25024^{t} \mathrm{~N}$ and longitude $80027^{\prime} \mathrm{W}$ and is on the Homestead, Florida quadrangle map. The site is 15 meters west of Card Sound Road and 2 meters souh of the westbound unimproved road south of the Naval Reservation and nonh of the quary and radio towers. The core was collected with the rigid plastic tube.

EGNP-3 core (Everglades National Park). The site is located at approximately latudude $25025^{\prime} 30^{\prime \prime} \mathrm{N}$ and longitude $80040^{\prime} 45^{\prime \prime}$ and is on the Long Pine Key, Florida quadrangle map. The sample was collected east of the Pinelands Trail and approximately 20 meters north of old US 27 using the rigid tube.

B. Surface samples were collected from these sites because the sites were not suitable for coring. These samples were retained for future study.

\$-333 surface sample (South Florida Water Management District spillway $\mathrm{S} .333$ ). The site is located at approximately latitude $250450^{\prime \prime} \mathrm{N}$ and longitude $80^{\circ} 40^{\prime} 30^{\prime \prime} W$ and is on the Long Istand, Florida guadrangle. The sample consisted of botom sediments from canal $\mathrm{C}-11$ and was collected upstream from gate $\mathrm{S}-333$ and canal $\mathrm{C}-4$. Upstream as defined by $S \mathrm{FWMD}$ is from the same side of the cement barrier where the metal gate rests in the water.

$50 \mathrm{MB}$ surface sample (Finty Mile Bend Primitive Campground). The site is located approximately latiude 25051' $\mathrm{N}$ and longinde $8005530^{\prime \prime}$ W and 
is on the Fifty Mile Bend, Morida quadrangle. The sample was taken from the bothom sediments of a small canal which is not recorded on ether the topographical map or the South Florida Water Management District map, 15 meters west of the northwest comer of the rock lake.

MSLR surface sample (Monroe Station Logging Road). The site is located at approximately latitude $25047^{\circ} 30^{\circ} \mathrm{N}$ and longitude $81006^{\circ} \mathrm{W}$ and is on the Monroe Station, Florida quadrangle. The site is 3 miles south of US 41 in Monroe Station and 2 meters east of the old logging road.

FCEG-2 surface sample (Frog City Everglades). The site is located at latiude $25043^{\circ} \mathrm{N}$ and longitade $8003630^{\circ} \mathrm{W}$ and is on the South of Coopertown, Florida quadrangle. The sample is from the mud at the edge of a cut into the hammock 10 meters east of the FCEG-1 sample site.

HDWD surface sample (Koward Drive West Dade). The site is located at approximately latiude $25038^{\prime} \mathrm{N}$ and longitude $80031^{\prime} \mathrm{W}$ and is on the South of Coopertown, Florida quadrangle. This sample was taken in Dade county 10 meters south of Howard Drive (SW 136th Ave) approximalely half way between SW 217th and $212 \mathrm{~m}$ Avenues.

NWPP surace sample (Navy Well Pineland Preserve). The site is located approximately at latifude $25026^{\circ} \mathrm{N}$ and longitude $80030^{\prime} 30^{\prime \prime} \mathrm{W}$ and is on the Royal Palm Ranger Station, Florida quadrangle. It is 30 meters south of the parking area in the Navy Wells Pineland Preserve, approximately $.2 \mathrm{~km}$ west of state road Florida 9336. south of Florida City and north of the Dade County Correctional Instifution.

TP-2 surace sample (Turkey point). The sile is approximately 15 meters from the north side of $\mathrm{SW} 344 \mathrm{th} \mathrm{St}$ and the Florida City canat at 
latilude $25027^{\circ} \mathrm{N}$ and longitude $80020^{\prime} 45^{\circ} \mathrm{W}$ and can be found on the Arsenicker Keys, Florida quadrangle.

S-178 surface sample (South Florida Water Management District spillway S-178). The site is located at approximately latiude $2502430^{\prime \prime} \mathrm{N}$ and longitude $80033^{\prime} 30^{\circ} \mathrm{W}$ and is found on the Royal Palm Ranger Station, Florida quadrangle. The sample is from the canal botom in approximately .8 meters of water, downsteam from gate $\$-178$ on the $C+11$ L canal just of Florida 9336 route which leads 10 Flamingo, Florida. Downstrean in the context of the South Florida Water Management District is the opposite side of the cemont barrier from where the metal gate rests in the water.

EGNP-1 surface sample (Everglades National Park). The site is located at approximately latitude $25024^{\prime} 30^{\prime \prime} \mathrm{N}$ and longitude $80037^{\prime} 30^{\prime \prime} \mathrm{W}$ and is on the Long Plne Key, Florida quadrangle. The site is off the hiking/biking trail which wends east from the road leading from Florida 9336 to the Long Pine Key campground. The site is approximately .3 $\mathrm{km}$ east of the road near a very sharp bend toward the south and approximately 5 meters north of the bend in the trail. 


\section{APPENDIX B \\ SAMPLE COLLECTION}

Samples were collected by the use of some lype of coring apparatus, the selection of which was dependent upon the conditions encountered at any particular sampling site. The three types of coring apparatus which were selected and transponted to the field were 1) the Wildco Hand Cores 2420 , 2) a hand built, hand held piston coring device constructed from plastic lubing and silicon cauk, and 3) a rigid plastic tube of acrylic or cellulose acetate butyrate (CAB).

The wildeo Hand Corer is a device intended for shallow water coring in fresh, salt or brackish water. It consists of a brass core tube into which is inserted a $50.8 \mathrm{~cm}$ long liner tube of a chemically clean plastic such as $\mathrm{CAB}$, polycarbonate (Lexan) or acrylic (Plexiglass). The top of the unit contains a flutter valve which seals creating a partial vacum to prevent loss of the sediment upon retrieval. The bottom of the unir has an optional eggshell core catcher and nosepiece which are used to prevent washout of the sample. The unit has attachable handles whereby the end of the corer can be placed at the sampling site, pushed into the soil or sediment and then using the handles may be pulted free (Wildco Hand Corer Descriptive Pamphlet, Wildife Supply Company).

The second coring apparatus is a piston coring device constructed from two lengths of acrylic and $\mathrm{CAB}$ tubing of slightly different interior diameters. The smaller bored tube is seated in the larget bored lube and the space between is sealed by a snug fitting layer of silicon caulk which has been applied to the smaller tube, allowed to dry and then trimmed to fit with a razor blade. This caulked surace is then lightly lubricated with an 
inert vacuum grease allowing the two tubes 10 fut together, yet be adjustable and have a waterproof seal. The two tubes are placed on the sampling site surace and the outer tube is advanced downward into the sediments while the inner tube is gently pulled upward as the sediments enter the outer sampling tube.

The third sampling apparatus is to use a rigid plastic tube such as CAB. In this method the tube is placed at the sampling site, covered with a heavy board which is then struck with a hammer until the desired depth is reached. The tube is then removed with the sediments inside.

Once a sample obrained it is capped on both ends with plastic caps to prevent leakage or loss and the tube and caps are labelled with the site llame. The site name and location are recorded in the field notebook. The samples are then transported upright, to avoid disturbing any sedinentary structures which might be present, to an upright freezer where they are placed until frozen. Once frozen the cores are transferred in a recreational cooler (ice chest) to a freczer on campus where they are stored until prepared for analysis. 


\section{APPENDIX C}

\section{SAMPLE PREPARATION AND CHEMICAL ANALYSIS}

\section{Exambation and Division}

The frozen cores were transported to the fru physics deparment in a cooler where each frozen core was cut in half lengthwise with a band saw. Each half-core was wrapped securely in plastic wrap, labelled, renumed to the cooler, and transpored back to the geology deparment. Since the cut surface was now contaminated by the metal of the band saw the surfaces wete then cleaned using a teflon spatula. One pass was made across the width of the half-core with the teflon spatula removing the cut surface which had contacted the band saw. The spatula was then rinsed with tap water, then again with deionized, distilled water, and dried with a Chem wipe betore again coming in contact with the core. Rock fragments that were exposed to the band saw werc removed, washed with distilled, deionized water and replaced. Leaf litter, identifiable plant material located at the top of the core was removed.

Once the cut surfaces were removed the cores were photographed, and one half-core from each core sel aside for archival purposes. The remaining half core was then observed and described.

Once fully described, the hal-core was then divided into segments using a teflon spatula and taking care to avoid contamination between segments by rinsing as described above. Each segment was placed into a clean 4 ounce glass jar and labelled with its site location and numerically with denoting the lop segment. The division into cores had to be done in such a way as to try 10 allow adequate sample to be avaitable for andysis in each segment. Sample size was not a fixed constaint, but varied from 
segment to segment depending upon the stratigraphy of the material being segmented.

Each uncapped segment was dried in a $1100 \mathrm{C}$ oven. During drying the samples were trequenty sirred with a teflon spatula kept clean as detailed previously. This served to homogenize the samples and prevent clumping during drying. Once dry, the samples were removed and placed in the desiccator until cooled, then closed with labelled caps.

The cooled, dried samples were then sieved through an 18 mesh sieve (1 $\mathrm{mm}$ sieve opening). The coarse fraction of eack segment was placed into a clean plastic bag or glass jar, labelled and saved for future reference. The fine traction of eacli segment was returned to the 4 omee glass jar and recapped.

\section{Chemical Preparation}

Extraction of Fulvic and Humic Acids

1. A $4 \mathrm{gram} \pm .0040$ aliquot was removed from each fine fraction with the exception of these three samples, the weight of which comprised the entire fine fraction of each sample:

WCA3B2 1

WCA3B2-3 $\quad 3.0527 \mathrm{~g}$

WCA3B2-4 $\quad 3.0238 \mathrm{~g}$

2. Each $4 \mathrm{~g}$ aliquot was placed into a labelled centrifuge tabe and added to each was $40 \mathrm{ml}$ of $0.1 \mathrm{~N}$ sodium hydroxide (NaOH). The centrifuge tubes were capped and shaken for one hour on the wrist action shaker. 
3. After shaking was completed the supermatant fuid from each tube was filtered hrough a 40 Whatman filer paper in a plastic funnel into a clean, labelled glass beaker. They were allowed to rest for one hour to ensure all supernatant fluid had passed through the filter papers. The centrifuge tubes with the drained residue were capped and saved for the carbonate dissolution.

4. The supernatant was acidified to pH 1 by the addition of $4 \mathrm{ml}$ of $1.5 \mathrm{~N}$ nitric acid $\left(\mathrm{MNO}_{3}\right)$ to the beaker. The resulting precipitate was the humic acid; the fulvic acid remaned in solution.

5. The solution from each beaker was filtered through 40 whatman filter paper into clean, labelled centrifuge tubes to separate the humic acid from the fulvic acid.

6. The fulvic acid fraction was then diluted to a volume of 35 min by the addition of $0.1 \mathrm{~N} \mathrm{HNO}_{3}$ and capped.

\section{Dissolution of Humic Acid}

1. The precipiates from the above separation (humic acid) were each washed from the filter paper into a clean, labelled glass beaker using 1.5 $\mathrm{NHNO}_{3}$. (CSRA 1 was lefe ovemight to drain and the humic acid was unsalvagable as it would not rinse from the lller paper. This was discarded and repeated for this sample.)

2. The beakers were placed on a hot plate and the solutions allowed to evaporate to dryness.

3. To each beaker of dry residue $2 \mathrm{ml}$ of $\mathrm{HNO}_{3}$ was added. The solutions were again allowed to evaporate 10 dryness on the hot plate. 
4. Step three was repeated.

5. To each beaker of dry residue was added $4 \mathrm{ml}$ Aqua Regia (3ml $12 \mathrm{~N}$ $\mathrm{HCl}$ and $1 \mathrm{ml} 15.7 \mathrm{NHO}_{3}$.

6. The sofutions in the beakers were again brought to dryness on the hot plate.

7. The dried residue in each beaker was brought to a volume of $35 \mathrm{ml}$ by the addition of $1 \mathrm{NHCl}$. The solutions of dissolved humic acid were then transferred to clean, labelled centrifuge tubes and capped.

\section{Carbonate Dissolution}

1. The residue from step 3 of the extraction of fulvic and humic acid had been saved for each aliquot weighed out. Each centrifuge tube of residue was washed into a clean. labelled dry glass beaker using $\mathrm{HCl}$. Care was taken to keep the volume less than $30 \mathrm{mls}$. (FCEG1-3 was dinted to $40 \mathrm{ml}$ ).

2. The conents of the beakers was allowed to effervesce for approxim ately 10 minules, the beakers were switled occasionally.

3. The contents of the beakers were then filtered through 40 Whatman filter paper in a funnel into clean, labelled centrifuge tubes and capped. (One drop of FCEG1-3 was spilled).

4. The residue from each beaker was rinsed through the filter paper with $\mathrm{HCl}$ and allowed to filter through.

5. This solution was discarded.

6. The residue in the flifer papers were allowed to air dry Each filter paper was wrapped in plastic, labelled and saved for possible future analysis. 
7. The solutions in the labelled centrifuge tubes from step 3 were then diluted to a volume of $30 \mathrm{ml}$ with $1 \mathrm{NHCl}$

\section{Whole soil analysis}

1. The samples (previously aried to 1100 C) wete heated to $5500 \mathrm{C}$ to decompose the organic compounds which are resistant to aissolution. (A portion of the more volatile elements may have been lost during this procedure).

2. A 0.5 gram aliquot from each sample was weighed out and placed into a 30 ml teflon beaker.

3. $4 \mathrm{ml}$ of concentrated $\mathrm{HCl}$ was then added to each aliquot in the beakers and allowed to effervesce.

4. Once the effervescence ceased, $1 \mathrm{ml}$ of concentrated $\mathrm{HNO}_{3}$ was added to the solutions to oxidize any remaining organic compounds.

The samples were then treated as silicate/oxide mixures.

5. To the solutions in the beakers was added $3 \mathrm{ml} H F$ and one drop of perchloric acid.

6. The beakers were covered and the samples allowed to digest overnight.

7. The following day the samples were brought to dryness on the hot plate which drove off the Ho plus the Si as SiF4 and left the remaining cations as perchlorates.

8. The samples were picked up in $6 \mathrm{~N} \mathrm{HC}$ and then brought to dryness.

9. The previous step was repealed. 
10. The aried residue in each beaker was finally dissolved in $25 \mathrm{ml} 1 \mathrm{~N}$ $\mathrm{HCl}$

Trace metal grade reagents were used for this procedure and a blank (including all of them) was also analyzed. The whole soil analysis gives the composition of the whole sample. 
APPENDIX D

VOLATILE LOSS PROCEDURE

1. The samples were allowed to dry for 24 hours at $1100 \mathrm{C}$.

2. Approximately one gran of each sample was weighed into ia previously weighed quartz crucible.

3. The samples were heated to $5500 \mathrm{C}$ for one hour.

4. The were allowed to dry in a desiccator cabinet and reweighed.

The weight lost between $1100 \mathrm{C}$ and $550^{\circ} \mathrm{C}$ is the result mainly of the decomposition of organic material and the dehydration of clay and oxides if present.

5. The samples were heated to $10000 \mathrm{C}$ for one hour.

6. Step 4 was repeated.

The weigh lost between $5500 \mathrm{C}$ and $10000 \mathrm{C}$ is produced by the decarbonation of carbonate.

Each weight lost is a tough estimate of the proportion of each sample that is organic matter and calcium carbonate. 
Table 8

Volatile Loss Study

Percent weight lost as a result of heating to $5500 \mathrm{C}$ and $10000 \mathrm{C}$

\begin{tabular}{|c|c|c|c|c|}
\hline SITES & SAMPLEWT & $\times 550^{\circ} \mathrm{C}$ & $>550^{\circ} \mathrm{C}$ & \\
\hline LOTI-1 & 1.003 & $27.069 \%$ & 28.076 & $\%$ wt. loss \\
\hline IOTI.2 & 1.001 & 15.974 & 33.147 & \\
\hline LOTI.3 & 1.003 & 13.335 & 33.483 & \\
\hline LOT1-4 & 1.002 & 13.795 & 31.783 & \\
\hline FIU-1 & 1.000 & 6.870 & $\$ .900$ & \\
\hline FIU.2 & 1.000 & 0.644 & 1.640 & \\
\hline FIU-3 & 1.002 & 5.998 & 1.268 & \\
\hline FIU-4 & 1.002 & 4.450 & 0.718 & \\
\hline Flu. 5 & 1.000 & 2.309 & 0.300 & \\
\hline Fit 6 & 1.003 & 2.932 & 1.057 & \\
\hline Fiul 7 & 0.999 & 2.322 & 29.176 & \\
\hline FUU.8 & 1.000 & 1.579 & 38.331 & \\
\hline WCA3B2-2 & 1.003 & 11,168 & 38,508 & \\
\hline FCEGT. & 1.004 & 20.990 & 21.588 & \\
\hline FCEG1-3 & 1.007 & 21.560 & 23.953 & \\
\hline FCEOT-3 & 1.007 & 17.562 & 25.608 & \\
\hline FCEG 4 & 1.005 & 3.3 .42 & 24.923 & \\
\hline FCEGI.5 & $\$ .001$ & 10.120 & 27.173 & \\
\hline CSRA. 1 & 1.002 & 28.020 & $\$ 3.037$ & \\
\hline CSRA.2 & 1.002 & 17.136 & 13.373 & \\
\hline CSPA. 3 & 1.001 & 4.505 & 15.023 & \\
\hline $\operatorname{csm} A-4$ & 1.002 & 11.251 & 16.172 & \\
\hline CSRA-5 & 1.002 & 41.354 & 6.530 & \\
\hline CSRA. 6 & 1.004 & 26.958 & 2.500 & \\
\hline
\end{tabular}




\section{APPENOIX E}

\section{RAW DATA AND DATA QUALITY}

The following tables contain raw data obtained from the chemical analyses in the siddy. The element concentrations are recorded as parts per million in the sample solutions. For whole soil analyses the ppm in the soll sample is also indicated for comparison with published values.

In order to ensure accurate results and optimize reproducibility, the ICP was calibrated to standards used for the elcments analyzed in the study. The standards ased for the high calibration were obtained from the US Bureau of Standards and diluted to the necessay strength. The low standard consisted of an acid solution which was essentially blank for the elements in question. The lCP instrument was recalibrated to these standards after the aralysis of every loth sample to ensure lomgterm precision.

Each value is the average of measurements taken over a one minate interval. Typical standard deviations for these values (in \%) are also listed on the table. 
ON

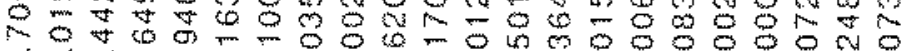

ठ 0 0ं

S

$\frac{0}{3}$
$\frac{1}{3}$
0
0

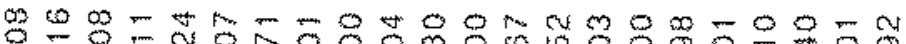
अ - d 0ं

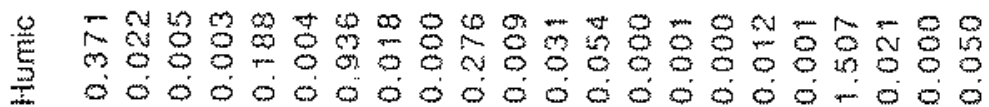

os

$\min _{0,5}^{\infty}$

$x$
0
0
0
0

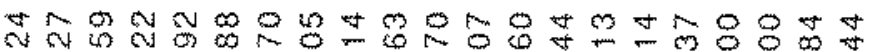

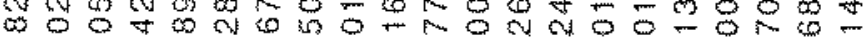

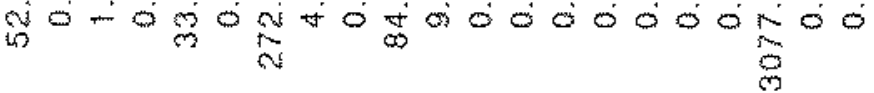

0
0
0
0
0
0

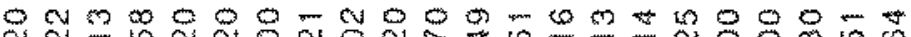

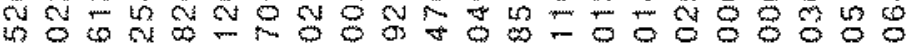

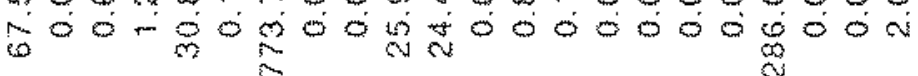
$\omega$ क

小心

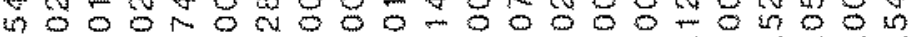
- 0 0 0 क 0 क

$\frac{5}{6}$

5

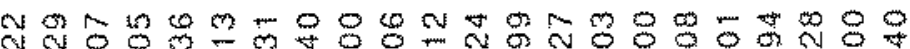

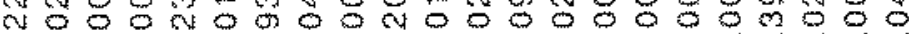

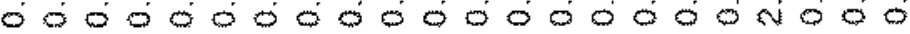

$\frac{x}{3}$

Nom tom जक

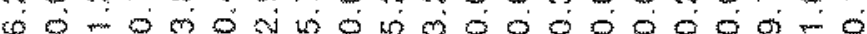

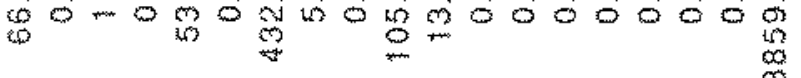

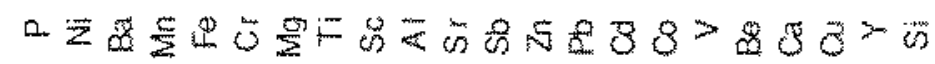




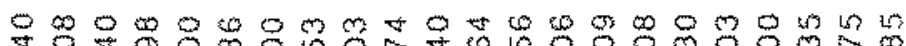
N 6 ज

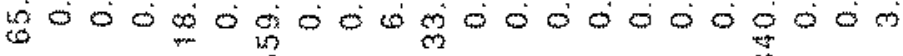

$\frac{15}{8}$ $\stackrel{\infty}{\circ}$

लm m

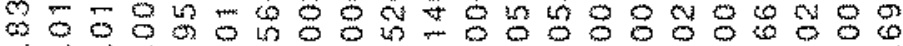
000்

世

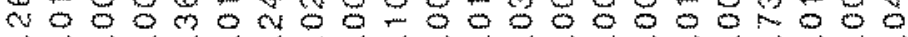

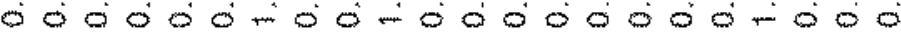

NAM

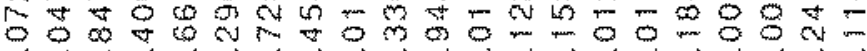

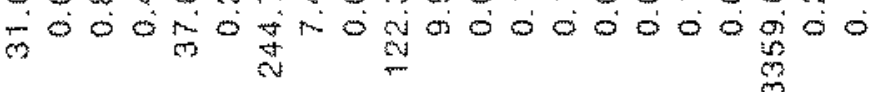

$\frac{5}{0}$

0

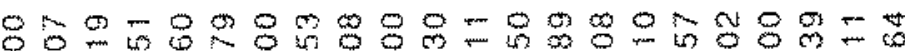

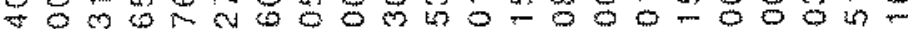

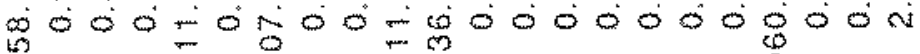

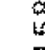

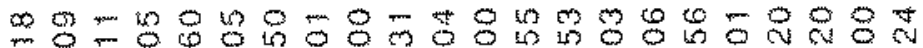

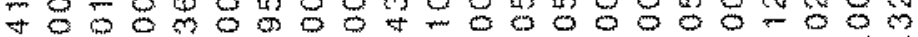

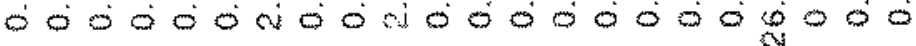

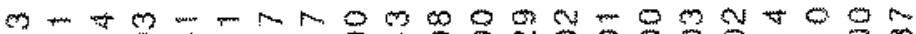
世

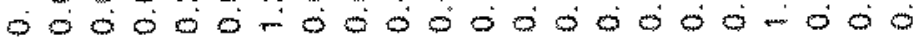

의 ๙ 0 \% m. O

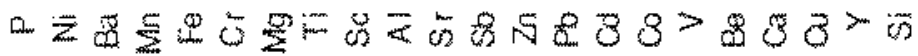




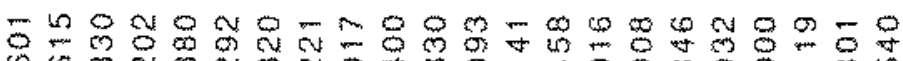

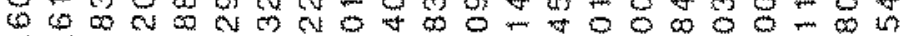
बino

5

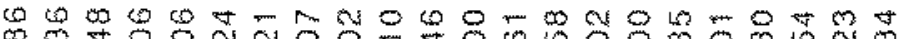

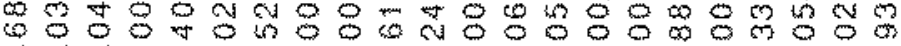

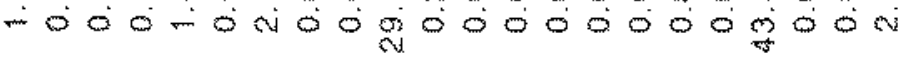

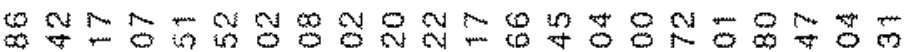
क०

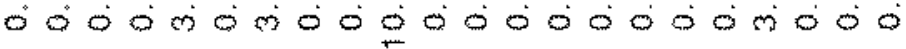

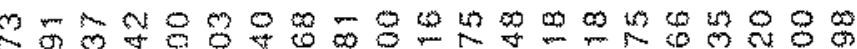

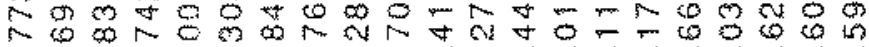
mono mo a d a w 0 क

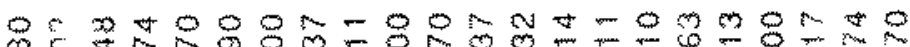
क ᄃ म क त

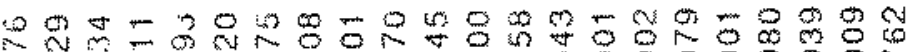

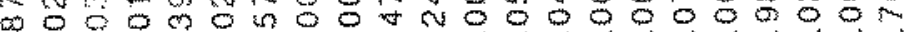

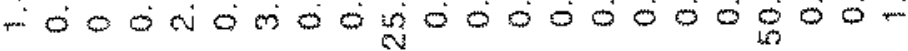

(1)

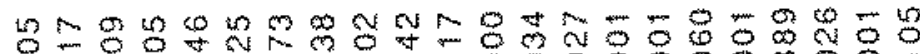

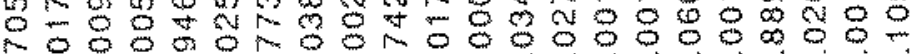

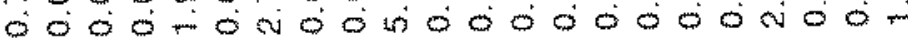

OSNOMOOUO-

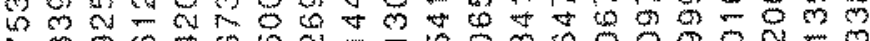

mo w w w w

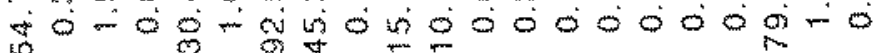
in $\frac{5}{6}$ $\infty$

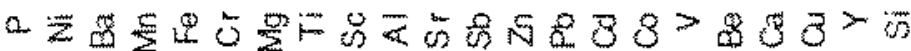




\begin{tabular}{|c|c|c|c|c|}
\hline $\operatorname{csn} A$ & Bulk sigma & Carb sigma o: & H.A. sigma $\%$ & F.A sigma $\%$ \\
\hline$p$ & 1.44 & 1.84 & 23.18 & 8.55 \\
\hline $\mathrm{Ni}$ & 18.56 & 35.80 & 30.43 & 70.67 \\
\hline $\mathrm{Ba}$ & 1.40 & 1.80 & 23.18 & 11.67 \\
\hline $\mathrm{Mn}$ & 1.59 & 1.41 & 9.18 & 10.72 \\
\hline $\mathrm{Fe}$ & 4.60 & 1.51 & 9.85 & 1.13 \\
\hline $\mathrm{Cr}$ & 2.93 & 2.82 & 25.40 & 62.67 \\
\hline $\mathrm{Mg}$ & 1.57 & 1.43 & 4.22 & 1.16 \\
\hline $\mathrm{Ti}$ & 2.21 & 1.69 & 8.82 & 30.33 \\
\hline So & 2.65 & 8.87 & 17.70 & 58.67 \\
\hline $\mathrm{Al}$ & 1.90 & 1.89 & 1.76 & 0.87 \\
\hline $\mathrm{sr}$ & 2.45 & 1.35 & 1.04 & 1.11 \\
\hline So & 64.17 & 114.67 & 84.33 & - \\
\hline 20 & 1.82 & 2.04 & 5.08 & 4.33 \\
\hline $\mathrm{Pb}$ & 4.17 & 24.80 & 24.90 & 60.00 \\
\hline$c d$ & 5.33 & 20.83 & 167.50 & 100.50 \\
\hline$\infty$ & 4.80 & 32.33 & 210.00 & 370.25 \\
\hline$V$ & 2.06 & 80.17 & 22.10 & 2.48 \\
\hline $\mathrm{Be}$ & 3.28 & 248.83 & 190.00 & 513.33 \\
\hline $\mathrm{Ca}$ & 1.13 & 2.47 & 1.49 & 1.02 \\
\hline$d$ & 1.35 & 7.40 & 8.77 & 4.02 \\
\hline$Y$ & 1.20 & 3.09 & 204.33 & 72.42 \\
\hline $\mathrm{Si}$ & & 2.01 & 10.33 & 3.60 \\
\hline
\end{tabular}




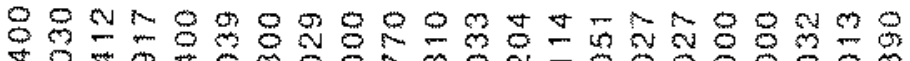

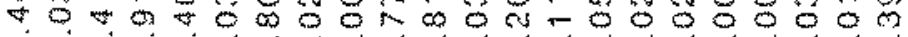
赑

?

no n०50\% Nó0

0

Nnow

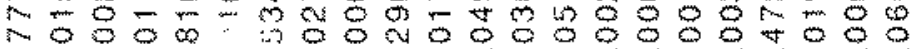

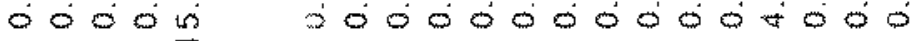

@

\%

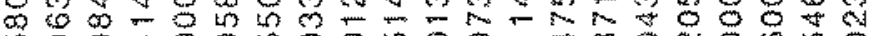

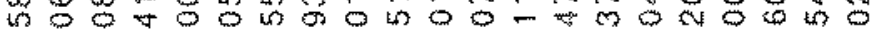
के ली

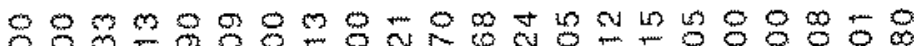

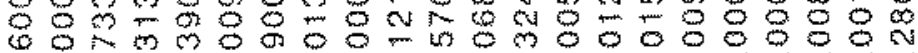

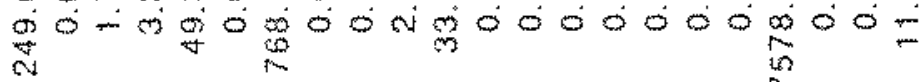

药

\%m-

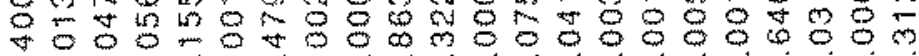

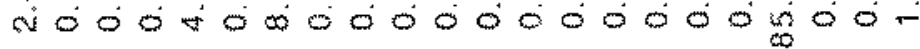

岁

9
0
0
0
0
0
0

N"

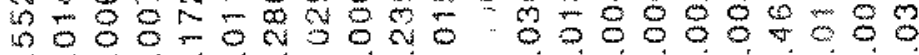

óóñ odoc

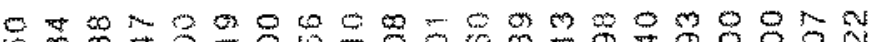

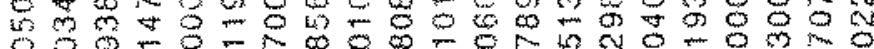

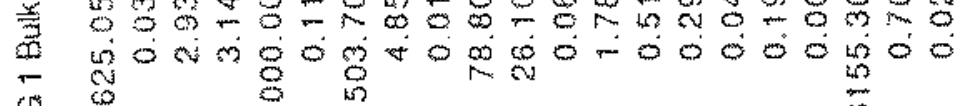

(4)

int

8 क

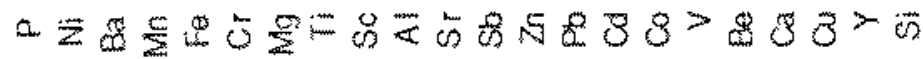




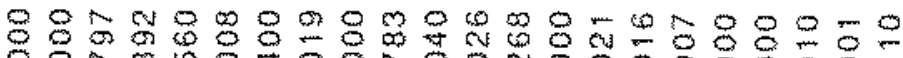

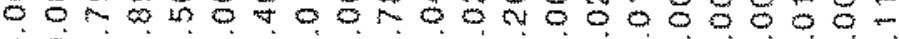

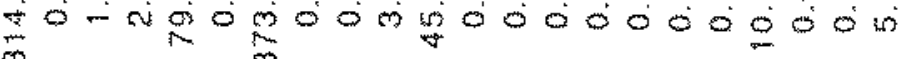
m

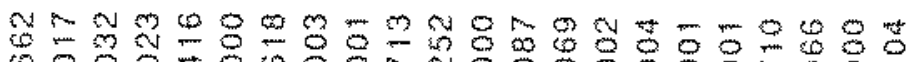
की

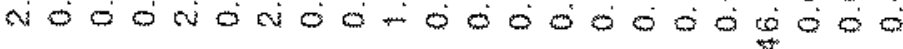

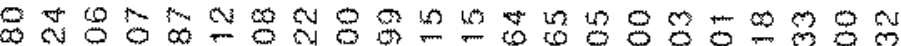

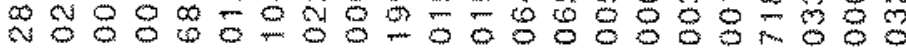
000 0 -

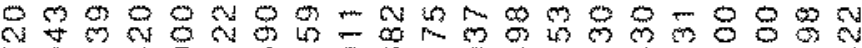

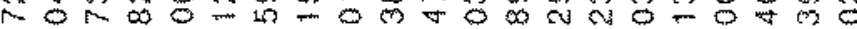

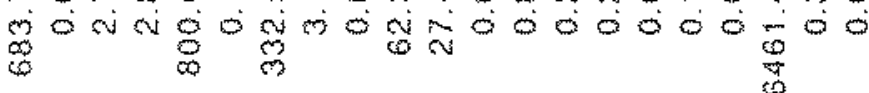

에

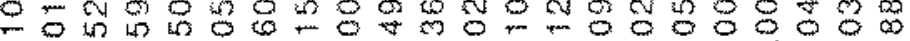

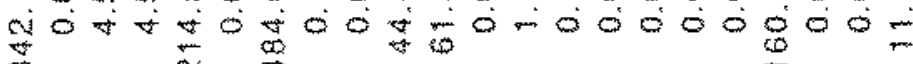
क क क

क त ल 내유 तो

崖

$\frac{2}{3}$

O \% 0 0 0

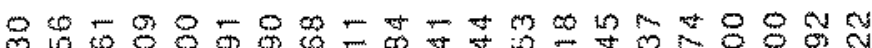
जम

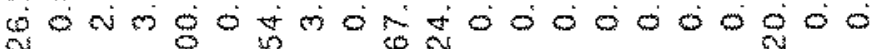
is 员

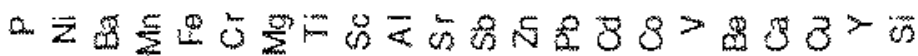




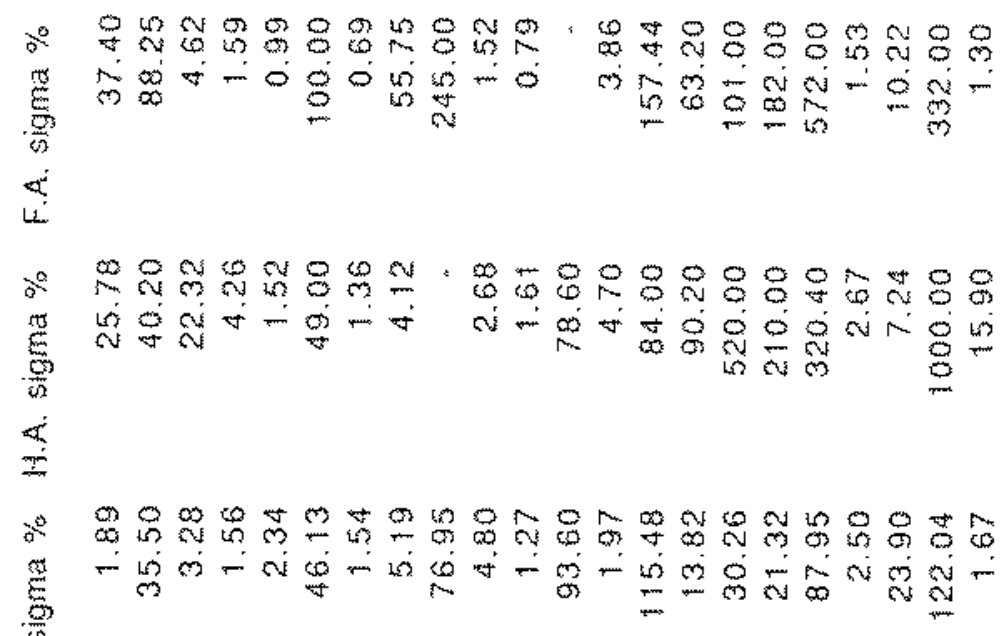

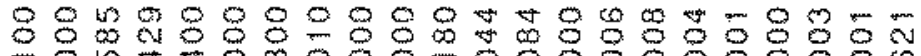
แ सं

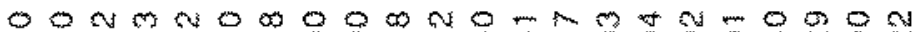

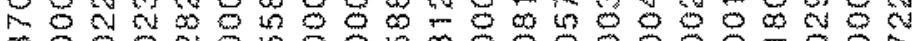

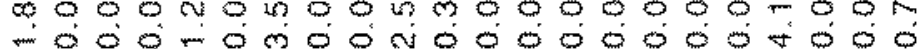

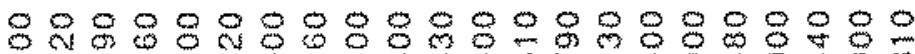
(लm क

- 0 in

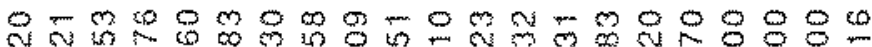

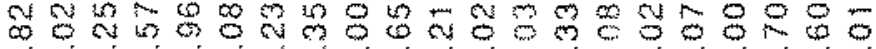
की

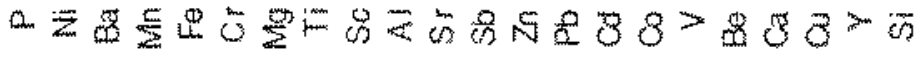




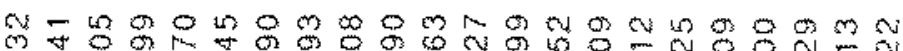
तु 2 स

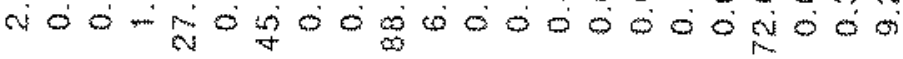
心

노

$m=$ m m ल5 एक

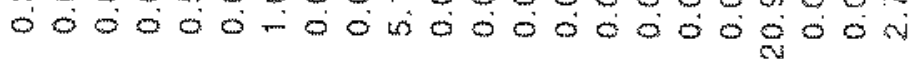

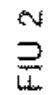

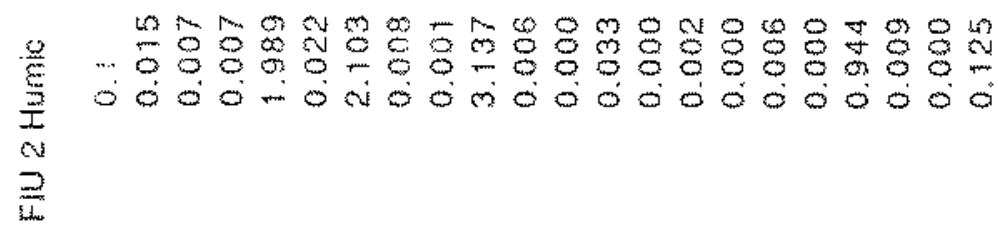

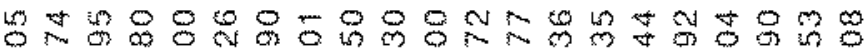

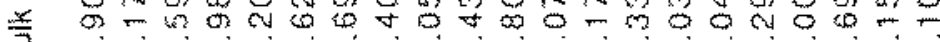

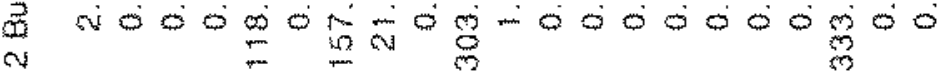

W.

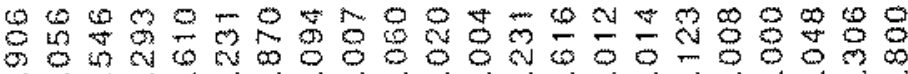

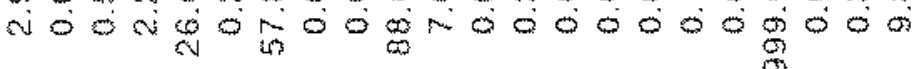

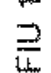

는 m

ल०0 की 0800808800 के

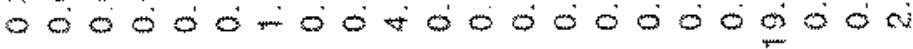

m

- 988 क

க00

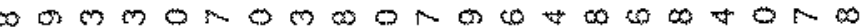

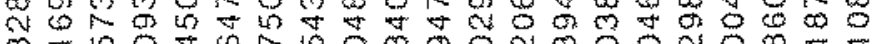

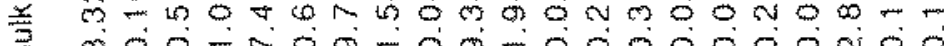

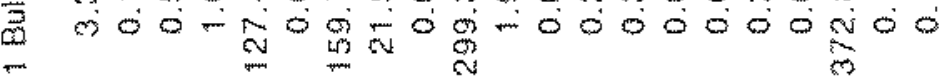

$\underline{i}$

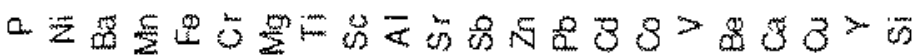




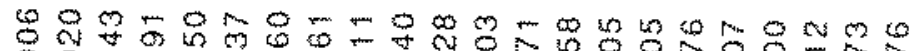

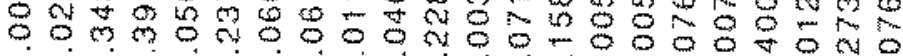

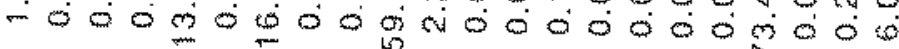

$?$

स

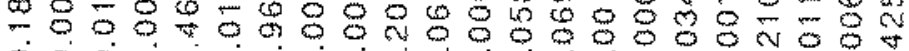

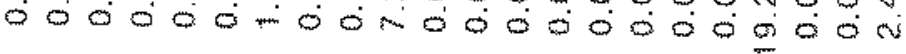

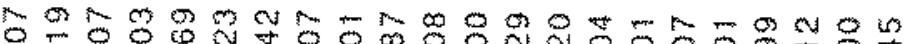
00 0 i

恙

क स

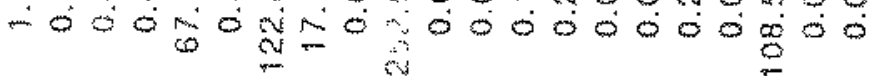

ल

in

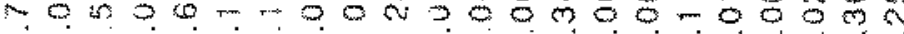
- o

$\stackrel{3}{2}$

0
$\frac{2}{3}$
0
0
0

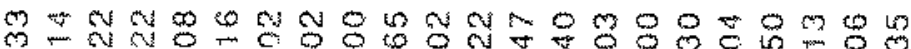

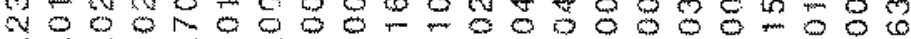
को

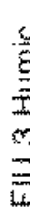

Wh $=$ m

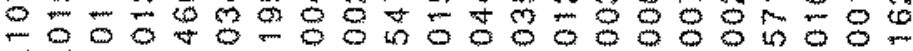

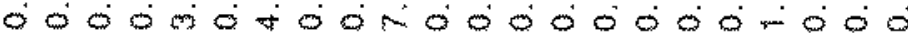

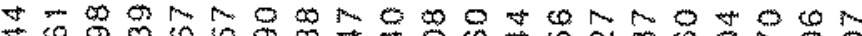

$\frac{x}{3}$

-

को

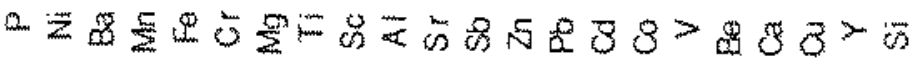




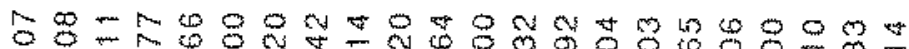

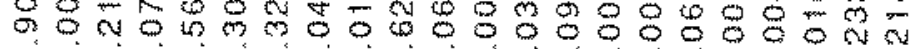
óóñóno 8

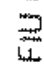

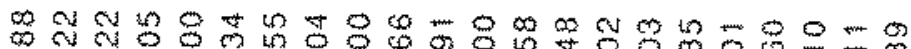

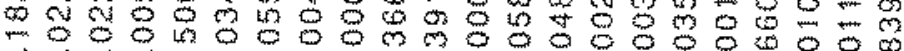

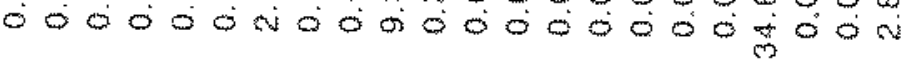

n o d

$\mathrm{N} N=\mathrm{O}=\mathrm{in}=0 \mathrm{~W}$

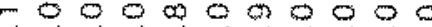

n

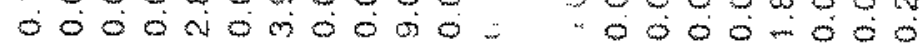

$\stackrel{1}{12}$

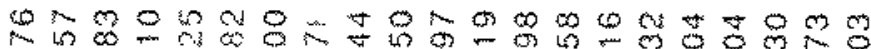

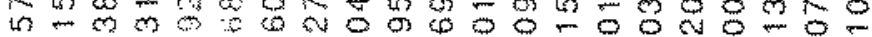

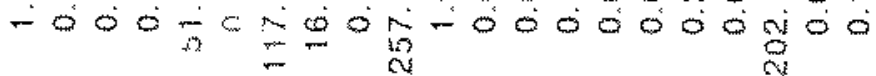

$\stackrel{2}{1 .}$

\%

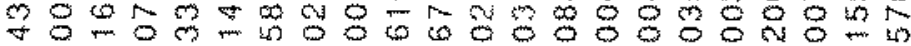
000 00 की

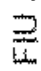

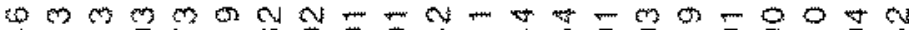
स

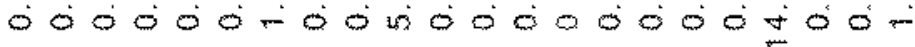

בn

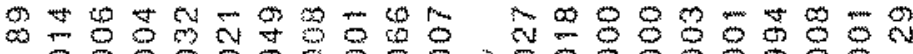

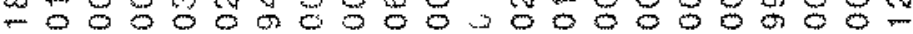

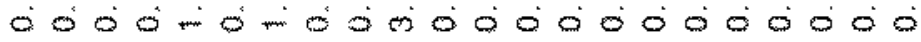

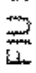

4

ब,

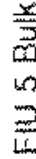

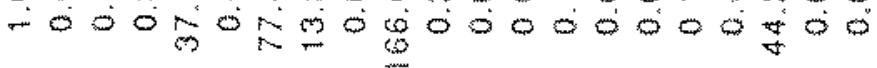

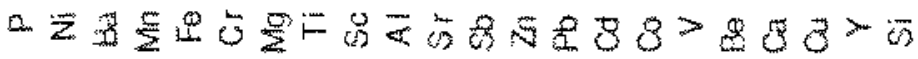




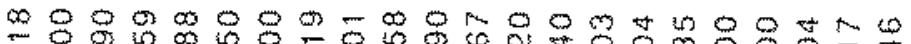
- ㅇㅇㅇㅇㅇㅢ

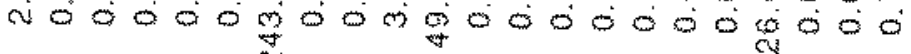
$\overline{0}$

\begin{tabular}{l}
$\frac{0}{3}$ \\
$\frac{1}{3}$ \\
0 \\
0 \\
\hline
\end{tabular}

Nong

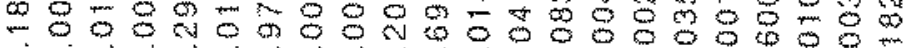
íb0

点

\%

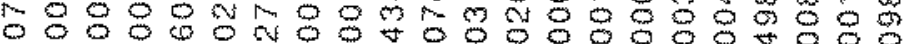

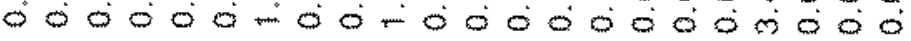

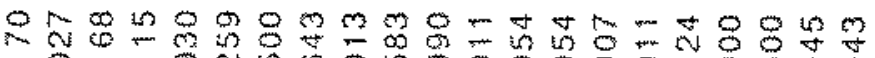

a 0 ?

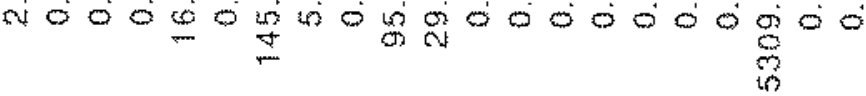

-

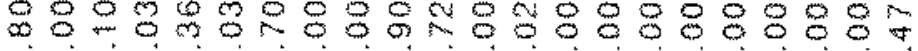

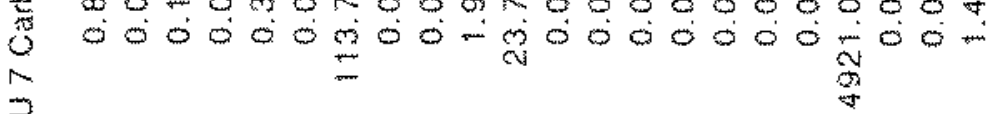

?

स

m5

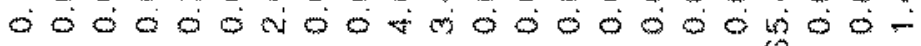

Li.

in

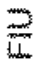

D

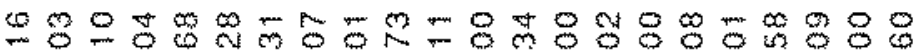

- $08080880888888808 \%$

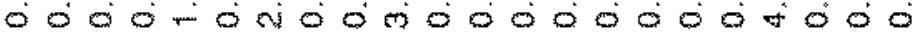

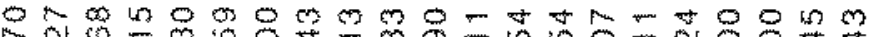

$\frac{x}{3}$
0
3
3

m5

No ó co

8

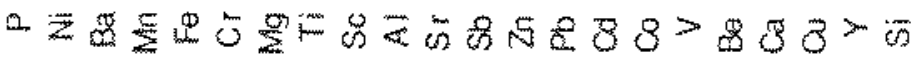


FU Buk sigma $\%$ Carb sigma $\%$ H.A. sigma $\%$ F.A. signa $\%$

$\begin{array}{rrrrr}P & 7.72 & 8.19 & 50.63 & 33.41 \\ \mathrm{Ni} & 13.32 & 39.80 & 95.50 & 46.83 \\ \mathrm{Ba} & 2.67 & 1.72 & 25.90 & 8.31 \\ \mathrm{Mn} & 2.18 & 1.27 & 4.20 & 4.50 \\ \mathrm{Fe} & 1.70 & 2.46 & 1.07 & 1.87 \\ \mathrm{Cr} & 3.41 & 6.98 & 15.63 & 28.11 \\ \mathrm{Mg} & 1.61 & 1.29 & 1.12 & 1.21 \\ \mathrm{Ti} & 1.96 & 2.48 & 13.33 & 54.25 \\ \mathrm{Sc} & 2.20 & 15.71 & 22.96 & 139.13 \\ \mathrm{Al} & 1.52 & 3.32 & 0.91 & 1.08 \\ \mathrm{SH} & 2.15 & 1.28 & 1.29 & 1.24 \\ \mathrm{Sb} & 56.27 & 235.76 & 94.00 & 195.00 \\ \mathrm{Zn} & 1.65 & 3.48 & 5.89 & 5.79 \\ \mathrm{~Pb} & 8.80 & 15.69 & 123.40 & 55.86 \\ \mathrm{Cd} & 4.45 & 81.99 & 79.38 & 130.75 \\ \mathrm{Co} & 6.46 & 59.14 & 250.00 & 167.50 \\ \mathrm{~V} & 1.45 & 45.96 & 32.10 & 9.55 \\ \mathrm{Be} & 4.10 & 157.40 & 313.19 & 363.25 \\ \mathrm{Ca} & 1.50 & 2.26 & 0.97 & 1.08 \\ \mathrm{Ou} & 2.77 & 12.49 & 16.28 & 24.85 \\ \mathrm{Y} & 1.57 & 1.78 & 131.82 & 8.74 \\ \mathrm{Si} & & 1.18 & 7.44 & 1.43\end{array}$


Tom-

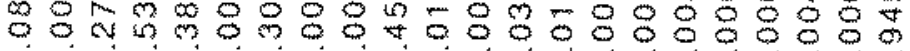

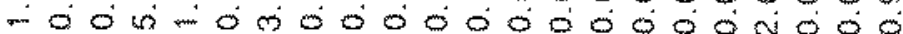

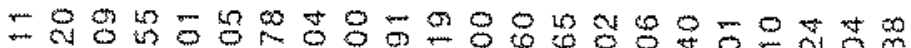
0000 용

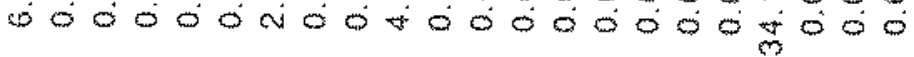

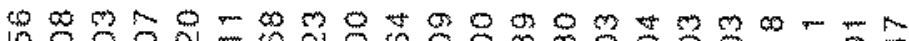

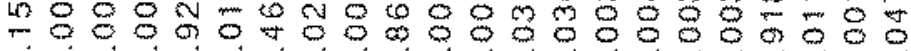

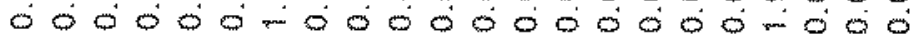

민

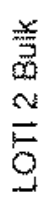

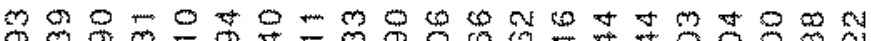

๓⿴囗十心

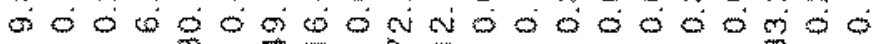

$\frac{0}{0}$

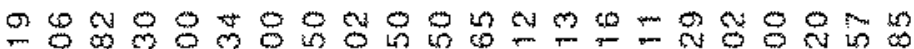
क

móm

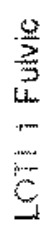

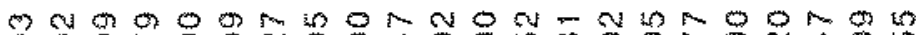

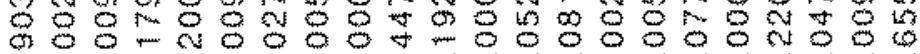
- ód

$\stackrel{5}{\underline{E}}$

NON

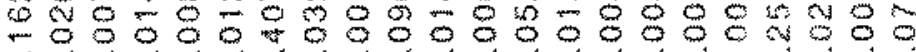
-

:

a NoO

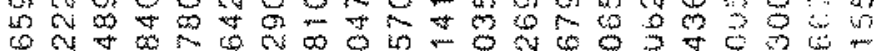

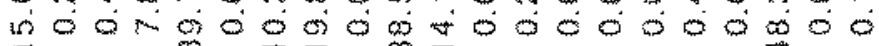

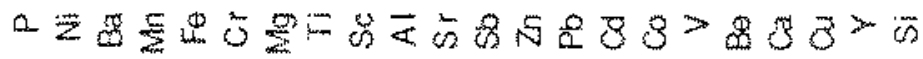




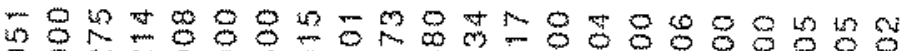

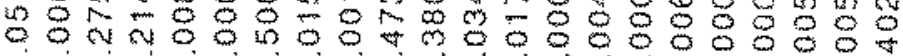

- 0 m-

$\stackrel{5}{0}$

-

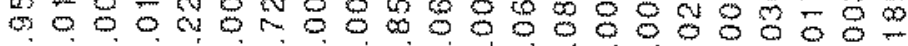

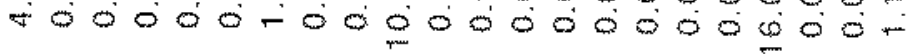

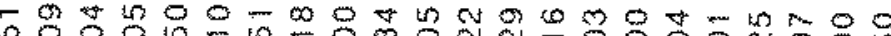

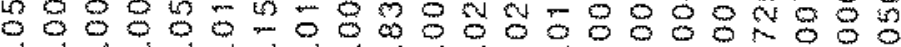

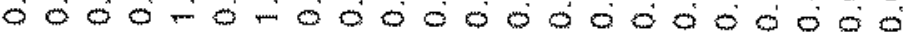

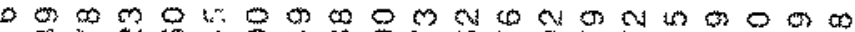

"ल

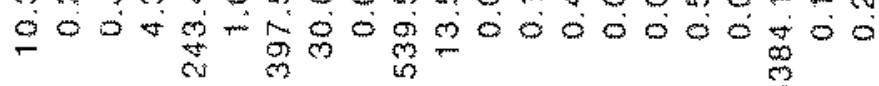

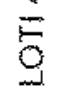

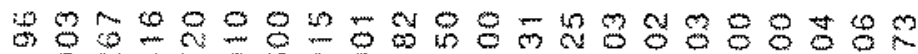

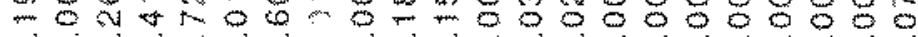

. 0 क

$\frac{m}{0}$

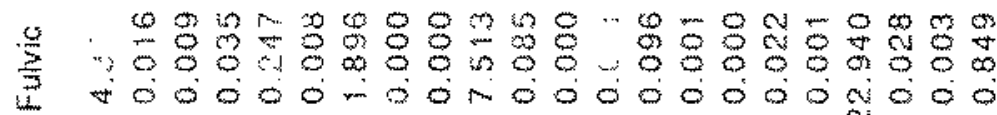

0

$\frac{5}{5}$

क-

\%

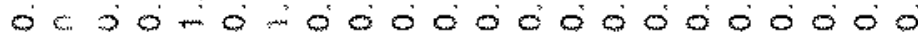

208

\# m

को

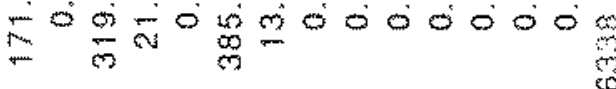

E

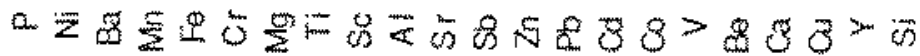




\begin{tabular}{|c|c|c|c|c|}
\hline $10 \pi$ & Bulk sigma \% & Carb sigma $\%$ & H.A. sigma \% & F.A. sigma $\%$ \\
\hline$p$ & 2.45 & 9.68 & 39.95 & 5.45 \\
\hline $\mathrm{Ni}$ & 5.65 & 170.00 & 52.25 & 207.50 \\
\hline $\mathrm{Ba}$ & 2.48 & 1.32 & 46.75 & 27.50 \\
\hline Mn & 1.77 & 1.05 & 7.92 & 2.20 \\
\hline $\mathrm{Fe}$ & 1.43 & 1.78 & 2.06 & 2,48 \\
\hline $\mathrm{Cr}$ & 3.98 & 191.30 & 28.00 & 71.00 \\
\hline $\mathrm{Mg}$ & 1.33 & 1.02 & 2.25 & 1.56 \\
\hline$T i$ & 1.67 & 3.23 & 4.35 & 50.33 \\
\hline $5 \mathrm{c}$ & 1.88 & 34.75 & 179.33 & 220.00 \\
\hline $\mathrm{Al}$ & 9.45 & 15.45 & 2.15 & 1.25 \\
\hline$S r$ & 1.96 & 5.15 & 2.46 & 1.48 \\
\hline $\mathrm{Sb}$ & 29.55 & 127.33 & 77.00 & 。 \\
\hline$Z n$ & 9.76 & 2.70 & 6.88 & 4.25 \\
\hline Po & 351 & 98.00 & 202,50 & 31.50 \\
\hline$c d$ & 2.02 & 35.25 & 68.00 & 85.33 \\
\hline$\infty$ & 2.87 & 47.33 & 66.00 & 69.00 \\
\hline$V$ & 1.81 & 23.00 & 43.75 & 90.53 \\
\hline $\mathrm{Be}$ & 2.89 & 87.50 & 263.70 & 585.00 \\
\hline $\mathrm{Ca}$ & 1.27 & 1.98 & 2.67 & 1.53 \\
\hline $\mathrm{Ou}$ & 1.81 & 28.40 & 15.43 & 7.82 \\
\hline Y & 2.13 & 9.97 & $\$ 72.50$ & 11.73 \\
\hline$\$ i$ & & 2.17 & 23.07 & 2.78 \\
\hline
\end{tabular}


0
0
0
0
0

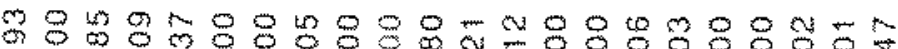
\% क

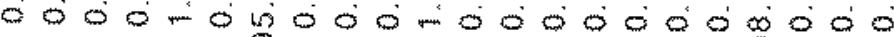

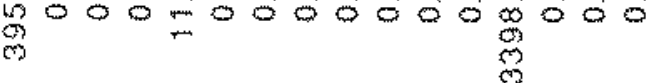

$\frac{3}{3}$

ष马@

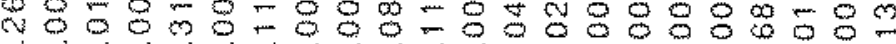

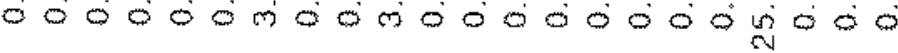

E

D.

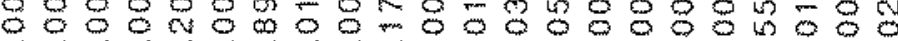

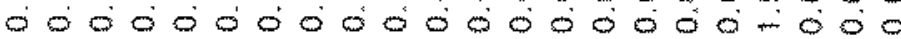

9800

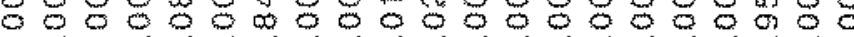

00000000000000000040

s)

$\frac{0}{0}$

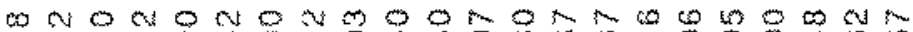
m

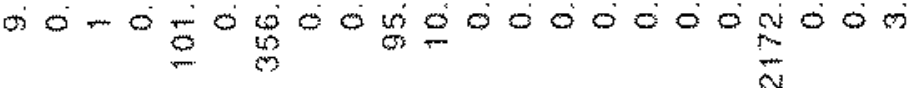

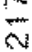

世 क० - 0 क क

3

$\frac{9}{5}$
3
$\frac{1}{9}$
0
0
0

क म \% 0 क 0ं 0 -

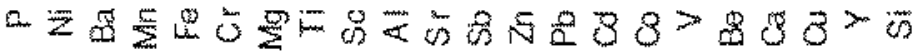




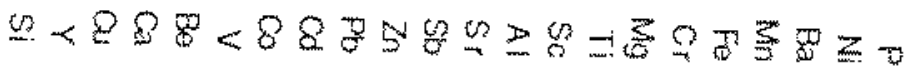

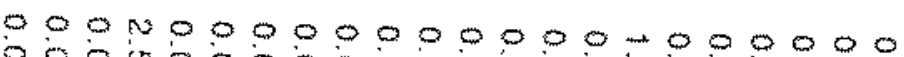

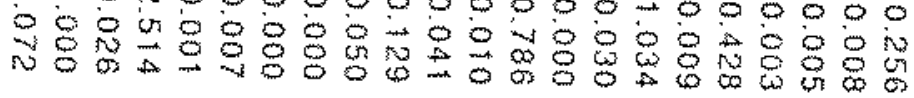

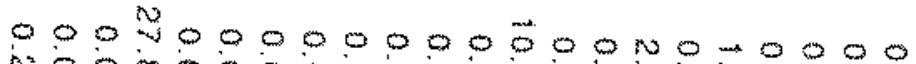

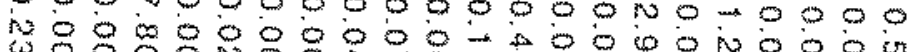
w.

$0000_{0}^{n}$

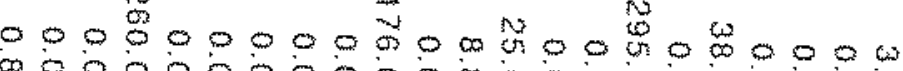

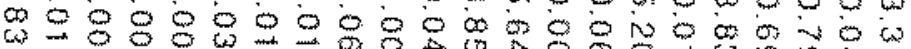

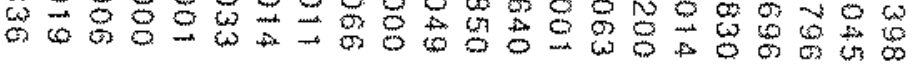

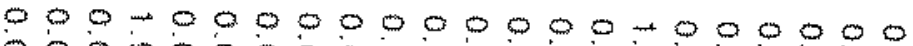
๑ᄋ

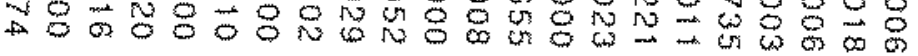

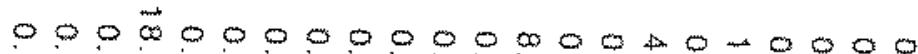
แ8 w 908 \%

\%

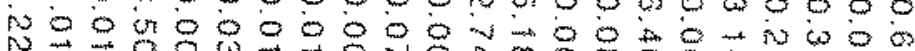

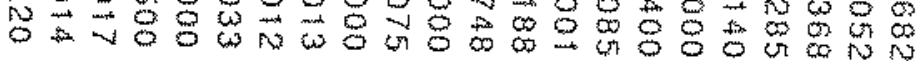


WCA3B Butk signa \% Carb sigma \% H.A. sigma \% F.A. sigma $\%$

\begin{tabular}{|c|c|c|c|c|}
\hline P & 12.00 & 7.820 & 181.60 & 41.25 \\
\hline Ni & 22.00 & 15.700 & 73.25 & 57.67 \\
\hline $\mathrm{Ba}$ & 0.65 & 1.140 & 46.50 & 23.75 \\
\hline $\mathrm{Mr}$ & 1.40 & 0.610 & 23.15 & 9.19 \\
\hline Fe & 1.60 & 0.890 & 1.61 & 2.83 \\
\hline C: & 32.00 & 18.450 & 45.50 & 114.00 \\
\hline $\mathrm{Mg}$ & 1.60 & 0.560 & 3.79 & 2.03 \\
\hline $\mathrm{TH}$ & 1.90 & 2.790 & 3.12 & 216.75 \\
\hline 30 & 17.00 & 35.500 & 92.00 & 100.00 \\
\hline Al & 2.30 & 0.660 & 2.84 & 1.38 \\
\hline Sr & $\$ .70$ & 1.310 & 1.79 & +60 \\
\hline So & 67.00 & 212.670 & 77.00 & . \\
\hline Zn & 0.44 & 3.940 & 4.58 & 2.55 \\
\hline $\mathrm{pb}$ & 22.00 & 27.200 & 93.50 & 51.25 \\
\hline $\mathrm{Cd}$ & 5.70 & 13.530 & 117.50 & 237.50 \\
\hline Co & 10.00 & 30.000 & . & 76.00 \\
\hline V & 3.00 & 22.050 & 42.50 & 11.98 \\
\hline Be & - & 90.500 & 390.28 & 715.00 \\
\hline $\mathrm{Ca}$ & 0.87 & 2.900 & 1.53 & 2.95 \\
\hline$a s$ & 1.50 & 14.700 & 10.00 & 3.65 \\
\hline$y$ & 2.50 & 78.750 & 500.00 & - \\
\hline$S \mathrm{i}$ & & 2.290 & 29.20 & 11.93 \\
\hline
\end{tabular}




\section{WHOLE SOLL CONCENTRATUONS CORRECTED FOR DULUTION}

The following table gives the concentration of elements in the whote soll samples, corrected for dilution, compared with the ranges of concentrations reported for soils worldwide.

Sources for the world ranges are:

+ Bohn et al. (1985) Tabte 11-3, p. 304

* Bohm el al. (1985) Table 11-4, p. 311

\# Browlow (1979) Table 7-3, p. 294-295

$\infty$ Kabata-Pendias and Pendias (1984), Tables 50 and 51. p. 94-95

- Kabara+Pendias and Pendias (1984), Table 53 and 54, p. 97

$\$ \quad$ Kabata-Pendias and Pendias (1984), Tables 83 and 84, p. 140

- Kabata-Pendias and Pendias (1984), Table 112, p. 178 
WOMOOMW * $\delta$ का $3 \stackrel{5}{n}$

औस

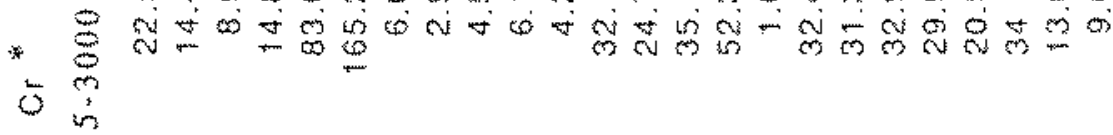

* ए 0 क $8 \stackrel{13}{2}$

母nल * $8 \div$

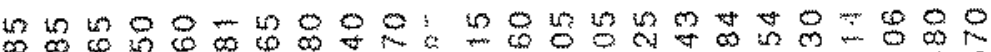

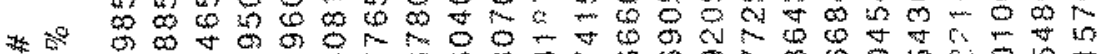

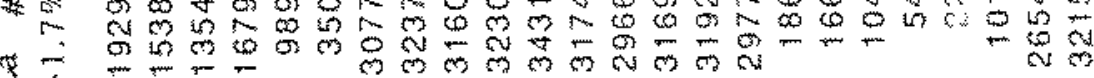
(3)

प8

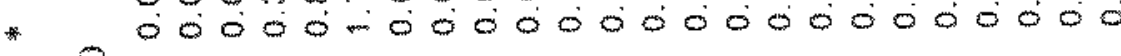

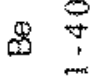
क N $\infty$

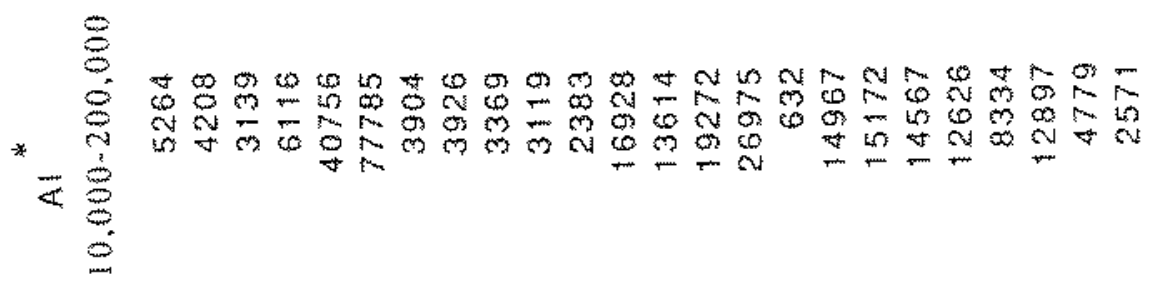

\footnotetext{
क

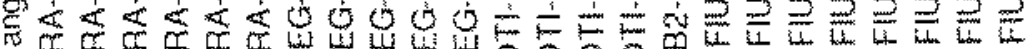

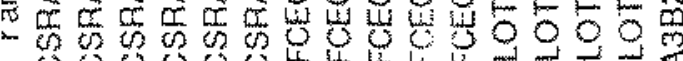



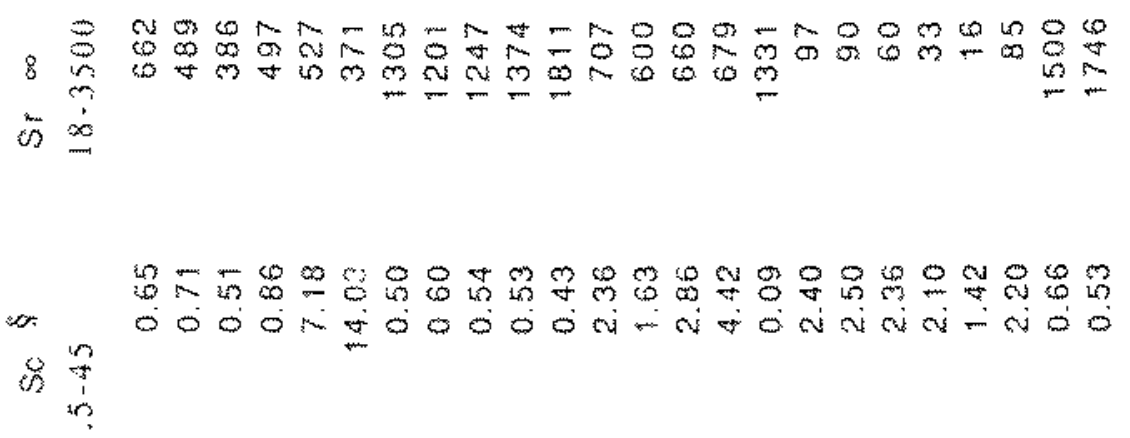

स以ूल

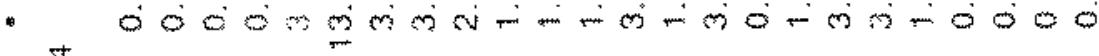
की

य $0 \mathrm{~N}$.

*

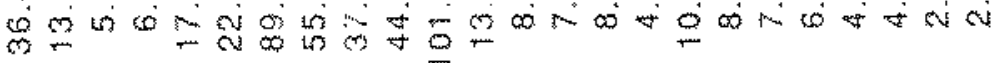
*.

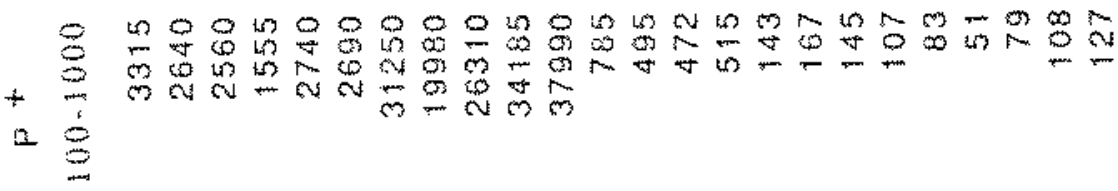

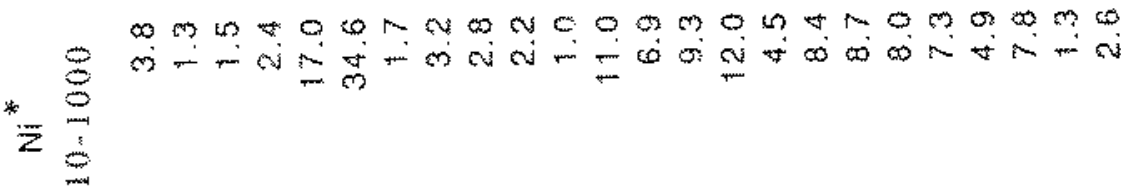
$* b_{0}^{1}$

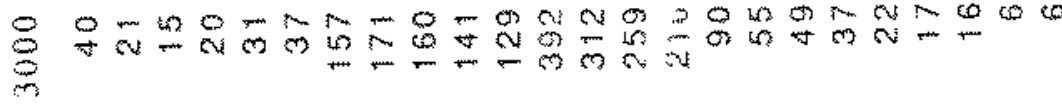

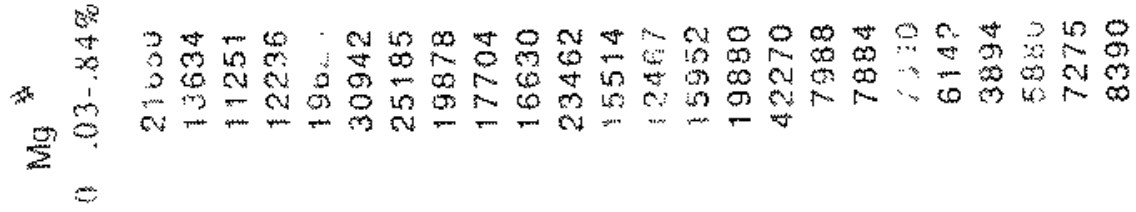

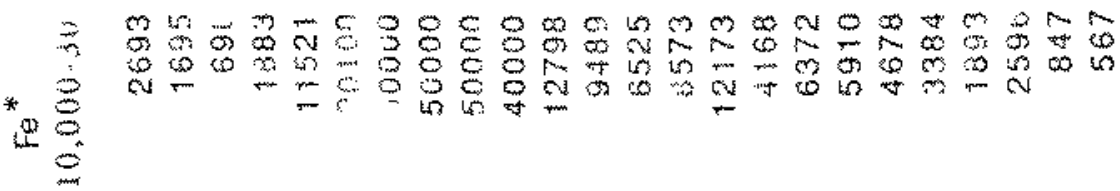




\begin{tabular}{|c|c|c|c|}
\hline $\begin{array}{c}\mathrm{Ti}^{*} \\
1000-10,000\end{array}$ & $\begin{array}{c}V^{*} \\
20-500\end{array}$ & $20-200$ & $\begin{array}{c}7 n * \\
10-300\end{array}$ \\
\hline 289 & 11.0 & 7.1 & 16.6 \\
\hline 225 & 6.9 & 7.2 & +2.2 \\
\hline 162 & 4.5 & 7.4 & 4.4 \\
\hline 373 & 9.0 & 5.5 & 7.6 \\
\hline 2263 & 49.9 & 16.9 & 32.4 \\
\hline 4438 & 58.3 & 29.9 & 50.9 \\
\hline 243 & 9.7 & 1.1 & 25.7 \\
\hline 197 & 10.3 & 1.2 & 23.7 \\
\hline 163 & 8.7 & 1.1 & 15.9 \\
\hline 158 & 6.6 & 3.1 & 12.6 \\
\hline 118 & 3.5 & 0.8 & 16.6 \\
\hline 990 & $2 \pm .8$ & 7.7 & 34.0 \\
\hline 831 & 15.2 & 6.1 & 15.8 \\
\hline 1085 & 17.6 & 8.9 & 14.6 \\
\hline 1502 & 25.2 & 14.4 & 20.1 \\
\hline 59 & 15.9 & 0.2 & 1.3 \\
\hline 1077 & 94.9 & 5.4 & 19.7 \\
\hline 1070 & 14.6 & 5.4 & 16.8 \\
\hline 909 & 13.0 & 5.3 & 12.8 \\
\hline 857 & 10.5 & 4.7 & 10.3 \\
\hline 665 & 6.5 & 3. & 6.3 \\
\hline 814 & 10.2 & 5.2 & 7.9 \\
\hline 282 & 6.2 & $2 . \uparrow$ & 2.7 \\
\hline 146 & 5,4 & 1.5 & 1.1 \\
\hline
\end{tabular}




\section{APPENDIX G TERMS AND DEFINTTONS}

adsorption: the process of sorption of chemical elements from solutions by soll particles (Kabata-Pendias and Pendias, 1984).

co-precipitation: the simultaneous precipitation of a chemical element with other elements by any mechanism and at any rate. Co-precipitation includes adsorption, inclusion and solid solution formation (Sposito, 1989).

inclusion: occurrence together as morphologically distinct solids (Sposito, 1989).

fulvic acid: the mixture of organic substances remaining in solution upon acidification of a dilute alkali extract of soil (FitzPatrick, 1980).

humic acid: the dark organic substances precipitated upon acidification of a dilute alkali extract of soils (FitzPatrick, 1980).

sorption: 1) the ability to fix many spectes of trace ions; 2) all phenomena at the solid solution boundary (Kabata-Pendias and Pendias, 1984). humic substances: the dark microbially transformed organic materials that persist in soil throughout profile development. The two nost investigated humic substances are bumic and fulvic acid. (Sposito, 1989)

translocation: the movement of material in solution, suspension, or by organisms from one horizon to another (FilzPatrick, 1980).

trace element: any chenical element whose mass concentration in a solid phase is less than or equal to $100 \mathrm{mg} \mathrm{kg}^{-1}$ (Sposito, 1989). 